\title{
Máquinas de gorjear: instrumentos para la representación del concepto paisaje sonoro
}

Covadonga Blasco Veganzones

Arquitecta. Máster en Proyectos Arquitectónicos Avanzados

Tesis doctoral, 2020 



\section{Máquinas de gorjear: instrumentos para la representación del concepto paisaje sonoro}

\section{Covadonga Blasco Veganzones}

Arquitecta. Máster en Proyectos Arquitectónicos Avanzados

Directores:

D. Juan Miguel Hernández León

Catedrático Emérito, Escuela Técnica Superior de Arquitectura de Madrid,

Universidad Politécnica de Madrid

\section{Dña. Concha Lapayese Luque}

Profesor Ayudante Doctor, Escuela Técnica Superior de Arquitectura de Madrid,

Universidad Politécnica de Madrid

Tesis doctoral, 2020 

Tribunal nombrado por el Mgfco. Y Excmo. Sr. Rector de la Universidad Politécnica de Madrid, el día

Presidente D.

Vocal D.

Vocal D.

Vocal D.

Secretario D.

Realizado el acto de defensa y lectura de Tesis el día en la Escuela Técnica Superior de Arquitectura de Madrid

Calificación:

EL PRESIDENTE

LOS VOCALES

EL SECRETARIO 
Resumen 


\section{¿Qué es lo que el paisaje puede esperar del sonido?}

Artistas, músicos y filósofos cuestionan las vías de representación del sonido con el fin de comprender su complejidad y riqueza. Más allá de las curvas y funciones matemáticas que evidencian las leyes físicas de la acústica, la atención sensible hacia las fuerzas y causas propias de los estímulos sonoros propicia la creación de nuevas formas visuales de expresión del sonido.

El concepto Soundscape o paisaje sonoro nace como consecuencia de la interrelación entre ciencia, arte, arquitectura y filosofía que se produjo desde finales del siglo XIX hasta los años setenta del siglo XX. La evolución de la tecnología sonora, la incorporación de esta tecnología a las prácticas artísticas, y el entendimiento contemporáneo del paisaje como proceso dinámico ligado a una acción, son sucesos que han convertido al sonido en un medio capaz de ensanchar el significado del paisaje.

Partiendo de la hipótesis de que la representación del concepto paisaje sonoro es, a priori, posible, la investigación se centra en el estudio de los instrumentos que permiten dicha representación. Imágenes, textos, partituras o mecanismos que sirven para representar el sonido del paisaje o el evento espacial asociado a las causas que lo producen.

Una vez respaldada la hipótesis de partida a través de las observaciones fenomenológicas y teorías del arte, la estética y el sonido de Edmund Husserl, Nelson Goodman, Hans Jonas, Pierre Schaeffer, Jean-Luc Nancy y Gilbert Simondon, entre otros, se presentan cinco tipos de instrumentos que posibilitan la representación del sonido del paisaje o de los aspectos espaciales y estructurales vinculados a él: la tecnología sonora, la partitura-evento, los surtidores de signos, las cajas de resonancia y el ritornelo. Cada uno de ellos es, a su vez, ejemplo de la fusión del conocimiento operativo con el pensamiento sonoro. En torno a los enfoques procesal, objetual y virtual de la representación que desarrolla cada uno de ellos, se despliega una reflexión sobre las variables semánticas, espaciales y temporales contenidas en el concepto paisaje sonoro.

Las obras que relacionan el sonido y el paisaje del compositor John Cage, el arquitecto Juan Navarro Baldeweg y el filósofo Gilles Deleuze, sirven para ejemplificar cada tipo de instrumento. La exposición cronológica de los acontecimientos que relacionan las trayectorias personales y profesionales de los tres entre los años 1939 y 1989, muestran la evolución del concepto paisaje sonoro desde una visión multidisciplinar.

Finalmente, se concluye que el sonido es un medio útil para clarificar las transformaciones morfológicas, estructurales y temporales asociadas al proceso de construcción del concepto paisaje, y se defiende la pertinencia del empleo de los instrumentos en la docencia de la arquitectura y el paisaje como método para incentivar la sensibilidad hacia el entorno y el medio ambiente. 
Abstract 


\section{What can the landscape expect from sound?}

Artists, musicians and philosophers question the ways in which sound is represented in order to understand its complexity and richness. Beyond the curves and mathematical functions that evidence the physical laws of acoustics, sensitive attention to the forces and causes of sound stimuli leads to the creation of new visual forms of sound expression.

The Soundscape concept was resulted as a consequence of the interrelationship between science, art, architecture and philosophy that took place from the end of the 19th century to the 1970s. The evolution of sound technology, the incorporation of this technology into artistic practice, and the contemporary understanding of landscape as a dynamic process linked to an action, are events that have made sound a medium capable of expanding the meaning of landscape.

Based on the hypothesis that the representation of the concept of soundscape is, a priori, possible, the research focuses on the study of the instruments that allow such representation. Images, texts, scores or mechanisms that serve to represent the sound of the landscape or the spatial event associated with the causes that produce it.

Once the initial hypothesis is supported through the phenomenological observations and theories of art, aesthetics and sound by Edmund Husserl, Nelson Goodman, Hans Jonas, Pierre Schaeffer, Jean-Luc Nancy and Gilbert Simondon, among others, five types of instruments are presented, which make it possible to represent the sound of the landscape or the spatial and structural aspects linked to it: sound technology, the event-scores, the sign sources, sound boxes and the ritornello. Each of them is, in turn, an example of the fusion of operational knowledge with soundthought. A reflection on the semantic, spatial and temporal variables contained in the concept Soundscape unfolds around the procedural, objective and virtual approaches to representation developed by each of them.

The works that connect the sound and the landscape of the composer John Cage, the architect Juan Navarro Baldeweg and the philosopher Gilles Deleuze, serve to exemplify each type of instrument. The chronological exhibition of the events that connect the personal and professional careers of the three between 1939 and 1989, shows the evolution of the concept Soundscape from a multidisciplinary view.

Finally, it concludes that sound is a useful means of clarifying the morphological, structural and temporal transformations associated with the process of constructing the landscape concept, and it defends the relevance of the use of instruments in the teaching of architecture as a method of encouraging sensitivity to the surroundings and the environment. 



\section{Agradecimientos}

Gracias, Juan Miguel, por ser el mejor sherpa que podría haberme acompañado en la subida a este Everest - Gracias, Concha, por hacerme llegar a la zona junto a Darío · Gracias, Enrique, Lisa y Matthias, por el salvoconducto berlinés - Gracias, Blanca, por ayudarme a sobrevivir en una jaula de grillos - Lucía, Rafa, gracias por vuestro tiempo tejano medido en un reloj suizo • Víctor, Elena-Emilio (y sus maravillosos hijos Elena, Manuel, Jaime y el que viene de camino), Ana, Rebeca, Patricia, Ana Matos, Román, Marco, Anabel, Carlos, Alberto, Rocío, Merche y Javier: gracias por vuestra amistad y aliento durante estos intensos años - Gracias, Mario y Alicia, por vuestro carińo y apoyo. 
ÍNDICE 
Resumen 6

$\begin{array}{lr}\text { Abstract } & 8\end{array}$

$\begin{array}{ll}\text { Agradecimientos } & 11\end{array}$

$\begin{array}{ll}\text { Derrotero } & 19\end{array}$

$\begin{array}{ll}\text { Prólogo en tres partes } & 23\end{array}$

i. Máquinas de gorjear 23

ii. La representación del concepto paisaje sonoro 26

iii. Instrumentos $\quad 27$

$\begin{array}{ll}\text { Fundamentos de la investigación } & 31\end{array}$

a. Orígenes de la investigación 32

b. Prototipo experimental 33

c. Hipótesis y objeto de estudio

$\begin{array}{ll}\text { d. Estado de la cuestión } & 38\end{array}$

i. Breve historia de la representación del sonido del paisaje hasta la Segunda Guerra Mundial 39

ii. Apostillas a The Soundscape. Our Sonic Environment and the Tuning of the World 49

iii. El pensamiento sonoro $\quad 52$

iv. Docencia y exposiciones en torno a instrumentos y dispositivos sonoros $\quad 55$

e. Cuestiones de método 63

f. Estructura de la tesis 64

Capítulo 1. La representación del concepto paisaje sonoro 69

$\begin{array}{ll}\text { 1.1.Un enfoque sonoro del paisaje } & 71\end{array}$

1.1.1. Aquello que vemos al decir 'paisaje' 71

1.1.2. El Stimmung o la visión sonora del mundo 78

1.1.3. La escucha como acción formalizadora del concepto paisaje 80

1.2. La construcción del concepto paisaje sonoro $\quad 82$

1.2.1. Variables semánticas: metáforas visuales para describir lo sonoro 83

1.2.2. Variables espaciales: pertenencia a y emancipación ante 85

1.2.3. Variables temporales: la conversión del tiempo en espacio 87 
1.3. Factores que intervienen en la construcción de la imagen del sonido

1.3.1. Procesos de conversión de señales: auscultación, transducción y reproducción

1.3.2. Actitud del sujeto y modos de escucha 98

1.3.3. Estructuras de percepción $\quad 102$

1.3.4. Articulaciones de la representación $\quad 106$

$\begin{array}{ll}\text { 1.4. Vías de representación del paisaje sonoro } & 108\end{array}$

1.4.1. Vía directa 111

1.4.2. Vía indirecta 112

1.5. Instrumentos y conocimiento operativo 113

Capítulo 2. Vértices y diagonales: interacciones en las trayectorias y el pensamiento de John Cage, Juan Navarro Baldeweg y

Gilles Deleuze (1939-1989) 123

Eje 1. 1939-1961: John Cage, Pierre Boulez y György Kepes 127

1937-1941: John Cage y György Kepes en la Escuela de diseño de Chicago 128

1949: El viaje a París. Primer contacto de John Cage con Pierre Boulez 130

1945-1956: De los nuevos paisajes a la forma urbana.

Geörgy Kepes y John Cage en el MIT 132

1961: Ritmo Etc. 137

Cuadrado 1. 1967-1975: Maryanne Amacher, John Cage, György Kepes y Juan Navarro Baldeweg 139

1967: Inicio de la serie City-Links de Maryanne Amacher 141

1971-1975: Centre for Advanced Visual Studies. Punto de encuentro de G. Kepes, M. Amacher y J. Navarro Baldeweg 144

1975: Lecture on the Weather. Amacher, Cage y la ecología acústica 149

Cuadrado 2. 1977-1989: Gilles Deleuze, Pierre Boulez, Paul Klee y John Cage 151

1977: Sobre la música. Seminario de Gilles Deleuze en

la Universidad de Vincennes 153

1978: El seminario Le temps musical. Deleuze, Boulez y el paisaje sonoro 157

1986: Ocupar sin contar: Boulez, Proust y el Tiempo 161

1989: Le pays fertile. Consideraciones musicales sobre la obra 
Capítulo 3. Instrumentos para la representación del concepto paisaje sonoro

3.2. Partitura-evento

3.3. Surtidores de signos

1. Comprobación de la hipótesis de partida 237

2. Aportaciones: El sonido como medio para establecer una ontología del paisaje

2.1. Apreciación sensible de la simultaneidad de la experiencia y la representación del paisaje

2.2. Conciencia de la individuación del sujeto 
Ves, hijo mío. Aquí el tiempo se convierte en espacio 
Du siehst, mein Sohn, zum Raum wird hier die Zeit R.Wagner, Parsifal 


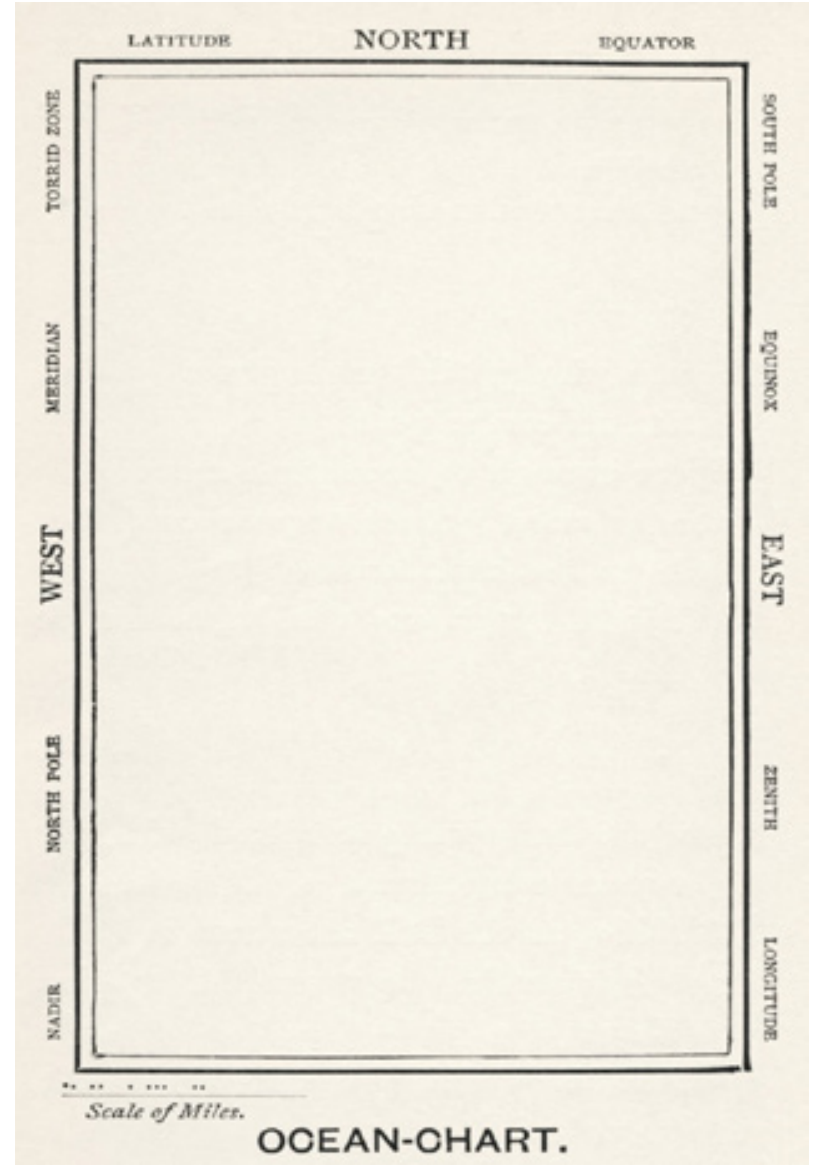




\section{Derrotero}

Durante el resto del año quisiera hablar de pintura. No estoy seguro -veremos eso despuésde que la filosofía haya aportado algo a la pintura. No lo sé. Pero quizás no es así como hay que plantear las cosas. Me gustaría más plantear la pregunta inversa: la posibilidad de que la pintura tenga algo que aportar a la filosofía. ${ }^{1}$

G. Deleuze, Pintura. El concepto de diagrama

Como un filósofo que habla sobre pintura. Así se presentó Gilles Deleuze en 1981 ante sus alumnos de la Universidad de Vincennes en el comienzo de su seminario sobre el diagrama, dispuesto a aplicar el extrańamiento como método para desvelar los destellos que la pintura pudiera arrojar sobre los conceptos filosóficos.

Estas primeras palabras del curso Pintura. El concepto de diagrama fueron la base de un ejercicio de intertextualidad ${ }^{2}$ en el que la palabra se convirtió en un cruce de palabras. Mediante asociaciones equivalentes, los sustantivos deleuzianos (filosofía, pintura y diagrama) se sustituyeron por los intereses de la presente investigación, obteniendo el siguiente resultado:

Durante el resto de la tesis quisiera hablar de sonido. No estoy segura de que el paisaje haya aportado algo al sonido. No lo sé. Pero quizás no es así como hay que plantear las cosas. Me gustará más plantear la pregunta inversa: la posibilidad de que el sonido tenga algo que aportar al paisaje. Y que la respuesta no sea para nada univoca, es decir que uno no pueda calcar la misma respuesta para el sonido que para la música, por ejemplo. La música nos ha llegado por necesidad, por gusto

1. Gilles Deleuze, Pintura: el concepto de diagrama (Buenos Aires: Cactus, 2016), 21.

2. Sobre la intertextualidad, Cfr. Julia Kristeva, Sèmeiòtikè Semiótica (Madrid: Fundamentos, 1981), 190. 
o elección de un propósito de investigación.

$$
\text { Pero, ¿Qué es lo que el paisaje puede esperar del sonido? } 3
$$

El resultado de este ejercicio literario se convirtió en derrotero para desarrollar la tesis. ¿Qué puede aportar el sonido al paisaje? ¿Hacia dónde lo arrastra? ¿Cuál es la necesidad que impulsa la creación del concepto ${ }^{4}$ paisaje sonoro? La búsqueda de respuestas a estas preguntas condujo al estudio del último (y escurridizo) nivel en el que se comunican las disciplinas creativas: el espacio-tiempo. ${ }^{5}$ En él se encontraba el sonido mismo, provocando las resonancias entre arte, arquitectura y filosofía que anhelan ampliar la percepción ${ }^{6}$ del paisaje en la arquitectura . $^{7}$

3. El texto original ha sido modificado por la autora de la tesis con el fin de transmitir los intereses de la investigación.

4. Sobre la invención de los conceptos, indica Deleuze: «La filosofía también es una disciplina de creación, tan inventiva como cualquier otra disciplina, y consiste en crear conceptos. Los conceptos no existen ya hechos en una especie de cielo en el cual esperarían a que el filósofo los alcanzase. Los conceptos hay que fabricarlos...Es preciso que haya una necesidad tanto en la filosofía como en los demás órdenes, si no, no hay nada que hacer». Gilles Deleuze, “¿Qué es el acto de creación?”, en Dos regimenes de locos. Textos y entrevistas (Valencia: Editorial Pre-Textos, 2008), 282.

5. Ibid., 283.

6. «Ampliar la percepción quiere decir hacer sensibles, sonoras (o visibles), fuerzas ordinariamente imperceptibles. [...] Hacer del sonido el intermediario que hace sensible el tiempo, que hace perceptibles los Números del tiempo, organizar el material para captar las fuerzas del tiempo y hacerlo sonoro [...].» Gilles Deleuze, "Ocupar sin contar: Boulez, Proust y el tiempo”, en Dos regímenes de locos. Textos y entrevistas (Valencia: Editorial Pre-Textos, 2008), 268.

7. Ibid., 283. Siguiendo las palabras de Deleuze: «Si cualquiera puede hablar con cualquiera, si un cineasta puede hablar a un científico, y un científico puede tener algo que decirle a un filósofo y viceversa, ello sucede en función de la actividad creadora de cada uno de ellos. No porque en ese punto pueda hablarse de creación -la creación es algo más bien solitario- sino que es en nombre de mi creación como yo tengo que decirle a alguien». Hablaremos, por tanto, en nombre de la arquitectura, disciplina en la que se enmarca esta investigación. 


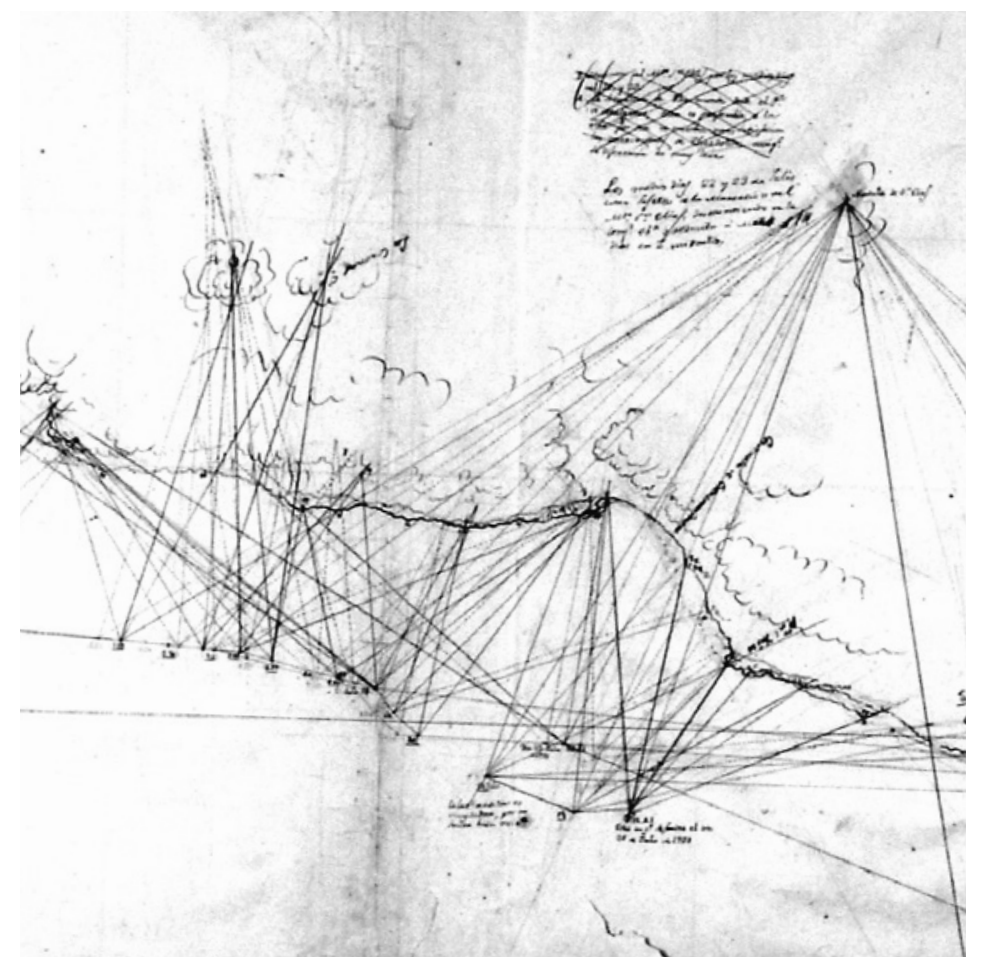

Figura 1. (página 16). Lewis Carroll, The Hunting of the Snark (1876). Mapa para la tripulación

Figura 2. Expedición de Malaspina. Detalle del borrador del levantamiento de la costa desde Puerto Mulgrave hasta Cabo Engaño, incluido el Puerto de Desengaño (1791) 


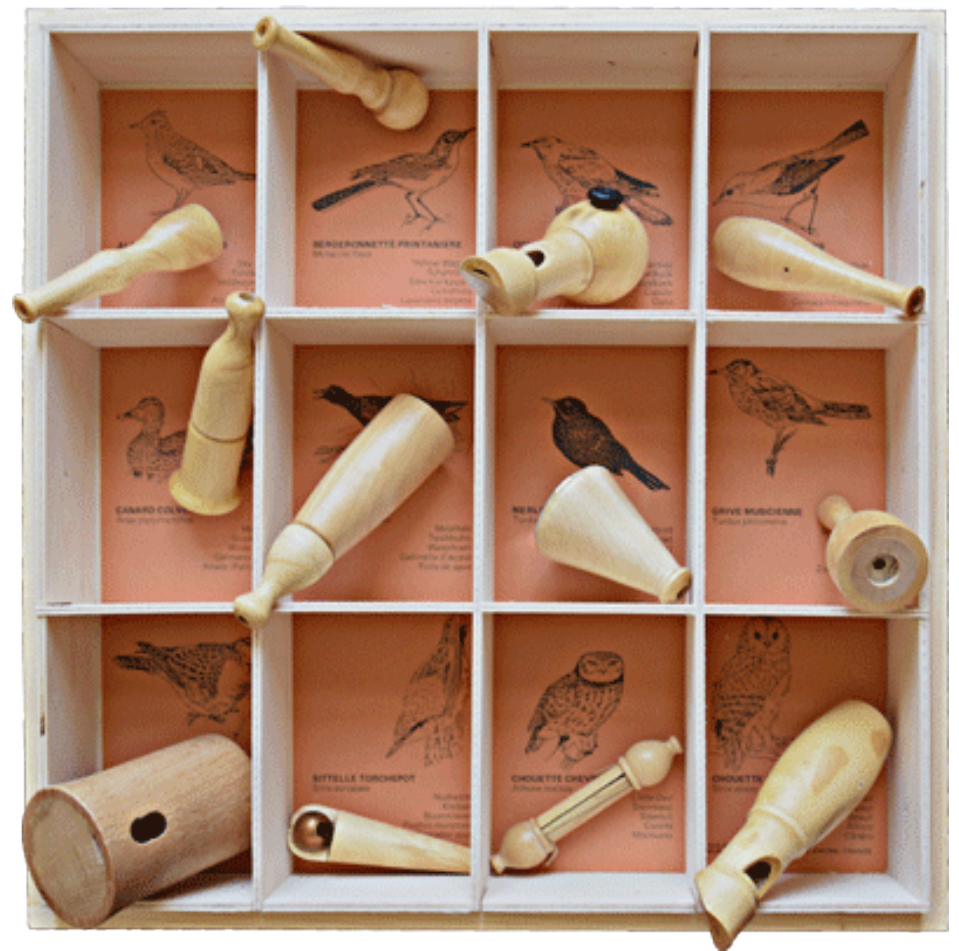

Figura 3. Quelle est Belle Company. Doce reclamos de pájaros de Europa 


\section{Prólogo en tres partes}

\section{MÁQuinas DE GORJEAR}

Desmovilizado tras el fin de la Primera Guerra Mundial, Paul Klee (1879-1940) comenzó a poner en práctica muchas de las técnicas que había aprendido siendo pintor de aviones ${ }^{1}$ durante los dos años en los que sirvió al ejército alemán. ${ }^{2}$ La tela de las alas o las plantillas con las que pintaba el fuselaje conformaron las reminiscencias que forjaron posteriormente el conocido 'método de transferencia de trazas'3 que Klee comenzó a desarrollar a partir de 1919. Este sistema consistía en transferir un dibujo a línea de un papel a otro utilizando un tercer papel que, pintado en una de sus caras con pintura negra al óleo, se intercalaba entre las otras dos. Para ello, Klee realizaba un primer dibujo a línea que colocaba en la parte superior. Después, trazaba meticulosamente con una aguja los contornos que serían recibidos por la

1. En sus diarios, Paul Klee relata su experiencia en el ejército entre 1916 y 1918. Su incorporación a la Escuela de Vuelo 5 como pintor jefe la describe como «una aventura más para evitar que la guerra sea tan aburrida». Paul Klee y Felix Klee, The diaries of Paul Klee, 1898-1918 (Berkeley: University of California Press, 1964), 363-64.

2. La exposición Klee in Wartime, organizada por el Zentrum Paul Klee, mostró los aspectos del trabajo de Paul Klee que se originaron durante este tiempo e influyeron posteriormente en su carrera: «The artist commented on his life as a soldier in his diary and in letters with startlingly ironic detachment. In spite of the terrible events of the war, the years from 1914 until 1918 proved to be a very fertile time for Klee. He discovered new materials, such as the cloth of aeroplane wings, and new tools such as the stencils with which he had to paint aeroplanes. He developed his work further in a formal sense, opened up new subjects and creative media and delved further into those he had already tried out.» Zentrum Paul Klee, Bern, Klee in Wartime, 6 de diciembre, 2017 - 3 de junio, 2018, Zentrum Paul Klee, accedido 3 de enero de 2020, https://www.zpk.org/en/exhibitions/review_0/2017/kleein-wartime-1563.html.

3. Museum of Modern Art (New York, N.Y.), Paul Klee centennial: prints and transfer drawings : [exhibition] January 8-April 3, 1979, the Museum of Modern Art, New York (The Museum of Modern Art, 1978), 3, www.moma. org/calendar/exhibitions/1825. 
hoja de papel de dibujo colocada bajo la superficie pintada de negro y, una vez transferido el dibujo, las figuras -a veces acompañadas por las inevitables manchas producidas por el apoyo de la mano sobre el lienzo- se rellenaban de color con acuarela. La impermeabilidad del aceite permitía la convivencia independiente de las líneas definitorias del dibujo protagonista con los colores al agua que caracterizaban los imprecisos y complejos fondos de muchos de los cuadros de Paul Klee.

Reflejo de esa técnica es Die Zwitscher-Maschine (La máquina de gorjear, 1922), uno de los cuadros que más interpretaciones ha suscitado en el último siglo. El título de la obra sugiere una suerte de caja de música en la que mediante un mecanismo activado por una manivela se aprecia el gorjeo de cuatro pájaros posados sobre un alambre. La técnica de la transferencia empleada en este cuadro nos conduce a buscar, dentro de la ingente obra del pintor suizo, el dibujo a línea que sirvió como base del dibujo final. Como referencia, encontramos que Klee utilizó un dibujo realizado en 1921, siendo profesor de la Bauhaus de Weimar: Konzert auf dem Zweig (Concierto en la rama). En él, cuatro pájaros muy similares a los representados en La máquina de gorjear, se encuentran posados en una sinuosa rama empotrada en su extremo derecho. El dibujo capta el momento en el que los pájaros cantan. Los gestos de las aves -la posición de los picos abiertos, con sus lenguas tensadas- y el título de la obra -conciertoinducen a pensar en su gorjeo. ${ }^{4}$

Más allá de encontrar similitudes y diferencias entre las figuras que protagonizan las dos obras, el análisis cronológico de los procedimientos seguidos para obtener la imagen final de La máquina de gorjear desvela una lógica en el pensamiento de Klee de gran interés para esta investigación. El paso de un dibujo a otro, del concierto a la máquina, implica la transformación de una escena vinculada a un sonido natural -cuatro pájaros que cantan en la rama de un árbolen una representación mecánica. Esta transición es análoga al proceso lógico que realizan los constructores de reclamos. Mediante la observación de la naturaleza, el artesano ${ }^{5}$ estudia las características del canto de un pájaro para, posteriormente, idear un sistema mecánico que permita reproducir un sonido semejante. Pequeños instrumentos que surgen del estudio de la naturaleza y que son capaces de convertir un instante determinado en una duración.

Estableciendo un paralelismo entre las operaciones implícitas en el proceso de realización

4. Cfr. Maurice L. Shapiro, "Klee's Twittering Machine», The Art Bulletin Vol.50, n. 1 (March. 1968): 67-69, https://doi.org/10.2307/3048514.

5. Destaca en este campo el trabajo del artesano francés François Morel. «Quelle est Belle Company», accedido 3 de enero de 2020, https://www.qbc.fr/. 

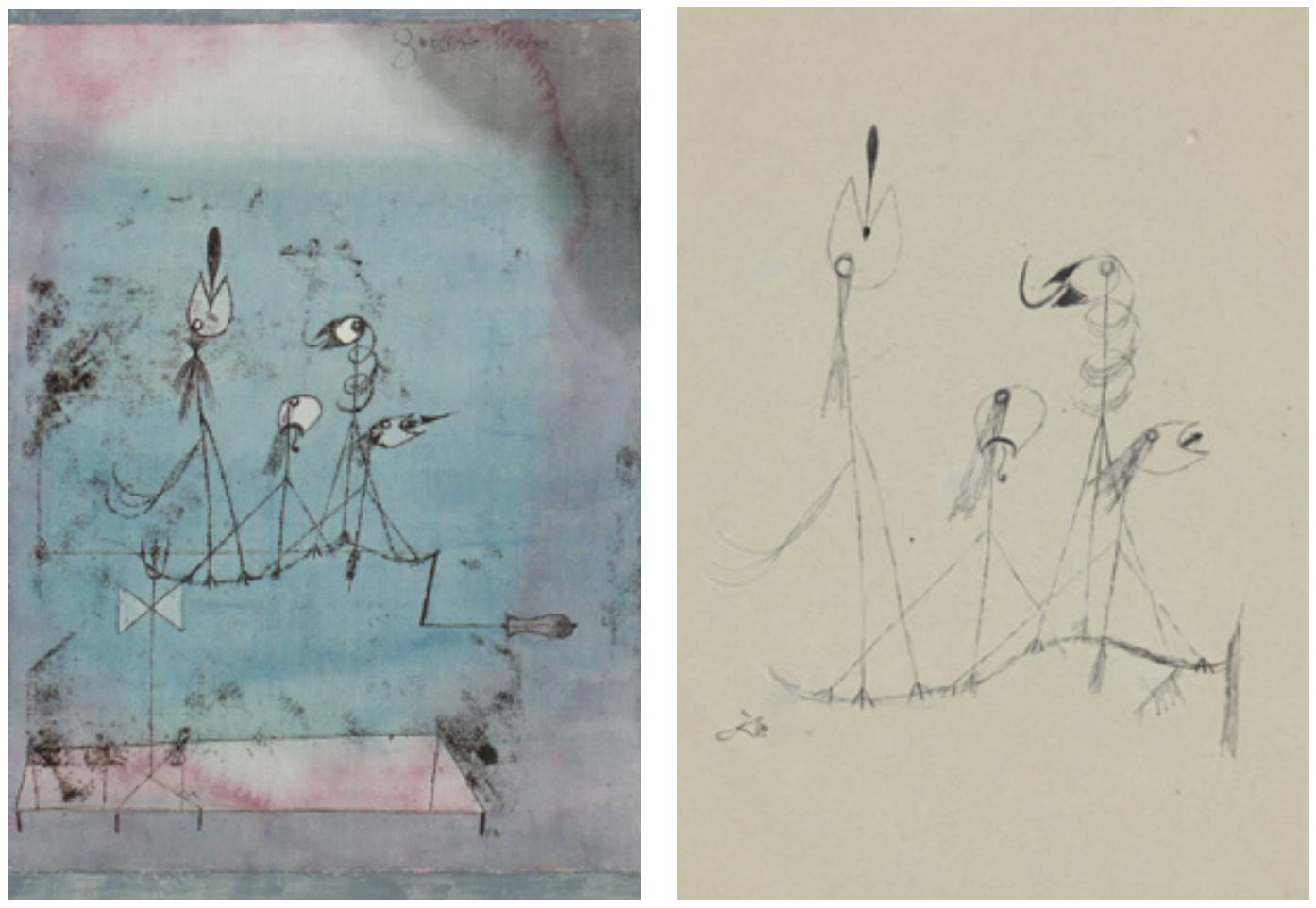

Figura 4. Paul Klee, Die Zwitscher-Maschine (1922)

Figura 5. Paul Klee, Konzert auf dem Zweig (1921) 
de la pintura de Klee y los intereses de esta investigación, se toma prestado el título Maquinas de gorjear para designar, en esta tesis, a los instrumentos que sirven para representar el concepto paisaje sonoro. Un concepto en el que confluyen, al igual que en el artilugio de los cuatro pájaros, el sonido, la técnica y la naturaleza.

\section{LA REPRESENTACIÓN DEL CONCEPTO PAISAJE SONORO}

Con motivo de la exposición Staatliches Bauhaus in Weimar 1919-1923, la Bauhaus publicó su primer libro en 1923. En él, además de mostrar fotografías de los trabajos realizados por los alumnos en los diferentes talleres, se recopilaron textos firmados por todos los profesores de la escuela. Entre ellos se encontraba Paul Klee, maestro de pintura de la Bauhaus en aquellos ańos. Su ensayo Wege des Naturstudiums ${ }^{6}$ propone ampliar los modos de conocimiento de la naturaleza establecidos históricamente, y explica mediante un diagrama las diferentes formas de relación entre el sujeto y la naturaleza. Más allá de la relación visual entre sujeto y objeto, Klee plantea transcender toda relación óptica estableciendo entre ellos una relación por resonancia. Este tipo de vinculación permitiría sintetizar la mirada exterior y la visión interior en un único gesto para alcanzar, en su unidad, un conocimiento de la realidad interior de los objetos. ${ }^{7}$

Derivado de la palabra latina resonare, 'resonancia' es un término de gran importancia en el estudio de las ciencias naturales. Así, los físicos hablan del fenómeno de la 'resonancia mecánica’ cuando una partícula hace vibrar a otra al someterla a una frecuencia oscilante, los astrónomos identifican la resonancia cuando dos cuerpos en órbita ejercen una influencia gravitatoria regular y periódica sobre cada uno de ellos, y los químicos pueden hablar de varias 'estructuras de resonancia' en los electrones deslocalizados de ciertas moléculas. ${ }^{8} \mathrm{Si}$ bien las raíces etimológicas de la palabra se encuentran en el ámbito acústico, su significación generalizada como 'influencia de un cuerpo en otro' ha extendido el uso metafórico del término en el campo de las humanidades. Hasta principios del siglo XX, la resonancia ocupó una posición predominante en un extenso terreno conceptual, abarcando prácticamente toda la

6. Paul Klee, "Wege des Naturstudiums», en Staatliches Bauhaus in Weimar 1919-1923 (Weimar - München: Bauhausverlag, 1923), 24-25.

7. Paul Klee, "Vías diversas en el estudio de la naturaleza», en Teoría del arte moderno, 1. ${ }^{a}$ ed. (Buenos Aires: Cactus, 2007), 43-47.

8. Veit Erlmann, «resonance», en Keywords in sound, ed. David Novak y Matt Sakakeeny (Durham; London: Duke University Press, 2015), 173-82. 
ciencia, el arte y la filosofía europea, proporcionando una nueva visión del papel del sonido en Occidente a través de la práctica cultural. Un papel que ha sido obviado por los discursos predominantemente visuales. ${ }^{9}$

Teniendo en cuenta la naturaleza arquitectónica de la tesis, el objetivo del proceso de investigación ha sido encontrar la resonancia que permitiera, por un lado, encontrar un vínculo espacial entre las diferentes materias independientes que aglutina el concepto paisaje sonoro, como son la ciencia, la filosofía y el discurso estético; y por otro (manteniendo presente de nuevo la estela de Klee), lograr mediante su exploración un conocimiento profundo de la representación del concepto paisaje sonoro.

La investigación es el reflejo de la búsqueda de una resonancia que facilitase la difícil tarea que impone el estudio del paisaje sonoro: descifrar la correlación entre la inmaterialidad de los signos y la materialidad de las cosas. Es decir, entender la inmaterialidad del concepto paisaje sonoro a través de la materialidad de su representación. En ese proceso de interpretación, la percepción tiene la misión de captar el objeto sensible (el sonido), mientras que a la inteligencia tiene como cometido aprehender los significados objetivos del concepto (la construcción de la lógica del sonido). Se produce así un equilibrio en el que la inteligencia se interesa por la objetividad (por el conocimiento del concepto paisaje sonoro) y la percepción por el objeto (por aquellos instrumentos que permiten su representación). ${ }^{10}$

\section{INSTRUMENTOS}

Las palabras 'persona' y 'personaje' provienen del término personare, que significa 'resonar a través de una máscara'. La máscara original de la tragedia se entendía como un dispositivo diseñado para hacer sonar de una forma más potente y audible la voz del actor. ${ }^{11}$ Los instrumentos que el título de la tesis presenta como medio para alcanzar la representación del concepto paisaje sonoro, se corresponden con herramientas como las máscaras, capaces de servir a la

9. Cfr, Ibid., 180. Afirmación basada en el análisis de Derrida El oído de Heidegger. Jacques Derrida, Politicas de la amistad: seguido de El oído de Heidegger (Madrid: Trota, 2010).

10. Cfr. Gilles Deleuze, Proust y los signos (Barcelona: Editorial Anagrama S.A., 1995), 39.

11. Según la etimología tradicional de 'persona' la palabra viene del latín personare, que aludía a la máscara que los actores usaban en el teatro para hacer 'resonar' su voz. Esta máscara tenía un orificio a la altura de la boca y daba a la voz un sonido penetrante y vibrante. Así pues, persona significaría primero 'máscara', 'papel del actor', 'carácter' y finalmente 'persona'. Alois Walde, Lateinisches etymologisches Wörterbuch, 1910, 578, http://archive.org/details/ Lateinisches-etymologisches-woerterbuch. 
imagen de lo representado.

Tres máscaras -John Cage, Juan Navarro Baldeweg y Gilles Deleuze-, a quienes su obra les distingue como exponentes en sus respectivos campos de acción, intervienen en los tres actos que han marcado la evolución del concepto: en primer lugar, experimentan los procesos de conversión del sonido del paisaje en su representación en formas objetivas; en segundo lugar, exploran a través de sus obras estructuras conceptuales mediante soportes reales; $\mathrm{y}$, por último, su sinergia produce la transgresión de los códigos estéticos clásicos.

Los tres, unidos tangencialmente por los contextos artísticos y académicos en los que se insertan sus trayectorias, se convierten en un conjunto, conectados por un mismo hilo narrativo. La aproximación de sus obras, afinadas en la frecuencia del paisaje y el sonido, genera una vibración cuya oscilación máxima afecta, al unísono, a la arquitectura, la música y la filosofía. 


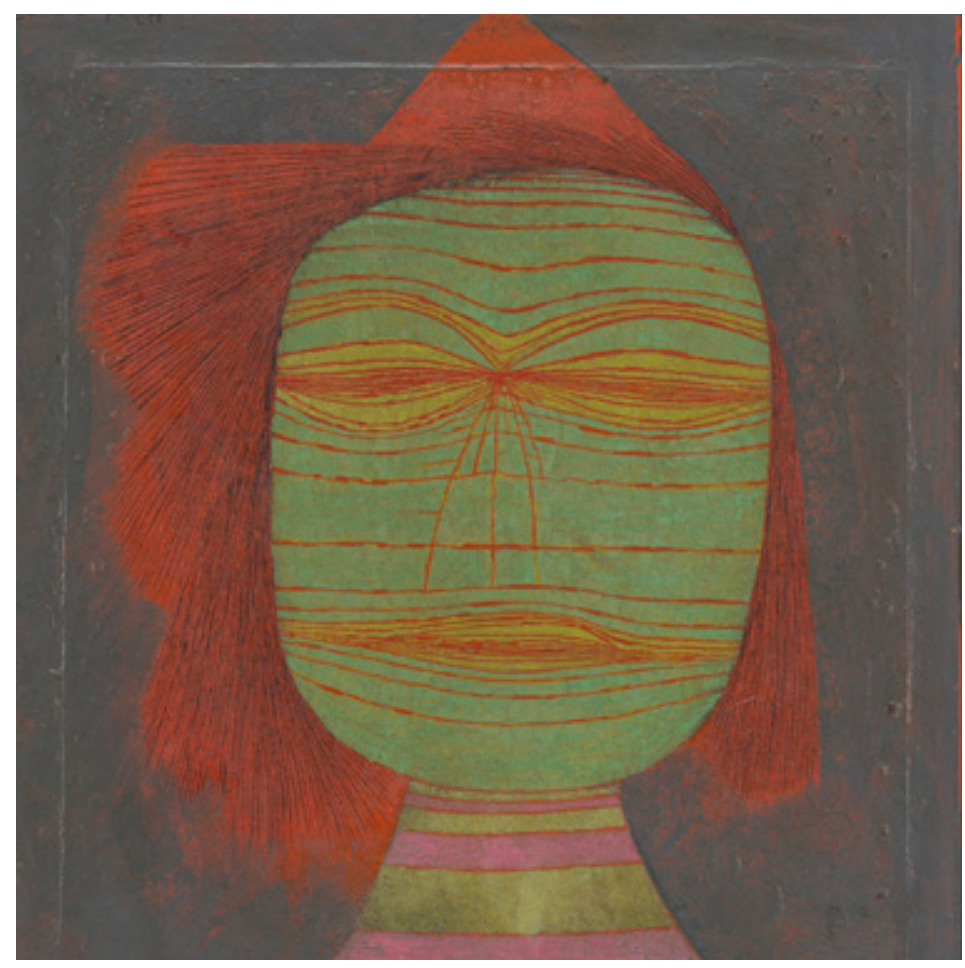

Figura 6. Paul Klee, Actor's Mask (1924) 


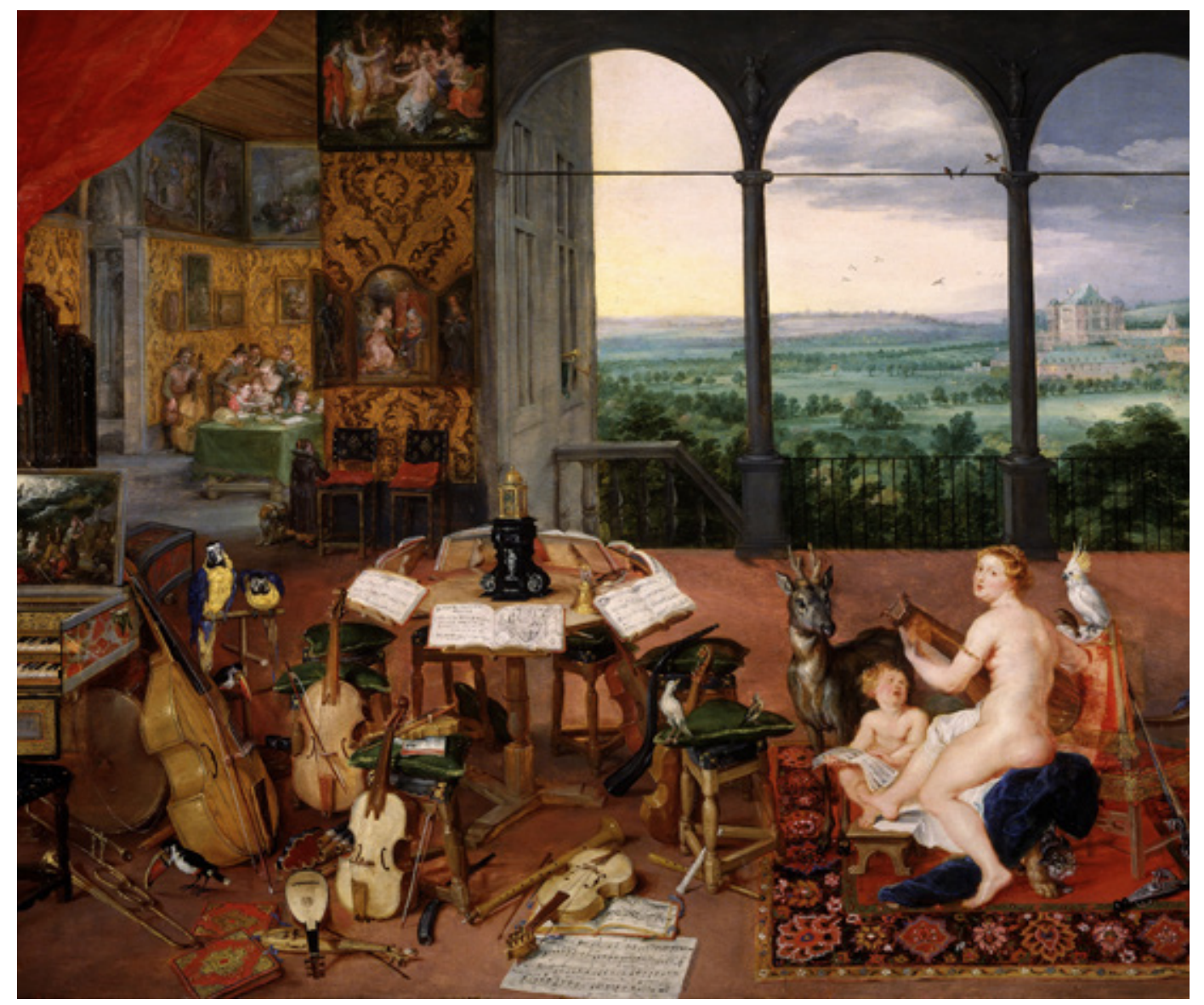

Figura 7. Jan Brueghel y Predro Pablo Rubens, El Oido (1617) 


\section{FUNDAMENTOS DE LA INVESTIGACIÓN}

En los siglos XVI y XVII, los cuartos de maravillas o Wunderkammer mostraban las curiosidades científicas, libros y piezas artísticas más modernas de la época. Todos los objetos se clasificaban por temáticas en habitaciones que, una vez organizadas, se dibujaban con gran perfección y detalle, dando lugar al género de pintura denominado gabinete d'amateur. ${ }^{1}$

El Oído (1617-1618), una de las cinco obras que componen la alegoría de los cinco sentidos ${ }^{2}$ de Jan Brueghel el Viejo y Pedro Pablo Rubens, ejemplifica las características de esta tradición pictórica. La escena del cuadro exhibe los elementos relacionados con el sentido de la escucha: relojes, instrumentos musicales, partituras...todos ellos agrupados en una sala doméstica en la que se intuye una agradable atmósfera sonora. Un grupo de cantantes e instrumentistas se aprecian al fondo de un espacio con techos de madera. Los tapices y las paredes enteladas inducen a pensar que disfrutan de una acústica amortiguada y en un plano intermedio, entre el interior y el exterior, la logia que preside la estancia enmarca los sonidos del paisaje. Tanto las golondrinas apoyadas en los tirantes de la arquería como las trompetas que avisan de la cacería que se avista en el jardín, recuerdan al espectador, silenciosamente, que el sonido del paisaje es también un personaje invisible dentro del cuadro.

1. «El Oído - Colección», Museo Nacional del Prado, accedido 5 de marzo de 2019, https://www.museodelprado. es/coleccion/obra-de-arte/el-oido/074adedf-40f0-476f-b132-fe450e71e0f3.

2. El Oído es una de las obras estudiadas dentro del Proyecto Iconografía Musical UCM, 2011 (Grupo 930823/ I+D+i, HAR2009-10029), en el que el Museo Nacional del Prado y la Universidad Complutense de Madrid llevaron a cabo una larga investigación sobre la representación visual de la música y la danza. «El sonido de la pintura en el Museo del Prado@es|||», Museo Nacional del Prado, accedido 5 de marzo de 2019, https:/www.museodelprado.es/ actualidad/multimedia/el-sonido-de-la-pintura-en-el-museo-del-prado/eb949e8a-bcc6-4c21-8a2e-b6d5cbbb9acc. 
$\mathrm{Al}$ igual que el cuadro de Brueghel y Rubens, la tesis Máquinas de gorjear: instrumentos para la representación del paisaje sonoro ahonda en la representación del oxímoron generado por la unión de los términos 'sonido' y 'paisaje' a través del estudio de una serie de instrumentos. Tras la exposición de las intuiciones iniciales en el prólogo, este capítulo de introducción presenta los fundamentos de la investigación.

\section{A. OrÍGENES DE LA INVESTIGACión}

La presente tesis doctoral ha sido desarrollada en el Departamento de Proyectos Arquitectónicos (DPA) de la Escuela Técnica Superior de Arquitectura (ETSAM) de la Universidad Politécnica de Madrid (UPM) y en el Institut für Architektur und Städtebau de la Universität der Künste de Berlín (UdK). Tiene su origen en la conjunción del aprendizaje adquirido durante los cursos de Proyectos Arquitectónicos desarrollados por Darío Gazapo y Concha Lapayese -basados en la hibridación de la arquitectura y las acciones artísticas en el paisaje- y en los seminarios titulados Transferencias, proyecto arquitectónico y pensamiento contemporáneo impartidos por Juan Miguel Hernández León en el Máster en Proyectos Arquitectónicos Avanzados de la UPM entre 2013 y 2018. Las investigaciones de Gazapo, Lapayese y Hernández León defienden el estudio del paisaje como medio capaz de ampliar los horizontes de la Arquitectura ${ }^{3}$. Una inquietud compartida que impulsa, asimismo, esta tesis.

¿Desde dónde se construye el paisaje?, obra referencial en el pensamiento de Darío Gazapo y Concha Lapayese, describe un método de investigación basado en un recorrido de ida y vuelta. Partiendo de lo particular, de las miradas sensibles que generan múltiples tipos de paisaje, se retorna a lo genérico con lo aprendido en el análisis de lo específico:

La definición de "Paisaje" lleva implícita la idea de construcción, y en consecuencia, el empleo de una "lógica específica" que posibilite esa acción de formalización del concepto. La primera acción del proceso, supone una elección sobre la posición referencial en la que se localiza el constructor de paisajes. Es a partir de esa hipótesis o decisión inicial, desde donde, a continuación, se desarrollará un proceso vertiginoso e imprevisible, que concluirá con la formalización de un determinado paisaje. Es a partir del análisis de tales

3. Los artículos y ensayos ¿Desde dónde se construye el paisaje? (el cual presenta los fundamentos del pensamiento de Darío Gazapo y Concha Lapayese) y Ser-Paisaje (obra en la que Hernández León profundiza en la ontología del concepto paisaje) son de especial relevancia para esta investigación. Darío Gazapo de Aguilera y Concha Lapayese Luque, «¿Desde dónde... se construye el paisaje?», AUS, n. 7 (2010): 12-15, https://doi.org/10.4206/aus.2010.n703.; Juan Miguel Hernández León, Ser-paisaje (Madrid: Abada Editores, 2016). 
situaciones, desde donde es posible la discusión y la crítica. Es desde el origen del proceso de pensamiento, desde donde se establece la especificidad en la forma de la mirada... ${ }^{4}$

Tomando como guía las palabras de Gazapo y Lapayese, el posicionamiento sonoro como decisión inicial para llevar a cabo la construcción del paisaje abre un proceso imprevisible que permite profundizar en el conocimiento de lo sensible a través de su representación.

\section{B. Prototipo experimental}

Lo abstracto construye la realidad. No me interesa la abstracción por sí misma, sino porque nos ayuda a comprender la realidad, sobre todo la realidad interior de las cosas. ${ }^{5}$

\section{P. Boulez}

El Laboratorio de paisaje del Máster en Proyectos Arquitectónicos Avanzados 5 de la ETSAM $\mathrm{UPM}^{6}$ propuso a sus alumnos como ejercicio de curso explorar los campos de batalla de la costa de Normandía y los paisajes de guerra de la Segunda Guerra Mundial desde una mirada creativa y personal. Para abordar esta tarea, y profundizando en los resultados de investigaciones previas realizadas en torno a la relación entre sonido y paisaje ${ }^{7}$, se fabricó un artefacto, el prototipo Two Twittering Boxes, diseńado para el estudio del paisaje del acantilado del Pointe du Hoc (Francia) a través de la representación del paisaje sonoro pretérito de la batalla acaecida en el lugar en $1944 .{ }^{8}$

El 6 de junio de 1944, el conocido como día D, comenzó la denominada Operación Overlord, en la que las tropas de los Aliados iniciaron la liberación de la Europa Occidental ocupada por

\footnotetext{
4. Darío Gazapo de Aguilera y Concha Lapayese Luque, «¿Desde dónde... se construye el paisaje?», AUS, n. 7 (2010): 12-15, https://doi.org/10.4206/aus.2010.n7-03.

5. Jesús Ruiz Mantilla, «Pierre Boulez: "A mí lo que me mueve es la transgresión”, EL PAÍS Semanal, 19 de junio de 2013, https://elpais.com/elpais/2013/06/18/eps/1371549174_474928.html.

6. Laboratorio de Paisaje del Máster en Proyectos Arquitectónicos Avanzados 5 (ETSAM-UPM). Curso 20132014. Línea de investigación: paisaje y gran escala. Dirigido por Concha Lapayese Luque.

7. Covadonga Blasco Veganzones, Proyecto Fin de Carrera: Digitopia-Centro de investigación de la Música y el Sonido Digital. Premio Fin de Carrera de la XII Bienal Espańola de Arquitectura y Urbanismo. Publicado en: Bienal Española de Arquitectura y Urbanismo et al., eds., XII Bienal Española de Arquitectura y Urbanismo = 12th Spanish Architecture and Urbanism Biennial (Barcelona: Fundación Caja de Arquitectos, 2013), 476.

8. Covadonga Blasco Veganzones, «La dimensión sonora del paisaje. Herramientas, modelos y prototipos aplicados para la interpretación del paisaje sonoro pretérito» (Máster en Proyectos Arquitectónicos Avanzados, E.T.S. Arquitectura (UPM), 2014), http://oa.upm.es/35474/.
} 



1112

Figura 8. Pointe du Hoc. Estado actual

Figuras 9-10. Vista aérea del Pointe du Hoc en 1944

Figuras 11-12. Covadonga Blasco. Caja del evento sonoro. Planos de ejecución y pasos para su puesta en funcionamiento (2014) 
la Alemania nazi durante la Segunda Guerra Mundial. Situado entre las playas Omaha y Utah, un acantilado de 30 metros que domina la vista de ambas playas, el Pointe du Hoc, resultó ser un punto estratégico debido a su topografía y localización. La posición fue atacada durante todo el mes de mayo de 1944, dos meses antes del desembarco, con bombardeos continuos de día y de noche, y los días 2, 3 y 4 de junio. Como resultado de los bombardeos, la topografía se transformó en un paisaje lunar, lleno de hundimientos producidos por los impactos de las bombas sobre el terreno. Actualmente, cientos de cráteres esparcidos por el lugar conforman uno de los paisajes de la Segunda Guerra Mundial que mejor conservan la crudeza de la batalla. ${ }^{9}$

Tras la visita del lugar, se consideró que los cráteres resultantes de los ataques aéreos conformaban la huella sonora de las detonaciones de las bombas lanzadas sobre el territorio. Mediante el estudio de fotos aéreas, se descubrió que la aparente aleatoriedad de la disposición de los cráteres seguía un patrón lineal consecuencia de las formaciones en estrella de los aviones que sobrevolaron el acantilado. Este hallazgo fundó una descripción gráfica de la que emerge la perspectiva histórica del acontecimiento, siendo lo visual, el resto material de los impactos, el vestigio sonoro susceptible para el análisis del mismo. Este planteamiento pretendía revelar la génesis del paisaje actual del Pointe du Hoc, haciendo sonora la lógica espacial del evento destructivo que lo conformó. Partiendo de esta premisa, se fabricó un prototipo para llevar a cabo la lectura sonora del lugar.

El prototipo Two Twittering Boxes se compone de dos cajas aparentemente idénticas: la caja del evento sonoro y la caja del sonido del paisaje.

La primera caja, la caja del sonido del paisaje, contiene el registro de los sonidos del lugar, recogidos el día 8 de noviembre de 2013. En la grabación se distinguen tres agentes sonoros mezclados: el viento, el rumor amortiguado del mar, y las voces de los habitantes. Esta caja se basa en el término acuñado por Murray Schafer esquizofonía ${ }^{10}$, que consiste en la separación electroacústica de los sonidos de la fuente original que los emite. La caja del sonido del paisaje presenta, por tanto, una doble dislocación (espacial y temporal) de los sonidos registrados, pues al reproducirse la grabación mediante un pequeño amplificador oculto en el interior de la

9. Fotografías y descripción de la batalla en Paul Williams, Hitler's Atlantic Wall: Normandy: Construction and Destruction (Pen and Sword, 2013).

10. «Esquizofonía: del griego schizo, "escindir”, y fono, “voz, sonido”. La primera vez que utilicé este término fue en El nuevo paisaje sonoro para referirme a la escisión entre un sonido original y su reproducción electroacústica. Los sonidos originales están ligados a los mecanismos que los producen. Los sonidos reproducidos de manera electroacústica son copias y pueden ser repetidos en otros momentos o lugares. Empleo esta palabra nerviosa para hacer hincapié en el efecto aberrante del desarrollo del siglo XX.» R. Murray Schafer, El paisaje sonoro y la afinación del mundo (Barcelona: Intermedio, 2013), 369. 
caja, esta se desplaza en el tiempo, cada vez más lejano, de su fecha de registro, y de su espacio original ${ }^{11}$.

La segunda caja, la caja del evento sonoro, contiene en su interior la recreación a escala ${ }^{12}$ del conjunto de bombardeos que tuvieron lugar entre abril y junio de 1944, y supone una reflexión sobre la movilidad del espacio acústico y sus componentes. Partiendo del objeto sonoro $^{13}$, se desvela el acontecimiento acústico por adición de objetos. Es decir, el impacto de una bomba en el terreno es el objeto sonoro de estudio, y la suma de todos los impactos, en el orden en que se producen, conforma el acontecimiento acústico analizado. Las trayectorias y posiciones fueron extraídas de la observación de las fotografías aéreas realizadas por los aviones de reconocimiento en los momentos posteriores a los bombardeos. Antes de accionar la caja, las trayectorias reconstruidas deben cargarse con la munición a escala ${ }^{14}$. Esta caja dispone de una tarjeta horizontal marcada con once segmentos que, al retirarla en once segundos, haciendo coincidir cada marca con un segundo de tiempo, consigue recrear la velocidad de vuelo de los aviones sobre el territorio. A medida que se desliza esta tarjeta, la munición a escala golpea progresivamente la caja de resonancia interna que alberga el cubo. El sonido del golpeteo secuenciado que se obtiene es captado por un micrófono interior que desplaza en tiempo real el sonido de la segunda caja al altavoz escondido en el interior de la primera.

Mediante el prototipo fabricado, la lógica de la construcción del paisaje del Pointe du Hoc se hace legible mediante la lectura sonora de las huellas de las bombas que quedaron en el territorio. El sonido de la recreación del ataque contiene un ritmo, un orden que se desvela en la dislocación del espacio, al mismo tiempo que la percepción temporal del acontecimiento nos da la clave para entender la agresividad de la batalla.

Finalmente, la puesta en marcha del prototipo ante una multitud, consigue que un grupo de individuos actúen como una sola mente, y que todos los participantes se sumerjan en la escucha y en la construcción individualizada de la imagen de un paisaje a partir de un estímulo sonoro común.

De la experiencia del prototipo se obtuvieron las siguientes conclusiones:

- La escucha es un proceso de captación de información, un acto consciente y

11. También podría haberse realizado el experimento en el propio lugar, en Francia, y se suprimiría la dislocación espacial, quedando solo la temporal.

12. Escala en el eje X: 1: 10.000 / Escala en Y: 1: 100.000 / Escala espacio/tiempo 1:1

13. El objeto sonoro será desarrollado más adelante. Ver Capítulo 1. Apartado 1.3.3. Estructuras de percepción.

14. Perdigones redondos de $4,5 \mathrm{~mm}$. 
direccionado, una percepción activa que permite analizar un acontecimiento sensible. Al igual que la vista, la escucha proporciona imágenes de fondo e imágenes figura. El oyente, mediante la inmersión en el proceso y según su familiaridad con los sonidos, conforma una imagen virtual a partir del reconocimiento de los estímulos sonoros captados.

- En consecuencia, se establece así el sonido y su acción consciente asociada, la escucha, como medio de conocimiento sensible válido para alcanzar una comprensión profunda de la realidad.

- El valor del artefacto ideado reside en que no sólo transforma el entendimiento de un lugar catalizando las relaciones espaciales que existen en él, sino que además determina aquello que puede ser un motivo de reflexión en el ámbito en el que se emplea.

Tras experimentar el prototipo Two Twittering Boxes, el ensayo determinó la necesidad de una reflexión más profunda sobre el transvase de lo visual a lo sonoro y la representación de aquello que se escapa de los ojos sin abandonar el campo perceptivo de lo sensible.

Este ejercicio académico se convirtió en condición a priori de la existencia de casos similares en otros contextos y disciplinas. Una vez presentado el prototipo en congresos internacionales ${ }^{15}$ y tras debatir sus posibilidades científicas con arquitectos y artistas ${ }^{16}$, se inició esta investigación en torno a los aspectos que ligan la representación del paisaje y el sonido mediante instrumentos.

\section{Hipótesis y objeto de estudio}

Artistas, músicos y arquitectos cuestionan las vías de representación del sonido con el fin de comprender su complejidad y riqueza. Más allá de las curvas y funciones matemáticas que evidencian las leyes físicas de la acústica, la atención sensible hacia las fuerzas y causas propias de los estímulos sonoros propicia la creación de nuevas formas visuales de expresión del sonido.

El concepto Soundscape o paisaje sonoro nace como consecuencia de la interrelación entre

15. Presentado en el congreso Sound Thought, Universidad de Glasgow, 2016 «SOUND THOUGHT 2016», Issuu, accedido 7 de junio de 2020, https://issuu.com/soundthought/docs/st_program_final. ; resultados publicados en: Covadonga Blasco Veganzones, "Two Twittering Boxes: A spatial intermediary for studying the soundscape of the past», Displacements Journal, n. ${ }^{\circ}$ (enero de 2018): 191-201.

16. Mi agradecimiento a Juan Navarro Baldeweg y Juan de Dios Hernández por su tiempo y apoyo. 
ciencia, arte, arquitectura y filosofía que se produjo desde finales del siglo XIX hasta los años setenta del siglo XX. La evolución de la tecnología sonora, la incorporación de esta tecnología a las prácticas artísticas, y el entendimiento contemporáneo del paisaje como proceso dinámico ligado a una acción, son sucesos que han convertido al sonido en un medio capaz de ensanchar el significado del paisaje.

En la percepción directa de un fenómeno sonoro, el sujeto obtiene una información, unas reglas que crean un mundo al mismo tiempo que lo representan. Partiendo de la hipótesis de que la representación del concepto paisaje sonoro es, a priori, posible, la investigación se centra en el estudio de los instrumentos que permiten dicha representación.

La representación del concepto paisaje sonoro es, en consecuencia, el objeto de estudio de la investigación. A partir del análisis de las teorías que respaldan la hipótesis de partida y del estudio de la evolución del concepto, se presentan cinco tipos de instrumentos. Las obras que relacionan el sonido y el paisaje del compositor John Cage, el arquitecto Juan Navarro Baldeweg y el filósofo Gilles Deleuze, se emplean para ejemplificar cada tipo. En torno a estas tres figuras, se despliega la reflexión sobre las variables semánticas, espaciales y temporales contenidas en el paisaje sonoro, al mismo tiempo que la exposición cronológica de los acontecimientos que relacionan sus trayectorias personales y profesionales entre los ańos 1939 y 1989, muestran la evolución del concepto paisaje sonoro desde un enfoque multidisciplinar.

\section{ESTADO DE LA CUESTIÓN}

Así pues, conviene, con vistas a promover una teoría de la serie generalizada, definir las características propiamente dichas del universo sonoro sobre el que ésta ha de regir; debemos, por lo tanto, estudiar los constituyentes de este universo, los espacios en los que se moverán, encontrarles criterios comunes. Es necesario, de hecho, ampliar nuestro horizonte a universos diferentes a aquel al que estamos acostumbrados. ${ }^{17}$

P. Boulez, Pensar la música hoy

Para encontrar el lugar que ocupa el paisaje sonoro en el panorama arquitectónico actual, será necesario, como advertía Pierre Boulez, ampliar nuestro horizonte a universos diferentes. Para

17. Pierre Boulez, Pensar la música hoy (Murcia: Colegio Oficial de Aparejadores y Arquitectos Técnicos de la Región de Murcia : Consejería de Educación y Cultura de la Región de Murcia : Fundación Cajamurcia, 2009), 125 . 
ello, tras un breve repaso por la historia de la representación del sonido del paisaje, se presentan en este apartado las disciplinas involucradas en el desarrollo del objeto de estudio, así como una muestra de las investigaciones, exposiciones y publicaciones internacionales sobre paisaje y sonido, haciendo hincapié en aquellas que estén vinculadas con proyectos docentes en el contexto académico de la arquitectura.

\section{i. Breve historia de la representación del sonido del paisaje hasta la Segunda Guerra Mundial}

In theory, at least, the whole of Australia could be read as a musical score. There was hardly a rock or creek in the country that could not or had not been sung. One should perhaps visualise the Songlines as a spaghetti of Iliads and Odysseys, writhing this way and that, in which every 'episode' was readable in terms of geology. ${ }^{18}$

\section{B. Chatwin, The Songlines}

Movido por la voluntad de conocer el significado de las antiguas huellas de sueños o Songlines $^{19}$, el escritor Bruce Chatwin ${ }^{20}$ (1940-1989) viajó a Australia para estudiar cómo los aborígenes australianos cartografiaron el territorio a través de un laberinto de caminos invisibles, los songlines. Como explica el arquitecto Francesco Careri en su ensayo Walkscapes ${ }^{21}$, estos recorridos van ligados a un cántico que trata sobre una o más historias mitológicas ambientadas en el territorio. Las Songlines son un modo particular de entender el paisaje a través del sonido en el que los elementos físicos de la naturaleza se ordenan en una descripción secuencial cantada, en una cartografía sonora. Cada montaña y cada río pertenecen a un conjunto de historias que enfatizan el espacio del territorio, propiciando una forma de deambulación musical donde la música crea el territorio ${ }^{22}$.

Desde los albores de la humanidad, los sonidos producidos por los elementos de la naturaleza (el sonido del mar, la velocidad del viento, los truenos...) conforman el fundamento del paisaje

18. Bruce Chatwin, The songlines, Penguin classics (New York, N.Y: Penguin Books, 2012), 13.

19. Ibid., 12.

20. Novelista y escritor de libros de viajes inglés.

21. Francesco Careri, Walkscapes: walking as an aesthetic practice, 6th print run, Land \& scape series 1 (Barcelona: Gili, 2009).

22. Chatwin, The songlines, 14. El canto hace la existencia del mundo porque existir, como reflexiona el protagonista del relato, es ser percibido. La acción de hacer aparecer el mundo no es otra cosa que hacer poesía, en el sentido original de la poiesis griega, que significa creación. 
sonoro primordial ${ }^{3}$. Su imitación es un rasgo característico de la evolución humana, pues a través del vocabulario onomatopéyico, el ser humano reproduce con su voz los elementos de la naturaleza, estableciendo un proceso de comunicación con el entorno en el que «se recibe una impresión y, a cambio, se devuelve una expresión $»^{24}$ :

Uno debe escucharlos [los sonidos de la naturaleza] para darse cuenta de la manera extremadamente realista en la que los aborígenes imitan los ruidos de los animales y los sonidos de la naturaleza. Incluso organizan conciertos de la naturaleza en los que el cantante imita un sonido concreto (las olas, el viento, los crujidos de los árboles, los chillidos de los animales asustados): conciertos de una sorprendente magnificencia y belleza ${ }^{25}$.

La imitación de sonidos se fue haciendo cada vez más culta gracias a la evolución de los instrumentos musicales. Este hecho, la evolución de la imitación de los sonidos de la naturaleza mediante onomatopeyas al empleo de instrumentos, sirve como arranque de uno de los escritos más importantes de la arquitectura moderna, El Modulor de Le Corbusier. En la búsqueda de un instrumento visual que permitiera la unificación de las medidas americanas y europeas, Le Corbusier se pregunta: «Cómo seccionar la continuidad del fenómeno sonoro?» ${ }^{26}$. El inicio de El Modulor recuerda que, al igual que la cinta métrica de Le Corbusier, los instrumentos musicales tienen un origen espontáneo que surge de la relación que establece el ser humano con el mundo. ${ }^{27}$

Los primeros instrumentos musicales, ligados a la caza y a la guerra, aspiraban a la armonía del hombre con el universo, y manifestaban al mismo tiempo, como indica Bernard Sève ${ }^{28}$ en su estudio filosófico del instrumento musical ${ }^{29}$, «un gusto por la experimentación, por

23. Se adopta la denimonación de Schafer. Schafer, El paisaje sonoro y la afinación del mundo, 36.

24. Ibid., 70

25. Marius Schneider: «Primitive Music», en The New Oxford History of Music, vol. 1, Londres:s.n., 1957, p.9. citado en R. Murray Schafer, El paisaje sonoro y la afinación del mundo (Barcelona: Intermedio, 2013), 68.

26. Le Corbusier, El Modulor (Argentina: Poseidón, 1953), 15.

27. «Durante milenios se ha podido hacer uso del sonido para cantar o para tocar y danzar. Fue la primera música que se transmitió oralmente. Pero un día -seis siglos antes de J.C.- alguien se preocupó de hacer transmisible para siempre una de estas músicas de otro modo que no fuera de boca a oreja, y por tanto, escribirla, para lo cual no existía método ni instrumento; y como se trataba de fijar el sonido en puntos determinados, rompiendo así su perfecta continuidad, había que representarlo por medio de elementos captables, y, por consiguiente, recortar $e l$ continuo de acuerdo con un cierto convenio y hacer graduaciones, las cuales constituirían los peldaños de una escala (artificial) del sonido.» Ibid., 15.

28. Bernard Sève (Clermont-Ferrand, Francia) es profesor de Filosofía y Estética en la Universidad de Lille, Francia, desde septiembre de 2013. Sus áreas de investigación abarcan la historicidad, los instrumentos, la literatura, la música, la filosofía del arte y el tiempo, principalmente. «Bernard SEVE - Université de Lille», accedido 8 de junio de 2020, https://pro.univ-lille.fr/bernard-seve/.

29. Bernard Sève, El instrumento musical: un estudio filosófico, 2018. 
la exploración sonora, por el disfrute del ruido» ${ }^{30}$. La idea del origen imitativo que, según Lucrecio $^{31}$, tenían los instrumentos, fue decayendo a medida que la evolución cultural introdujo una gran cantidad de posibilidades sonoras con nuevos instrumentos. Ya no era necesaria la intervención de los dioses para explicar la necesidad de estos, sino que existían por el placer de producir nuevas formas de temporalidad. Con el instrumento, además de imbricar el sonido y el tiempo, Sève defiende que «se configuran los ritmos, las duraciones, las intensidades, las respiraciones, las velocidades, todo cuanto constituye la riqueza y singularidad del tiempo musical $\aleph^{32}$.

La música descriptiva, propia de los compositores del siglo XVIII, crearía 'paisajes' tratando de evocar atmósferas sonoras ideales en la imaginación de los oyentes ${ }^{33}$. Las obras de Händel, Haydn o Schubert son una suerte de retablos panorámicos ${ }^{34}$ en los que el compositor observa la naturaleza y reproduce los sonidos como un observador en la distancia, como el pintor paisajista que entiende el paisaje como una representación ajena a él. Así lo explica Murray Schafer:

La imitación consciente del paisaje en la música se corresponde en la historia con el desarrollo de la pintura de paisaje, que, según parece, fue inicialmente cultivada por los pintores flamencos del Renacimiento, para acabar convirtiéndose en el principal género pictórico durante el siglo XIX. [...] Las imitaciones de la naturaleza se creaban entonces para ser exhibidas en decorados artificiales. Su función era aquí la de servir de múltiples ventanas, arrojando al espectador hacia diferentes vistas. [...] Igualmente, una pieza de música descriptiva convierte las paredes del auditorio en ventanas que dan a diversos paisajes. Mediante estas ventanas metafóricas rompemos los confines de la ciudad para llegar hasta el libre paysage que hay más allá. ${ }^{35}$

A lo largo del siglo XVIII, el pensamiento estético había construido un sistema artístico en el que las Bellas Artes se definían por su naturaleza imitativa. ${ }^{36}$ En el caso de la música, esta sistematización abría importantes interrogantes. ¿Qué puede imitar la música? ¿con qué

30. Ibid., 59.

31. Lucrecio, «De la naturaleza de las cosas: poema en seis cantos», versos 1995-2010. trad. José Marchena, Biblioteca Virtual Miguel de Cervantes, accedido 6 de noviembre de 2019, http://www.cervantesvirtual.com/obravisor/de-la-naturaleza-de-las-cosas-poema-en-seis-cantos--0/

32. Sève, El instrumento musical, 2018, 15.

33. Schafer, El paisaje sonoro y la afinación del mundo, 154.

34. Ibid., 155.

35. Ibid., 154.

36. Alberto Hernández Mateos, prólogo a Sobre la música, de Arthur Schopenhauer, (Madrid: Casimiro Libros, 2016), 11. 
medios puede hacerlo? El hecho de que la música se convirtiera en un arte imitativo fue muy criticado por Arthur Schopenhauer (1788-1860), quien en 1819 publicó El mundo como voluntad y representación. Para Schopenhauer, la música va más allá de la imitación, otorgándole una dimensión que trasciende al resto de artes. ${ }^{37}$ En consecuencia, Schopenhauer criticó Las estaciones de Haydn o la Pastoral de Beethoven, al considerar que en esas obras la música es una representación pictoralista de los fenómenos naturales y de las actividades humanas. En ellas, la música resulta ser la copia (imitación) de una copia (el mundo como representación). Para Schopenhauer, la música, ajena a la imitación del mundo como representación, es en sí misma un universo autónomo y sujeto a unas normas propias que escapan de la mímesis. ${ }^{38}$

Otro ejemplo de la exaltación de la naturaleza en la música, ya en el Romanticismo, es la Sinfonía $\mathrm{n}^{\circ} 1$ de Gustav Mahler. Al comienzo de la partitura de la introducción de la obra, Mahler anotó: Wie ein Naturlaut (Como un sonido de la naturaleza), indicando que el sonido de los instrumentos debía evocar el sonido de la naturaleza.

Doce años antes del estreno de esta sinfonía en Viena, Thomas Alva Edison (1847-1931) había patentado en 1877 el primer sistema de grabación analógica en el que las ondas sonoras eran transformadas mediante un transductor acústico-mecánico en un registro legible. El fonógrafo fue uno de los primeros sistemas capaces de convertir la estructura invisible del sonido en una imagen reproducible, haciendo posible que el sonido volviera a presentarse, en otro espacio y otro tiempo, separado de su fuente emisora. Progresivamente, el fonógrafo constituyó un gran debate epistémico al tratarse de una máquina capaz de reproducir el pasado. Gracias a él, los sonidos de la naturaleza ya no solo se representaban, sino que la naturaleza misma podía re-presentarse $e^{39}$.

La tecnología sonora es el origen del concepto paisaje sonoro. ${ }^{40}$ A principios del siglo XX, los artistas se convirtieron en inventores combinando sus visiones estéticas con los nuevos instrumentos de reproducción y almacenamiento del sonido que aumentaban la sensibilidad

37. Cfr. Ibid., 16.

38. Ejemplo de esta idea es el preludio de El oro del Rin (Richard Wagner, 1854) que «plasma la gestación de la música a partir de lo no musical. El nacimiento wagneriano de la música se realiza con instrumentos, no con la voz. [...] siendo los instrumentos los que garantizan el paso del silencio al ruido y después del ruido al sonido musical, para convertirse este más tarde al "lenguaje” de la música.» Bernard Sève, El instrumento musical: Un estudio filosófico, trad. Javier Palacio Tauste, Edición: 1 (Acantilado, 2018), 114-15.

39. Dieter Daniels, «Artist as Inventors and Invention as Art: A Paradigm Shift from 1840 to 1900 », en Artist as inventors, inventors as artists (Hatje Cantz, 2008), 40.

40. Cfr. Stefan Helmreich, «Listening Against Soundscapes», Anthropology News 51, n. ${ }^{\circ} 9$ (diciembre de 2010): 10-10, https://doi.org/10.1111/j.1556-3502.2010.51910.x. 



151617
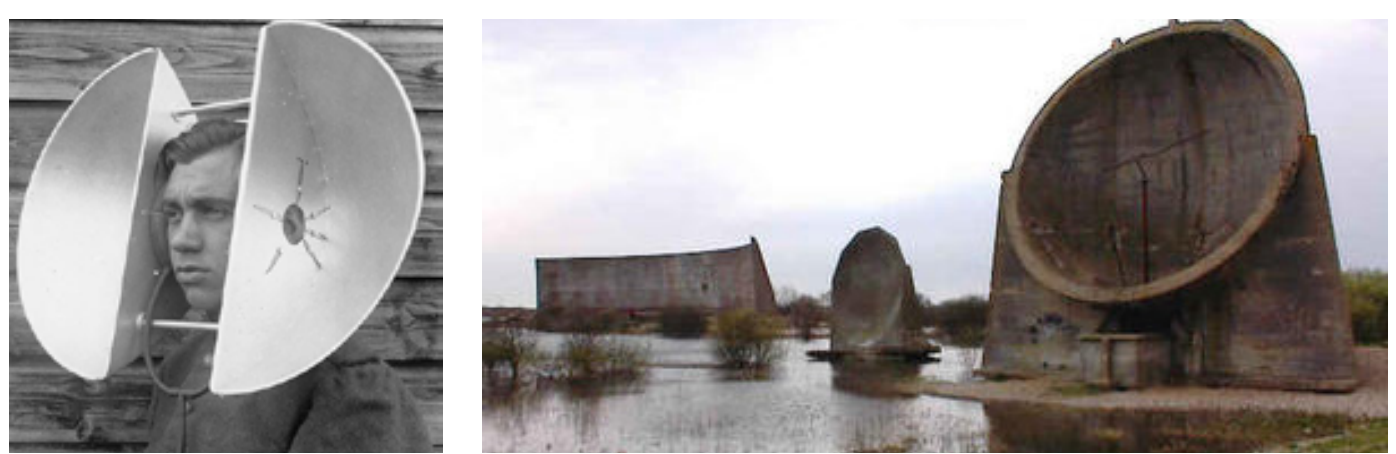

Figura 13. Película de 35-mm. Parte izquierda: registro visual del sonido en el minuto anterior al final de la Primera Guerra Mundial. Parte derecha: registro después de que las armas dejaran de disparar a las 11 a.m. del 11 de noviembre de 1918

Figura 14. Sound Rangers del ejército alemán, 1917

Figura 15. Localizador acústico alemán, 1917

Figura 16. Sistema de localización acústica de dos trompas en Bolling Field, USA, 1921

Figura 17. Localizador acústico de cuatro cuernos, 1920-1930

Figura 18. La parábola individual holandesa, 1930-40

Figura 19. Espejos acústicos en Kent, Inglaterra 


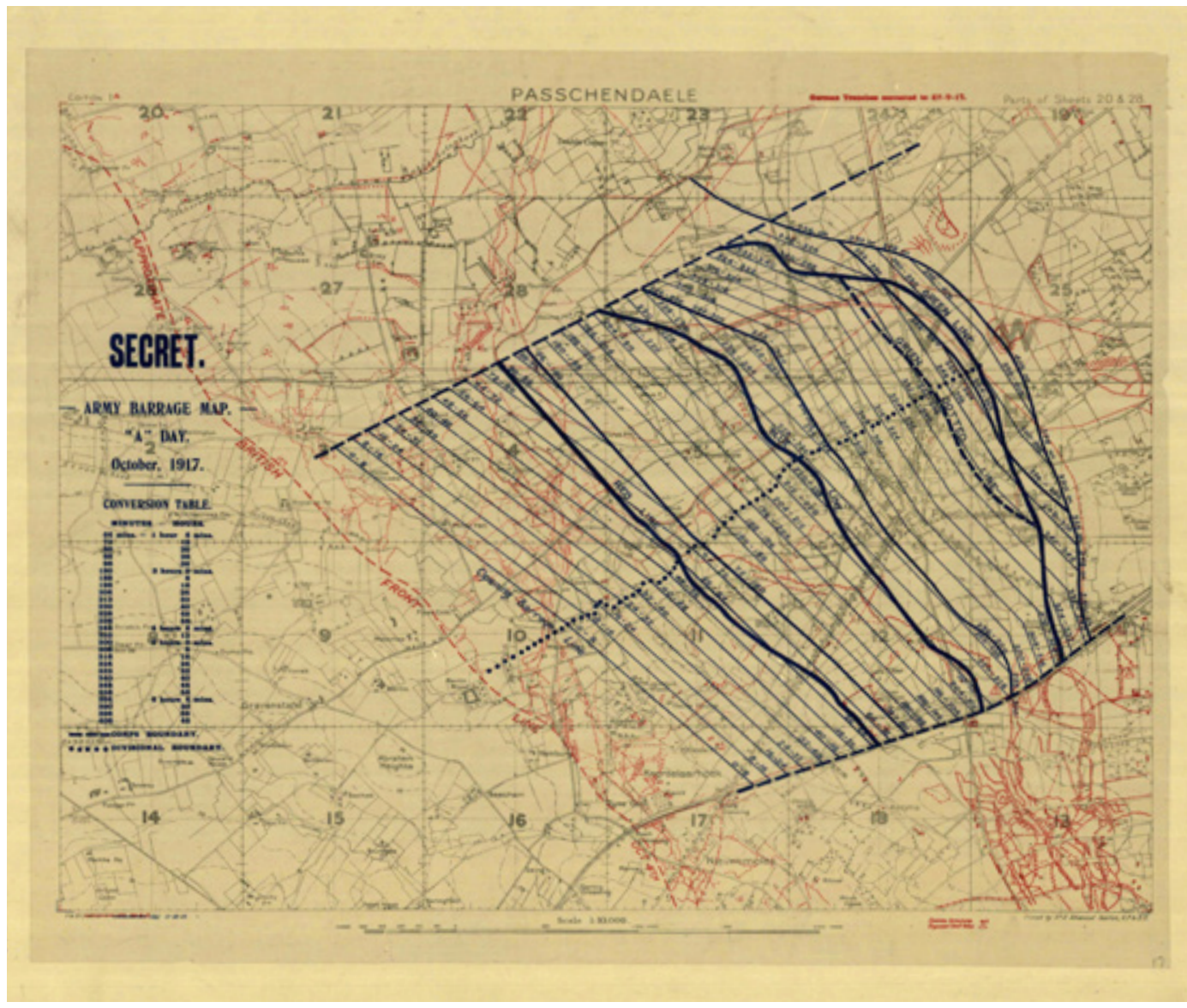

Figura 20. Mapa de barrido de la primera batalla de Passchendaele, Bélgica, 1917 
auditiva del ser humano más allá de su capacidad natural. ${ }^{41}$ El teléfono y el fonógrafo fueron los primeros sistemas en revocar la (hasta entonces imposible) separación del lenguaje oral y el cuerpo. La tecnología hacía posible la presencia invisible de un cuerpo, al mismo tiempo que el lenguaje se hacía físico en las marcas en un disco de cera que permitían su reproducción. La irrupción de los sistemas de almacenamiento y reproducción del sonido que comenzaron a emplearse a finales del siglo XIX, provocaron un salto metafísico en la imitación de los sonidos de la naturaleza, pues su representación podía sustituirse por sonidos reales grabados previamente. Una distorsión que permitiría cambiar la relación entre sujeto y objeto, entre obra escuchada y oyente de la misma.

La Primera Guerra Mundial fue el laboratorio en el que se ensayó la teledetección, la geolocalización acústica y otras muchas técnicas basadas en la transducción sonora. En octubre de 1915, el oficial de artillería y premio Nobel de Física William Lawrence Bragga2 (18901971) desarrolló el Sound Ranging ${ }^{43}$, el método de ubicación que empleaba el sonido para localizar baterías de artillería. El sistema consistía en una serie de micrófonos enterrados en el territorio enemigo. El desarrollo tecnológico permitió crear micrófonos capaces de detectar y diferenciar entre la detonación de las armas y la caída de los proyectiles en el suelo la presión del aire. Estos dos momentos, recogidos por los micrófonos situados en diferentes puntos del territorio, se convertían en una señal electroacústica que informaba de la posición exacta del fuego enemigo sin necesidad de enfrentarse cuerpo a cuerpo. Para reflejar las posiciones calculadas, se realizaban unos mapas de posición que aportan una localización concreta del sonido en el tiempo y el espacio. El Sound Ranging demuestra la viabilidad del empleo del sonido como medio para el conocimiento del espacio a gran escala. De forma similar, los espejos acústicos del canal de la Mancha permitín ver más allá de las nubes o de las montañas gracias a la refracción del sonido. La localización acústica se empleó desde la Primera Guerra Mundial hasta los primeros años de la Segunda, cuando todos estos sistemas fueron sustituidos por radares electromagnéticos más precisos.

Tras el desastre moral y político de la Primera Guerra Mundial, la experimentación tuvo

41. Algo que posteriormente, siguiendo el mismo propósito, ampliará el artista Geögy Kepes en la exposición The New Landscape. Ver capítulo 2, Eje 1.

42. William Van der Kloot, "Lawrence Bragg's role in the development of sound-ranging in World War I", Notes and Records of the Royal Society 59, n. 3 (22 de septiembre de 2005): 273-84, https://doi.org/10.1098/ rsnr.2005.0095.

43. El Sound Ranging fue valioso en la victoria británica en Cambrai en 1917 y vital en la batalle de Amiens en 1918. El canal del Imperial War Museums explica esta técnica en el siguiente video: Sound Ranging and the End of The War, accedido 13 de noviembre de 2019, https://www.youtube.com/watch?v=1pjY9W-S3cI. 
lugar en todos los rincones de la sociedad y el arte. Siguiendo la estela de la ciencia, los artistas intuyeron el potencial que tenían los nuevos medios para la expresión artística y, autores como László Moholy-Nagy ${ }^{44}$ o Walter Benjamin ${ }^{45}$ comenzaron a plantearse los problemas epistemológicos derivados de la reproducción.

En 1919, Rainer Maria Rilke (1875-1926) describe en el texto titulado Ur-Geräusch (Sonido primario) sus impresiones tras su primer contacto con un fonógrafo. Rilke confiesa en él que lo que más le impresionó de aquella máquina no fue el sonido que emergía del embudo del aparato, sino ver el sonido plasmado en forma de marcas. La mezcla de esta fascinación con su obsesión por las calaveras, le llevaron a hacer una analogía entre la cicatriz de la sutura coronal y los surcos del cilindro de cera del fonógrafo:

La sutura coronal del cráneo (esto tendría que investigarse primero) tiene, supongamos, cierta similitud con la línea casi ondulada que la aguja de un fonógrafo graba en el cilindro receptor del aparato que gira. ¿Qué pasaría si uno cambiara la aguja y la dirigiera en su viaje de regreso a lo largo de un trazado que no se derivó de la traducción gráfica de un sonido, sino que existía de forma natural? Bueno, para decirlo claramente, a lo largo de la sutura coronal, por ejemplo ¿qué pasaría? Resultaría necesariamente un sonido, una serie de sonidos, música...

Sentimientos, ¿`cuáles? Incredulidad, timidez, miedo, asombro, cuál de todos los sentimientos posibles aquí me impide sugerir un nombre para el sonido primordial que luego haría su aparición en el mundo...

Dejando ese lado por el momento:[...] ¿no se podría poner debajo de la aguja y probar? ¿Hay algún contorno que uno no pueda, en cierto sentido, completar de esta manera y luego experimentarlo, cómo se hace sentir, así transformado, en otro campo de los sentidos? $?^{46}$

Las intuiciones de Rilke reflejan lo que fue para los artistas de vanguardia la tecnología de su tiempo: un estímulo de percepción y, al mismo tiempo, un desafío para la búsqueda de nuevos

44. En el ensayo Production-Reproduction de 1922, Moholy-Nagy sugiere que las tecnologías de reproducción como el gramófono podrían emplearse podrían emplearse con fines productivos de arte. La exposición ProductionReproduction (MOMA, diciembre 2014-marzo 2015) parte de este escrito para presentar una cronología de la fotografía modernista. «Production-Reproduction: The Circulation of Photographic Modernism, 1900-1950 | MoMA», The Museum of Modern Art, accedido 8 de junio de 2020, https://www.moma.org/calendar/ exhibitions $/ 1500$.

45. Walter Benjamin, La obra de arte en la época de su reproducción mecánica, 2017. De interés en esta obra, es la definición del aura como «la manifestación irrepetible de una lejanía (por cercana que pueda estar)».

46. Ibid.; Traducción de la autora. Cfr. Rainer Maria Rilke, Primal Sound (1919) (Juan Andrés Mucarquer, 1919), http://archive.org/details/rilkeprimalsound; «1919 Rainer Maria Rilke: Ur-Geräusch», accedido 17 de abril de 2019, https://www.uni-due.de/lyriktheorie/texte/1919_rilke2.html. 
medios artísticos. Como indica Dieter Daniels en su estudio sobre la relación entre artistas e inventores, «fue entonces cuando la tecnología se convirtió en motivación objetiva y subjetiva, en expresión e impresión al mismo tiempo» ${ }^{47}$. Los propios artistas comenzaron a construir máquinas que respondían y cuestionaban con una visión estética el impacto de la tecnología en la percepción del ser humano ${ }^{48}$.

A principios del siglo XX, los descubrimientos en los campos de la psicología, las técnicas de comunicación y la ergonomía, alimentaron los debates sobre la extensión del dominio de las percepciones humanas. Los artistas comenzaron a imaginar máquinas capaces de aumentar la sensibilidad. Entre ellos, destacó el austriaco Raoul Hausmann (1886-1971), uno de los primeros artistas en proporcionar una teoría moderna de las nuevas formas de percepción sensorial. Basándose en el optófono de d'Albe ${ }^{49}$, Hausmann escribió Optophonétique (1923), obra en la que expone sus ideas sobre la transformación de una percepción sensorial en otra, como la conversión de la luz en sonido y viceversa. ${ }^{50}$ Estas ideas y las experiencias asociadas a ellas, además de aplicarse en las prácticas artísticas, perfilaron una teoría de la percepción moderna $^{51}$ en la que el arte se consideraba un medio de experimentación científica. ${ }^{52}$

A través de la experimentación científico-artística, los instrumentos que componían a principios del siglo XX el paisaje sonoro de la modernidad ${ }^{53}$, se convirtieron en una 'extensión del hombre' que copiaba y mejoraba los sentidos. Dispositivos que mostraban nuevas dimensiones del espacio y el tiempo, permitiendo estar (al menos acústicamente) presentes en un lugar donde no está el cuerpo. Por primera vez, la dimensión acústica del espacio y el tiempo podían manipularse. La experiencia auditiva, dónde construir y cómo articular el espacio de la escucha,

47. Cfr. Dieter Daniels y Barbara U. Schmidt, eds., Artists as inventors, inventors as artists (Ostfildern, Germany: Hatje Cantz, 2008), 9. Traducción de la autora.

48. Uno de estos artistas fue Luigi Russolo (1885-1947). En su manifiesto para Un nuevo arte del ruido, Russolo escribe sobre el nuevo entorno sonoro del mundo post-industrial. Construyó el intonarumori, una máquina que imitaba el sonido de las máquinas.

49. Ver Capítulo Primero. Apartado 1.3.1. Procesos de conversión de señales: auscultación, transducción y reproducción.

50. Raoul Hausmann, «Optophonétique», en Raoul Hausmann et les avant-gardes, ed. Timothy Benson y Hanne Bergius (Dijon: Les Presses du Réel, 2014), 457-64.

51. Timothy O. Benson, ed., Raoul Hausmann et les avant-gardes, L' écart absolu (Dijon: Les Presses du Réel, 2014), 224.

52. Para ampliar sobre esta vision ver Cornelius Borck, «Blindness, Seeing, and Envisioning Prosthesis: The Optophone between Science, Technology, and Art», en Artist as inventors, inventors as artists (Hatje Cantz, 2008), 108-29.

53. Expresión tomada de Emily Thompson, The Soundscape of Modernity: Architectural Acoustics and the Culture of Listening in America, 1900-1933 (Cambridge, Mass.: The MIT Press, 2004). 


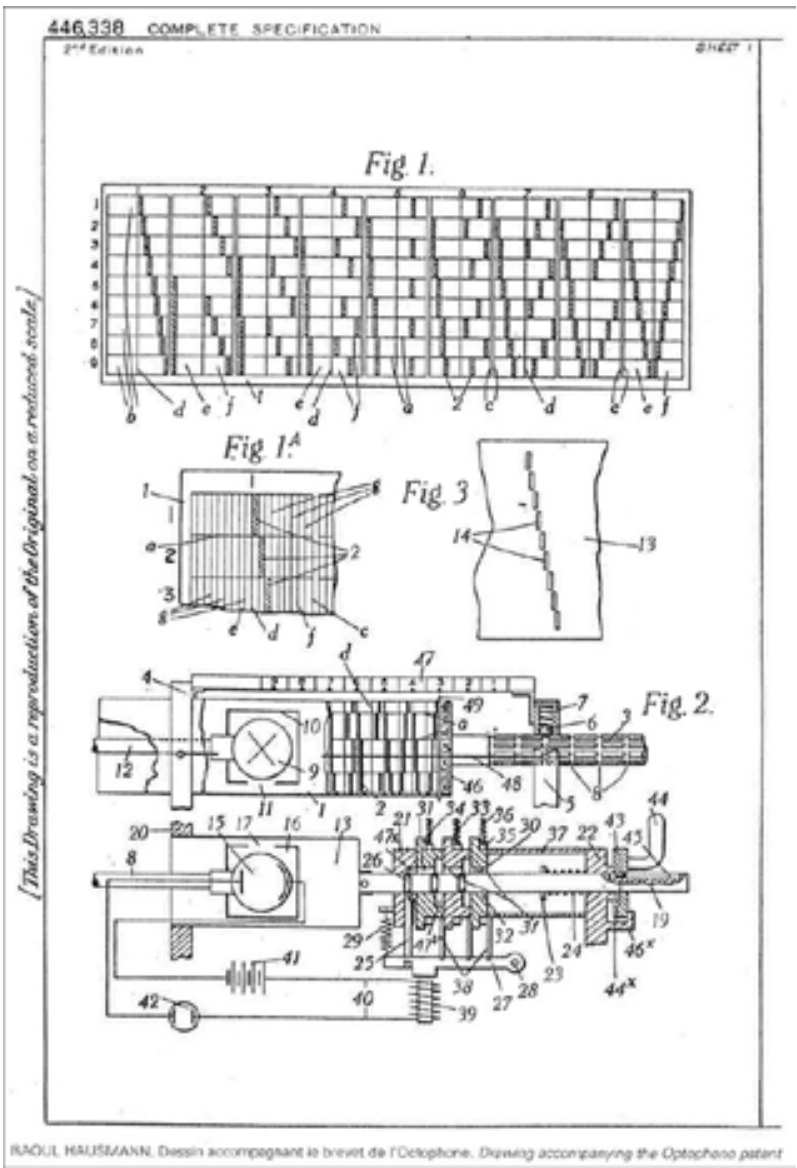

Figura 21. Raoul Hausmann. Dibujo que acompañaba a la patente del optófono (1936) 
se diseñaba y determinaba según las decisiones de un individuo, marcando así los primeros pasos del camino de la experimentación musical y el arte sonoro.

\section{Apostillas a The Soundscape. OuR Sonic EnVIRONMENT AND the Tuning of the WORLD}

Aesthetics and ecology are more closely connected than one thinks, and that two things suffer whenever this connection is not considered, namely the natural regeneration of resources, and fulfillment of the observer's expectations of the landscape. ${ }^{54}$

\section{BurcKhardT. Aesthetics and Ecology}

El mensaje de Lucius Burckhardt ${ }^{55}$ (1925-2003) en su texto Aesthetics and Ecology, remarca la importancia de la convivencia entre ecología y estética para lograr un equilibrio entre los recursos naturales y las expectativas culturales del hombre. Tal y como se expuso como avance de esta investigación en el congreso ECLAS 2017 Creation Reaction ${ }^{56}$, sumergidos en el debate entre forma artificial y forma natural, paisajistas y arquitectos se convierten en responsables de la construcción de un paisaje en el momento en el que se plantea controlar el curso natural del ecosistema. Durante los años setenta del siglo XX, el descontento con las nuevas formas de vida en la ciudad demandó un mayor conocimiento de la naturaleza. Un movimiento similar a lo que actualmente lleva a que el paisaje esté constantemente presente en los discursos arquitectónicos. ${ }^{57}$

La ecología acústica, impulsada por una nostalgia del 'sonido primario', nació con el fin de promover la revalorización del sonido como agente cultural activo mediante la conservación de los sonidos del ecosistema a través de su registro. El paisaje natural se revalorizó gracias a movimientos artísticos que surgieron en paralelo a la ecología acústica, como el Landart. Estos aportaron una mayor conciencia del medio ambiente, y de ellos emergieron propuestas de

54. Jesko Fezer y Martin Schmitz, Lucius Burckhardt Writings. Rethinking Man-made Environments: Politics, Landscape \& Design (Wien: Ambra, 2012), 212-23.

55. Sociólogo y economista suizo, teórico de la arquitectura y la teoría del diseńo. «Lucius Burckhardt Biography», accedido 8 de junio de 2020, https://www.lucius-burckhardt.org/English/Biography/Lucius_Burckhardt.html.

56. Covadonga Blasco Veganzones y Lucía Jalón Oyarzun, "War destruction and landscape design: from preserved memory to ecological listening», en ECLAS Conference 2017. Creation/Reaction, University of Greenwich Department of Architecture \& Landscape London UK, 2017), 189-200.

57. Cfr. Michael Jakob, What is landscape? Ediz. illustrata (List, 2018), 7. 
diseño o modificación de los entornos acústicos para reducir el nivel de ruido de los mismos. ${ }^{58}$

En su faceta como docente, a principios de los años setenta, el compositor R. Murray Schafer (1933- ) inició junto a otros expertos en acústica el proyecto World Soundscape Project ${ }^{59}$ en la Universidad Simon Fraser (Burnaby, Columbia Británica). El WSP tenía como objetivo aumentar la conciencia sobre los efectos que el sonido tiene en el ser humano mediante el análisis y el registro de sonidos ambientales a través de grabaciones, formando así una importante base de datos que permitía organizar talleres e impulsar proyectos de investigación ${ }^{60}$.

Con la intención de recopilar sus experiencias en el WSP y los resultados obtenidos en estudios previos ${ }^{61}$, Schafer publica The Soundscape. Our Sonic Environment and the Tunign of the World en 1977, obra referencial en el estudio del paisaje sonoro. El libro es, fundamentalmente, un manual docente cuya importancia radica en el glosario de términos que ofrece y que dejó estipulados como vocabulario básico para este campo de estudio (paisaje sonoro, objeto sonoro, acontecimiento sonoro, sonografía...). La influencia de dicho manual ha supuesto grandes avances, sobre todo en su labor sensibilizadora con el entorno acústico, pero también son muchos los expertos que señalan las imprecisiones que contiene.

Como establece Brandon LaBelle en su estudio cronológico de la relación entre sonido, espacio y prácticas artísticas Background Noise, Schafer y la ecología acústica buscan una ruta de escape del ruido de la ciudad moderna para reclamar la armonía del mundo a través del diseño acústico de los entornos antropizados mediante la imaginación del sonido a gran escala. ${ }^{62}$ LaBelle, volviendo la mirada al lenguaje, considera que Schafer busca una apertura cultural inventando un diccionario de términos esenciales, categorizando los sonidos como fenómenos efímeros y primarios de origen cósmico y mitológico. Otros expertos en acustemología como David Toop o Bill Fontana, son críticos con The Tuning of the World, ya que consideran que ha

58. Brandon LaBelle, Prólogo a Background noise: perspectives on sound art, Second edition (New York: Bloomsbury Academic, 2015), xiv-xv.

59. «Organización con sede en el Departamento de Investigaciones Sonoras y de Comunicaciones de la Universidad Simon Fraser de Columbia Británica (Canadá) y dedicada al estudio comparativo del paisaje sonoro mundial. La organización nació en 1971 y desde aquel momento ha llevado a cabo un buen número de trabajos de investigación nacionales e internacionales sobre la percepción auditiva, el simbolismo sonoro, la contaminación acústica, etc., todos los cuales han tratado de unir las artes y las ciencias del sonido a fin de desarrollar un campo de estudio interdisciplinario: el diseño acústico.» Schafer, El paisaje sonoro y la afinación del mundo, 370-71.

60. LaBelle, Background noise, 201.

61. La obra que marcará el camino de las siguientes publicaciones será The New Soundscape, un manual docente en el que se plantea la convivencia entre sonido y ruido y se intenta 'regularizar' el vocabulario musical incorporando los avances y las observaciones de John Cage. R. Murray Schafer, The New Soundscape; a Handbook for the Modern Music Teacher (Scarborough, Ont.: Berandol Music; sole selling agents: Associated Music Publishers, New York, 1969).

62. Ver LaBelle, Background noise, 219. 
arrastrado al paisaje sonoro a la simplicidad de ser entendido exclusivamente como la percepción del sonido del entorno. Entre los conceptos del glosario de Schafer que más controversia suscitan actualmente, se encuentran paisaje sonoro, marca sonora y sonografia.

Paisaje sonoro: El entorno sonoro. Técnicamente, es cualquier porción del entorno sonoro observado como campo de estudio. El término puede aplicarse, ya a entornos reales, ya a constructos, por ejemplo, de composiciones musicales o los montajes de cinta, especialmente cuando se los considera en calidad de entorno. ${ }^{63}$

Schafer, en la acepción de paisaje sonoro que ofrece en su glosario, habla de un 'entorno sonoro observado' empleando un inevitable lenguaje metafórico. Schafer deja todo el ámbito de aplicación de la expresión abierto (a la música, a lo real, a lo ficticio, a la composición...) manteniendo el término en una indefinición premeditada. No hay tampoco en él una referencia directa al paisaje, al landscape, sino al 'entorno', a un espacio mensurable, circundante, que no recoge la complejidad real del término.

En cuanto a la marca sonora, Schafer la define como «aquel sonido exclusivo a una comunidad o aquel cuyas cualidades hacen que sea observado o percibido de una manera determinada por la gente de esa comunidad». El teórico y artista sonoro François J. Bonnet ${ }^{64}$ considera que las características principales del sonido (su fugacidad y desvanecimiento constante), al convertirse en un registro permanente mejora el conocimiento de los eventos sonoros. Pero, al mismo tiempo, advierte de que la marca sonora, tal y como la entiende Schafer, queda limitada al sonido del pasado, a las huellas que produce un sonido siempre y cuando suene. ${ }^{65}$ Bonnet va más allá en el entendimiento de la marca sonora, y define a partir de ella la traza sonora:

The trace is not necessarily a material, physical host; it precedes the pertinence of any such distinction. It is that which testifies to a passage, that which harbors and reveals a past presence by continuing to manifest it. Sound disappears the very moment it appears, or more exactly in the moment of its appearing, and so the trace is the primordial means by which it can be integrated into a regime of permanence. ${ }^{66}$

63. Schafer, El paisaje sonoro y la afinación del mundo, 370.

64. Director artístico del Groupe de Recherches Musicales de la National Audiovisual Institute (INA-GRM) de Paris. The MIT Press, «François J. Bonnet» (The MIT Press), accedido 8 de junio de 2020, https://mitpress.mit.edu/ contributors/francois-j-bonnet.

65. Francois J. Bonnet, The Order of Sounds: A Sonorous Archipelago (Oxford: Urbanomic Media Ltd, 2016), 58-59.

66. Ibid., 7. 
Es decir, que antes de materializarse como señal, lo sonoro ${ }^{67}$, para llegar a serlo, debe seguir una traza. Sin ser presencia, la traza dibuja un sonido. Este proceso de 'conservación' se plantea desde un enfoque diferente al de la marca de Schafer, sensiblemente superior, pues tiene en consideración la manifestación suprasensible y sensible que rodea al sonido. Siguiendo una postura similar, David Toop defiende que la historia del sonido solo puede reconstruirse por medio del estudio de las trazas, lo que obliga a adentrarse en dominios artísticos extrasonoros en busca de huellas mudas que testifiquen la presencia del sonido ${ }^{68}$.

El estudio de las trazas sonoras y los eventos sonoros mediante procesos imaginativos que involucran al cuerpo, a la memoria y a los sentidos son fundamentales para actualizar la definición de sonografía que Schafer describe como:

El arte de la notación del paisaje sonoro. Puede incluir métodos tradicionales de notación, como la espectrografía o la grabación del nivel de sonido, pero más allá de estos también buscará el registrador de la distribución geográfica de los eventos sonoros. ${ }^{69}$

De la revisión del glosario de Schafer por autores contemporáneos se desprende que la representación del sonido no tiene por qué ser sólo una notación estrictamente acústica que haga referencia a todo lo que suena en un lugar, sino que, además, el espacio y los elementos suprasensibles ligados a él, son factores que definen el concepto, y por tanto, forman parte de su representación.

\section{El PENSAMiento SONORO}

We must repeat, listening speaks. ${ }^{70}$

R.BARTHES. La escucha

La aparición de una cultura auditiva, tal y como demuestra la gran cantidad de exposiciones

67. El diccionario de la RAE recoge en la definición de sonoro su condición de potencialidad, definiéndolo como aquello que suena o que puede llegar a sonar. RAE- ASALE y RAE, «sonoro, sonora - Diccionario de la lengua española», "Diccionario de la lengua espańola» - Edición del Tricentenario, accedido 10 de noviembre de 2019, https://dle.rae.es/sonoro.

68. David Toop, «The Mediumship of Listening: Notes on Sound in the Silent Arts», ed. Margaret Schedel y Andrew V. Uroskie, Journal of Visual Culture 10, n. ${ }^{\circ} 2$ (agosto de 2011): 169-76, https://doi.org/10.1177/1470412911402887.

69. Schafer, El paisaje sonoro y la afinación del mundo, 372.

70. Roland Barthes, The Responsibility of Forms: Critical Essays on Music, Art, and Representation, Reprint edition (Berkeley: University of California Press, 1991), 259. 
celebradas en los últimos años y los programas académicos dedicados a la relación entre arquitectura y sonido, revela un interés hacia las sensaciones y una vuelta hacia la fenomenología de Edmund Husserl y Maurice Merleau-Ponty.

Siguiendo la estela de la tradición dodecafónica de Schönberg, el pensamiento creativo de los compositores John Cage y Pierre Schaeffer promulgó el tratamiento del sonido como materia, dando lugar a una corriente de pensamiento en los años setenta y ochenta del siglo XX que profundizaba en la experiencia, la semiótica y la relación entre imagen y sonido. Autores como Michel Chion o Pauline Oliveros formaron una primera generación de pensadores que, situados entre la electrónica y la digitalización del sonido, se convirtieron en teóricos de la escucha. No eran filósofos, pero se dedicaron a la filosofía en tanto que comenzaron a pensar el sonido en sí mismo.

También en el campo de la 'filosofía pura', muchos pensadores han reflexionado sobre el sonido y la percepción. La fundación del Institut de Recherche et Coordination Acoustiquel Musique, IRCAM en 1977 y la brillante capacidad para teorizar de su primer director, Pierre Boulez, remarcó el viraje hacia la sensibilidad sonora de filósofos como Gilles Deleuze (Del Ritornelo), Jacques Derrida (El oído de Heidegger), Roland Barthes (La escucha) o Jean LucNacy (A la escucha). Si bien la reflexión sobre la música convirtió a los filósofos Schopenhauer y Theodor Adorno en dos grandes referentes, la filosofía acogió al sonido como un asunto propio al considerar que su proceso de percepción suponía un orden del entendimiento ${ }^{71}$. Con el impulso de estos autores, nace una segunda generación de pensadores del sonido, como Peter Szendy, David Toop, Brian Eno, Christoph Cox o Brandon LaBelle. Impulsores del giro auditivo del pensamiento ${ }^{72}$, estos autores encuentran en la estética de la escucha una deriva que impulsa el pensamiento creativo de otras disciplinas no sonoras.

Los denominados Sound Studies, habitualmente considerados parte de las humanidades y las ciencias sociales, afrontan con los medios de la filosofía, la semiótica y la historia del arte el estudio de los procesos relacionados con el sonido y la escucha ${ }^{73}$. Las áreas que abarca

71. Jean-Luc Nancy, $A$ la escucha (Buenos Aires: Amorrortu Editores, 2008), 11. Nancy se pregunta retóricamente si la escucha es un asunto que pueda abordar la filosofía o bien, la filosofía se ha apropiado esta acción como sinónimo de 'entendimiento'. Nancy juega con el idioma francés, donde oír y escuchar es también entender.

72. Cfr. Peter Szendy, En lo profundo de un oido: una estética de la escucha (Santiago de Chile: Metales Pesados, 2015), 33.

73. De entre las múltiples recopilaciones de artículos y ensayos que se han publicado en los últimos diez años sobre el tema (On listening, Keywords of Sound, The Sound Studies Reader, Audio Culture...y una lista inabarcable dado el auge de esta disciplina en muchas escuelas de arte y arquitectura), se señala la calidad de los ensayos que componen Sonic thinking: a media philosophical approach, Thinking media (New York: Bloomsbury Academic, an imprint of 
el pensamiento sonoro son la audición, el diseño, las artes y la percepción, pero ¿qué es el pensamiento sonoro ${ }^{74}$ ? Holger Schulze ${ }^{75}$, cofundador del programa de Master en Estudios Sonoros de la Universität der Künste de Berlin, en su artículo How to think Sonically? ${ }^{76}$, enumera las características que ha de cumplir el pensamiento para considerarse sonoro.

For sound studies in general the potential of ambitious and poetically suggestive narration lies in exactly this transference of sensation. The individual but also highly intersubjective interpretation of sonic situations might analyze via its ripples on the imagination of a particular, highly responsive listener. A sonic fiction is manifest in an artwork, on a sound piece, in conceptual sketches, on in a fiction in any medium the listener likes to choose. ${ }^{77}$

¿Cómo podemos pensar con, a través y más allá del sonido? Schulze se pregunta si es posible una forma de pensamiento del sonido que sea material, una escucha que sea un método de investigación. Schulze indica que el pensamiento sonoro no se rige por fórmulas o cálculos matemáticos como la acústica, sino que tiene en cuenta, en primer lugar, la consideración de aquello que interfiere en la percepción del sonido más allá de que sea o no audible (no se ignoran, por tanto, los entornos espaciales y dinámicos que condicionan la experiencia, por lo que se considera el lugar, el espacio específico y las condiciones espaciales donde se produce el sonido); y en segundo lugar, se discurre a través de la corporeidad inherente a cualquier experiencia sonora, por lo que el cuerpo se emplea como herramienta para la formulación del pensamiento.

Por último, el pensamiento sonoro tiene en cuenta la imaginación, en la medida en la que el cuerpo se convierte en instrumento resonador del exterior y produce una respuesta interior. Por lo tanto, el pensamiento sonoro tiene en cuenta las respuestas y condiciones que generan el espacio, el cuerpo y la imaginación en relación al sonido que se produce en ellos.

Los eventos sonoros son espaciales, pero la terminología empleada para su descripción y análisis, llena de metáforas visuales, hace necesario buscar una forma de pensar el sonido a través

Bloomsbury Publishing, Inc, 2017).

74. Habitualmente, las traducciones dan lugar a usos confusos (y erróneamente empleados como sinónimos) de los términos acústico, sonoro y aural. Este hecho obliga a la revisión de la constelación de términos que engloba el estudio del paisaje sonoro para ampliar su significado.

75. «Prof. Dr. Holger Schulze», accedido 10 de noviembre de 2019, http://www.soundstudieslab.org/author/ admin/.

76. Schulze, Holger. "How toThink Sonically? On the Generativity of the Flesh", en: Sonic thinking: a media philosophical approach, Thinking media (New York: Bloomsbury Academic, an imprint of Bloomsbury Publishing, Inc, 2017). pp 217-242.

77. Ibid., 237. 
del espacio. Para Schulze, y como se verá posteriormente en esta investigación, los dispositivos sonoros se convierten en un medio con muchas posibilidades para analizar espacialmente el sonido, pues son, en sí mismos, espaciales, materiales y físicos. Es decir, los dispositivos permiten explorar el espacio construyendo espacio, y son entendidos como un recurso útil para transmitir narraciones espaciales mediante experiencias espaciales.

\section{DOCENCIA Y EXPOSICIONES EN TORNO A INSTRUMENTOS Y DISPOSITIVOS SONOROS}

Dentro de la investigación, resultan de especial interés las exposiciones sobre arte sonoro, así como los catálogos y publicaciones asociados a ellas. Exposiciones como Proceso Sónico. Una nueva geografia de los sonidos (MACBA, 2002), Volume: Bed of Sound (MOMA, 2000), Landscape Futures (Nevada Museum of Art, 2011), Cartografias contemporáneas (Caixa Forum, 2012), \pm 1961 , La expansión de las artes (MNCARS, 2013), o la reciente ¿Arte Sonoro? (Fundación Joan Miró, 2019), muestran el creciente interés durante los últimos veinte años por la reflexión sobre la relación entre sonido y espacio, así como la pertinencia del planteamiento de esta investigación en el marco internacional.

Estados Unidos y Alemania han sido los países donde más se ha desarrollado la tecnología del sonido. El apoyo a los inventores que desarrollaron las patentes de sistemas para la reproducción y el almacenamiento del sonido (Werner von Siemens, Max Braun, Emil Berliner, Thomas Edison...), sumado al gran impulso científico que produjeron las Guerras Mundiales, dio lugar a una cultura del diseńo de los aparatos sonoros domésticos en la que participaron algunos de los mejores arquitectos de la historia. Ejemplo de ello son el transmisor Radio Nurse de Isamu Noguchi (1938), la radio Radiola 248A inspirada en Le Corbusier (1958), o las estaciones de sonido de Alvar Aalto para la sala de poesía de la Universidad de Harvard (1949).

El diseño y la experimentación sonora, impulsados por las artes emergentes y el movimiento Fluxus, generaron un interés creciente por el arte sonoro. En consecuencia, el sonido entró a formar parte de la programación de muchos museos, obligando a modificar el sentido del espacio expositivo. Las exposiciones realizadas por el Museo de Arte Moderno de Nueva York (MOMA) en el siglo XX son ejemplo de la evolución progresiva del discurso sujeto-objeto al modelo inmersivo de la instalación artística. La exposición Machinery Art (1934), la cual validó la entrada de objetos técnicos e industriales en un museo de arte en una apuesta por la estética de lo cotidiano, fue el precedente que permitió introducir años más tarde los instrumentosescultura de los hermanos Baschet (Structures for Sound, 1966) en las mismas salas. Así mismo, 



SARYARD

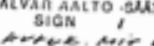

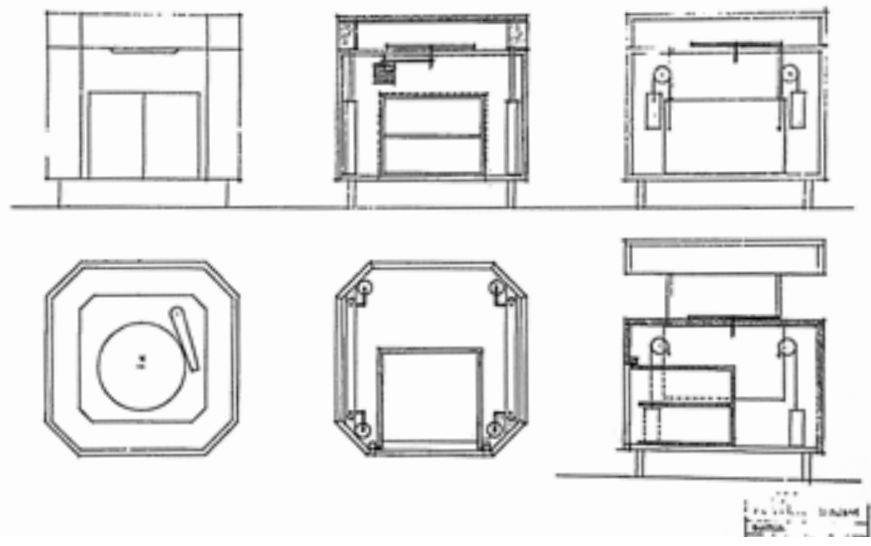

Figuras 22-23. Isamu Noguchi, Radio Nurse. Fabricado por Zenith Radio Corporation (Chicago, Illinois), 1937

Figura 24. Radio modelo RA248A. Fabricada por Radiola (1958-59)

Figuras 25-26. Aalvar Aalto, Consola para fonógrafos. Woodberry Poetry Room (1948) 
la exposición Sound (PS1, 1978) convirtió el cuerpo del visitante en parte de la obra de arte mediante las instalaciones sonoras.

Desde 1962, en Alemania, las reuniones Fluxus en Wiesbaden ${ }^{78}$ congregaban a los artistas experimentales que hicieron de la invención de nuevos (y singulares) instrumentos musicales un nuevo campo artístico de exploración. Destaca la exposición Für Augen und Ohren: Von der Spielubr zum akustischen Environment ${ }^{79}$ (1980), organizada por Academia de las Artes de Berlín. En ella se recorre la historia del sonido a través de los instrumentos, desde los autómatas del siglo XV hasta las prácticas de arte sonoro de los ańos ochenta del siglo pasado, haciendo evidente la unión indisoluble entre técnica y prácticas artísticas en este campo.

Paralelamente, la omnipresencia del paisaje en la cultura contemporánea se hace patente en la gran cantidad de trabajos colectivos publicados por universidades e instituciones que exponen transversalmente los debates sobre el concepto y el pensamiento sonoro por un lado, y sobre paisaje por otro. Esto genera un problema, como advierte el compositor Ryuichi Sakamoto, quien afirma que dos géneros establecidos que se ponen juntos crean confusión sobre cómo interpretar la relación entre ambos y dónde dibujar el límite entre ellos, convirtiendo el problema en el punto más interesante. ${ }^{80}$

El estudio del sonido y las prácticas asociadas al arte sonoro resultan relevantes en el campo de la arquitectura y el paisaje en la medida en la que el sonido fuerza la disolución del límite existente entre experiencia y representación, generando un conflicto conceptual que se define en el plano abstracto desde el cual es posible comprender la realidad interior al paisaje. En el límite difuso entre arquitectura, arte y paisaje, la arquitectura encuentra un prolífico espacio para la docencia de proyectos arquitectónicos. Apreciado como referente académico, el programa Sound Studies de la UdK plantea un distanciamiento de la música para aproximarse

78. Recopilación de instrumentos en el catálogo de la exposición, 1962 WiesbadenFLUXUS1982. Eine kleine Geschichte von Fluxus drei Teilen., Belines Künstler programm des DAAD (Wiesbaden, Kassel, Berlin, 1983).

79. Réne Block et al., Für Augen und Ohren. Von der Spieluhr zum akustischen Environment. Objekte - Installationen - Performances, 1. edition (Akademie der Künste Berlin, 1980).

80. Céleste Boursier-Mougenot et al., Art \& Music: Search for New Synesthesia (東京: Museum of Contemporary Art Tokyo, 2012), 25. Sakamoto se plantea el problema de lo sonoro desde una perspectiva semántica «It's interesting that this matter of semantics brings us such very different distinctions. The words "art" and "music" were both very new conceptions when they were introduced into the Japanese language some 150 years ago in Meiji period. Over time the have gained the gravitas of precedent, history, Works and personalities, and so they invoke all these associations, and distinctions. Personally, I don't think that we should worry too much about when something is called "sound art", or "art and music". If we call it "at the cusp of sound and art," maybe that will make easier to grasp. Any time two stablish genres are put next to each other, like "art and music," I think there is a bound to be some confusion about how to interpret the relationship, and where to draw the line. Maybe it creates complication, but that too is also an interesting point. » 

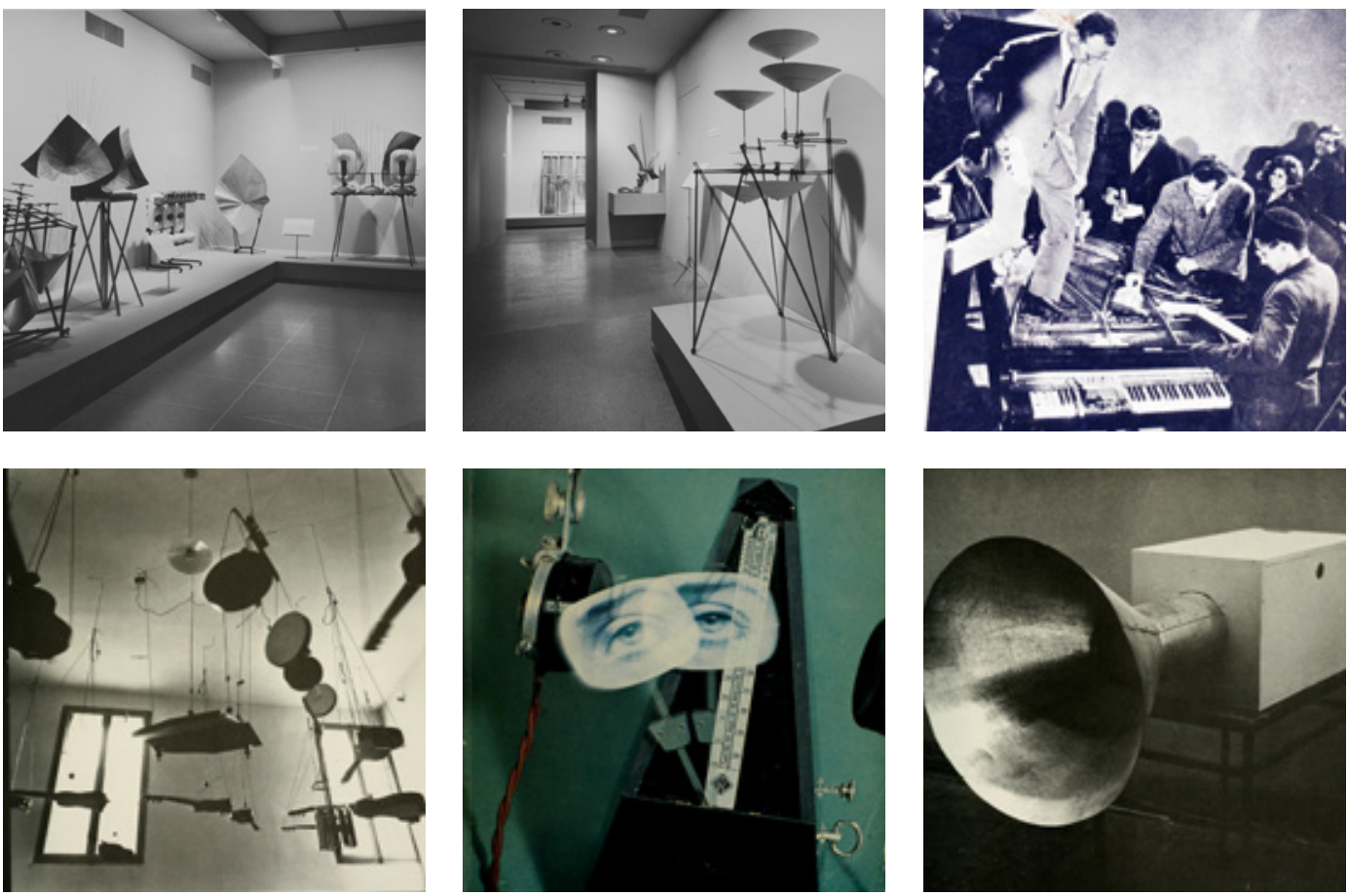

303132
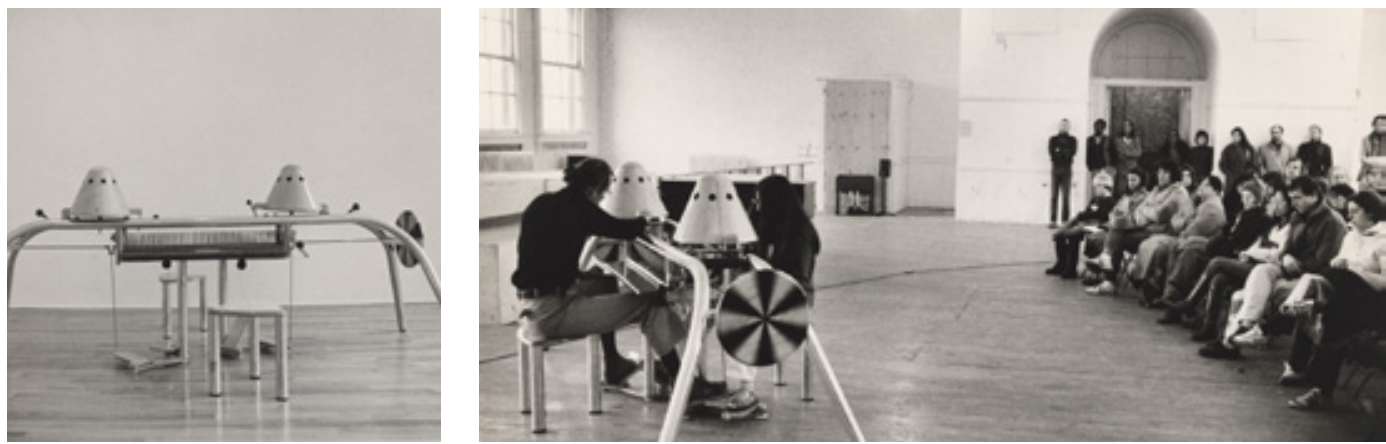

Figuras 27-28. Structures for Sound - Musical Instruments by Francois and Bernard Baschet. MoMA, NY. (1966)

Figura 29. Portada del catálogo de la exposición 1962Wiesbaden. FLUXUS1982. Eine kleine Geschichte von Fluxus in drei Teilen. Wiesbaden, Kassel, Berlin: Berliner Künstlerprogramm des DAAD, (1982-1983)

Figuras 30-32. Exposición Für Augen und Ohren: Von der Spieluhr zum akustischen Environment.Berlin: Akademie der Künste, (1980)

Figuras 33-34: Exposición Sound. MoMa PS1, NY (1979) 
a la producción, el arte sonoro y la ingeniería de sonido desde el espacio. Este programa surge como respuesta a la idea generalizada de tratar los objetos sonoros como objetos visuales, con el fin de evitar que el software y el mundo digital aleje el diseño sonoro del espacio, perdiendo sensibilidad en el diseño de soluciones. ${ }^{81}$

La búsqueda de la armonía a través de la construcción de instrumentos se ha practicado también en escuelas de arquitectura como la Cooper Union (NY, EEUU) o la Architectural Association School of Architecture (Londres, UK). En la Cooper Union, tras la primera recopilación en 1971 de los trabajos llevados a cabo durante sus años como decano de la Irwin S. Chain School of Architecture de la Cooper Union, John Hejduk publica Education of an Architect en $1988 .{ }^{82}$ El libro, estructurado según líneas de investigación, presenta varios ejercicios enfocados a la construcción y el análisis de objetos, como el curso de doctorado Instruments $^{83}$ o Architectonics de Elisabeth Diller $^{84}$, en el que los alumnos estudian a través de la construcción de piezas, las fuerzas, el equilibrio, la tensión o la gravedad. Un pensamiento sobre el proceso que promueve eliminar la palabra en la arquitectura al considerar el lenguaje como una infiltración que debe ser subvertida. Diller propone, en oposición al lenguaje, estudiar el espacio y las fuerzas contenidas en él a través de la construcción de objetos. Espacio para estudiar espacio. En la misma línea, Tod Williams, en su proyecto docente Object, explica el propósito de los objetos en la docencia:

The objective is to represent an architectural idea at one-to-one scale. This is the architectural act in a compressed form. Its reduced nature encourgaes clarity of ideas with a focus on particularization and detail. It necessitates and undestanding of resources

81. Entrevista al cofundador del programa Holger Schulze, Diedrich Diederichsen y Constanze Ruhm, «Interview with Holger Schulze», en Utopia of Sound: Immediacy and Non-Simultaneity, ed. Christoph Cox (Wien: Schlebrugge Editor, 2012), 246-59.

82. John Hejduk et al., eds., Education of an architect (New York: Rizzoli, 1988). En el prefacio de este libro, encontramos un pasaje de Hejduk que demuestra su sensibilidad hacia el paisaje y el sonido: «During a certain season in Texas, at dusk, some tree tunks seem to be phosphorescent...they give off a dull, blazing light. Upon close scrutiny it is found that the trunk of the tree is completely covered with discarded shells which were the outer body of certain insects. The starling fact is that the shell is intact; the form is exactly as it was when its original inhabitant was inside, with one difference. The inside has left, leaving the outer from which looks like an $\mathrm{x}$-ray, producing the luminous effect. Suddenly we hear a chorus of sound coming from the dark leaves above. Is is the sound of the insects hidden in the tree in their new metaphysical form. What is strange about the phenomenon is that we can see the insects' shell forms clinging to the tree, empty shells, a form that life has abandoned. While we fix our eyes on these apparitions, we hear the sound of the insect in its new form hidden in the trees. We can hear it but we cannot see it. In a way, the sound we hear is a soul sound».

83. Las obras del taller Instruments, pueden consultarse en el archivo digital de la Cooper Union «Cooper Union Archive : Search Projects : instruments», accedido 1 de junio de 2020, https://archswc.cooper.edu/Search/ projects?search=instruments.

84. Hejduk et al., Education of an architect, 32-40. 

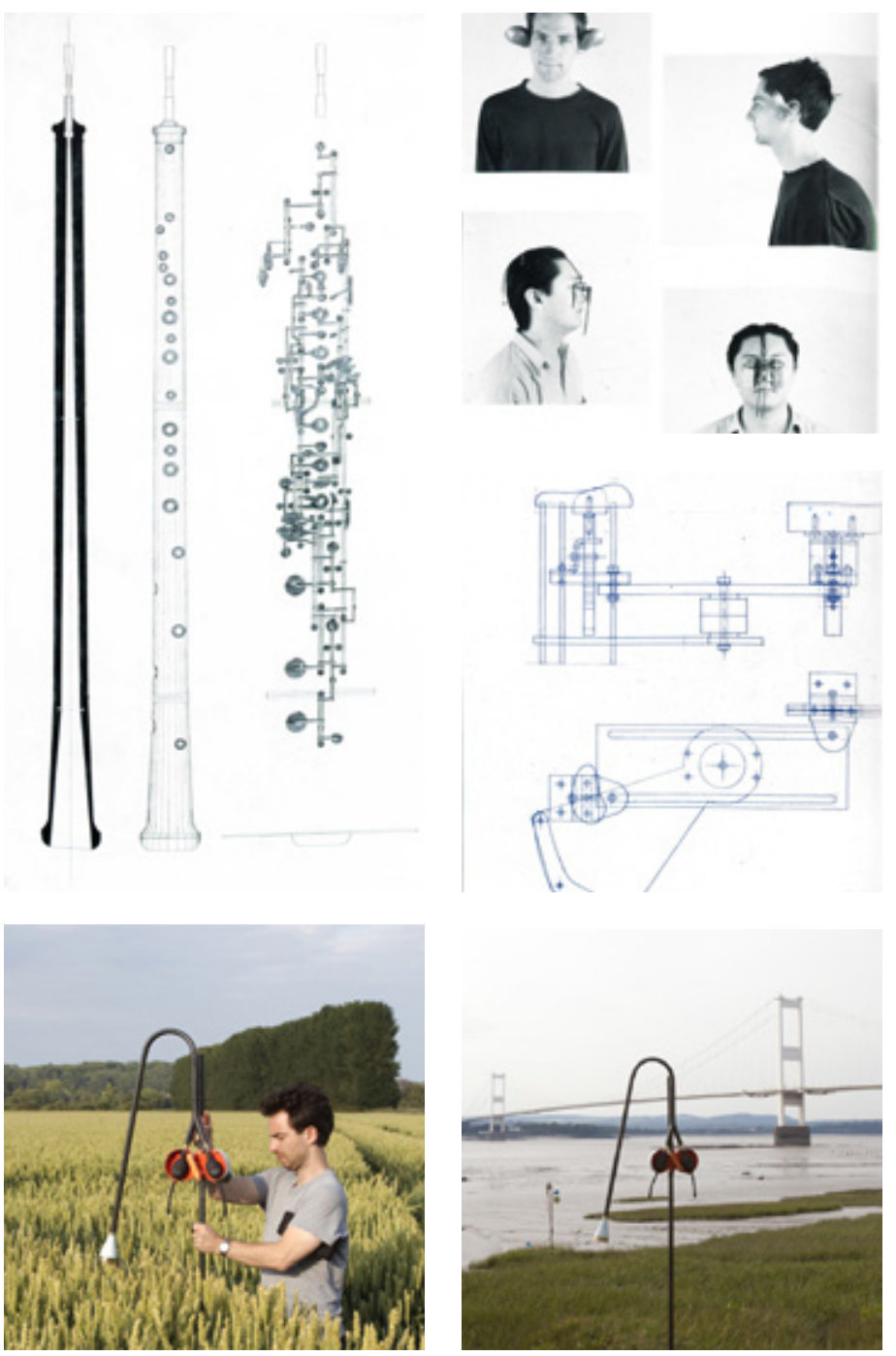

353637

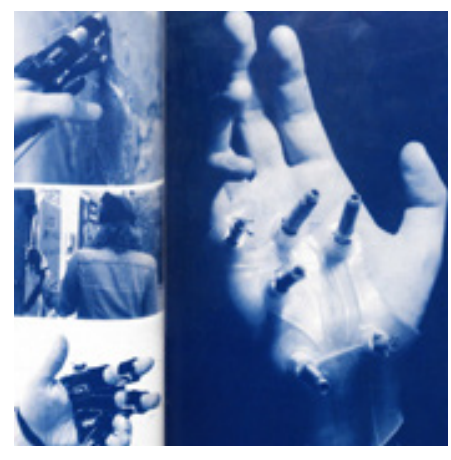

3839

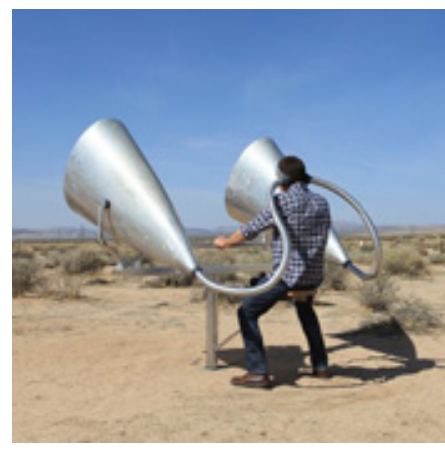

Figura 35. Stephen Isola, oboe (1980-81)

Figura 36. Urban details (1984-85)

Figura 37. James Richards, The connection: a study in stasis and animation (1984-85)

Figuras 38-39. Devices: A Manual of Architectural + Spatial Machines (2006)

Figuras 40-42. Mark Smout y Laura Allen, Envirographic Instruments (2015) 
and promotes an economy means. It requires a positive reckoning with and respect for the precise requirements of fabrication. Finally, the physical labor of making and object recognizes the coexistance through time of art, architecture and engineering. What is produced is a testable an irrefutable fact. ${ }^{85}$

De igual manera, con el fin de incentivar la práctica y el estudio de las acciones creativas que relacionan al hombre con su entorno natural, el Center for Art + Environment de Nevada (EEUU), organizó en el año 2011 la exposición Landscape Futures: Instruments, Devices and Architectural Inventions ${ }^{86}$. Comisariada por Geoff Manaugh ${ }^{87}$, la exposición reunió a artistas y arquitectos que usan la tecnología para visualizar e interpretar lo que les rodea, persiguiendo fórmulas interdisciplinarias para la redefinición de los límites entre arte, arquitectura, diseño y ciencia. ${ }^{88}$

Entre los artistas y arquitectos que participaron en la exposición, los profesores de la AA Mark Smout y Laura Allen ${ }^{89}$, presentaron su línea de investigación de conocimiento del entorno a través de objetos, los dazzle objects. Estos objetos son la base de lo que Smout y Allen denominan la Arquitectura entornográfica, aquella en la que el diseño arquitectónico permite hacer visibles las complejas estructuras que conforman un entorno. A través de la unión de arte y ciencia, Smout y Allen defienden la necesidad de nuevos lenguajes abstractos que, mediante la provocación de imágenes sensoriales, transformen la forma de entender el paisaje. ${ }^{90}$

El origen de los dazzle objects (también denominados devices of wonder ${ }^{91}$ o máquinas performativas $^{92}$ en investigaciones similares) se encuentra en las tecnologías espaciales que han permitido interpretar el mundo mediante instrumentos que no sólo facilitan ver lo visible y oír lo audible, sino que posibilitan, además, pensar en las fuerzas que, aun siendo invisibles o

85. Ibid., 63.

86. Landscape Futures: Instruments, Devices and Architectural Inventions, Nevada Museum of Art y Geoff Manaugh (comisario invitado). Center for Art + Environment. Agosto 2011 - febrero 2012.

87. Escritor, editor y fundador de BLDGBLOG. «BLDGBLOG», accedido 1 de julio de 2019, http://www. bldgblog.com/.

88. Geoff Manaugh y Nevada Museum of Art, eds., Landscape Futures: Instruments, Devices and Architectural Inventions (Barcelona New York: Actar, 2013), 11.

89. Responsables de la unidad 11 de la UCL - Bartlett School of Architecture. Sus investigaciones en torno a la representación del paisaje y las intervenciones en el mismo han sido de gran interés para la esta investigación. En especial, el «British Exploratory Land Archive», accedido 25 de enero de 2018, http://bartlettdesignresearchfolios. com/british-exploratory-land-archive.

90. Manaugh y Nevada Museum of Art, Landscape Futures, 18.

91. Barbara Maria Stafford, Frances Terpak, y Isotta Poggi, Devices of wonder: from the world in a box to images on a screen (Los Angeles, CA: Getty Research Institute, 2001).

92. Daniels y Schmidt, Artists as inventors, inventors as artists, 26. 
inaudibles, están presentes en él. Instrumentos, sensores, mecanismos y otros instrumentos científicos (como los radiotelescopios, los sismógrafos o los radares de penetración en el suelo utilizados en los estudios geológicos), reconfiguran nuestra comprensión de un paisaje al revelar, a través de los datos que producen los instrumentos, la existencia de espacios y fuerzas que de otra manera no se podrían percibir.

Education of an Architect (Cooper Union, John Hejduk, 1988), Devices: A manual of Architectural + Spatial Machines (UCL, C.J. Lim, 2006), Alternative Guide to the Isle of Portland (AA, Shin Egashira y David Greene, 1998), British Exploratory Land Archive (UCL, Smout and Allen, 2012) o Landscape Futures (G. Manugff, 2012) presentan un método docente sugestivo y tentativo en el que los estudiantes, mediante la construcción de instrumentos, documentan, investigan y analizan el entorno y las fuerzas para aportar un conocimiento creativo de lo que es el paisaje y el entorno, aprendiendo a ver a través del pensamiento. Este método propone aislar algunas de las múltiples fuerzas que forman el paisaje hasta concebir un bloque de sensaciones como objeto, considerando cualquier configuración en la naturaleza, un objeto físico, una sensación, o un pensamiento, como un contorno que marca la intersección de fuerzas existentes en un lugar.

La tecnología sonora (como el teléfono, el optófono, el fonógrafo...), pertenece a ese grupo de instrumentos que permiten expandir las funciones del cuerpo en nuevos ámbitos del espacio y el tiempo. Estos instrumentos, inicialmente surgidos como herramientas técnicas para ampliar la percepción, se convierten en una tecnología performativa que depende de la acción interpretativa del hombre. Herramientas técnicas, propias de la ingeniería, se convierten en amplificadores de significado del mundo sensible, en instrumentos que buscan evidenciar la compleja interacción entre arte, ciencia y entorno.

Por último, se destaca la labor del IRCAM, Institut de Recherche et Coordination Acoustiquel Musique que, siguiendo el legado intelectual de Pierre Boulez, ha renovado por completo sus estrategias experimentales en los últimos cinco años. El IRCAM, institución ligada al Centro Pompidou de París, explora desde el año 1978 la espacialización del sonido, incorporando la investigación transdisciplinar de vanguardia en sus talleres, cursos y residencias.

El panorama actual de la cultura auditiva, las numerosas exposiciones y los programas académicos sobre arte sonoro, atestiguan el alto interés que el sonido produce mucho más allá de la mera audición. Su condición evanescente y paradójica materialidad, hacen que denpenda del diálogo de todas las disciplinas para ser entendido, dando lugar a resultados muy diversos y difícilmente clasificables en un campo específico. 


\section{e. Cuestiones de mÉtodo}

Quien está familiarizado con la práctica de la investigación en ciencias humanas sabe que, contra la opinión común, la reflexión sobre el método muchas veces no precede, sino que es posterior a la práctica. ${ }^{93}$

\section{G. Agamben. Signatura rerum: sobre el método}

Los estudios relacionados con el sonido y el paisaje, tratan del conocimiento asociado a la experiencia. En ambos existe, por un lado, una componente física, y en consecuencia medible, ligada al espacio; y por el otro, al relacionar al ser humano con su mundo circundante, comprenden el estudio de la relación afectiva e íntima que se produce en este vínculo. Investigar sobre sonido y paisaje obliga, por tanto, a mantener una tensión entre lo teórico y lo empírico. ${ }^{94}$

Una investigación sobre los sentidos y las cualidades sensibles implica, necesariamente, un empirismo de ida y vuelta en el que resulta difícil distinguir claramente cuándo la teoría es consecuencia de la práctica y viceversa, pues como explica Bernard Sève:

Si nos ceñimos a los problemas a priori se corre el riesgo de no alcanzar jamás el espacio de la experiencia o, al menos, de no alcanzarlo allá donde se convierte propiamente en artístico y en algo verdaderamente interesante; y si nos ceñimos a los problemas a posteriori resultará muy difícil sustraerse a la dispersión de lo empírico y a la pretensión de desplegar conceptos y tesis que serán poco más que simples calcos de la experiencia. El método que he intentado aplicar es de naturaleza decididamente doble: ir de los problemas del filósofo a los del músico, y de los problemas del músico a los del filósofo. El instrumento musical interroga a la filosofía, del mismo modo que la filosofía interroga al instrumento musical. ${ }^{95}$

Bajo la decisión de aplicar el método del empirismo de ida y vuelta para lograr un análisis riguroso de un concepto que participa tanto en las ciencias sociales y humanas como en el conocimiento técnico, la tesis parte de las conclusiones y resultados de la construcción del prototipo experimental anteriormente presentado. Tras este ensayo, se procedió a la búsqueda y recopilación de referencias y casos prácticos similares que avalasen este planteamiento, y se formularon las primeras premisas intuitivas sobre las que se asienta esta investigación.

93. Giorgio Agamben, Signatura rerum: sobre el método (Barcelona: Anagrama, 2010), 9.

94. Se introduce aquí la Filosofía del paisaje de G. Simmel: «La vida empírica contiene en todo momento indicios y elementos de esas formaciones, de unas formaciones que parten de la vida empírica para extraer de ella un conocimiento autónomo, construido con ideas y principios que le son propios.» Simmel, Georg, Filosofía del paisaje (Madrid: Casimiro Libros, 2014), 13.

95. Sève, El instrumento musical, 2018, 31-32. 
Del estudio de las teorías que respaldan la hipótesis de partida se extraerán las consecuencias lógicas y deducciones que justifiquen la pertinencia de la aplicación del pensamiento analógico y el conocimiento operativo para la representación del concepto paisaje sonoro. Se seleccionará una vía de estudio original, propia de esta investigación, que acote el campo de estudio y clarifique, al mismo tiempo, las transformaciones morfológicas, estructurales y sensoriales asociadas a los instrumentos para la representación del concepto paisaje sonoro. Para su elección se considerará como requisito primordial que su contenido enraíce coherentemente con la naturaleza gráfica del arquitecto.

La tesis se ha desarrollado consultando, principalmente, los fondos documentales del archivo del Deutscher Akademischer Austauschdienst (DAAD, Servicio Alemán de Intercambio Académico), el archivo y biblioteca de la Universität der Künste de Berlín (UdK), y la biblioteca y centro documental del Museo Nacional Centro de Arte Reina Sofía (MNCARS).

\section{F. ESTRUCTURA DE LA TESIS}

Tras la exposición de los fundamentos de la investigación en este capítulo de introducción, la tesis se divide en tres capítulos:

- Capitulo primero. Marco teórico: La representación del concepto paisaje sonoro: Exposición de las principales teorías sobre la escucha y los procesos de conversión del sonido en imagen desde la invención del fonógrafo (1887) hasta los años cincuenta del siglo XX, de los factores que intervienen en la representación del sonido del paisaje, las variables semánticas, espaciales y temporales que contiene el concepto paisaje sonoro, así como las posibles vías para su representación. Finalmente, se propone el pensamiento analógico aplicado y el conocimiento operativo como método para su representación.

- Capitulo segundo. Contexto disciplinar: Vértices y diagonales: Presentación del contexto académico y artístico al que pertenecen las obras estudiadas en el capítulo tercero. Para ello se describen los acontecimientos compartidos por John Cage, Juan Navarro Baldeweg y Gilles Deleuze en momentos concretos de sus trayectorias profesionales. Este capítulo abarca un periodo de estudio de cincuenta años, desde 1939 (primer Imaginary Landscape de John Cage) hasta 1989 (publicación de Le Pays fertile de Pierre Boulez). 
- Capitulo tercero. Casos y ejemplos: Instrumentos: Se exponen cinco instrumentos para la representación del concepto paisaje sonoro. Una serie de obras seleccionadas, respaldadas por su trascendencia en la historia del arte y la arquitectura, sirven como ejemplo para desarrollar cada uno de los instrumentos propuestos para la representación del concepto paisaje sonoro. Así, las obras 'paisajísticas' del compositor americano John Cage, los ensayos sobre sonido y teorías del territorio formulados por el filósofo Gilles Deleuze, y las piezas sonoras del arquitecto Juan Navarro Baldeweg sirven para clarificar, a través de su análisis, cinco tipos de instrumentos de representación del paisaje sonoro. A continuación se resume la justificación de la pertinencia de su elección:

- Obras paisajisticas de John Cage: Se ha demostrado que el paisaje sonoro es una metáfora especialmente duradera dentro del discurso de la música experimental que proviene directamente del título de una serie de obras electroacústicas de John Cage (Imaginary Landscape, 1-5) ${ }^{96}$ compuestas entre 1939 y 1952 . Las instalaciones que sitúan al sonido en relación directa con la arquitectura, las formas espaciales, el espacio como objeto móvil, los trabajos relacionados con el contexto sonoro y con la interferencia entre cuerpo y lugar... forjan los intereses de artistas como Maryanne Amacher o George Brecht. Sus obras son ejemplo de la conexión, a través del sonido, del tiempo y el espacio, así como de la potencialidad del lenguaje en las instalación sonoras que preceden a las prácticas de la ecología acústica y el nacimiento del paisaje sonoro.

- Piezas sonoras de Juan Navarro Baldeweg: Desarrolladas a partir de las energías presentes en un espacio y un tiempo concretos, las piezas sonoras de Juan Navarro Baldeweg surgen del sentir de la estructura sonora de un espacio. Se analizan sus obras sonoras más importantes (Arado, Espejo sonoro, Casa de la lluvia) que cuestionan el registro y la representación del paisaje sonoro mediante la creación de analogías perceptivas. Sus piezas demuestran la viabilidad de la representación de estructuras sensibles de un espacio mediante objetos, artefactos o instrumentos acústicos.

96. Cfr. David Grubbs, Records ruin the landscape: John Cage, the sixties, and sound recording (Durham: Duke University Press, 2014), 46.; Javier Maderuelo Raso, La idea de espacio en la arquitectura y el arte contemporáneos, 1960-1989 (Ediciones AKAL, 2008), 247-48. 
- El pensamiento musical de Gilles Deleuze y su intersección con Pierre Boulez, Felix Guattari y Paul Klee: se presenta la discusión que bajo la temática musical, realizó el filósofo francés Gilles Deleuze en torno a los componentes esenciales del paisaje sonoro (tiempo y espacio). Deleuze recalcará la influencia de Boulez, Guattari y Klee en sus escritos, siendo de especial importancia para esta investigación el ensayo del Ritornelo. 

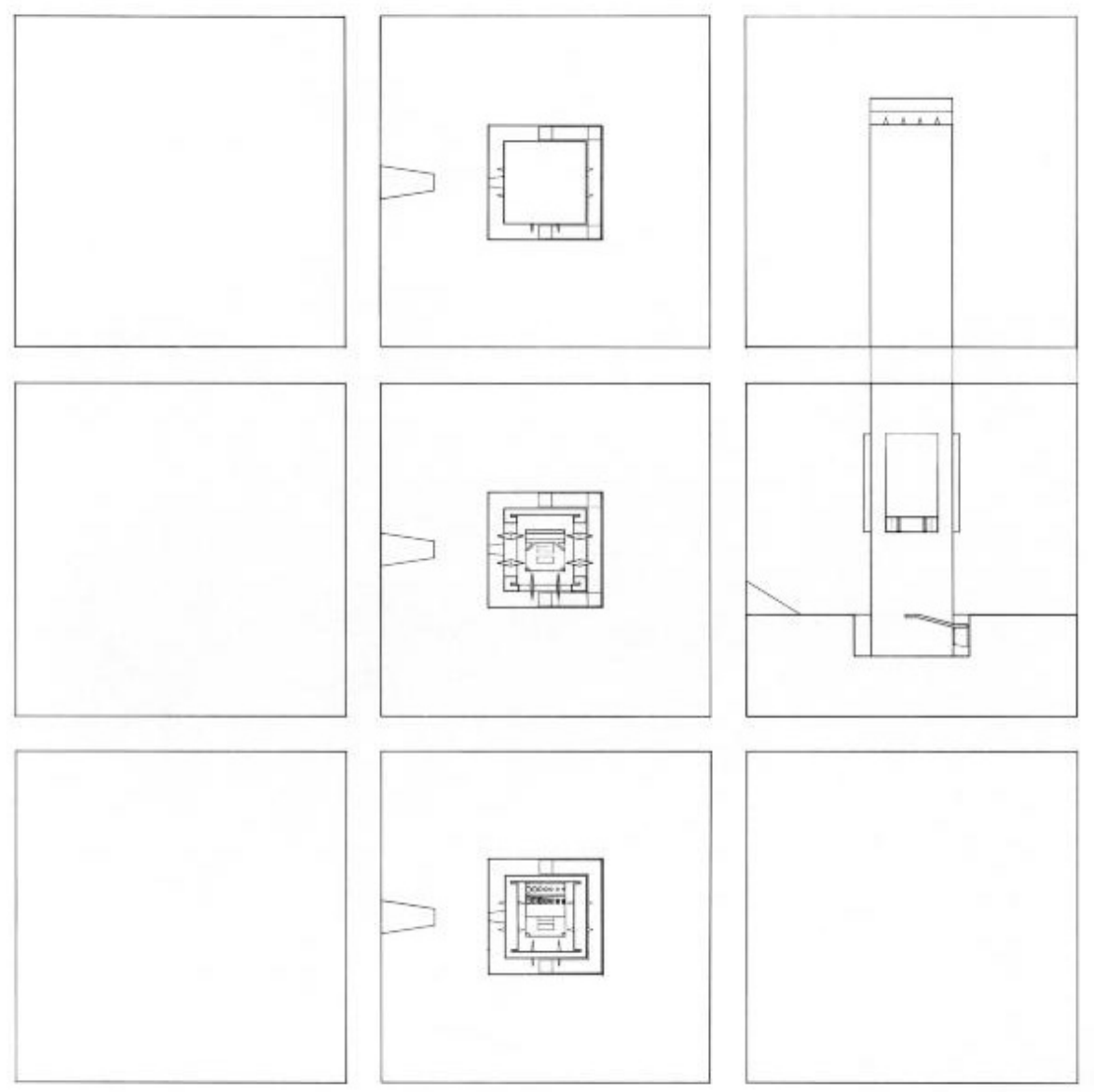

Figura 43. Donald Scott Springer, City of Keyboard, Pipe Organ (1990-91) 


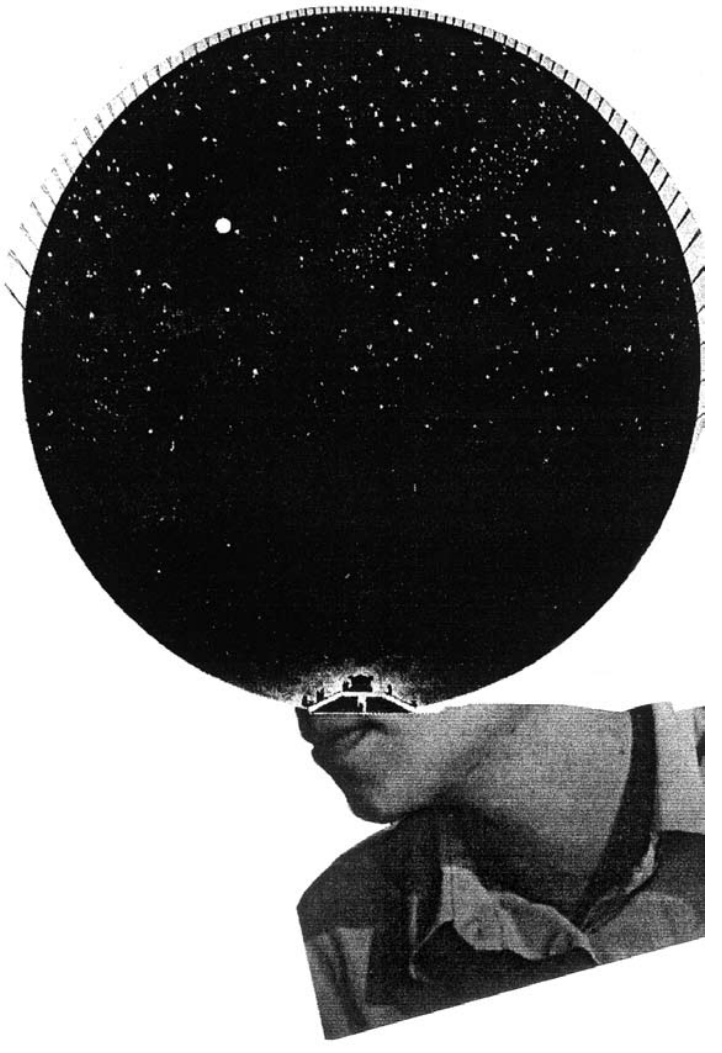

Figura 44. Bernhard Leitner. Headspaces. Sound Stars (2007) 


\title{
Capítulo 1. La REPRESENTACión DEL CONCEPTO PAISAJE SONORO
}

\begin{abstract}
Condillac comienza su libro célebre: «Por más alto que subamos y más bajo que bajemos, nunca salimos de nuestras sensaciones». Nunca desembarcamos de nosotros. Nunca llegamos a otro sino oteándonos mediante la imaginación sensible de nosotros mismos. Los verdaderos paisajes son los que nosotros mismos creamos, porque así, siendo dioses de ellos, los vemos como verdaderamente son, que es como han sido creados. ${ }^{1}$

F. Pessoa. Libro del desasosiego
\end{abstract}

Representar, ser imagen de algo ${ }^{2}$, más aún cuando ese algo está ligado al sonido, obliga a la búsqueda del reconocimiento de lo audible, lo legible y lo invisible mediante la figurabilidad ${ }^{3}$ como condición de certificación de la verdad. Este requisito impulsa a abordar el estudio de la representación del concepto paisaje sonoro partiendo de las disciplinas que le son originariamente 'ajenas'.

1. Fernando Pessoa, Livro do Desasocego, ed. Jerónimo Pizarro, vol. xii, Ediçao crítica (Lisboa: Imprensa Nacional - Casa da Moeda, 2010), 287. Cfr traducción en Fernando Pessoa, Antonio Sáez Delgado, y Jerónimo Pizarro, Libro del desasosiego (Valencia: Pre-Textos, 2014).

2. RAE- ASALE y RAE, «representar | Diccionario de la lengua española», «Diccionario de la lengua española» Edición del Tricentenario, accedido 9 de junio de 2020, https://dle.rae.es/representar.

3. «El problema es aquí bien distinto: se trataría solamente - pero sería ya mucho- de entender en qué la noción freudiana de figurabilidad, si "abre", como lo hemos dicho, el concepto clásico de representación, puede concernir o alcanzar a la mirada que ponemos sobre las imágenes del arte. En resumen, en qué la representación que "se abre" puede mostrarnos algo más en lo que llamamos habitualmente las representaciones de la pintura.» Georges DidiHuberman, Ante la imagen: pregunta formulada a los fines de una historia del arte (Murcia: CENDEAC, Centro de Documentación y Estudios Avanzados de Arte Contemporáneo, 2010), 204. 
Es innegable que la realidad denominada por la palabra paisaje está condicionada por una primacía de la imagen. Al mismo tiempo, la imagen que habitualmente representa una atmósfera sonora es la de una envoltura imprecisa, en la que la pluridireccionalidad de los sonidos que invaden al sujeto, invita a discernir otra manera de percibir el mundo físico. Lo sonoro conlleva asumir que un parámetro invisible, móvil y en constante transición, convierte al paisaje en un espacio dinámico en tres dimensiones. En consecuencia, el reto primordial que plantea el estudio de la representación del concepto paisaje sonoro es la de ensanchar la conquista de lo visible mediante la representación de aquello que no vemos.

Investigar el concepto paisaje sonoro deriva en la exploración de la correspondencia entre el concepto y el discurso visual que lo desarrolla, pues al pensar y aprender desde lo visible, entre lo visual y lo conceptual, hay más isomorfismo que entre lo sonoro y lo conceptual aunque solo sea, como dirá Nancy, en virtud de que la morphe, la 'forma', está implicada en la idea de 'isomorfismo'4 - Entendemos entonces que solamente mediante las imágenes y figuras que suscita la percepción de lo que identificamos como paisaje sonoro será posible estudiar la representación del concepto. Para ello, como propone el historiador W. J. T. Mitchell ${ }^{5}$, nos adentramos en la visualidad de lo ilegible:

Thus, landscape (whether urban or rural, artificial or natural) always greets us as space, as environment, as that within which "we" (figured as "the figures" in the landscape) find -or lose- ourselves. An account of landscape understood in this way therefore cannot be content simply to displace the illegible visuality of the modernist paradigm in favour of a readable allegory; it has to trace the process by which landscape effaces its own readability and naturalizes itself and must understand that process in relation to what might be called "the natural histories" of its own beholders. What we have done and are doing to our environment, what the environment in turn does to us, how we naturalize what we do to each other, and how theses "doings" are enacted in the media of representation we call "landscape" are the real subjects of Landscape [...].

Por tanto, será necesario rastrear el proceso mediante el cual el paisaje borra su propia legibilidad para comprender la reciprocidad de las acciones que se producen entre el paisaje, el sonido y el sujeto, y cómo estos hechos son transmitidos a través de los medios de representación

4. Jean-Luc Nancy, A la escucha (Buenos Aires: Amorrortu Editores, 2008), 12.

5. W. J. T. Mitchell, referente fundamental del panorama de los estudios visuales. Es catedrático del Departamento de Filología y Literatura Inglesa y del Departamento de Arte de la Universidad de Chicago y editor de la revista Critical Inquiry. «W. J. T. Mitchell | Department of English Language and Literature», accedido 9 de junio de 2020, https://english.uchicago.edu/faculty/w-j-t-mitchell.

6. W. J. T. Mitchell, ed., Landscape and Power, 2. ed., [Nachdr.] (Chicago, Ill.: Univ. of Chicago Press, 2009), 2. 
propios de lo que llamamos paisaje. Ese proceso nos llevará a entender la correspondencia entre discurso y concepto, así como su representación.

En este primer capítulo se profundiza en el estudio de los factores que intervienen en el proceso de formación de las imágenes ligadas al concepto paisaje sonoro con el fin de confirmar la hipótesis de la viabilidad de su representación. Para ello, se han considerado aquellas capacidades, tanto activas como pasivas, de la dotación natural del hombre para la escucha, así como la relación entre el 'objeto sensible’ y el 'ojo-oído' del sujeto. Finalmente se esquematizan las vías de representación del concepto, y se analiza la aplicación del conocimiento operativo para la fabricación de los instrumentos-transductores que hagan posible la representación del concepto.

\section{I.I.UN ENFOQUE SONORO DEL PAISAJE}

Tras una expedición a los acantilados de Bandiagara, el etnólogo Dominique Zahan (19151991) explicaba en su estudio Notes Sur un luth dogon ${ }^{7}$ el ritual de construcción de un laúd. Para los dogones, una de las etnias más misteriosas del planeta, el laúd es un instrumento sagrado cuya construcción supone un minucioso proceso cargado de gestos simbólicos. Con el fin de reflejar la estructura del mundo, el adivino del grupo, lutier y músico al mismo tiempo, entierra durante cuatro días la madera con la que fabrica el instrumento. Una vez terminado, el adivino lo toca, y es entonces cuando las diferentes piezas del laúd se unifican en el sonido que desvela la razón de ser del instrumento: la resonancia armónica entre la escala humana y el cosmos.

Mucho antes de emerger el Soundscape, el hombre ya se relacionaba con el paisaje mediante instrumentos sonoros. Se presentan en este apartado las palabras y acciones que conforman un posible enfoque sonoro del paisaje.

\section{I.I.I. AQUeLlo QUe Vemos AL DECIR 'PAISAJE'}

Empleado en el Renacimiento como el tecnicismo que denominaba la representación pictórica de un fragmento enmarcado de la naturaleza, el paisaje es un concepto engendrado

7. Dominique Zahan, "Notes sur un luth dogon», Journal de la Société des Africanistes tomo 20, n. 2 (1950): 193-207. 
y desarrollado por el sentido de la vista. Su acepción más extendida sobreentiende una dominación visual de un territorio que se traduce en una representación, siendo el ojo el mediador obligado para su existencia. ${ }^{8}$ El sentido de la vista, cuya supremacía sobre el resto de sentidos en este campo de estudio es evidente, se proclama históricamente como modelo de la percepción general y, en consecuencia, como criterio para evaluar los demás sentidos. ${ }^{9}$ Esta situación obliga a platear el estudio de cualquier forma derivada de paisaje o atributo impuesto al mismo (como lo sonoro), a partir de una reflexión inicial sobre su condición visual, sobre aquello que vemos al decir paisaje ${ }^{10}$.

La manifestación clásica del paisajees una visión de la naturaleza a través de una representación. La palabra 'paisaje" "posibilita representar» ${ }^{11}$ y mediante la abstracción de las diferencias entre imagen real e imagen construida, se llega al concepto. Este modelo de formación del concepto a partir de la representación del mismo defiende que existe una realidad exterior al sujeto que, como apunta Hernández León en Ser Paisaje, «le damos un significado desde la idea y el lenguaje, desde la distancia y mediante algo que venimos a entender como perspectiva» ${ }^{12}$. Así, encontramos paisajes pictóricos, literarios, un paisaje geográfico o un paisaje fantástico. Una invención histórica debida esencialmente a la obra de pintores y jardineros, pero cuyo problema estético, como advierte Raffaele Milani, no acaba en la representación artística. Teniendo en cuenta que «el paisaje es una entidad relativa y dinámica, en la que desde tiempos antiguos naturaleza y sociedad, mirada y ambiente, interactúan sin cesar» ${ }^{13}$, será necesario detenerse en la relación hombre-naturaleza para esbozar su sentido completo. Para ello, se revisan las consideraciones estéticas sobre la naturaleza de los siglos XVIII y XIX, cuando la naturaleza se entendía como «aquello universal e inmutable en el pensamiento, en el sentimiento, en el gusto, y, al mismo tiempo, aquello familiar e íntimo a cada individuo.» ${ }^{14}$

Los múltiples intereses del filósofo y sociólogo alemán Georg Simmel (1858-1918) quedaron reflejados en su prolífica e inusual obra. En unos pocos años, Simmel escribió desde ensayos de arte sobre Miguel Ángel, Rodin, Rembrandt o Böcklin, hasta reflexiones transdisciplinarias en los que el paisaje, la cultura y la naturaleza se entrecruzan con el arte, la sociología y la filosofía

8. Cfr. Juan Miguel Hernández León, Ser-paisaje (Madrid: Abada Editores, 2016), 10.

9. Hans Jonas, "La nobleza de la vista", en: El principio vida: Hacia una biología filosófica, Edición: 1 (Madrid: Editorial Trotta, S.A., 2000), 191-217.

10. Hernández León, Ser-paisaje, 128.

11. Ibid., 119.

12. Ibid., 128.

13. Raffaele Milani, El Arte del paisaje (Madrid: Biblioteca Nueva, 2008), 56.

14. Ibid., 35. 


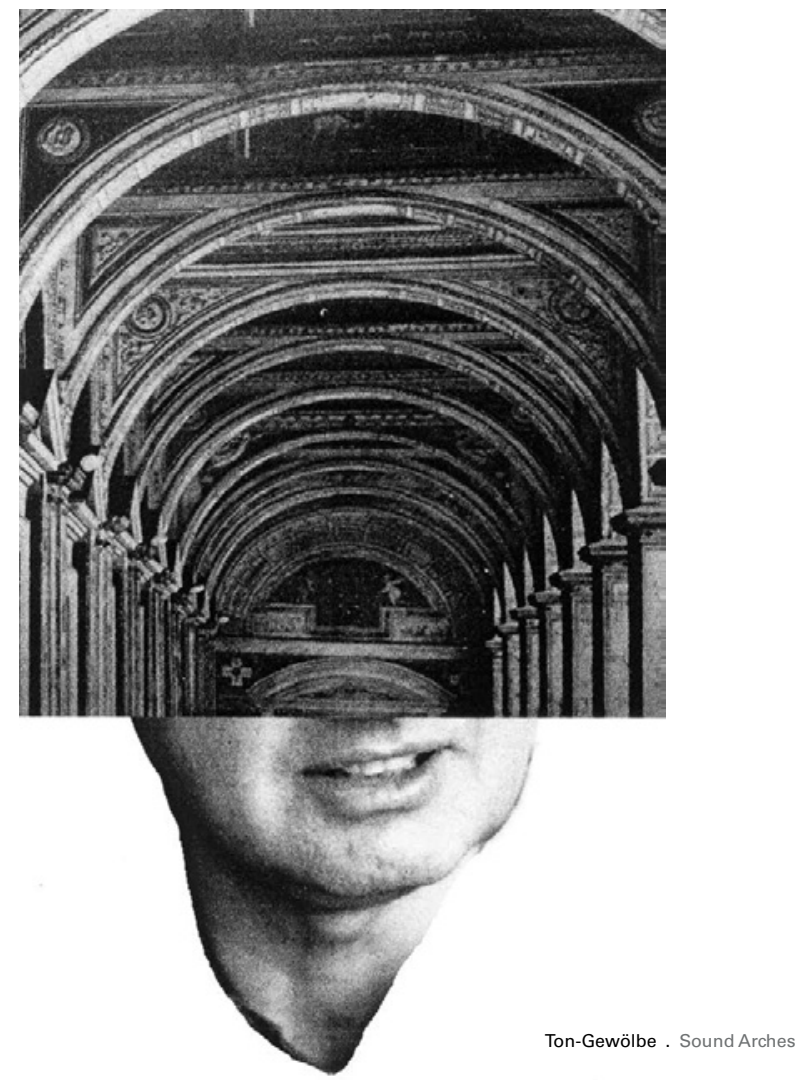

Figura 45. Bernhard Leitner. Headspaces. Sound Arches (2007) 
neokantiana. ${ }^{15}$ Su interés por la música (como refleja su primera tesis doctoral) ${ }^{16}$, lo llevó a entender el paisaje a través de las dinámicas de intercambio entre la experiencia sensorial y la racionalidad de las estructuras de la representación. Este pensamiento quedó recogido en dos ensayos de 1907 y 1913, Böcklins Ländschaften ${ }^{17}$ y Philosophie der Landschaft' ${ }^{18}$, de gran interés para esta investigación.

En Filosofia del paisaje (Philosophie der Landschaft) encontramos el siguiente pasaje sobre los límites de la naturaleza y la diferencia entre naturaleza y paisaje:

"Un trozo de naturaleza" es en verdad una expresión contradictoria: la "naturaleza" no tiene partes, es la unidad de un todo; tan pronto le desgajamos un fragmento, éste deja de ser "naturaleza", puesto que sólo puede ser "naturaleza" dentro de esa unidad sin límites, sólo como ola de esa corriente global que llamamos "naturaleza".

En el paisaje, sin embargo, la delimitación, el estar comprendido en un horizonte visual -momentáneo o duradero- es esencial; la base material o los distintos elementos serán "naturaleza", pero, representados como "paisaje", esa base y esos elementos se proponen ensí-mismos, como singularidad -óptica, estética o sentimental- que se desgaja de esa unidad indivisible de la naturaleza, en la que cada trozo sólo puede ser lugar de tránsito de las fuerzas universales de la existencia. Ver como paisaje un trozo de tierra significa considerar como unidad lo que sólo es fragmento de "naturaleza", lo cual nos aleja completamente del concepto de "naturaleza". ${ }^{19}$

Según Simmel, la primera condición necesaria para que surja el paisaje es la existencia de límites. En su existencia o ausencia se encuentra la diferenciación entre naturaleza y paisaje. Más adelante, en el mismo ensayo, Simmel definirá la naturaleza como «la conexión sin fin de las cosas, el interrumpido surgir y desvanecerse de formas, la unidad fluida del devenir que se expresa en la continuidad de la existencia espacial y temporal $»^{20}$. Cuando designamos como

15. David Lazcano, «Los escritos de Georg Simmel», Reis: Revista española de investigaciones sociológicas, n. ${ }^{\circ} 89$ (2000): 269-88, https://dialnet.unirioja.es/servlet/articulo?codigo=250167.

16. En 1881, Georg Simmel presentó su estudio Psycgologische und ethnologishe studien über Musik (Estudios psicológicos y etnológicos sobre música) en la facultad de filosofía de la Universidad de Berlín para acceder a la evaluación que le convertiría en doctor. El tribunal, habiendo reconocido que el tema de investigación presentado era extraordinario, no aceptó el trabajo al considerar que su desarrollo era poco preciso. Poco después, Simmel se doctoró con un trabajo sobre Kant, pero a pesar del primer rechazo, continuó profundizando en las intuiciones e ideas sobre etno-psicología, lingüística y arte que recogían su primera tesis. Simmel, Georg, "Psycgologische und ethnologishe studien über Musik», Zeitschrift für Völkerpsychologie und Spachwissenschaft 13 (1882): 261-205.

17. Publicación original: "Böcklins Ländschaften”, Die Zufunft, 12, 1895, pp. 272-277.

18. Publicación original: Simmel, Georg, «Philosophie der Landschaft», Die Güldenkammer. Norddeutsche Monatshefte 3 (1913): 635-44. .[rna y domina una región baja De la misma manera que

19. Simmel, Georg, Filosofia del paisaje (Madrid: Casimiro Libros, 2014), 8-9.

20. Ibid., 8. 
'naturaleza' una realidad, nos estamos refiriendo a una cualidad interna, que la diferencia del arte y lo artificial, así como de lo ideal e histórico. No hablamos, por tanto, de límites visuales, sino espaciales y temporales. Es decir, de un confín en el tiempo.

De igual manera, ya en el siglo XXI, encontramos ejemplos que comparten esta visión. Venturi Ferriolo, en Estetica del paessaggio ${ }^{21}$, define la naturaleza como un concepto complejo que comprende lo trascendente, aquello que va más allá de los límites de cualquier conocimiento posible. Al contrario del paisaje, apostilla, la naturaleza es unidad de una totalidad, sin partes ni contornos. Ferriolo subraya la necesidad de percepción de los confines para que exista el paisaje, así como la condición de compresión en un horizonte momentáneo o duradero; «es ser per se, relieve individual y característico respecto de la unidad indisoluble de la naturaleza» ${ }^{22}$.

Volviendo al ensayo de Simmel, en él se recalca la singularidad de los elementos de la naturaleza, en tanto que existen en sí mismos. Elementos singulares que se desgajan de la unidad en la que cada trozo solo puede ser lugar de tránsito de las fuerzas universales de la existencia. La posibilidad de percepción de un fragmento de fuerzas, conduce al entendimiento contemporáneo del término 'paisaje' como descripción de un proceso en contraposición a su definición de imagen estática. Un proceso en el que «aislamos fragmentos de lo múltiple hasta concebir un bloque de sensaciones como objeto, en una operación en la que es imprescindible la distancia» ${ }^{23}$. La distancia entre sujeto y objeto posibilita la visualización de una parte de la naturaleza como imagen de un fragmento de fuerzas en el mismo lugar en el que el sujeto produce dicha imagen, coincidiendo en el tiempo la experiencia del paisaje y su representación.

Si anteriormente veíamos cómo Simmel ya advertía de los límites necesarios para construir el paisaje, más adelante, en su filosofía, describirá el paisaje como acto que liga espacio y movimiento:

Así procedería el acto espiritual mediante el cual el ser humano agrupa una serie de fenómenos y los agrupa a la categoría de "paisaje": Sería una visión cerrada en sí misma y sentida como unidad autosuficiente, aunque enlazada con un espacio y un movimiento infinitamente más extensos, cuyos confines el sentimiento no puede aprehender y que pertenecen a un estrato más profundo, el del Uno divino, el de la naturaleza como Todo. ${ }^{24}$

21. Massimiliano Venturi Ferriolo, «Lineamentidi estetica del paessagio», en Estetica del Paessaggio, de Massimiliano Venturi Ferriolo, L. Giacomini, y E. Pesci (Milán: Guerini, 1999), 15., citado por Milani, El Arte del paisaje, 36.

22. Milani, El Arte del paisaje, 36.

23. Hernández León, Ser-paisaje, 119.

24. Simmel, Georg, Filosofía del paisaje, 8. 
En el entendimiento del concepto paisaje como acto, se fundamentan los estudios más recientes sobre paisaje, los cuales se apoyan en la apreciación holística del concepto para identificar los fragmentos de los flujos territoriales mediante neologismos, dando lugar así a los warscapes, urbanscapes, soundscapes.... y todos los $(x)$ scapes posibles que fraccionan la multiplicidad inherente al concepto paisaje en visiones sesgadas que diluyen el límite entre la representación del fenómeno y su experiencia. ${ }^{25}$ Este perspectivismo, tal y como enunciaba Ortega y Gasset, es la razón del carácter poliédrico del paisaje. ${ }^{26}$

El análisis de la historia semántica del término paisaje demuestra que tanto la visión clásica (representativa) como la contemporánea (experiencial-representativa) se encuentran incluidas en la palabra, dando lugar a su convivencia. Para ello hay que tener en cuenta los significantes que eluden a un mismo significado dentro del contexto europeo. Landscape, landschaft, landschap...La raíz Land- designa la región, el área, la tierra; la terminación -scape conlleva el sentido de lo colectivo, de lo holístico, el que se contiene en to shape (ship). Progresivamente, el sufijo (-scape, -ship, -schap), se ha desdoblado para ir más allá de la forma y significar, además, acción.

La historia de la palabra francesa paysage y del término paisaje en castellano son, desde el punto de vista etimológico, reveladoras. Paysage, pays-age, se entiende como 'todo', 'descripción general', 'en su totalidad' o 'totalidad'. ${ }^{27}$ No se abandona en este sentido el entendimiento de lo múltiple en una primera interpretación. Pero, teniendo en cuenta que sage en francés significa 'deseo', esto no deja de remitirnos a esa porción de 'tierra' deseada mediante una acción dominante: mirar el paisaje.

Análogamente, en castellano el término 'paisaje' hace referencia a una realidad múltiple que aglutina efectos sensibles focalizados en un mismo panorama. Pero al igual que alunizaje

25. Hernández León, Ser-paisaje, 13.

26. «Desde distintos puntos de vista dos hombres miran el mismo paisaje. Sin embargo, no ven lo mismo. La distinta situación hace que el paisaje se organice entre ambos de distinta manera. Lo que para uno ocupa el primer término y acusa con vigor todos sus detalles, para el otro se halla en el último y queda oscuro y borroso. Además, como las cosas puestas unas detrás de otras se ocultan en todo o en parte, cada uno de ellos percibirá porciones del paisaje que al otro no llegan. ¿Tendría sentido que cada cual declarase falso el paisaje ajeno? Evidentemente, no; tan real es el uno como el otro. Pero tampoco tendría sentido que puestos de acuerdo, en vista de no coincidir sus paisajes, los juzgasen ilusorios. Esto supondría que hay un tercer paisaje auténtico, el cual no se halla sometido a las mismas condiciones que los otros dos.»José Ortega y Gasset, "La doctrina del punto de vista», en El tema de nuestro tiempo, vol. III, cap. X, Obras completas (Madrid: Revista de Occidente, 1966), 197-203.

27. Cfr. Alain Roger, «Histoire d'une passion théorique ou comment on devient un Raboliot du paysage», en $\mathrm{La}$ théorie du paysage en France : (Seyssel: Champ Vallon Editions, 2009), 438-51.

Champ Vallon, Seyssel 1995, 438-451. Citado por Michael Jakob, What is landscape? Ediz. illustrata (List, 2018), 18. 
expresa la acción de alunizar y aterrizaje la de aterrizar, el sufijo -aje (que en castellano afecta tanto a sustantivos como a verbos), remite, por un lado, a la acción de crear un territorio o un espacio, y por otro, si pensamos en $p a i s^{28}$ como sustantivo, el sufijo-aje nos devuelve a la imagen múltiple, a la idea de conjunto (como lo hacen cordaje o ramaje). El concepto paisaje, por tanto, expresa una acción capaz de construir un espacio, al mismo tiempo que desprende la idea de conjunto.

Por todo ello, la acepción contemporánea del concepto paisaje se manifiesta mayoritariamente contraria a la interpretación única del 'scape' como 'ver distraído'29, y se liga a la acción fragmentaria, donde el punto de vista, la especificidad de la mirada que indicaban Gazapo y Lapayese, es lo que determina el paisaje. De esta forma, lo que en castellano toma el valor de atributo (por ejemplo, urbano o sonoro), en otros idiomas, como el inglés, las construcciones land-scape, art-scape o sound-scape, no solo indican que hablamos de paisaje, sino que además especifican la posición referencial desde donde se construye el mismo, estableciendo una dirección entre las múltiples posibles sin olvidar la esencia múltiple del término.

En el plano en el cual convergen espacio y sonido, el paisaje sonoro surge como un oxímoron en el cual lo visual y lo invisible se enfrentan en la determinación de su significado como conjunto. Pues, si el paisaje es una realidad fundamentada en la imagen, el sonido es una sensación invisible y evanescente que opera a través y con el tiempo y el espacio. ${ }^{30} \mathrm{El}$ paisaje sonoro forma parte de esa familia de neologismos que toman los flujos de energía que atraviesan la naturaleza como base para conformar el paisaje. La distancia y los límites espacio-temporales se perfilan como condicionantes a evaluar para determinar en qué medida el paisaje existe dentro del paisaje sonoro.

28. Joan Coromines, Breve diccionario etimológico de la lengua castellana, 3. ed. muy rev. y mejorada, Biblioteca románica hispánica : 5, Diccionarios ; [2] (Madrid: Gredos, 1973), 433.

29. Hernández León, Ser-paisaje, 10.

30. Sobre esta afirmación, nos remitimos al capítulo dedicado a Kant en Historia de la Filosofía II de Martínez Marzoa, en el explica la diferencia entre sensibilidad y afección en Kant. «La receptividad, capacidad de ser afectado, inherente al conocimiento, es lo que llamaremos sensibilidad, mientras que la afección, el hecho de ser afectado, es lo que llamaremos sensación.» Se entiende, por tanto, el sonido es sensación que, como cualquier otra, «tiene (u “ocupa”) alguna extensión», y que esa extensión, para la sensación sonora, es "tiempo" y "espacio". Para Kant, «toda sensación tiene lugar "en" el tiempo, o sea, de acuerdo con la condición del tiempo; por otra parte, en cuanto a la clase de relaciones que designamos como de distancia y posición, cualquier sensación o bien no tiene en absoluto tales relaciones o bien está con respecto a cualquier otra sensación que las tenga en una y sólo una relación de esa clase cumpliendo todas las leyes que sean inherentes a esa clase de relaciones, y esto es lo que queremos decir cuando decimos que toda sensación tiene lugar o bien "en" el espacio con todas las consecuencias, o sea, en todo de acuerdo con la condición del espacio, o bien sin espacialidad alguna». En el caso del sonido, se considera que tiene lugar en el tiempo y el espacio, inherentes al mismo por el hecho de ser sensación. Felipe Martínez Marzoa, Historia de la Filosofía II: Filosofia moderna y contemporánea, Edición: 1 (Madrid: Ediciones Istmo, S.A., 2003), 116-17. 


\section{I.2. El STIMMUNG O LA VISIÓN SONORA DEL MUNDO}

En el siglo XVI, el médico y astrólogo inglés Robert Fludd (1574-1637), en el tercer volumen de su enciclopedia ${ }^{31}$, De Musica Mundana (1617), describió sus teorías sobre la relación entre música y el macrocosmos. Para ello, Fludd dibuja un monocordio donde el universo entero aparece ordenado según las proporciones divinas. Una reminiscencia del concepto pitagórico de la armonía del mundo ligada a la teoría de cuerdas y esferas, en la que la unificación de lo diverso (los acordes), sintonizan el hombre con el universo a través de la resonancia. La teoría de Fludd es uno de los ejemplos clásicos de la expansión de la música a otros campos que, aparentemente, nada tienen que ver con ella. Cuatro siglos después, la obra referencial para los estudios sobre paisaje sonoro, The Soundscape. Our Sonic Environment and the Tunning of the World de Murray Schafer, comienza con la imagen del monocordio de Fludd, el instrumento que desde el mito de Apolo hasta el laúd Dogón de Mali, refleja el pensamiento armónico del mundo a través de la música y el sonido.

En la cultura occidental, existe una palabra que quiere expresar la unidad de sentimientos que pueden sentirse ante la visión de la naturaleza, de un paisaje o de otro ser humano sin abandonar la idea de armonía del mundo: la palabra alemana Stimmung. Georg Simmel, en su Filosofía del paisaje, escribió que la conciencia de estar ante un paisaje, de una unidad que sintetiza la multiplicidad de afecciones, exige un soporte que se denominaría Stimmung:

En la medida en que el paisaje posee toda su objetividad en cuanto "paisaje" en virtud de nuestra actividad, la Stimmung, que es una expresión o dinámica específica de esta actividad, basa su objetividad en el paisaje. ${ }^{32}$

El término, de difícil traducción en castellano, unifica en un mismo concepto la armonía con el mundo y la resonancia del alma con el entorno. ${ }^{33}$ Stimmung significa al mismo tiempo 'atmósfera', 'estado de ánimo' y 'tonalidad espiritual'. El hispanista austríaco Leo Spitzer (18871960) hizo un profuso estudio de la historia semántica del término Stimmung y las palabras que históricamente congrega bajo su significante, considerando además las connotaciones emocionales del término con sus variaciones y fluctuaciones en el tiempo.

31. Robert Fludd, Utriusque Cosmi, Maioris scilicet et Minoris, metaphysica, physica, atque technica Historia. 1617. «Robert Fludd's Utriusque Cosmi maioris salicet et minoris metaphysica... (1617-1619 CE)», accedido 6 de noviembre de 2019, http://billheidrick.com/Orpd/RFludd/.

32. Simmel, Georg, Filosofía del paisaje, 20.

33. Ibid., 18. Nota del traductor. 

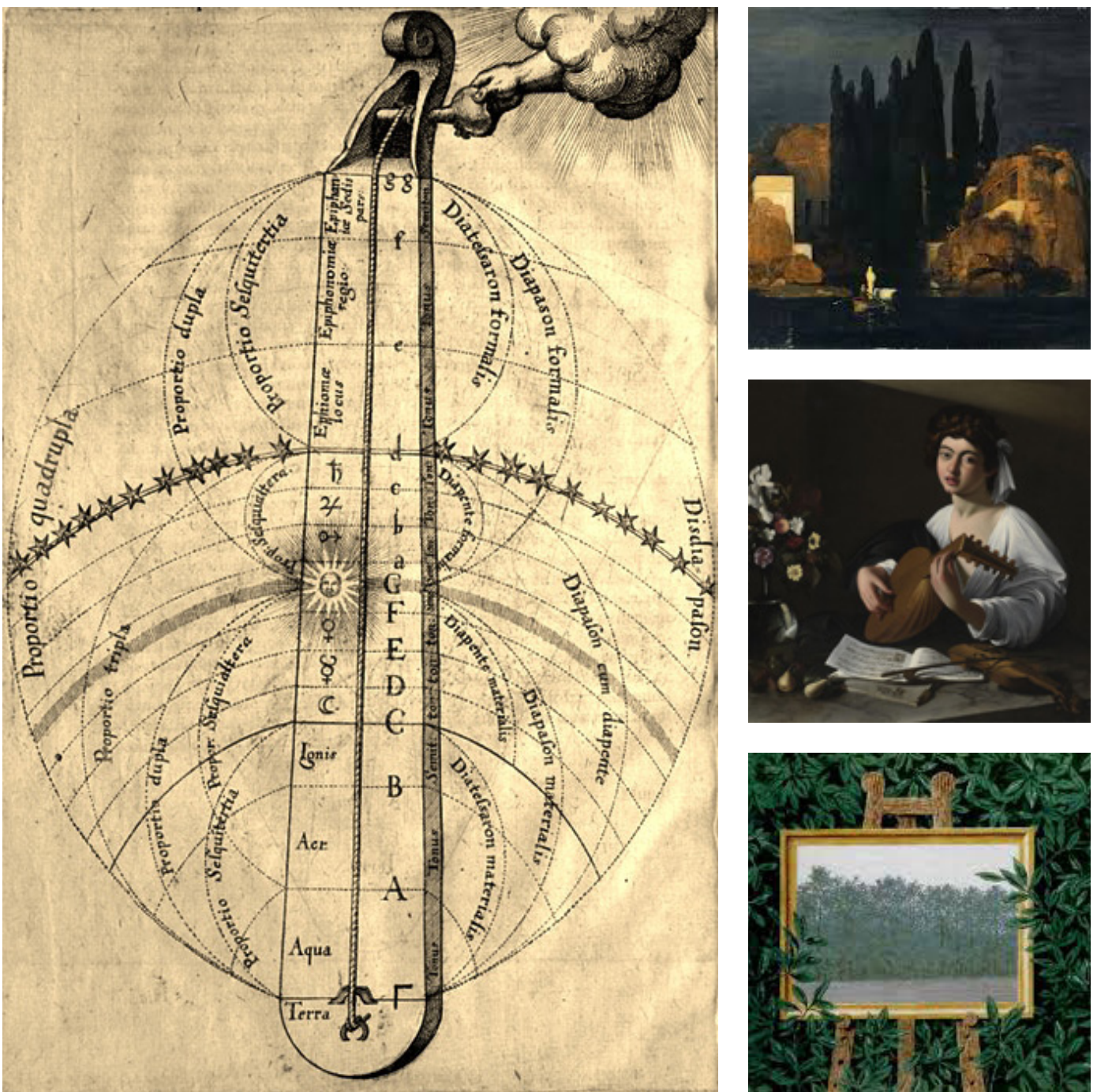

49



Figura 46. Robert Fludd, Monocordio (1617)

Figura 47. Arnold Böcklin, Detalle de La isla de los muertos II (1880)

Figura 48. Caravaggio, Apolo tocando el laúd (1596)

Figura 49. René Magritte, La Cascade (1961) 
[...] para un alemán, Stimmung está fundida con el paisaje, el cual a su vez está animado por el sentimiento del hombre: es una unidad indisoluble en la que hombre y naturaleza están integrados.[...] Pero lo que falta en los principales idiomas europeos es un término que exprese la unidad de sentimiento experimentados por el hombre ante su entorno (un paisaje, la naturaleza, otro ser humano) y comprenda y suelde lo objetivo (fáctico) y lo subjetivo (psicológico) en una unidad armoniosa ${ }^{34}$.

Spritzer demuestra en su estudio la remisión constante que existe entre gestimmt sein (estar afinado) y Stimmung, cuya referencia a realidades más amplias que la instrumental (una persona, un paisaje, está afinado con respecto a 'algo') no olvida su origen musical. Instrumento, música y paisaje se ligan entonces en un mismo concepto, génesis de una visión sonora del mundo ancestral que tiene su origen en el pensamiento armonizador de los griegos. ${ }^{35}$ Es a la cultura griega a quien debemos la primera imagen del mundo visto en una armonía que tiene por modelo la música, un mundo donde î́ć $\alpha$ (idea; 'forma' o 'apariencia') y عî̉os (eidos; 'forma', 'aspecto', 'tipo' o 'especie'), Denken y Anscheuen, pensar y mirar, eran una sola cosa ${ }^{36}$.

Entre la imagen y el pensamiento, nos dice Spitzer, se producía un flujo continuo de metáforas que partían de la esfera humana (y divina) hacia la naturaleza y volvían a las actividades humanas. ${ }^{37}$ Se consideraba que estas imitaban el orden y la armonía de la naturaleza. Un camino de ida y vuelta que, al igual que el recorrido seguido para el estudio de la formalización del paisaje, enfrenta a su imagen al pensamiento mediante palabras engendradas en lo sensible.

\section{I.I.3. LA ESCUCHA COMO ACCIÓN FORMALIZADORA DEL CONCEPTO PAISAJE}

Cuando, ante un paisaje, la unidad de la existencia natural pretende envolvernos en su trama, el desgarro entre un yo que ve y un yo que siente resulta doblemente equivocado. Pues es con todo nuestro ser como estamos ante un paisaje, ya sea este natural o artístico, y el acto que mira y un acto que siente, un acto que solo cabe desgajar en virtud del ejercicio del pensamiento. ${ }^{38}$

34. Leo Spitzer, Ideas clásica y cristiana de la armonía del mundo: prolegómenos a una interpretación de la palabra «Stimmung», trad. Alfredo Brotons Muńoz, Lecturas de teoría literaria (Madrid: Abada, 2008), 15.

35. Cfr. ibid., 15-18.

36. Ibid., 17.

37. Ibid., 18 .

38. Simmel, Georg, Filosofía del paisaje, 22. 
Del pensamiento de Simmel se desprende que el paisaje exige un desdoblamiento entre lo que se siente (o experimenta) y lo que se ve (o representa), que debe entenderse como un acto formado por dos acciones simultáneas que hacen conscientes al hombre de sí mismo. Productos del intelecto y la sensibilidad que, al ser engendrados en la escucha como acción formalizadora de paisaje, producen un redoble de subjetividad.

El lenguaje otorga a cada órgano sensorial un par de acción en el que el grado de tensión que existe entre sujeto y entorno genera términos ligados a percepciones más o menos voluntarias. Es el par auditivo el que mantiene una relación particular con el sentido en la acepción intelectual de la palabra. El sentido del verbo escuchar, nos indica Jean-Luc Nancy, combina el uso de un órgano sensorial, el oído ${ }^{39}$ y una tensión, una intención y una atención marcadas por la parte reflexiva del término ${ }^{40}$. Oír, como recalca Roland Barthes, es un fenómenos fisiológico, mientras que escuchar es un acto psicológico. ${ }^{41}$

Profundizando en la etimología francesa de la palabra, advertimos que entendre (escuchar) es al mismo tiempo 'entender' (comprender algo, relacionado o no con el sonido) y 'escuchar' (oír con atención un sonido). Inversamente, sentire, en italiano, significa 'oír'. Ese doble papel que juega el sentido (sensato y sensible), nos aproxima a la justificación de la elección de la escucha como medio para entender el paisaje, en tanto que esa relación sentir - pensar está presente tanto en la escucha misma como en el 'paisaje'. Por tanto, la percepción acústica no implica solo percibir, sino, como indica Nancy, estar tendido hacia un sentido presente más allá del sonido ${ }^{42}$ :

Si "entender" es comprender el sentido (ya sea en sentido figurado o en el que denominamos sentido propio: oír una sirena, a un pájaro o un tambor ya es comprender en cada ocasión, por lo menos, el esbozo de una situación, de un contexto, si no de un texto), escuchar es estar tendido hacia un sentido posible y, en consecuencia, no inmediatamente accesible. ${ }^{43}$

Siguiendo el razonamiento propuesto por Jean Luc Nancy en su ensayo $A$ la escucha, la

39. 'Oreja' y 'oído', derivan del latín auris, palabra presente en la primera parte del verbo auscultar, del que proviene 'escuchar'. Cfr. Coromines, Breve diccionario etimológico de la lengua castellana, 422; 426; 246.

40. Nancy, A la escucha, 16.

41. Roland Barthes, The Responsibility of Forms: Critical Essays on Music, Art, and Representation, trad. Richard Howard, Reprint edition (Berkeley: University of California Press, 1991), 245-260.

42. En otras palabras, en todo decir, hay un entender, y en el propio entender una escucha; lo cual, sugiere Nancy, implica que tal vez sea preciso que el sentido no se conforme con ser logos, sino que además resuene. Nancy, $A$ la escucha, 17-18.

43. Ibid., 18-19. 
investigación se apropia del sonido como medio para la formalización del concepto paisaje. La escucha proporciona el acceso al ultrasenstido ${ }^{44}$ del paisaje, a la lógica que va más allá de la percepción. El sonido se convierte en un mediador que permite pasar de los abstracto inherente al concepto paisaje a una materialidad concreta (que no tiene por qué ser la suya propia) para hacerse comprensible.

La palabra 'escucha' contiene, además, un espacio físico en su evolución, en tanto que el término designaba el lugar desde el cual podía escucharse en secreto. "Estar a las escuchas" consistió, ante todo, en situarse en un lugar escondido para poder sorprender desde él una conversación o una confesión.» ${ }^{45}$ Un lugar en el que se producía la percepción y el entendimiento.

Teniendo en cuenta que lo oido es un sentido (escuchado) y una verdad (que entendemos), aunque, en última instancia, uno no pueda prescindir de lo otro, se considera el paisaje sonoro como producto, a priori, de la escucha sentida, percibida por el oído. Paisaje y escucha forman cada uno de ellos un plano de significado que, en ambos casos, remite al producto de una reflexión y percepción simultáneas. Esta circunstancia provoca que el resultado de la conjunción de ambos términos sea, por tanto, un retruécano semántico y conceptual, lo que nos lleva a preguntarnos ¿Qué significa entonces estar a la escucha del paisaje? ¿Qué elementos de la experiencia del paisaje se ponen en juego? ¿Es la escucha misma, sonora? $\mathrm{O}$, como formula Peter Szendy ${ }^{46}$, «intentar ver el oír no obedecería al intento de hallar un paralelismo con aquello que quizá la vista todavía no ha aprendido a controlar y a sujetar?»» ${ }^{47}$

\section{I.2. LA CONSTRUCCIÓN DEL CONCEPTO PAISAJE SONORO}

Gilles Deleuze y Felix Guattari, en su obra ¿Qué es la filosofía? indican que «todo concepto remite a un problema, a unos problemas sin los cuales carecería de sentido, y que a su vez solo pueden ser despejados o comprendidos a medida que se vayan solucionando [...].» ${ }^{48}$ En el caso del concepto paisaje sonoro, las variables semánticas, temporales y espaciales que contiene

\footnotetext{
44. Ibid., 63.

45. Ibid., 15-16.

46. Filósofo francés y musicólogo. «Peter Szendy | Cogut Institute for the Humanities | Brown University», accedido 9 de junio de 2020, https://www.brown.edu/academics/humanities/people/peter-szendy.

47. Peter Szendy, En lo profundo de un oído: una estética de la escucha (Santiago de Chile: Metales Pesados, 2015),

48. Gilles Deleuze y Félix Guattari, ¿Qué es la filosofía? (Barcelona: Círculo de lectores, 1995), 22.
} 
obligan al arquitecto a adentrarse en otros campos creativos para encontrar el origen de los problemas a los que se enfrenta al estudiar el concepto. Este apartado trata de plantear los problemas que dan lugar al concepto paisaje sonoro, más aún que de resolverlos.

\section{I.2. I. VARIABLES SEMÁNTICAS: METÁFORAS VISUALES PARA DESCRIBIR LO SONORO}

Sounds cannot be known the way sights can be known, seeing is analytical and reflective. It places things side by side and compares them (scenes, slides, diagrams, figures...). This is why Aristotle preferred sight as 'the principal source of knowledge."

Sights are knowable. Sights are nouns.

Sounding is active and generative. Sounds are verbs. Like all creation, sound is incomparable. ${ }^{49}$

\section{R. M. Schafer. I've Never Seen a Sound}

Uno de los debates abiertos actualmente en el campo del paisaje es la diferenciación entre la 'experiencia del paisaje', y la palabra 'paisaje'. El paisaje, considerado como centro de una sofisticada red semiótica ${ }^{50}$, es un terreno invadido por muchos, que acoge reflexiones que fluctúan entre la fenomenología y el empirismo. El en caso del Soundscape, el lenguaje asociado al pensamiento en este ámbito se encuentra distorsionado o limitado por la supremacía de lo visual, por lo que la imperceptible transformación de una imagen sonora en una imagen visual provoca, habitualmente, la presentación como equivalentes de los lenguajes de la imagen y el sonido. $^{51}$

Tanto en Eskimo Realities como en Explorations in communication ${ }^{52}$, Marshall MacLuhan y Edmund Carpenter definen el espacio acústico y su relación con el lenguaje.

The essential feature of sound, however, is not its location, but that it $b e$, that it fill space.

We say "the night shall be filled with music," just as the air is filled with fragrance; locality

49. R. Murray Schafer, «I Have Never Seen a Sound», Canadian Acoustics 37, n. 3 (1 de septiembre de 2009): 32-34, //jcaa.caa-aca.ca/index.php/jcaa/article/view/2123.

50. Jakob, What is landscape?, 11.

51. «Le langage de la vue diffère de celui de l'oreille, les príncipes acoustiques ne sont pas du tout les mêmes que ceux de la couleur. Toutes les comparaisons qui ont été tentées sont confuses, tirées par les cheveux, ou réduites à d'inconsistantes équations ». Pierre Boulez, Le pays fertile: Paul Klee (Paris: Gallimard, 1989), 51.

52. Edmund Carpenter y Marshall McLuhan, «Acoustic Space», en Explorations in Communication: An Anthology, ed. Edmund Carpenter y Marshall McLuhan, 6th print, Beacon Paperback Language 218 (Boston: Beacon Press, 1970), 65-70. 
is irrelevant. The concert-goer closes his eyes.

Auditory space has no point of favored focus. It's a sphere without fixed boundaries, space made by the thing itself, not space containing the thing. It is not pictorial space, boxed in, but dynamic, always in flux, creating its own dimensions moment by moment. It has no fixed boundaries; it is indifferent to background. The eye focuses, pinpoints, abstracts, locating each object in physical space, against a background; the ear, however, favors sound from any direction. We hear equally well from right or left, front or back, above or below. If we lie down, it makes no difference, whereas in visual space the entire spectacle is altered. We can shut out the visual field by simply closing our eyes, but we are always triggered to respond to sound. ${ }^{53}$

Considerando el estudio de Paul Rodaway ${ }^{54}$, Sensuous Geographies, se diferencian dos niveles de relación entre el lenguaje sonoro y el lenguaje visual. Un nivel metafórico, cuando se trasladan y aplican en sentido figurado las palabras del campo visual al sonoro; y un nivel estructural, cuando se establece una relación figurativa a través de una analogía entre estructuras visibles y audibles. Este último nivel se basa en la comunicación visual de la señal o signo sonoro. En él, el sujeto desempeña un papel decodificador ${ }^{55}$.

En la mayoría de los casos, el empleo de la palabra Soundscape se realiza en el primer nivel, y hace referencia a un acto interpretativo (metafórico). Una vez superado el nivel léxico, se accederá al nivel semántico (estructural), en el que el lenguaje remite al problema conceptual. O como lo expresa el paisajista Rossario Assunto:

nuestro problema, aquí, no es lexicográfico, más bien, es propiamente filosófico: es el problema de definir la esencia del paisaje, su significado y valor para el hombre; y el momento lexicológico solo puede ser, si no inicial, preliminar a nuestra investigación: preliminar y útil, quizás valioso, en tanto que nos ha permitido pasar al estudio de los que nos ocupa -que ya no es terminológico, sino conceptual- después de aprender que el paisaje es, según los diccionarios, un territorio más o menos extenso, como se le aparece a la vista, convirtiéndose en objeto (al menos potencialmente) de una representación pictórica. ${ }^{56}$

53. Edmund Carpenter et al., Eskimo realities, 1st ed. (New York: Holt, Rinehart and Winston, 1973), 35-37. citado en R. Murray Schafer, «Acoustic Space», Circuit: Musiques Contemporaines 17, n. 3 (2007): 83, https://doi. org/10.7202/017594ar. Traducción del autor.

54. Paul Rodaway, Sensuous Geographies: Body, Sense, and Place (Routledge, 1994), 82-83. Paul Rodaway profesor de Human Geography en el Edge Hill College, Lancashire. Sus investigaciones incluyen trabajos sobre fenomenología, la orientación en el espacio de los discapacitados y las diferencias culturales en conceptos espaciales y actitudes hacia el entorno. "Book Reviews», Journal of Environmental Psychology 17, n. 1 (1 de marzo de 1997): 75-79, https:// doi.org/10.1006/jevp.1996.0041.

55. Barthes, The Responsibility of Forms, 249.

56. Rosario Assunto, Il paesaggio e l'estetica (Palermo: Novecento, 2005), 22. Citado en Jakob, What is landscape?, 
En consecuencia, el primer problema al que remite el concepto paisaje sonoro es que la «necesidad de una correspondencia entre las categorías históricas del lenguaje y la posibilidad de interpretación de la imagen ${ }^{57}$ da lugar al uso constante de metáforas que tienden a simplificar la complejidad del concepto.

\section{I.2.2. VARIABLES ESPACIALES: PERTENENCIA $A$ Y EMANCIPACIÓN ANTE}

David Bohm ${ }^{58}$ (1917-1992), uno de los físicos teóricos más influyentes del siglo XX, escribió Wholeness and the Implicate Order (1980) para explicar el proceso dinámico de la materia, la vida y la conciencia. Para Bohm, la estructura objeto-sujeto de nuestro lenguaje enfatiza una visión estática del mundo, una interpretación visual de la realidad en la que es muy difícil describir fenómenos dinámicos. En la cultura occidental, el sujeto que piensa (el Ego) es, en principio, una realidad separada de la realidad que piensa. La interpretación fragmentada de la realidad, el conocimiento científico moderno y la predominancia de los sustantivos frente a los verbos en el lenguaje (haciendo predominar el objeto sobre la acción), nos enfrenta, según Bohm, a un desafío complejo: ¿Cómo debemos pensar coherentemente la realidad como un todo dinámico que contiene tanto el pensamiento (conciencia) como la realidad externa a medida que la experimentamos?59 Una cuestión que nos aproxima al problema de la representación de

23. Traducción de la autora. Sobre la definición de paisaje, ambiente y territorio, véase: «Rosario Assunto, Paesaggio - Ambiente - Territorio. Un tentativo di precisazione concettuale, in "Bollettino CISA", n. XVIII, 1976, pp. 45 - 48.", Palladio Museum, accedido 21 de julio de 2019, https://www.palladiomuseum.org/annali/1976/2/pdf.

57. Hernández León, Ser-paisaje, 16.

58. «David Bohm | American physicist | Britannica.com», accedido 7 de noviembre de 2019, https://www. britannica.com/biography/David-Bohm.

59. David Bohm, Wholeness and the Implicate Order, Edición: 1 (London ; New York: Routledge, 2002), 71. "What is required here, then, is not an explanation that would give us some knowledge of the relationship of thought and thing, or of thought and 'reality as a whole'. Rather, what is needed is an act of understanding; in which we see the totality as an actual process that, when carried out properly, tends to bring about an harmonious and orderly overall action, incorporating both thought and what is thought about in a single movement, in which analysis into separate parts (e.g., thought and thing) has no meaning.» Para abordar la cuestión del cambio de enfoque 'objetualestático' predominante al 'procesal-dinámico', Bohm trató de desarrollar un enfoque experimental del lenguaje - un "nuevo modo" de utilizar los lenguajes existentes - que llamó el rheomode: «For the sake of convenience we shall give this mode a name, i.e. the rheomode ('rheo' is from a Greek verb, meaning 'to flow'). At least in the first instance the rheomode will be an experiment in the use of language, concerned mainly with trying to find out whether it is possible to create a new structure that is not so prone toward fragmentation as is the present one. Evidently, then, our inquiry will have to begin by emphasizing the role of language in shaping our overall world views as well as in expressing them more precisely in the form of general philosophical ideas. For as suggested in the previous chapter these world views and their general expressions (which contain tacit conclusions about everything, including nature, society, ourselves, our language, etc.) are now playing a key role in helping to originate and sustain fragmentation in 
realidades dinámicas como son el sonido y el paisaje.

Todo lo que reconocemos como espacio, como el paisaje, está ligado a nuestra presencia ${ }^{60}$. Y si el paisaje real es, según Michael Jakob, una representación de una representación ${ }^{61}$, la pertenencia a y la emancipación ante un mismo ente (la naturaleza), esta condición plantea un problema doble en torno a tres elementos: imagen, realidad y sujeto.

El problema de la doble naturaleza del paisaje es algo que ya advertía Simmel en la filosofía del paisaje, quien sitúa el origen del paisaje en una pulsión vital, y al mismo tiempo habla de él como producto resultante. El producto resultante, dentro de sus límites espacio-temporales «se abre, desde sí mismo, para acoger lo ilimitado de la vida universal, de la naturaleza». ${ }^{62}$ Una representación del paisaje dentro del paisaje que implica, como indica Michel Foucault en su ensayo dedicado a René Magritte, una distancia interior ${ }^{63}$, una divergencia entre el cuadro y aquello que imita. Los cuadros de Magritte, como La Condition Humaine o La Casacade, simbolizan la continuidad entre la escena vivida y la representada, así como la posición ambigua del sujeto, dentro y fuera al mismo tiempo.

¿Qué ocurre entonces con la relación sujeto - objeto en el paisaje sonoro? Al producirse la sensación del sonido dentro del sujeto, el cuerpo se convierte, en el intermediario que impone coherencia al caos y trata de ordenar nuestra experiencia. Es el instrumento básico con el que hacemos inteligible nuestra experiencia, tal y como explicará György Kepes en The New Landscape:

With it, we articulate the constant stream of impressions on our senses, differentiating the world into discrete entities and unifying it into an interrelated whole. Our body defined axes of reference: position, size, direction, density. Though repeated comparisons, we build the realm of things, of objects which have their separate existences in a space framed by these axes. We fill the world with stones, mountains, leaves, trees, men and animals. Theses, even if they move, do not lose their fixed identities. We still see them as things and our self as the central thing- the subject- that observes, measures and understands all the others. ${ }^{64}$

every aspect of life. So we will start by using the rheomode mainly in an experimental way. As already pointed out, to do this implies giving a kind of careful attention to how thought and language actually work, which goes beyond a mere consideration of their content.» Ibid., 39.

60. Cfr. Hernández León, Ser-paisaje, 122.

61. Cfr, Jakob, What is landscape?, 29.

62. Simmel, Georg, Filosofia del paisaje, 11.

63. Michel Foucault, This Is Not a Pipe (Berkeley: University of California Press, 1983), 50.

64. Gyorgy Kepes, The New Landscape in Art and Science (Academy Editions Ltd, 1956), 204. Ampliación en el 
El cuerpo es el instrumento en el que se produce un nuevo movimiento de ida y vuelta, un repliegue/despliegue que pliega el adentro en el afuera, y viceversa, convirtiendo el cuerpo una caja de resonancia antes de que se presente una figura visible del paisaje. Se produce entonces una remisión de remisiones (de un signo a una cosa, de un sujeto a sí mismo), y el sonido del paisaje resuena en el cuerpo generando el sujeto, pues «mientras que el sujeto de la mirada ya está siempre dado, postulado en sí en su punto de vista, el sujeto de la escucha siempre está aún por venir ${ }^{65}$.

Comprender que el sonido no solo se difunde en el espacio, sino que abre un espacio, el suyo propio -el espacio de su resonancia, dilatación y reverberación ${ }^{66}$ - que puede ser representado en lenguaje propio (sonoro) o ajeno (visual) es el horizonte a alcanzar para que el paisaje sonoro pueda considerarse como paisaje.

\section{I.2.3. VARIABLES TEMPORALES: LA CONVERSIÓN DEL TIEMPO EN ESPACIO}

La frase con la que comienza esta investigación, aqui el tiempo se convierte en espacio, pertenece al primer acto de la escena I de la ópera de Richard Wagner Parsifal (1882). En el momento en el que la ambientación de la obra pasa del exterior del bosque al interior de la sala del Grial, Parsifal percibe una extraña sensación. El tiempo pasa muy rápido, pero ellos no avanzan en su recorrido - «Apenas he caminado, y lejos me encuentro ya»-. El motivo de esta percepción, advierte el caballero Gurnemanz, se encuentra en el tiempo, pues en el reino del Grial, se convierte en espacio. ${ }^{67}$ Wagner formula en su ópera el problema más complejo que entraña el estudio del paisaje sonoro: cómo representar el tiempo, inherente y necesario para la existencia del sonido, que construye un espacio.

Edmund Husserl (1859-1938), en Fenomenología de la conciencia inmanente del tiempo, afronta el problema de la reproducción y percepción del tiempo tomando como ejemplo la escucha de una melodía. ${ }^{68}$ Husserl analiza el reencuentro que se produce entre el presente

Capítulo segundo, apartado: 1945-1956: De los nuevos paisajes a la forma urbana. Geörgy Kepes y John Cage en el MIT.

65. Nancy, A la escucha, 46.

66. Jean-Luc Nancy, A la escucha (Buenos Aires: Amorrortu Editores, 2008), 32.

67. Cfr. Fernando Herrero, "Parsifal" de Wagner y su centenario», Biblioteca Virtual Miguel de Cervantes, accedido 26 de octubre de 2019, http://www.cervantesvirtual.com/obra-visor/parsifal-de-wagner-y-su-centenario/ $\mathrm{html} / .$.

68. Edmund Husserl, Fenomenología de la conciencia inmanente del tiempo (Buenos Aires: Prometeo Libros, 
percibido que se reformula constantemente (la impresión que causa un sonido concreto del compás de una melodía en un instante), y su confrontación con los recuerdos ${ }^{69}$ (una vez escuchada toda la melodía, se identifica una estructura similar al conjunto de todos los sonidos que la conforman en el archivo mental de recuerdos primarios). La melodía, para Husserl, se convierte en medio para pensar la unidad de y en la diversidad, así como lo contrario, pensar una diversidad de y en la unidad. ${ }^{70}$ El ejemplo de la melodía de Husserl plantea, asimismo, el conflicto del orden de las acciones que dan lugar al paisaje sonoro. Puesto que el sonido no aporta únicamente un conocimiento sobre el mundo, que viene a nosotros desde la reflexión y el pensamiento introspectivo, sino que también provoca un pensamiento en el mundo. Se reconocen, en consecuencia, dos direcciones de acción de la escucha, pasiva y activa, del interior al exterior y viceversa.

En la misma línea de pensamiento ${ }^{71}$, Henri Bergson (1859-1941) expone que el concepto de tiempo defendido por la tradición científica y filosófica occidentales no hace referencia al tiempo real sino, más bien, a un concepto de tiempo entendido como la suma de la sucesión de instantes que lo convierte, por tanto, en un fenómeno divisible. Pero el tiempo, nos dice Bergson, es la duración real, es el tiempo percibido como indivisible:

No tenemos ningún interés en escuchar el zumbido interrumpido de la vida profunda. Y sin embargo, la duración real está ahí. Gracias a ellas tienen lugar en un solo y mismo tiempo los cambios más o menos largos a que asistimos en nosotros mismos y en el mundo exterior. $^{72}$

En el paisaje sonoro, lo estable -figurado en el más permanente de los estados internos, la percepción visual de un objeto exterior inmóvil ${ }^{133}-$, se enfrenta al sonido, que es la experiencia interna del tiempo. Así lo explica Jean-Luc Nancy:

\section{4), 80-83.}

69. Debemos recordar la estrecha relación que etimológicamente guardan el término empleado para designar una grabación en inglés (record) con la afección sensible, ligada al recuerdo. Su origen se encuentra en la palabra latina recordari, formado por el prefijo re- (volver) y la raíz -cor (genitivo de cordis) que significaba corazón. Coromines, Breve diccionario etimológico de la lengua castellana, 497.

70. Nancy, $A$ la escucha, 41.

71. «Cuando escuchamos una melodía, tenemos la impresión más pura de sucesión que podemos tener -una impresión tan alejada como es posible de la simultaneidad-, y sin embargo es la continuidad misma de la melodía y la imposibilidad de descomponerla lo que causa en nosotros esa impresión. Si la descomponemos en notas distintas, en tantos "antes" y tantos "después" como nos plazca, estamos mezclando imágenes espaciales e impregnamos la sucesión de simultaneidad: en el espacio, y sólo en el espacio, hay distinción nítida de partes exteriores unas a otras.» Henri Bergson y Gilles Deleuze, Memoria y vida (Madrid: Alianza, 2016), 27.

72. Ibid.

73. Ibid., 14 . 
Escuchar es ingresar a la espacialidad que, al mismo tiempo, me penetra: pues ella se abre en mí tanto como en torno a mí, y desde mí tanto como hacia mí: me abre en mí tanto como afuera, y en virtud de esa doble, cuádruple o séxtuple apertura, un "sí mismo" puede tener lugar. Estar a la escucha es estar al mismo tiempo afuera y adentro, y por consiguiente de uno a otro y de uno en otro. La escucha constituiría así la singularidad sensible que expresa en el modo más ostensivo la condición sensible o sensitiva (aiestética) como tal: la partición de un adentro/afuera, división y participación, desconexión y contagio. ${ }^{74}$

La condición aiestética de la escucha definida por Nancy, la aparición de un adentro y un afuera, es compartida con el paisaje, en tanto que en su definición de imagen interior y exterior que genera un dinamismo entre la experiencia y la representación, encontramos un paralelismo entre ambos procedimientos que da como resultado un modo de ser en el espacio. Esta relación entre pares constituye una realidad en el momento en el que se representa. Reflexionando a través del ejemplo de Husserl, podemos pensar en la representación del paisaje evocado internamente por la impresión causada por la percepción de un sonido, o trabajar en sentido inverso y plantear qué tipo de medios consiguen representar visualmente un sonido que parte de la percepción interna, de la memoria y el recuerdo.

Para pasar de un conocimiento interior a otro exterior y viceversa, se hace necesaria una imagen ${ }^{75}$ en la que el tiempo quede contenido en la representación del paisaje. Una representación del mundo interior, germen del pensamiento objetivo y exterior, que ayude a entender la realidad.

Las imágenes se convierten así en el punto de inicio del pensamiento sonoro, pues es a través de ellas como se crean patrones sensibles. La forma mediante la cual se toma conciencia de la forma y las estructuras del mundo, movilizando el pensamiento para desarrollar ideas y conceptos. ${ }^{76}$

Mirando hacia atrás, creo que fue muy natural para mí el dibujar. A veces estaba dibujando

74. Nancy, A la escucha, 33.

75. Ver Capítulo tercero, apartado 3.5. Ritornelo. Abriendo el camino del estudio de las imágenes de pensamiento y la imagen cristal de Gilles Deleuze, Caraës y Marchand-Zanartu explican que las imágenes de pensamiento no son a priori ni a posteriori, sino que son contemporáneas de lo que capturan. Funcionan mediante un doble impulso. Por un lado, se sumerge en las profundidades de la mente para alcanzar el secreto de un mundo interior y, por otro, se elevan a la superficie de pensamientos e ideas materiales necesarios para la invención. La pertenencia a ambos mundos hace que la imagen de pensamiento no pueda ser considerada como objeto, pues nunca representa el mundo tal y como existe, sino que es la base potencial de una realidad que aún no ha sucedido. La imagen de pensamiento «es un lugar estratégico, donde la intuición y la razón luchan sin cesar».Marie-Haude Caraës, Nicole Marchand-Zanartu, y Jean Lauxerois, Images de pensée (Paris: RMN, 2011).

76. Cfr. Kepes, The New Landscape in Art and Science, 22. 


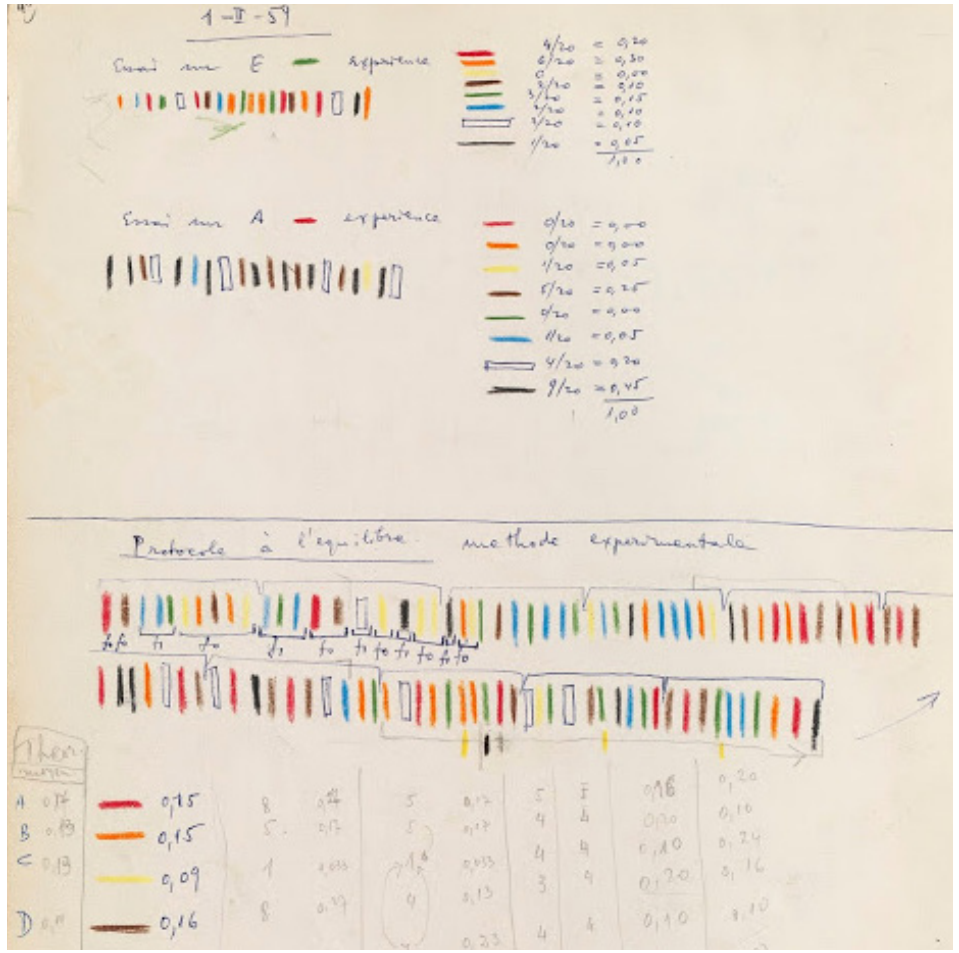

Figura 50. Iannis Xenakis. Sin título (1959) 
y mis dibujos eran símbolos musicales. Conocía la teoría tradicional, pero una cierta libertad de espíritu no puede producirse a través de ella. Estaba convencido de que podríamos inventar otra manera de escribir música. Empecé por imaginar el fenómeno del sonido, utilizando el dibujo. ${ }^{77}$

Imaginar el fenómeno del sonido utilizando el dibujo, como Xenakis, o mediante objetos o piezas materiales, es una de las posibles maneras de enfrentarse al conflicto entre tiempos (pasado, presente y futuro). Las imágenes, como determina Georges Didi-Huberman, «son capaces de hacer visibles las relaciones de tiempo más complejas que incumben a la memoria en la historia ${ }^{78}$. Porque la imagen misma, como nos indica Deleuze, "hace sensibles, visibles, las relaciones de tiempo irreducibles al presente» ${ }^{79}$.

\section{I.3. FACTORES QUE INTERVIENEN EN LA CONSTRUCCiÓN DE LA IMAGEN DEL SONIDO}

¿Qué propiedades convierten al sonido en imagen de paisaje y viceversa? ¿Cómo estudiar un mecanismo de proyección que es, al mismo tiempo, interior y exterior, visual y sonoro?

El homo faber y el homo pictor, ambos 'hombres de acción', protagonizan dos importantes obras que sirven como soporte al estudio de este proceso: Tratado de los objetos musicales ${ }^{80}$, de Pierre Schaeffer (1910-1995) -obra fundamental en la música del siglo XX- y Homo pictor: la libertad de la imagen ${ }^{81}$, del filósofo alemán discípulo de Heidegger, Hans Jonas (1903-1993). Ambos sostuvieron la importancia de la acción y la creación como paso previo al pensamiento en un período marcado por el auge de la fenomenología y los estudios semióticos. Además, el desarrollo de la técnica que vivieron durante su vida les convirtió en analistas de la experiencia bruta (tanto sonora como visual).

En la misma línea, la tesis del físico y filósofo Gilbert Simondon (1924-1989), El modo

77. Rey, Anne y Pascal Dusapin, "XENAKIS “Si Dieu existait, il serait bricoleur”", Le Monde de la Musique $\mathrm{n}^{\circ} 11$ (1979): 92-97.. Traducción de la autora.

78. Georges Didi-Huberman et al., Cuando las imágenes tocan lo real, trad. Inés Bértolo Fernández, Edición: 1 (Madrid: Editorial Círculo de Bellas Artes, 2018), 38.

79. Gilles Deleuze, «El cerebro es la pantalla», en Dos regímenes de locos. Textos y entrevistas (Valencia: Editorial Pre-Textos, 2008), 260-61.

80. Pierre Schaeffer, Tratado de los objetos musicales (Madrid: Alianza, 2008).

81. Hans Jonas, «Homo Pictor: La libertad de la imagen», en El principio vida: Hacia una biología filosófica, Edición: 1 (Madrid: Editorial Trotta, S.A., 2000), 217-45. 
de existencia de los objetos técnicos, presenta un análisis de las prácticas científico-técnicas de la primera mitad del siglo XX de especial relevancia en este apartado. Siendo el paisaje sonoro un concepto que surge a raíz de la implantación de la tecnología sonora doméstica, la postura instrumental desde la que se desarrolla el pensamiento Simondon (reflexionando a partir de la capacidad de transmisión de la voz de una línea telefónica, los motores de combustión o los campos electromagnéticos) lo convierten en una figura indispensable para el análisis fenomenológico del concepto.

Atendiendo al juego de imágenes reales y mentales que engloba el concepto paisaje sonoro, el objetivo de este apartado es valorar los factores que intervienen en la representación del concepto paisaje sonoro. Para ello se estudiarán los primeros instrumentos para la conversión de señales, las diferentes teorías sobre los modos de escucha que paulatinamente han surgido en paralelo a las teorías científicas puras, y cuyo objeto de estudio gira en torno a la imaginación aura $^{82}$, las estructuras de percepción y las articulaciones entre representaciones 'objetivas' y 'subjetivas' en las diferentes fases de formación de la imagen asociada al sonido.

\section{I.3.I. Procesos de CONVERsión de SeŃales: auscultación, transducción Y REPRODUCCIÓN}

El oído humano es la máquina auditiva más compleja que existe. La anatomía del oído nos enseña que la audición humana se produce gracias a un sistema de trasmisión mecánica que desencadena un proceso mental de reconocimiento de estímulos sonoros mediante un juego de presiones, vibraciones y cambios de medio. El conocimiento de los procesos de conversión de señales sonoras a imagen y viceversa, resulta ser fundamental para el estudio de la representación del concepto paisaje sonoro. Tomando como punto de partida la investigación de Jonathan Sterne ${ }^{83}$ The Audible Past, en la que explica detalladamente cada uno de los estadios de la evolución de la tecnología sonora, se atiende en este punto a los procesos de conversión de señales auditivas en ópticas y viceversa.

Como explica Sterne, las tecnologías modernas de reproducción de sonido utilizan

82. Cfr. Brandon LaBelle, Background noise: perspectives on sound art, Second edition (New York: Bloomsbury Academic, 2015), 29.

83. Jonathan Sterne es titular de la cátedra James McGill en el Culture and Technology en el Department of Art History and Communication Studies de la McGill University. «sterneworks», accedido 9 de junio de 2020, https:// sterneworks.org/. 
dispositivos llamados transductores, que hacen que el sonido se convierta en algo diferente. ${ }^{84}$ La historia de los medios de reproducción y almacenamiento del sonido son una muestra de la búsqueda de la amplificación sensorial y la transformación de los modos de percepción que, en consecuencia, refleja paralelamente la historia de la transformación del cuerpo humano en objeto de conocimiento.

La abstracción del proceso natural de la percepción auditiva define, por tanto, las técnicas de reproducción y representación tal y como las conocemos hoy. ${ }^{85}$ Los inventos del siglo XIX planteaban la representación visual del sonido mediante una relación causal entre señales. Según el proceso de cambio de señal que se produzca, se exponen tres casos: la auscultación, la transducción y la reproducción.

\section{Auscultación: conversión del sonido en imagen mental.}

En 1816, el médico francés René Laënnec (1781-1826) inventó el primer fonendoscopio, que consistía en un tubo de papel enrollado en forma de embudo. La geometría del tubo, colocado entre el oído del médico y el pecho del enfermo, amplificaba los sonidos del interior del organismo de sus pacientes al mismo tiempo que evitaba el contacto físico directo con ellos. Laënnec bautizó su invento como estetoscopio -tomando del griego las palabras stethos (pecho) y skopein (ver)-. Consecuentemente, el método de uso del estetoscopio se denominó 'auscultación', remitiendo al término latín auscultare, que significa escuchar. Este proceso inauguraba, como explica Peter Szendy, la escucha mediada que permite ver aquello que está oculto.

Al auscultar sin mediación, aplicando inmediatamente el oído al objeto de la exploración auditiva, se correría el riesgo de no escuchar otra cosa que a sí mismo. Como si al adherirse a lo que quiere oír el oído provocara unas especies de acúfenos, un murmullo a la escucha que también es enmascaramiento. Esa será la distancia introducida por el estetoscopio, que la remediará: para Laënnec, inventor de la auscultación mediata, al interponer un dispositivo técnico entre los dos cuerpos resonantes se puede empezar a escuchar al otro sin escucharse a sí mismo. ${ }^{86}$

84. «Even though transducers operate on a very simple set of physical principles, they are also cultural artifacts» Jonathan Sterne, The Audible Past: Cultural Origins of Sound Reproduction, 47701st edition (Durham: Duke University Press Books, 2003), 22.

85. Cfr. Ibid., 50-51. Como apunta Sterne, la historia de la reproducción del sonido es a su vez la transformación del cuerpo humano como objeto de conocimiento y la problematización del sonido ha dado lugar a las tecnologías sonoras tal y como las conocemos hoy.

86. Szendy, En lo profundo de un oído, 58. 

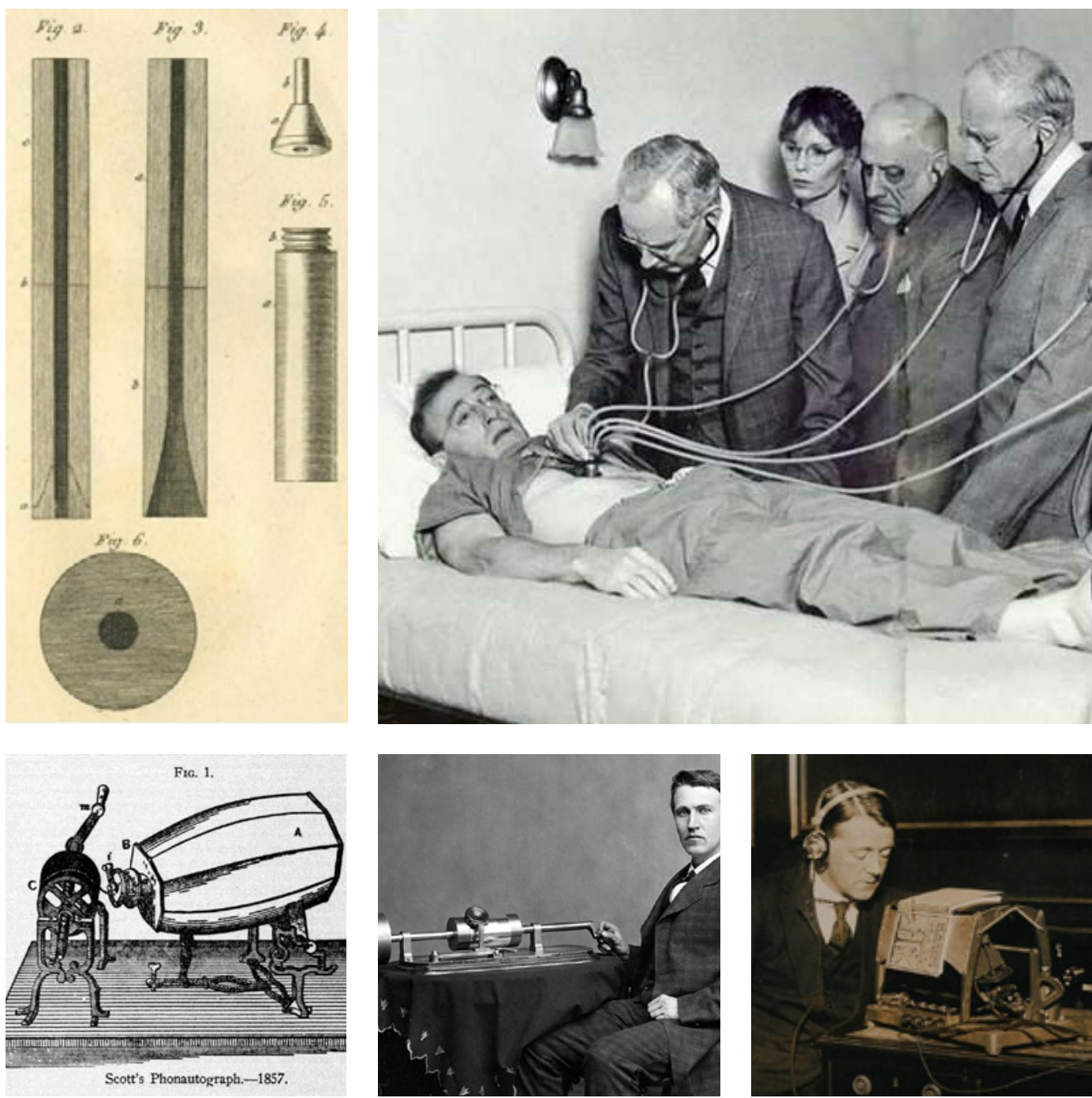

Figura 51. René Laënnec, Estetoscopio (1819)

Figura 52. Fotograma de la película Zelig (1983), dirigida por Woody Allen Figura 53. Fonoatógrafo de Édouard-Léon Scott de Martinville (1857)

Figura 54. Thomas Alva Edison junto a su fonógrafo (1877)

Figura 55. Optófono de Fournier d' Albe (1921) 
Más allá de su uso práctico y lógico, el tubo de Laënnec ejemplifica cómo los objetos interpuestos entre la realidad escuchada y el sujeto que escucha generan una distancia (pudiendo ser física o conceptual) que le permiten al oído salir de la escucha propia para centrar la atención en lo otro, y generar así una imagen virtual correspondiente a lo percibido.

\section{Transducción: conversión del sonido en imagen y viceversa.}

El fonoautógrafo patentado por Édouard-Léon Scott de Martinville (1781-1826) en 1857 fue el primer dispositivo capaz de traducir una señal sonora en imagen. Imitando el funcionamiento del oído medio, Scott entendió el fonoautógrafo como una máquina para transformar el sonido en escritura. ${ }^{87} \mathrm{Su}$ máquina canalizaba los sonidos a través de un embudo cónico que hacía vibrar una membrana pequeña y delgada conectada a una aguja. Los diferentes sonidos proporcionaban vibraciones diversas, quedando dibujados en un cilindro los diferentes patrones sinusoidales de las ondas según la frecuencia recogida.

Inversamente, el optófono inventado por Fournier d'Albe (1868-1933) en 1920, convertía la escritura mecanografiada en sonido para que las personas ciegas pudieran leer. Mientras que la primera versión, el llamado optófono explorador, había sido diseñado para que los invidentes navegasen en el espacio, sorteando los obstáculos de una habitación mediante el sonido cambiante de un zumbido al localizar una fuente de luz, el optófono de lectura traducía la letras en música, produciendo diferentes tonos según la forma de los caracteres del alfabeto. Se suponía que la persona ciega debía entrenar su oído para el reconocimiento correcto de las veintiséis variaciones de acordes que representaban las letras del alfabeto y progresar así en reconocimiento de las palabras en forma de melodías. La sofisticación del instrumento derivó en una unidad óptica de reconocimiento de caracteres que procesaba palabras impresas. ${ }^{88}$

La transducción de señales que realizan ambos instrumentos, da como resultado un estado alternativo de lo sonoro. Como apunta en su estudio de la transducción y la reproducción François Bonnet ${ }^{89}$, «la impresión resultante de la transducción, en particular la impresión gráfica, no debe considerarse como una representación simbólica del sonido, sino más bien como una re-exhibición de energía sonora en diferentes formas, con la energía convirtiéndose en prisionero de su nueva materialidad $»^{90}$. Bajo esta interpretación, las marcas en el cilindro del

87. Sterne, The Audible Past, 35-36.

88. Cornelius Borck, «Blindness, Seeing, and Envisioning Prosthesis: The Optophone between Science, Technology, and Art», en Artist as inventors, inventors as artists (Hatje Cantz, 2008).

89. Ver Estado de la cuestión, apartado ii.

90. Francois J. Bonnet, The Order of Sounds: A Sonorous Archipelago (Oxford: Urbanomic Media Ltd, 2016), 37. 


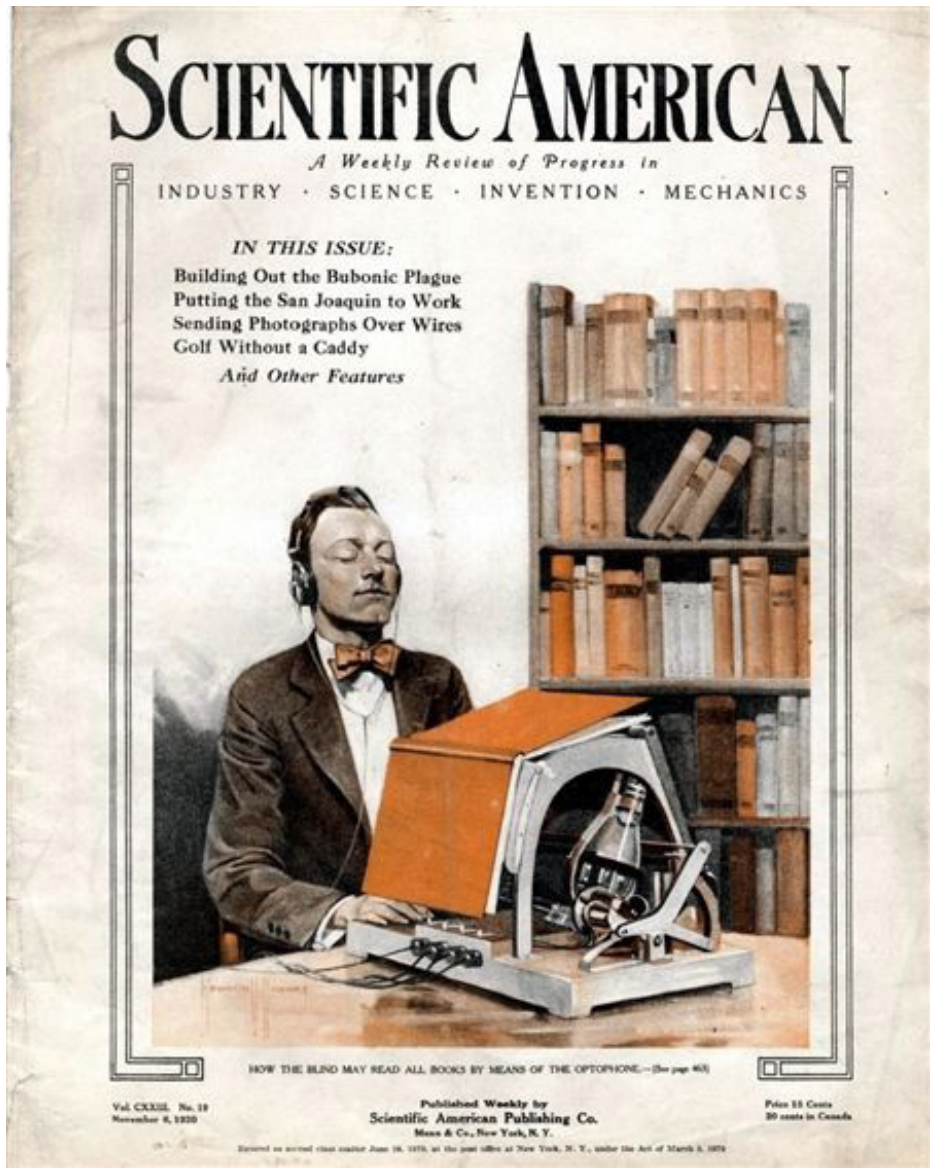

Figura 56. El optófono de lectura en la portada de la revista Scientific American (1920) 
fonoautógrafo no suponen una representación del sonido, sino que ellas mismas son sonido. La transducción no 'presupone' la reproducción de lo que deja una huella, sino que predispone a dicha reproducción.

\section{Reproducción: conversión de sonido en sonido.}

La reproducción del sonido mediante estos primeros inventos, puede entenderse como una doble transducción consecutiva en la que el sonido se convierte en imagen, y esta, en sonido. El resultado deriva de un proceso de re-producción, puesto que existe un sonido original que vuelve a presentarse en un simulacro de presencia.

En 1876, Thomas A. Edison (1847-1931) presentó el primer aparato que reproducía el sonido grabado. Un sistema de grabación analógica derivado del fonoautógrafo de Scott en el que las ondas eran transformadas en vibraciones mediante un transductor acústico-mecánico que, posteriormente, podía convertir el sonido registrado de nuevo en sonido mediante la transformación de las huellas sonoras en impulsos eléctricos.

Dentro de los dos procesos vinculados al fonógrafo, la reproducción y el almacenamiento, este último se entiende comúnmente como un proceso cultural que recopila el conocimiento oral. Al igual que en el caso del fonoautógrafo, resultaría incorrecto decir que el fonógrafo lee los sonidos; lo que lee es la energía que expresan sus huellas. ${ }^{91}$ El fonógrafo constituyó una revolución, pues se trataba de una máquina que volvía reproducible el pasado.

La telefonía, la fonografía, la acústica arquitectónica, 'el paisaje sonoro de la modernidad'92, permitieron que el sonido fuera aprehendido como una abstracción ideal. Los inventos de Laënnec, Scott, Edison y d'Albe comparten un rasgo común: instrumentos inicialmente surgidos como herramientas técnicas para ampliar la percepción, se convierten en una tecnología performativa que depende de la acción interpretativa del hombre, en amplificadores de significado del mundo sensible. Con su uso e invención, aquello que pertenece a un lenguaje permite inmiscuirse en otro para enriquecerlo. Los cuatro inventos aportaron un nuevo tipo de lenguaje cientifico donde las imágenes revelarían una componente figurativa del sonido.

\footnotetext{
Traducción de la autora.

91. Ibid., 35.

92. Expresión en referencia a Emily Thompson, The Soundscape of Modernity: Architectural Acoustics and the Culture of Listening in America, 1900-1933 (Cambridge, Mass.: The MIT Press, 2004).
} 


\section{I.3.2. Actitud del Sujeto y modos De ESCUCha}

En el retrato sobre la alta sociedad romana que Federico Fellini regala en su obra La Dolce Vita (1960), la escena central de la película muestra una reunión de intelectuales y burgueses en un lujoso apartamento. Alrededor de un gramófono, los personajes recitan poesía, tocan la guitarra, y discuten sobre arte. Un joven del grupo, atento a las conversaciones, comienza a grabar las voces. En un momento de silencio, el joven activa el gramófono, y vuelve a reproducir la conversación que acababan de tener el señor Steiner y la poetisa. Los personajes escuchan con atención sus voces cuando bruscamente irrumpe una grabación antigua. Lluvia, truenos, fuertes vientos. Pájaros que cantan. Todo el mundo juega a adivinar a qué corresponde cada sonido: ¡Es un bosque! ¡Son pájaros! Sonidos que dan placer, extremadamente estimulantes, como describe la mujer del anfitrión. La escena, una de las más crípticas de la película, no solo describe con sutileza el carácter sensible del aristócrata Steiner, sino que además da cuenta de la importancia que los instrumentos de grabación y reproducción tienen en el análisis del paisaje sonoro. Gracias a ellos, es posible una escucha en la que la imaginación individual se moviliza en torno a una fuente de información colectiva.

Los sonidos que dan placer, el murmullo de la brisa en los árboles, el suave fluir del arroyo, el canto de un pájaro, son el contraejemplo que utiliza Igor Stravinski (1882-1971) para definir el fenómeno musical. ${ }^{93}$ Lo que para muchos se convierte en 'música', nos dirá Stravinski, no lo es más que por comparación, pues esos elementos sonoros no son aún música. «Los elementos sonoros no constituyen la música sino al organizarse», lo que implica y presupone «una acción consciente del hombre» ${ }^{94}$. Stravinski reconoce esos sonidos como sonoridades elementales del material musical en estado bruto, agradables por sí mismos. Un goce pasivo que se diferencia de la música en que en ellos no existe una operación consciente de ordenación.

Stravinski aporta una de las claves para el estudio del paisaje sonoro, la actitud de la escucha. Esta puede ser de dos tipos, pasiva o activa. La estructura musical es activa, ya que escuchar una pieza musical en un concierto significa concentrar «la atención sobre el pasado (lo que acaba de

93. Igor Stravinsky, Poética musical: en forma de seis lecciones (Barcelona: Acantilado, 2013), 31. Sobre la diferenciación de las artes, dirá más adelante: «Las artes plásticas se nos ofrecen en el espacio: nos proporcionan una visión de conjunto de la que tenemos que descubrir y gozar los detalles poco a poco. La música, en cambio, se establece en la sucesión del tiempo y requiere, por consiguiente, el concurso de una memoria vigilante. Por tanto, la música es un arte diacrónico, como la pintura es un arte espacial. La música supone, ante todo, cierta organización del tiempo, una cronomía, si se me permite el uso de este neologismo.» Ibid., 35.; Cfr. Theodor W Adorno, «Sobre algunas relaciones entre la música y la pintura», en Sobre la música (Barcelona: Paidós, 2002), 41-64.

94. Stravinsky, Poética musical, 31. 

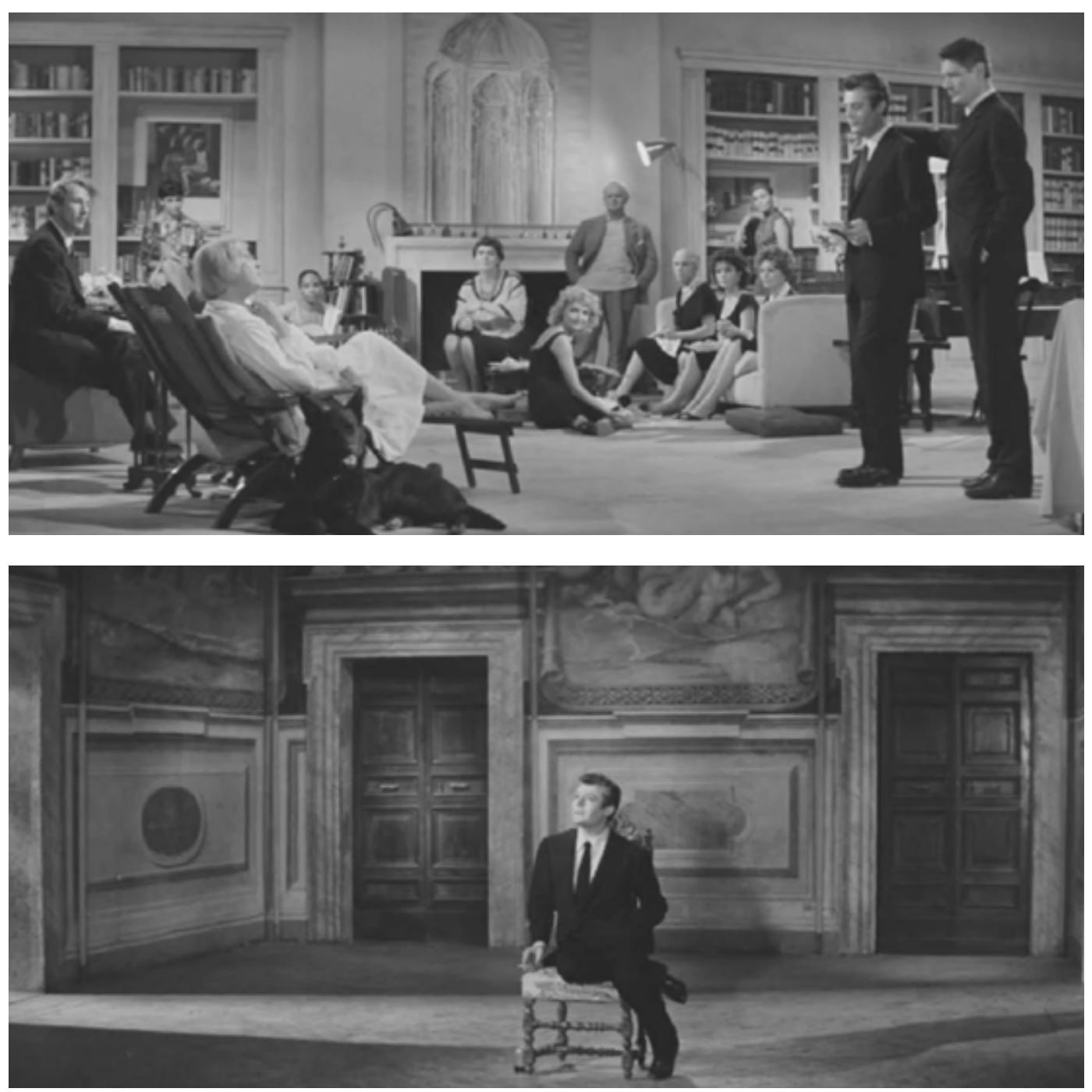

Figuras 57-58. Fotograma de la película La dolce vita (1960), dirigida por Federico Fellini. 
escucharse) y sobre el futuro (anticipación de lo que se escuchará) ${ }^{95}$. Pero escuchar los sonidos de un paisaje genera una controversia, en tanto que pueden entenderse como ruido de fondo o como la materia a ordenar para conformar una composición o una escena imaginaria. Es decir, la actitud del sujeto alterna entre la actividad y la pasividad:

Llegamos a la que quizá sea la peculiaridad más relevante para la comparación de la vista con el oído que venimos efectuando: el sonido, que en sí mismo es un suceso dinámico, se le viene encima a un sujeto pasivo. Para que llegue a producirse una sensación auditiva, el oyente depende por completo de que suceda algo situado fuera de su control, y en la audición misma está expuesto a los efectos de ese suceso. Lo único con lo que él puede contribuir a la situación es un estado de atenta disposición a la posible recepción de sonidos (a no ser que sea él mismo quien los emita). ${ }^{96}$

El estado activo o atento de la escucha, como lo describe Hans Jonas, no solo informa al sujeto de que se está produciendo una modificación del entorno, sino que lo vincula a una situación dinámica en la que elige actuar, o no. ${ }^{97}$ Del estudio de la actitud del sujeto frente a una fuente sonora surgen las teorías de la escucha. Estas, como argumenta B. LaBelle, «se basan en que a través de la escucha un individuo se extiende más allá de los límites hacia un espacio más amplio, necesariamente múltiple. La escucha rompe el límite corporal del sujeto y recibe, como sujeto pasivo, todo lo que le rodea ${ }^{98}$. Bajo esta premisa, Tanto Pierre Schaeffer, como Michel Chion y Roland Barthes, han definido las características básicas de los modos de escucha más frecuentes. Resultan de especial relevancia los estudios audio-visuales de Michel Chion ${ }^{99}$, que revisan las teorías de la escucha formuladas en los cincuenta por Pierre Schaeffer, mostrando los diferentes tipos de escucha en función de la actitud del sujeto y de la información que recibe

95. Bernard Sève, El instrumento musical: Un estudio filosófico, trad. Javier Palacio Tauste, Edición: 1 (Acantilado, 2018), 120.

96. Hans Jonas, El principio vida: Hacia una biologia filosófica, Edición: 1 (Madrid: Editorial Trotta, S.A., 2000), 195.

97. Ibid., 203.

98. LaBelle, Background noise, 245. Traducción de la autora.

99. Compositor, profesor e investigador francés, autor de numerosos libros y artículos sobre música contemporánea y la música y el audiovisual a lo largo de los siglos XX y XXI. Entre estos, destaca especialmente su libro L'audiovision. Son et image au cinema, un texto fundamental para entender las relaciones música-imagen. «Bibliography | Michel Chion», accedido 10 de noviembre de 2018, http://michelchion.com/books. En su libro Sound, Chion repasa la evolución del paisaje sonoro y cuestiona su significado. Chion localiza en el romanticismo el paisaje sonoro genuino: "During the Romantic period, however, no one spoke of a "Sonic environment" -nor of "environment" in general- as we do today (except perhaps in German, where the term Umwelt, literally the "world around", has long been in use).There was a sound and a person.» Michel Chion y James A. Steintrager, Sound: An Acoulogical Treatise (Durham: Duke University Press, 2016), 11. 
durante la acción. Para Chion, hay tres actitudes de escucha diferentes ${ }^{100}$ : la escucha causal, la escucha semántica y la escucha reducida. ${ }^{101}$

La escucha más extendida, la escucha causal, se sirve del sonido para informarse sobre su causa. La causa o fuente sonora puede ser visible (y que el sonido aporte, por tanto, una información suplementaria a la visual), o puede ser invisible. A través de la escucha causal se localizan los indicios para deducir con precisión la historia causal del propio sonido. Esta escucha, mediante asociaciones de imagen y sonido, es la que permite hacer ver un paisaje en la noche y no dudar, por tanto, de su existencia en la oscuridad.

Cuando se elimina la naturaleza representativa del sonido, este se convierte en agente 'significante'. Se formula así el segundo modo de escucha, la escucha semántica ${ }^{102}$, aquella que descifra un código o un lenguaje para interpretar un mensaje.

El último modo propuesto por Chion es la escucha reducida. Pierre Schaeffer bautizó como escucha reducida a aquella que afecta a las cualidades y las formas propias del sonido (independientemente de su causa -escucha causal-y de su sentido -escucha semántica-). Es por tanto una 'escucha científica' donde se toma el sonido como objeto de observación ${ }^{103}$. La escucha reducida permite el estudio del sonido en sí mismo. Gracias a ella las palabras 'analógicas' ${ }^{104}$ habituales se revelan como ambiguas («tal sonido es chirriante, decimos, pero, ¿en qué sentido? Chirriante, ¿es solo una imagen, o no es sino una remisión a una fuente que chirría? ¿O la evocación de un efecto desagradable?» ${ }^{105}$ ). La pretensión de objetivar el sonido, asociada a la escucha reducida, remite a los instrumentos que captan valores físicos sin diferenciar la fuente (analizadores de espectro, cronómetros, medidores de decibelios...).

En la película La Dolce Vita encontramos una segunda situación en la que la escucha

100. Michel Chion, L'audio-vision - 4 e éd. - Son et image au cinéma, Edición: 4 e édition revue et augmentée (Armand Colin, 2017), 31-44.

101. Antes de analizar los modos de escucha, Chion explica el circuito ordinario de las cuatro escuchas (comprender, escuchar, entender y oír). Ver Michel Chion, Guide des objects sonores: Pierre Schaeffer et la recherche musicale, Nouv. éd, Bibliothèque de recherche musicale (Paris: Buchet/Chastel [usw.], 1995), 26-28.

102. Chion denomina en sus escritos a esta escucha como Codale. Se toma la definición de Schaeffer, ya que como dice Chion, hacen referencia a lo mismo. Cfr. Chion, L'audio-vision - 4e éd. - Son et image au cinéma, 34.

103. Sin embargo, la objetivación pura pretendida por la escucha reducida es una quimera, pues como defiende Chion, «la perception n'est pas un phénomène purement individuel, puisqu'elle relève d'une objectivité née d'une " intersubjectivité » qu'entend se situer l'écoute réduite telle que Schaeffer l'a définie dans son Traité des Objets Musicaux.»Ibid., 35.

104. Palabras derivadas de la imitación de un sonido o desarrollo de una onomatopeya. Ibid.

105. Ibid. Cfr. Traducción en Michel Chion y Antonio López Ruiz, La audiovisión: introducción a un análisis conjunto de la imagen y el sonido (Barcelona, [etc.: Paidós, 2011). 
protagoniza la escena. El personaje principal, Marcello, sentado en una silla en una habitación de un palacio, escucha la voz de Maddalena, escondida tras un muro. La escena es un ejemplo de una situación acusmática ${ }^{106}$, es decir, describe una situación en la que se oye el sonido sin ver su causa. La situación acusmática modifica la actitud de la escucha en el sujeto, generando una atracción inconsciente hacia caracteres sonoros que habitualmente quedan enmascarados por la visión simultánea. Al reforzar la percepción de ciertos elementos (los del sonido) y ocultar otros (los visibles), se potencian todas las dimensiones sonoras.

Las técnicas de grabación electromagnética y el desarrollo tecnológico de los años sesenta se convirtieron en la cortina pitagórica ${ }^{107}$ que impulsó la experiencia acusmática y la escucha activa. Gracias a ella no solo se formaron nuevos fenómenos a través de las manipulaciones del sonido, sino que también dio pie a "nuevas condiciones de observación» ${ }^{108}$ del mismo. Tanto la experiencia acusmática como la actitud activa del sujeto frente a los sonidos del entorno son otros dos factores que, junto con los procesos de conversión de señales, intervienen en la representación del sonido.

\section{I.3.3. ESTRUCTURAS DE PERCEPCIÓN}

La disociación de la vista y el oído favorece aquí otra manera de escucha: la escucha de las formas sonoras, sin otro propósito que el de escucharlas mejor, a fin de poder describirlas a través de un análisis del contenido de nuestras percepciones.

A decir verdad, la cortina de Pitágoras no basta para desalentar una curiosidad por las causas, a la que casi instintivamente nos vemos avocados. Pero la repetición de la señal física que permite la grabación, nos ayuda a ello de dos maneras: al agotar esa curiosidad, nos impone poco a poco el objeto sonoro como una percepción digna de ser observada por ella misma; por otra parte, a condición de hacer escuchas más atentas y refinadas, nos revela progresivamente la riqueza de la percepción. ${ }^{109}$

P. SCHAEFFER. Tratado de los objetos musicales

106. El término "acusmática" nos recuerda a los discípulos de Pitágoras, que escuchaban las enseñanzas de su maestro a través de una cortina. Los matemáticos o conocedores podían escuchar y presenciar las demostraciones de su maestro y ver cómo trazaba las figuras de teoremas. Los acusmáticos (oyentes) no podían ver las demostraciones, solo escucharlas tras una cortina.

107. Schaeffer, Tratado de los objetos musicales, 56.

108. Chion, Guide des objects sonores, 19.

109. Schaeffer, Tratado de los objetos musicales, 57. 
La experiencia acusmática que trajeron consigo los electrodomésticos sonoros (la radio, el teléfono, los tocadiscos, el fonógrafo, las máquinas electromagnéticas de grabación...), abrió un campo inexplorado a la investigación sonora y la experimentación musical. En este contexto, el compositor francés Pierre Schaeffer fundó en 1951 el Groupe de Recherche de Musique Concrète, marcando un punto de inflexión en la evolución de los estudios acústicos. Su esfuerzo por explicar la experiencia y los componentes de la escucha y el sonido pormenorizadamente dio lugar a una corriente precursora de la música electrónica, con detractores ${ }^{110}$ y seguidores, donde un sonido grabado podía ser objetivado, aumentado, repetido, re-grabado y reproducido para escuchar todos sus detalles, y descubrir así la dinámica interna que se encuentra dentro de cada instante audible. Su Tratado de los objetos musicales, publicado en 1966, dio lugar, a un nuevo lenguaje basado en los 'objetos sonoros' de gran influencia en los estudio sobre ecología acústica de Murray Schafer:

Objeto sonoro: Pierre Schaeffer, el inventor de este término ( $l$ 'objet sonore), lo describe como un «objeto acústico para la percepción humana y no un objeto matemático o electroacústico para ser sintetizado». Por lo tanto, el oído humano define el objeto sonoro como la más mínima partícula autónoma de un paisaje sonoro, el cual es analizable por las características de su curva envolvente. Aunque el objeto sonoro puede ser referencial (por ejemplo, la campana, el tambor, etc.), fundamentalmente ha de ser considerado como una información sonora fenomenológica, sin tener en cuenta sus cualidades referenciales como acontecimiento sonoro. ${ }^{111}$

Mientras que Michel Chion y Pierre Schaeffer eliminan cualquier referente visual del objeto sonoro, Murray Schafer, tomando la obra de su antecesor Schaeffer como base, tendrá en cuenta que, si bien el paisaje sonoro asume el objeto sonoro como uno de sus componentes, el objeto no puede desvincularse del contexto o entorno en el que se produce. La diferencia entre Schaeffer y Schafer es que «ocupan dos extremos en el espectro sónico; uno elimina el contexto y el otro lo enfatiza» ${ }^{112}$.

Ligar la acción y el sonido es una de las claves para la interpretación espacial del concepto

110. Sin mencionar directamente a Schaeffer, John Cage también cuestionó la música concreta: «Hubo un tiempo (y a mí no me hubiera importado vivir en aquel entonces aunque por ningún dinero cambiaría mi lugar por alguien del pasado, presente o futuro) cuando, en la Música, hubo un espejismo de perfección -una relación entre la unidad y el todo, hasta el último detalle: tan elegante. ¿Cómo ocurrió esto (era un objeto)? Era un icono. Era un templo de una creencia. [...] Ahora todo está en situación de confundirnos, porque, en primer lugar, no estamos seguros de los nombres de las cosas que vemos ante nosotros.» John Cage, "Ritmo etc.», en Escritos al oído, Arquitectura 38 (Murcia: Colegio Oficial de Aparejadores y Arquitectos Técnicos de la región de Murcia, 2007), 119.

111. R. Murray Schafer, El paisaje sonoro y la afinación del mundo (Barcelona: Intermedio, 2013), 370.

112. LaBelle, Background noise, 208-9. 
paisaje sonoro. En una visión previa a la de M. Schafer, el filósofo Hans Jonas expone en su estudio fenomenológico de los sentidos La nobleza de la vista, dos formas de entender la objetualidad del sonido:

Lo que el sonido desvela directamente no es un objeto, sino un suceso dinámico que se produce en el lugar que ocupa el objeto, y por ello, indirectamente, el estado en que se encuentra el objeto en el instante en que se produce el suceso en cuestión. El crujido de la hojarasca cuando avanza sobre ella un animal, los pasos de una persona o el ruido de un coche al pasar delatan la presencia de esas cosas a través de la acción de las mismas. ${ }^{113}$

Por un lado, podemos entender que el sonido mismo es el objeto, y por otro, los sonidos «nos muestran otra cosa distinta, a saber, los procesos o acciones que dan lugar a esos sonidos $»^{114}$. Esta última relación, el sutil vínculo entre el sonido y su referencia externa a los objetos (lo que estrictamente identificaríamos como función representativa del sonido), es lo que hace que el sonido sea, según Jonas, «especialmente idóneo para construir su propia 'objetualidad' inmanente de valores acústicos en sí mismos, y por ello, exento como está de la obligación de representar otra cosa distinta de él, para representarse a sí mismo» ${ }^{115}$. Lo que ya Schopenhauer vislumbraba un siglo antes ${ }^{116}$, de nuevo vuelve a formularse. Cuando está sumergido en la dimensión temporal, el sonido se representa a sí mismo.

$\mathrm{Si}$, por ejemplo, tuviéramos que representar la escena acusmática de La Dolce Vita desde una perspectiva sonora, existirían varias posibilidades. Se podría dibujar el espacio en el que se produce el sonido, grabar el sonido de la escena y visibilizar las ondas de frecuencia, o generar una imagen de la percepción subjetiva de esa situación. Todas estas opciones refuerzan la idea de que el sonido remite al acontecimiento, pero no debe obviarse la representación ligada a su existencia. En la dicotomía de la representación de sí mismo o de las causas que lo producen, ¿a qué tipo de representación hace referencia el concepto paisaje sonoro? ¿Cuál es el objeto considerado en la relación sujeto-objeto que reside en este tipo de paisaje?

Volviendo al origen del capítulo, a aquello que vemos al decir paisaje, recordamos con las palabras de Hernández León que «había un "decir paisaje” que posibilita representar, y mediante la abstracción de las diferencias llega a construir el concepto, tan deudor de la semejanza» ${ }^{117}$.

113. Hans Jonas, «La nobleza de la vista», en El Principio Vida. Hacia Una Biologia Filosófica (Madrid: Trotta, 2000), 193

114. Ibid.

115. Ibid., 194.

116. Cfr. Arthur Schopenhauer, Sobre la música, Música (Madrid: Casimiro Libros, 2016).

117. Hernández León, Ser-paisaje, 119. 
Bajo el término Soundscape, a priori se acogen como posibles todas las representaciones del sonido de la naturaleza, tanto las que hacen objeto al sonido mismo, como aquellas que señalan al acontecimiento al que van ligados. Siguiendo el análisis del glosario de Schafer:

Acontecimiento sonoro: definición de acontecimiento en el diccionario: «algo que ocurre en un lugar concreto durante un determinado espacio de tiempo». Esto sugiere que el acontecimiento no puede ser abstraído de las coordenadas del tiempo y el espacio que le son otorgadas en su definición. El acontecimiento sonoro, como el objeto sonoro, es definido por el oído humano como la mínima partícula autónoma de un paisaje sonoro. Se diferencia del objeto sonoro en que este ultimo es un objeto acústico abstracto cuyo fin es ser estudiado, mientras que el acontecimiento acústico es un objeto simbólico, semántico o estructural para ser estudiado y, por tanto, es un punto de referencia no susceptible de ser abstraído, pues está relacionado con un todo mayor a él en sí mismo. ${ }^{118}$

Acontecimiento sonoro y objeto sonoro se solapan e intercambian bajo la palabra 'objeto', siendo la dimensión temporal y espacial la que convierte el objeto formal (aislado), en acontecimiento (objeto simbólico, semántico o estructural). La dimensión temporal es lo que lleva a entender la estructura de los sonidos como objeto-imagen, o como lo denominan Chion y Schaeffer, como una estructura de percepción ${ }^{119}$.

Tomando como referencia Idées directrices pour une phénoménologie de E. Husserl ${ }^{120}$, Schaeffer aporta la respuesta al tipo de relación objetual establecida en el paisaje sonoro: «Cada objeto de percepción es al mismo tiempo, un objeto en la medida en que se percibe como una unidad localizable en un contexto, y una estructura, ya que está compuesto por varios objetos» ${ }^{121}$. Por lo tanto, entendemos que el objeto al que hace referencia el paisaje sonoro, es aquel que identifica, simultáneamente, tanto el sonido del paisaje en el contexto de la estructura superior que lo contiene (el paisaje), como cada uno de los sonidos del paisaje que son identificables aisladamente como unidad en sí mismo. ${ }^{122}$

118. Schafer, El paisaje sonoro y la afinación del mundo, 367.

119. Schaeffer, Tratado de los objetos musicales, 168-69.

120. Cfr. Ibid., 160.

121. Chion, Guide des objects sonores, 56. Traducción de la autora.

122. Según en el análisis de Chion, cualquier objeto solo se percibe como un objeto en un contexto, una estructura que lo abarca. De la misma manera que cualquier estructura solo se percibe como una estructura de objetos componentes. Ibid. 


\section{i.3.4. Articulaciones de la Representación}

La posible representación técnica o científica del sonido mediante partituras o diagramas, remite a la discusión sobre las teorías de símbolos y los lenguajes del arte, así como al problema de la autenticidad de la representación. Nelson Goodman (1906-1998), en Los lenguajes del arte (1969), introduce una diferenciación entre las obras de arte alográficas y autográficas que derivará en el planteamiento de las etapas que constituyen la imagen-objeto:

Hablaremos de una obra de arte como autográfica si y sólo si la distinción entre el original y la falsificación es importante; o incluso mejor, si y sólo si ni siquiera la duplicación más exacta puede considerarse genuina. [...] Por tanto, la pintura es autográfica, y la música, no-autográfica, o alográfica. ${ }^{123}$

Así, un cuadro para Goodman es un trabajo cerrado que una vez terminado se abre a interpretaciones. La música, sin embargo, tiene para él la misma consideración que la literatura, en tanto que el texto o la partitura son medios para producir lecturas orales o sonoras, es decir, son medios para producir interpretaciones. Goodman explica la base de la diferencia entre artes a través de las etapas que contiene el proceso constitutivo de cada una de ellas:

Podríamos intentar decir que la literatura es un arte de dos etapas, de manera que la lectura silenciosa fuera su producto final, o constituyera ejemplos de la obra; pero entonces también se podría considerar que mirar un cuadro o escuchar una interpretación son resultados finales o ejemplos de la obra, de tal manera que la pintura, igual que la literatura, se convirtiera en un arte en dos etapas y la música en un arte de tres etapas. ${ }^{124}$

De forma análoga al planteamiento de etapas de Goodman, H. Jonas habla de las articulaciones o estratificaciones necesarias para llegar a construir una imagen:

La articulación completa es triple: el sustrato puede ser contemplado por sí mismo, la imagen por sí misma y el objeto de la imagen por sí mismo. La imagen, o el parecido de la misma, se cierne en el aire como una tercera entidad ideal entre esas dos entidades reales, conectándolas de la singular manera que denominamos representación. Es esta doble diferencia, o triple estratificación, la que hace posible para la imagen la presencia no causal que la aleja de la contingencia del acaecer real. ${ }^{125}$

123. Nelson Goodman, Los lenguajes del arte: aproximación a la teoría de los símbolos (Barcelona: Paidós, 2010), $110-11$.

124. Ibid., 111.

125. Jonas, «Homo Pictor: La libertad de la imagen», 225. 
Teniendo en cuenta la sucesión de etapas, la representación más elemental del paisaje sonoro -la que menos articulaciones contiene-, es resultado de la conversión de una señal sonora exterior en una imagen interior autónoma en la que el sujeto que capta el estímulo sonoro funciona como un transductor.

Para Gilbert Simondon, el ser humano es un transductor ${ }^{126}$ que realiza transducciones muy variadas (de materia, de energía, de capacidades corporales, de imaginación), lo que le otorga la capacidad de relacionar lo actual con lo virtual ${ }^{127}$. La transducción implica dos operaciones: un desplazamiento (en el espacio y en el tiempo), y una traducción (el paso de un registro a otro). La acción conlleva, por tanto, un transporte de energía o materia de un modo de ser a otro, y un desplazamiento en el espacio y el tiempo que da como resultado una transformación de lo transportado. Gracias a los procesos transductivos se atraviesan dominios de pensamientos diferentes y se opera el proceso de individuación del hombre ${ }^{128}$.

Retomando la palabra "transductividad", se podría decir que el arte es lo que establece la transductividad de los diferentes modos unos en relación con los otros: el arte es lo que permanece como no-modal en un modo, así como alrededor del individuo permanece una realidad preindividual asociada a él que le permite la comunicación en la institución de lo colectivo. ${ }^{129}$

La intención estética, según Simondon, es lo que permite pasar de un dominio a otro. Así, el arte se convierte en una herramienta de transducción que «anuncia, prefigura, introduce o alcanza, pero no realiza: es inspiración profunda y unitaria que comienza y consagra.» ${ }^{130}$

El hombre y el arte se convierten en transductores que permiten la articulación entre los

126. «El ser humano, y lo viviente en sentido más general, son esencialmente transductores. Lo viviente elemental, el animal, es en sí mismo un transductor cuando guarda en reserva energías químicas y luego las actualiza en el transcurso de las diferentes operaciones vitales.» Simondon Gilbert, El modo de existencia de los objetos técnicos (Buenos Aires: Prometeo Libros, 2014), 160.

127. Cfr. Pablo Rodríguez, «Prólogo. El modo de existencia de una filosofía nueva», en El modo de existencia de los objetos técnicos, de Simondon Gilbert (Buenos Aires: Prometeo Libros, 2014), 13.

128. Sobre la individuación y la transducción en Simondon, ver Fernando Tula Molina, «La individuación: a la luz de las nociones de forma y de información», Redes 20, n. ${ }^{\circ} 38$ (junio de 2014): 220. «La información determina un estado de sistema en el inicio de todos los individuos, y se traduce luego en su resonancia interna. Por este motivo resulta inadecuada la vieja idea hilemorfista de "moldear" - una forma eterna en una materia amorfa- y tendríamos que reemplazarla por la de "modular" - una frecuencia modulada a partir de un centro-. Esta es la propuesta del subtítulo: de la forma a la información. En términos metafísicos, en reemplazo del monismo filosófico, Simondon ofrece la hipótesis de la discontinuidad de fases que busca "liberar la noción de forma del esquema hilemórfico para aplicarse al ser polifásico". Esto implica "reemplazar la idea de identidad por la de resonancia"”

129. Gilbert, El modo de existencia de los objetos técnicos, 216.

130. Ibid., 217. 
procesos de formación de la imagen-objeto. El pensamiento de Goodman, Jonas y Simondon conforma las premisas que inducen a plantear la figurabilidad o materialización del paisaje sonoro como el resultado de una serie de transducciones concatenadas que transforman y transportan imágenes en el tiempo. Partiendo de este razonamiento, se desarrolla en el siguiente punto un registro de las etapas y transformaciones que confieren la morfología final que se le otorga al concepto.

\section{I.4. VÍAS DE REPRESENTACIÓN DEL PAISAJE SONORO}

Como resumen de los procesos y agentes que implica la representación del paisaje sonoro, se realiza en este apartado un análisis de la cadena de acontecimientos que intervienen en su desarrollo. En él se han tenido en cuenta los elementos involucrados en cada una de las etapas de formación, así como los factores y posibilidades que contienen. Todo ello se ha recogido en un esquema con el objetivo de localizar dónde se sitúan los diferentes modos de representación a lo largo del proceso y qué tipo de resultados se obtienen en cada etapa. Aunque se expongan verdades evidentes, estas constataciones no están desprovistas de consecuencias relevantes para la investigación.

Partimos, en primer lugar, de la hipótesis de que el proceso de construcción del concepto paisaje sonoro se origina en la estructura mayor que lo contiene, el paisaje. En este modelo de estudio, la palabra 'paisaje' hace referencia a un lugar real, físico, un entorno en el que será posible el pensamiento abstracto que parte del aislamiento de una situación sonora. Frente a las atmósferas urbanas o los acontecimientos acústicos extraordinarios, nos referimos a lugares que se suponen más adecuados para la situación ideal pura del paisaje sonoro. Puntos-clave, como los denominará Simondon, en los que existe una predisposición mayor para «una alianza sinérgica de los esquemas técnicos y de los poderes naturales» ${ }^{131}$ :

Se podría denominar a estos puntos singulares los puntos-clave ${ }^{132}$ que dirigen la relación

131. Ibid., 199.

132. «El universo mágico está estructurado según la más primitiva y pregnante de las organizaciones: la de la reticulación del mundo en lugares privilegiados y en momentos privilegiados. Un lugar privilegiado, un lugar que tiene un poder, es aquel que drena en él toda la fuerza y la eficacia del dominio que limita: resume y contiene la fuerza de una masa compacta de realidad; la resume y la gobierna como un lugar elevado gobierna y domina una región baja [...]. Así, el mundo mágico esta hecho de una red de lugares y de cosas que tienen un poder y que dependen de las demás cosas y lugares, que tienen, ellos también, un poder [...] Estos puntos clave son reales y objetivos, son las instancias en las que el ser humano se encuentra irremediablemente vinculado con el mundo, para 

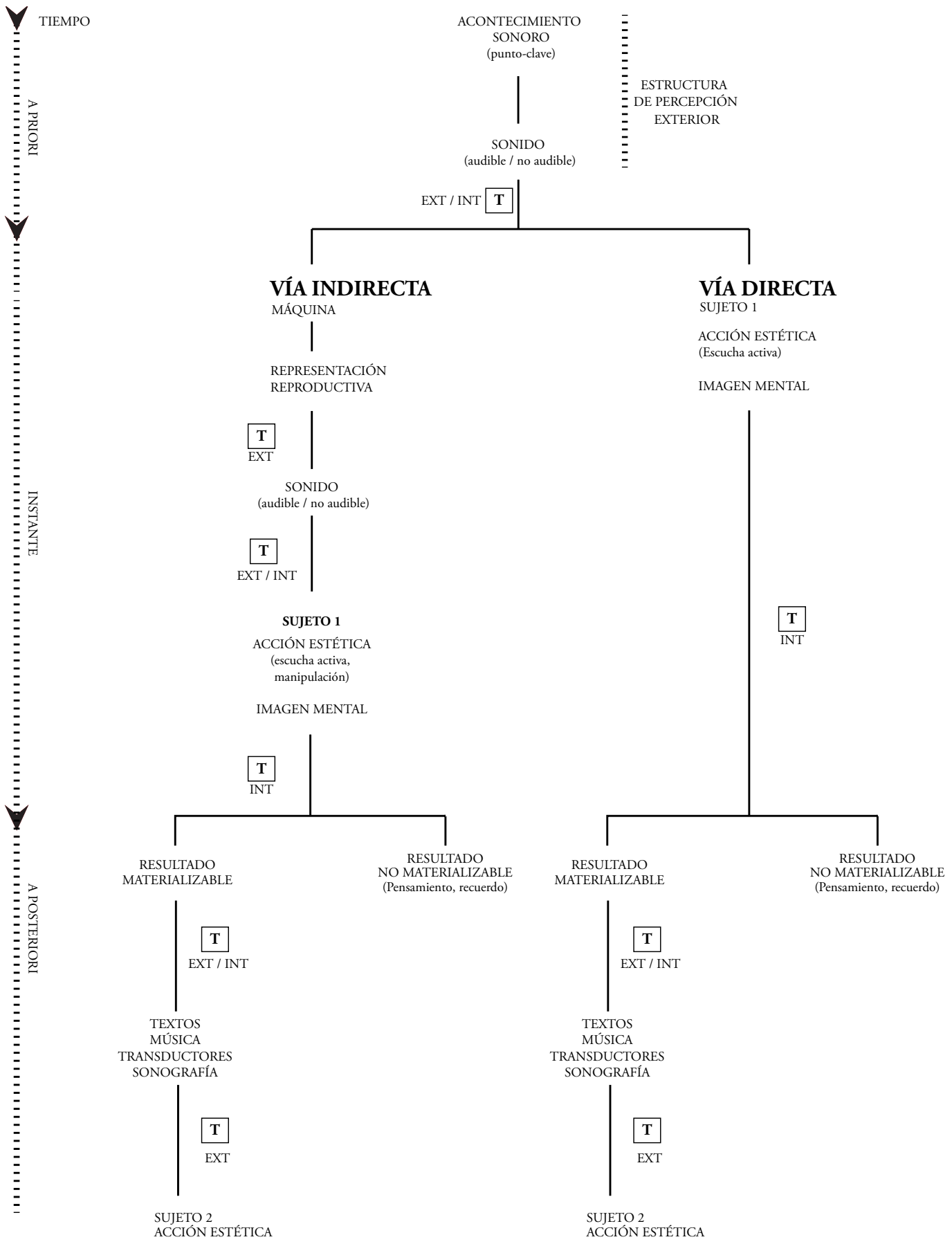

Figura 59. Diagrama de la cadena de acontecimientos que intervienen en la representación del paisaje sonoro 
hombre-mundo de manera reversible, porque el mundo influye sobre el hombre tanto como el hombre influye sobre el mundo. Estos son las cumbres de las montańas o ciertos desfiladeros, naturalmente mágicos, porque gobiernan una región. El corazón del bosque, el centro de una planicie no son sólo realidades geográficas representadas metafórica o geométricamente: son también realidades que concentran los poderes naturales del mismo modo en que focalizan el esfuerzo humano: son las estructuras figurales en relación con la masa que las soporta, y que constituye su fondo. ${ }^{133}$

En ese punto clave, abierto a la interacción entre el interior del hombre y su entorno exterior, se produciría el acontecimiento sonoro que da lugar al estímulo que desencadena el proceso de construcción del paisaje: el sonido primario (aquel que no ha sido manipulado y que es el resultado de la interacción de fuerzas en un entorno físico). Audible o no ${ }^{134}$, es el elemento que le atribuye al paisaje la condición de sonoro.

En función de qué o quién se enfrente al sonido, se diferencian dos vías de representación tomando como base el modelo estipulado por Pierre Schaeffer en Tratado de los objetos musicales $^{135}$ :

- Vía directa: cuando lo que recoge la señal sonora es una persona-sujeto 1- presente en el fenómeno sonoro. El individuo escucha con sus dos oídos en el recinto acústico original, en el instante en el que el fenómeno se produce. Su audición se acompaña de visión, entre otras percepciones.

- Vía indirecta: cuando lo que recoge la señal sonora es una máquina de grabación. El oyente, en este caso, escuchará posteriormente la reproducción «también con sus oídos, pero a partir de un punto sonoro que es el altavoz, en un recinto diferente, lejos del instante, de las circunstancias y el lugar donde se produce el fenómeno original. No tiene la ayuda del espectáculo, ni de ninguna manifestación directa del entorno» ${ }^{136}$.

Tanto en la vía directa como en la indirecta, la actitud del oyente será siempre activa, predominando además la experiencia acusmática en la indirecta. A partir de la diferenciación

recibir su influencia y a la vez actuar sobre él; son los puntos de contacto y de realidad mixta, mutua, de los lugares de intercambio y de comunicación porque están hechos de un nudo entre las dos realidades.» Ibid., 182-83.

133. Ibid., 183.

134. No solo debe tenerse en cuenta el sonido audible en la construcción del paisaje sonoro, sino también el no audible. La traza sonora se revela visualmente, como ocurre en la vibración y la resonancia.

135. Cfr. Schaeffer, Tratado de los objetos musicales, 50.

136. Ibid. 
entre quién o qué recoge la señal sonora, comienza la concatenación de transducciones que genera las posibles representaciones del sonido del paisaje. Se expone a continuación el análisis de cada vía.

\section{I.4. I. VÍA DIRECTA}

Una primera transducción producida por el tranductor-hombre, convierte el sonido en una imagen interior, a la vez objetiva y subjetiva, interior y exterior. En ese instante de percepción, el sonido se introduce en la memoria humana, la cual «recibe contenidos que tienen un poder de forma en el sentido de que se recubren ellos mismos, se agrupan, como si la experiencia adquirida sirviera de código a nuevas adquisiciones, para interpretarlas y fijarlas» ${ }^{137}$. Así, la escucha se convierte en lo viviente, aquello en lo cual lo a posteriori se convierte en a priori ${ }^{138}$, siempre orientado hacia la recepción de la información a interpretar.

La memoria del hombre puede devolver al presente una situación pasada cuando esta comparte las mismas significaciones y sentimientos que una actual. Tanto el asalto de lo a priori sobre lo a posteriori en un instante como el papel de la memoria en la formación de una imagen, definen el producto de la primera transducción de la escucha como imagen mental ${ }^{139}$.

Si el sonido sigue su proceso perceptivo 'natural' a través del sujeto, el cuerpo entonces se transforma en un instrumento capaz de transformar la imagen derivada de la acción estética de la escucha en su representación. Esto implica una transducción interior que pueda dar lugar a un resultado materializable (que devuelva la sensación al exterior con una materialidad propia o impropia), o no materializable (imagen mental subjetiva). En ambos casos, el resultado será una imagen del sonido del paisaje.

Los resultados materializables (textos, partituras, surtidores de signos, sonografías...) ejemplifican la articulación triple formulada por Jonas en el Homo Pictor. La imagen u objeto derivado de la percepción del sonido del paisaje tendrá valor por sí mismo y podrá ser contemplado por un segundo sujeto (Sujeto 2). El resultado será una entidad ideal entre dos entidades reales (el sonido del paisaje y su imagen), conectándolas de la singular manera que

137. Gilbert, El modo de existencia de los objetos técnicos, 140-41.

138. Cfr. Ibid.

139. Ver Capítulo tercero, apartado 3.5. Ritornelo 
denominamos representación ${ }^{140}$. Es decir, que el objeto, dibujo o esquema resultante, se aleja de su referente, quedando su sentido bajo la voluntad interpretativa de un segundo sujeto ajeno al acontecimiento sonoro de origen. La muestra material, la concreción en la materia, hace posible la valoración estética y, en consecuencia, el análisis del paisaje original desde su representación.

\section{I.4.2. VÍA INDIRECTA}

Partiendo de la misma situación de origen que en el caso de la vía directa (el punto-clave y el acontecimiento sonoro), si lo que registra el sonido primario es una máquina, la construcción del paisaje sonoro se identifica como vía indirecta. La primera transducción que se produce corresponde al registro de la representación reproductiva ${ }^{141}$ del sonido, una huella sonora en la que "codificación y contenido permanecen separados como condición y condicionado» ${ }^{142}$. Es decir, el simbolismo y la abstracción de los lenguajes de transducción escapan de la literalidad aportando nuevas 'formas' del sonido, abriendo camino a la creación de nuevas imágenes.

La representación reproductiva hace posible una segunda acción estética, diferente a la escucha: la manipulación. Cambiando los parámetros físicos del sonido (modulación, frecuencia, ritmo, volumen...) se obtiene una espacialidad ficticia, virtual, denominada históricamente como Soundscape (o su traducción, paisaje sonoro) producida por la voluntad del sujeto-artistacreador de hacer ver un paisaje a través del sonido, una voluntad de representación del mundo mediante un instrumento: el sonido. El resultado es un objeto cerrado, terminado. Es pintura paisajística en la que el encuadre consiste en dar prioridad a una fuente, tomada de cerca, en detrimento de las otras, alejadas. ${ }^{143} \mathrm{La}$ manipulación del sonido mediante técnicas de grabación y composición tiene como finalidad construir la imagen de un paisaje, y es en el sonido donde la imagen del paisaje está contenida ${ }^{144}$.

La memoria de la máquina es la huella de la energía del sonido. ${ }^{145}$ Esta primera huella se lee para producir una re-presentación. Es decir, el sonido vuelve a presentarse separado de su fuente original de emisión, en otro lugar y desplazado en el tiempo. La percepción de ese

140. Jonas, «Homo Pictor: La libertad de la imagen», 225.

141. Ibid., 222-23.

142. Gilbert, El modo de existencia de los objetos técnicos, 141.

143. Schaeffer, Tratado de los objetos musicales, 52.

144. Ver Capítulo segundo, Cuadrado 2. 1978: El seminario Le temps musial. Deleuze, Boulez y el paisaje sonoro.

145. Gilbert, El modo de existencia de los objetos técnicos, 141. 
sonido procesado por una nueva máquina nos devolvería al punto inicial de la cadena de transducciones. ${ }^{146} \mathrm{Si}$, por el contrario, es un sujeto (sujeto 1) quien percibe mediante la escucha activa el sonido procesado del paisaje, la acción estética de la escucha da lugar, de nuevo, a una imagen mental, quedando el estímulo, como ocurría en la escucha del gramófono de La Dolce Vita, encerrado en una experiencia individual que activa la imaginación. Esta imagen mental es diferente a la que se producía en la vía directa, puesto que la representación del paisaje y la experiencia del mismo, en este caso, pueden ser simultáneas o no serlo.

A partir de ese punto, vuelve a desencadenarse el proceso de transducciones. Transformaciones de un tipo de señal en otro que se mueven entre el interior y el exterior, lo alográfico y lo autográfico, que amplían las posibles representaciones de lo que se reconoce como paisaje sonoro.

Las secuencias de transducciones que componen las dos vías de construcción del concepto paisaje sonoro desembocan, como posible resultado, en ambos casos, en una representación material del sonido. Se trata de un proceso de objetualización de la percepción sonora en la que la imagen mental deviene comunicable, pasando a ser patrimonio común de cuantos la contemplan. Cada una de las imágenes generadas en cada etapa es, en sí misma, independiente, y permite el reconocimiento del concepto paisaje sonoro mediante un parecido que incluye en sí desemejanza. ${ }^{147}$ Es decir, algunas representaciones no abandonarán el dominio de origen al que pertenecen (seguirán siendo sonoras), mientras que otras se moverán a otro diferente (a un dominio no sonoro como la pintura o el dibujo).

\section{I.5. INSTRUMENTOS Y CONOCIMIENTO OPERATIVO}

La mediación entre el hombre y el mundo se convierte ella misma en un mundo, la estructura del mundo. ${ }^{148}$

G. Simondon. El modo de existencia de los objetos técnicos

146. No se contempla en el esquema esta opción.

147. Cfr. Jonas, «Homo Pictor: La libertad de la imagen», 219-23.

148. Gilbert, El modo de existencia de los objetos técnicos, 199. 
El khane ${ }^{149}$, khan u órgano de boca es un instrumento de la familia de los aerófonos originario de Laos que consiste en una serie de cańas de bambú de distintas longitudes dispuestas en dos filas y unidas por una pieza transversal de madera hueca. En uno de sus extremos, la madera tiene una apertura por donde se insufla el aire que es conducido hacia las cañas. Cada tubo posee una lengüeta en su interior y un pequeño orificio al alcance de los dedos. Cuando el intérprete sopla por la pieza de madera y tapa alguno de los agujeros, en ese momento comienzan a vibrar las lengüetas y se produce un sonido inventado hace 7000 años.

Otros instrumentos muy diferentes, como son las gafas y guantes de realidad virtual, fueron desarrollados en la década de los ochenta del siglo XX por el músico, compositor e informático americano Jaron Lanier (1960- $)^{150}$. Al igual que Raoul Hausmann ${ }^{151}$, Lanier entiende la tecnología como una extensión del ser humano que debe alejarse de la limitación y suplantación de identidades para cambiar la forma en que el hombre se concibe a sí mismo y al mundo. Su objetivo es ampliar las capacidades del ser humano para resolver problemas complejos mediante herramientas virtuales. ${ }^{152}$

Para explicar la realidad virtual, Jaron Lanier comienza sus conferencias tocando el khane. ${ }^{153}$ Tras hacer una demostración de su sonido, Lanier expone brevemente la evolución lógica que sostiene la tesis del origen musical de la tecnología de la información actual, afirmando que el khane -compuesto por una serie ordenada de objetos que se abren y se cierran en su interiorfue el primer instrumento capaz de generar bits ${ }^{154}$. Poco a poco en su evolución, el khane fue aumentando de tamaño. Los griegos y romanos mejoraron su funcionamiento sustituyendo el aire de los pulmones humanos por un sistema de impulsión por agua, lo que dio lugar al órgano hidráulico. Este sistema, cada vez más grande y complejo, era operado por esclavos que movían las pesadas palancas que abrían y cerraban los tubos. Progresivamente, los paneles de apertura y

149. John Shepherd, Continuum Encyclopedia of Popular Music of the World: VolumeII: Performance and Production (A\&C Black, 2003), 486.

150. Jaron Lanier es compositor, escritor e informático. Fue uno de los pioneros de Internet en los ochenta y se le conoce por haber dado los primeros pasos de la realidad virtual. Es coleccionista de instrumentos y una de las personas más influyentes en el pensamiento contemporáneo. «Jaron Lanier’s Homepage», accedido 10 de junio de 2020, http://www.jaronlanier.com/.

151. Ver Estado de la cuestión. Apartado i. Breve historia de la representación del sonido del paisaje hasta la Segunda Guerra Mundial.

152. Jaron Lanier, You Are Not a Gadget: A Manifesto, Penguin Creativity (London: Penguin Books, 2011), 6.

153. Evan Mantri, Jaron Lanier plays 7000 year old instruments., accedido 5 de marzo de 2019, https://www. youtube.com/watch?v=XW1BBbvrEYA.; TEDxSF - Jaron Lanier - You Are Not a Gadget, accedido 10 de junio de 2020, https://www.youtube.com/watch?v=IwbGumZ-FYg.

154. Algo que recuerda a la señal de los primeros routers domésticos. 
cierre se automatizaron con un teclado que podía abrir y cerrar varios tubos simultáneamente, y se inventaron así los órganos automáticos. El máximo exponente de esta técnica fue la pianola (un piano al que se le incorporaba un sistema mecánico y neumático para la reproducción automática de una melodía mediante la lectura de un rollo de papel perforado). Este último sistema de automatización inspiró las tarjetas microperforadas ${ }^{155}$ que permitieron el desarrollo de los ordenadores actuales.

De la influencia de los instrumentos musicales en la concepción de los ordenadores emerge la idea del origen sonoro de la virtualidad. La situación nebulosa que produce un acontecimiento sonoro y la condición extracorporal del instrumento técnico o musical, confluyen en un espacio en el que los objetos materiales se funden con los patrones de información, y convierten el recinto de afección circunscrito por el sonido en un territorio ambivalente que es, al mismo tiempo, tanto físico como virtual.

Este tipo de realidades envolventes ${ }^{156}$ que propician los acontecimientos sonoros, se basan en la construcción o producción de un espacio fundado como eidos ${ }^{157}$, imagen de un objeto ideal que se considera en reposo, siendo su origen dinámico. Una idea que Hernández León explica como «reposo pensado como un "modo de movimiento". Una extracción de la totalidad de lo percibido que garantiza el dominio de lo que nos domina» ${ }^{158}$. O como lo expresa en otras palabras H. Jonas:

Al fin y al cabo, no basta concebir las imágenes, sino que además hay que hacerlas. Su existencia externa como resultado de la actividad humana también revela por ello un aspecto físico del poder que actúa en la facultad de elaborar imágenes: el poder que el hombre tiene sobre su cuerpo. En efecto, el poder interno sobre el eidos, con toda su libertad para la creación espiritual, sería ineficaz si no poseyese también el poder de dirigir

155. La pianola se desarrolló en la misma época que el telar de Joseph-Marie Jacqard a mediados del siglo XIX. También funcionaba con un sistema de tarjetas microperforadas: «By 1740, Vancanson was busy automating the French textile industry with punched cards - a technology that, as refined by Joseph-Marie Jacqard more that a half century later, would revolutionize weaving and, in the twentieth century, would be used to input data into computers and store information in binary form.» Barbara Maria Stafford, Frances Terpak, y Isotta Poggi, Devices of wonder: from the world in a box to images on a screen (Los Angeles, CA: Getty Research Institute, 2001), 44.

156. Sobre la construcción del espacio virtual y su vinculación con el paisaje y el sonido, ver: Ulrich Gehmann, Martin Reiche, y Gerd Stern, eds., Real virtuality: about the destruction and multiplication of world (Bielefeld: Transcript, 2014). La publicación recopila una serie de artículos en torno a la construcción, o "producción" del espacio, y la representación del mundo real mediante imágenes que van desde la perspectivas urbanas hasta diagramas de flujo.

157. «Hacer una imagen presupone la capacidad de percibir algo como una imagen, y percibir algo como una imagen y no solo como un objeto implica ser capaz también de hacer una.» Jonas, «Homo Pictor: La libertad de la imagen», 226.

158. Hernández León, Ser-paisaje, 124. 
el cuerpo en el curso de la ejecución. Solo así se puede pasar de la representación a la presentación, [...]. ${ }^{159}$

El dominio de lo que lo nos domina o el poder que el hombre tiene sobre su cuerpo, son sentencias que definen el cuerpo como el instrumento básico que primero afronta el caos exterior. Con él, dirá Kepes «articulamos el flujo constante de impresiones, diferenciando el mundo en entidades discretas y unificándolo en un todo interrelacionado $»^{160}$. La conversión del cuerpo en un instrumento integrado con su entorno exterior es la idea que defiende el artista sonoro Bernhard Leitner ${ }^{161}$ (1938- ) en su proyecto Headspaces (1983) ${ }^{162}$. Como explica Leitner, los espacios sonoros 'próximos' se miden acústicamente con todo el cuerpo. La audición en el cuerpo se convierte en una parte esencial de la percepción sonora ${ }^{163}$, puesto que la piel es una membrana porosa con sensores de presión. Las ondas sonoras penetran en la piel, entran en el cuerpo y fluyen a través de él. De esta manera, un espacio acústico -en contraste con el espacio visual- no solo puede localizarse alrededor del cuerpo, sino que también puede atravesarlo. El sonido conforma una realidad envolvente y la piel desencadena la audición desdibujando el límite entre el interior y el exterior, dando lugar a los espacios propios, a la autoconciencia del espacio y del propio individuo. El sonido permite de esta manera, como observa Nancy, sentise sentir:

Con seguridad, y como lo sabemos desde Aristóteles, el sentir (la aisthesis) es siempre un re-sentir, es decir, un sentirse sentir: o bien, si se prefiere, el sentir es sujeto, o no siente. Pero esta estructura reflexiva quizá se exponga de la manera más manifiesta en el registro sonoro, y en todo caso se propone como estructura abierta, espaciada y espaciadora (caja de resonancia, espacio acústico, apartamiento de una remisión), al mismo tiempo que como cruce, refriega, recubriendo en la remisión de lo sensible a lo sensato, así como a los otros

159. Jonas, «Homo Pictor: La libertad de la imagen», 233.

160. Kepes, The New Landscape in Art and Science, 204. "The basic instrument that we use to make our experience intelligible is our body itself. With it, we articulate the constant stream of impressions on our senses, differentiating the world into discrete entities and unifying it into an interrelated whole. Our body defined axes of reference: position, size, direction, density. Though repeated comparisons, we build the realm of things, of objects which have their separate existences in a space framed by these axes. We fill the world with stones, mountains, leaves, trees, men and animals. Theses, even if they move, do not lose their fixed identities. We still see them as things and our self as the central thing- the subject- that observes, measures and understands all the others.»

161. Artista sonoro y arquitecto. Uno de los referents más importantes de la Arquitectura Sonora y la experimentación espacial a través del sonido. «Bernhard Leitner Bios», accedido 10 de junio de 2020, https://www. bernhardleitner.at/bios.!

162. Bernhard Leitner y Boris Groys, Bernhard Leitner: P.U.L.S.E., ed. Z. K. M. Karlsruhe, Bilingual edition (Ostfildern: Hatje Cantz, 2008), 190.

163. En relación a la escucha a través del cuerpo, remitimos a la obra de la artista Laurie Anderson Handphone Table (1978). 
sentidos. ${ }^{164}$

Al igual que Nancy, Simondon emplea el registro sonoro para referirse a los procesos de individuación y formación del sujeto. ${ }^{165}$ Mientras que la máquina, al registrar un sonido, no diferencia los sonidos que tienen una forma del ruido o los sonidos transitorios del ambiente, «la percepción humana vuelve a encontrar las formas, las unidades perceptivas, en la visión o en la audición de los documentos grabados.» ${ }^{166}$ En la memoria humana, la forma se conserva, y mientras «la memoria de la máquina triunfa en lo múltiple y en el desorden; la memoria humana triunfa en la unidad de las formas y en el orden» ${ }^{167}$.

En la memoria humana, por el contrario, la forma se conserva; la conservación misma es sólo un aspecto restringido de la memoria, que es poder de selección de las formas, de esquematización de la experiencia.[...]. Se puede decir que la función de conservación de los recuerdos existe en la memoria, en el hombre, porque la memoria, concebida como "conjunto de formas, de esquemas" recibe el recuerdo que registra porque lo vincula con sus formas; por el contrario, el registro en una máquina se hace sin memoria previa. De esta diferencia esencial resulta para la memoria humana una incapacidad importante relativa a la fijación de elementos sin un orden. ${ }^{168}$

La memoria, el cuerpo y en definitiva, la experiencia, conforman en su conjunción el eidos de las realidades envolventes en las que se acoge el paisaje sonoro. Ese proceso de conservación de formas que reside en la mente humana es lo que permite proyectar un paisaje en las sucesivas transducciones necesarias para representar su imagen. Sin abandonar la terminología de Simondon, los transductores que se especificaban en el esquema de formación de la imagen del sonido, son instrumentos desarrollados como consecuencia de la aplicación de un conocimiento operativo.

164. Nancy, A la escucha, 22-23.

165. «Tomemos el caso de lo que denominamos memoria. Dejando de lado todas las asimilaciones mitológicas de las funciones vitales a los funcionamientos artificiales, podemos decir que el hombre y la máquina presentan dos aspectos complementariaos de utilización del pasado. La máquina es capaz de conservar durante un tiempo muy largo documentos monomórficos muy complejos, ricos en detalles precisos. Una cinta magnética de trescientos metros de largo puede conservar un registro de la traducción magnética de ruidos y de sonidos cualesquiera en las gamas que van de 50 a 10.000 Hertz, que corresponden a una duración de escucha de aproximadamente una hora, o de dos horas si se acepta reducir la banda de frecuencias superiores a 5.000 Hetz. [...] Ahora bien, lo que caracteriza aquí la función de conservación de la máquina carece absolutamente de estructura;» Gilbert, El modo de existencia de los objetos técnicos, 138.

166. Ibid., 139.

167. Ibid., 140.

168. Ibid., 139-40. 
Frente al conocimiento contemplativo, el conocimiento operativo, explica Simondon, da la posibilidad de construir el objeto de una realidad, pues hace aparecer una forma ${ }^{169}$. En este tipo de conocimiento, «el concepto es el instrumento de conocimiento operativo, es él mismo el resultado de una operación de ensamblaje, que implica procesos de abstracción y de generalización, a partir de la experiencia dada en la particularidad del hic et nunc.» ${ }^{170}$ Además, «gobierna la génesis de su representación a partir de elementos manipulables, como el artesano construye el objeto que pone delante de él ensamblando las piezas de manera coherente.» ${ }^{171}$

De la fusión del conocimiento operativo con el pensamiento sonoro emergen los transductores -denominados de forma genérica en esta investigación como 'instrumentos'-, cuya intención cognitiva es destilar la imagen de un acontecimiento sonoro dinámico. Si bien el hombre mismo es un transductor, la relación que establece con los objetos e imágenes que realiza para representar el concepto paisaje sonoro ${ }^{172}$ (es decir, los transductores que no son el propio sujeto), está basada en una relación doblemente analógica, puesto que se generan mediante una relación entre la naturaleza y su representación que va más allá de su semejanza aparente, y el origen de su invención se encuentra en una señal analógica ${ }^{173}$ (el sonido). Al igual que la relación que establecía Jaron Lanier entre el khane y la realidad virtual, la verdadera relación analógica entre el instrumento musical y el lenguaje binario se encuentra «entre el funcionamiento mental del hombre y el funcionamiento físico de la máquina» ${ }^{174}$. Dos funcionamientos que, como apunta Simondon, son paralelos en el momento de su invención:

Inventar es hacer funcionar el pensamiento como podría funcionar una máquina, no según la causalidad, demasiado unitaria, sino según el dinamismo de funcionamiento vivido, captado porque es producido y acompañado en su génesis. La máquina es un ser que funciona. Sus mecanismos concretizan un dinamismo coherente que alguna vez existió en el pensamiento, que fue el pensamiento. El dinamismo del pensamiento, en el momento de la invención, se convirtió en formas que funcionaban. A la inversa, la máquina en funcionamiento padece o produce un cierto número de variaciones alrededor de los ritmos fundamentales de su funcionamiento, tal como éstos resultan de sus formas definidas.

169. Ibid., 251.

170. Ibid.

171. Ibid.

172. Siguiendo este pensamiento, el concepto es el instrumento del instrumento.

173. Una señal analógica es un tipo de señal generada por un fenómeno electromagnético. Se representa por una función matemática continua en la cual hay que tener en cuenta que la variable se encuentra representada por el periodo y la amplitud teniendo como base el tiempo. Algunas magnitudes físicas analógicas son la temperatura térmica o la tensión eléctrica, entre otras. En la naturaleza hay muchas señales analógicas, como la energía, la luz o el sonido.

174. Gilbert, El modo de existencia de los objetos técnicos, 155. 
Estas variaciones son significativas, y son significativas en relación con el arquetipo de funcionamiento que es el del pensamiento en el proceso de invención. ${ }^{175}$

Dos invenciones analógicas sirven para ejemplificar la aplicación del conocimiento operativo: el clarinetista de Cornelis Jacobus van Oeckelen II (1838) y el diagrama Partiturskizze zu einer machanischen exzentrik (1924-5) de László Moholy-Nagy.

La visión cartesiana del cuerpo como máquina, impulsó un 'instrumento musical' cuya finalidad era reproducir mecánicamente las energías, fuerzas y movimientos que le permiten a un hombre tocar un clarinete. El androide clarinetista del organista holandés Cornelis Jacobus van Oeckelen $\mathrm{II}^{176}$ supone una abstracción de la actividad del cuerpo humano. Oeckelen fabricó este prototipo, capaz de tocar piezas de Beethoven, para sorprender al mundo con un ingenio que reprodujera una actividad compleja mediante una analogía mecánica. ${ }^{177}$ Lo importante de este ejemplo no es el parecido, más o menos exacto del clarinetista con un músico del XIX, sino la capacidad del organista para traducir y comprender a través de la fabricación de una máquina la complejidad de un cuerpo. El clarinetista es, en sí mismo, un cuerpo-instrumento. Una máquina de gorjear.

El segundo ejemplo, el diagrama Partiturskizze zu einer machanischen exzentrik, es un dibujo que pretende plasmar la multiplicidad de acciones que concurren en una representación teatral a través del tiempo en un diagrama de cuatro columnas. Cada columna corresponde a una acción que se realiza de forma simultánea en tres escenarios diferentes (forma y movimiento (1 y 2), luz (3) y música (4)). Moholy-Nagy dice en la descripción que acompaña al dibujo que «la sincronización en la partitura aparece en la horizontal» ${ }^{178}$. Existe, por tanto, una relación temporal entre las acciones que convierten el diagrama espacial en 'partitura', dando la posibilidad de interpretar la propuesta y de generar un espacio conjugando las instrucciones de acción. Siguiendo los principios básicos de abstracción y mecanización de los primeros años de la Bauhaus, los experimentos de Moholy-Nagy empleaban las tecnologías emergentes de principios del siglo XX para ver el mundo de manera diferente, aumentando la realidad y amplificando la capacidad de los órganos sensoriales para ver lo que es aparentemente invisible. La partitura de Moholy-Nagy es, en consecuencia, resultado de la aplicación del conocimiento

175. Ibid.

176. Biografía en Douglas Earl Bush y Richard Kassel, The Organ: An Encyclopedia (Psychology Press, 2006), 378.

177. Stafford, Terpak, y Poggi, Devices of wonder, 42.

178. László Moholy-Nagy:, «Partiturskizze zu einer mechanischen exzentrik», en Die Bühne im Bauhaus, ed. Oskar S chlemmer et al. (Munich: Albert Langen Verlag, 1924), 44-45. 

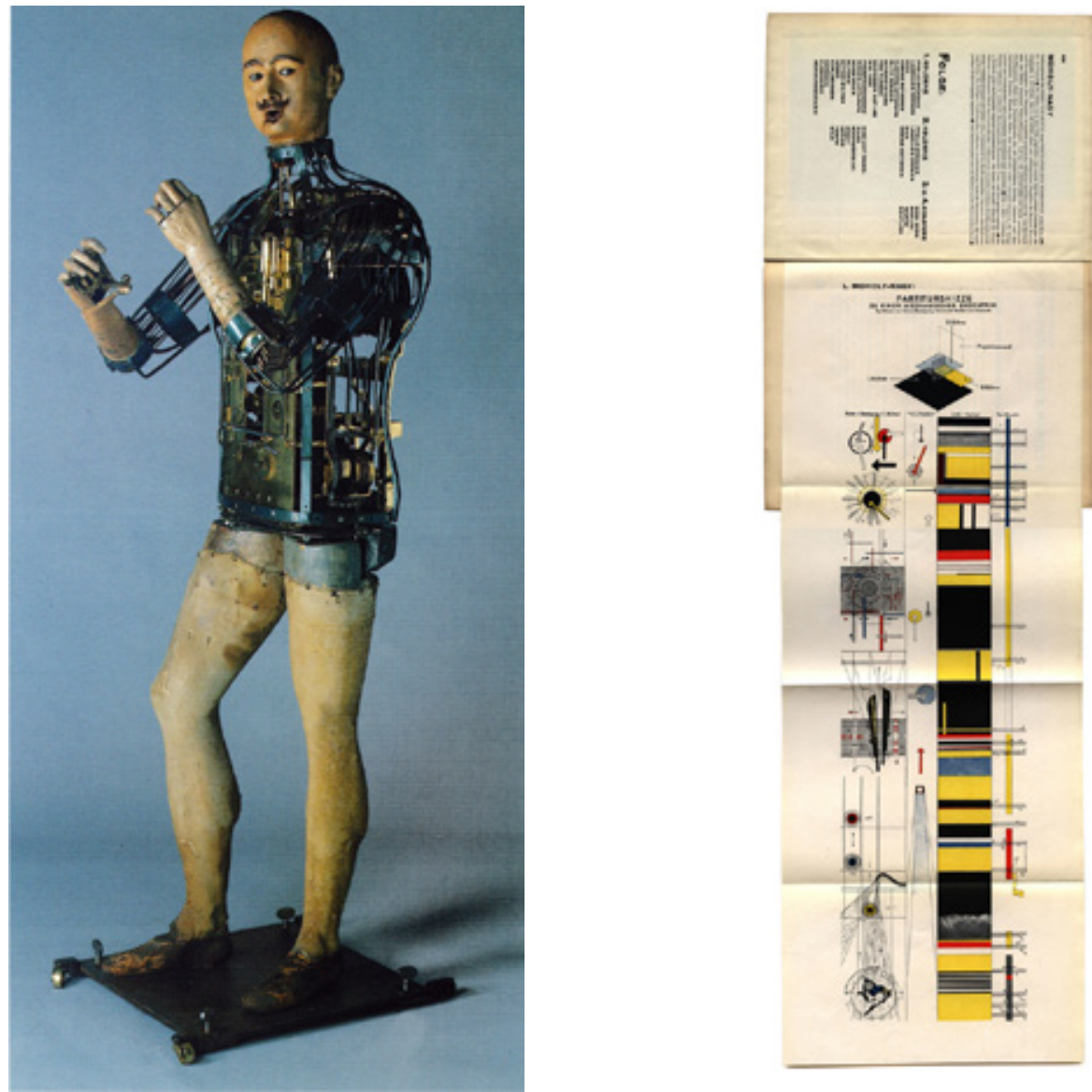

Figura 60. Clarinetista de Cornelis Jacobus van Oeckelen II (1838)

Figura 61. László Moholy-Nagy, Partiturskizze zu einer machanischen exzentrik (1924-5) 
operativo, pues da la posibilidad de construir el objeto de una realidad, hace aparecer una forma. ${ }^{179}$

En ambos ejemplo existe una analogía dinámica ${ }^{180}$ entre el proceso en el cual se piensa el instrumento y el proceso físico de funcionamiento del mismo una vez construido. A esa relación entre el hombre y la máquina, Simondon la denomina isodinamismo ${ }^{181}$. Sobre este sustrato teórico, comienza la exploración de los instrumentos analógicos que resultan de la aplicación del conocimiento operativo para representar el sonido del entorno. En ellos, la analogía es la acción que da forma a los transductores que permiten pasar «de un término a otro sin negación de un término por el siguiente» ${ }^{182}$. Instrumentos doblemente analógicos, algunos sonoros y otros silenciosos, que median la representación del concepto paisaje sonoro al mismo tiempo que la formalizan.

179. Cfr. Andreas Broeckmann, Machine Art in the Twentieth Century (MIT Press, 2016), 82.; Mariellen Sandford, Happenings and Other Acts (Routledge, 2003), 17.; y el artículo de La Coe y Jodi Lynn, "Constructing Vision: László Moholy-Nagy's Partiturskizze Zu Einer Mechanischen Exzentrik, Experiments in Higher Spatial Dimensions», 1 de mayo de 2019, https://vtechworks.lib.vt.edu/handle/10919/89334.

180. Gilbert, El modo de existencia de los objetos técnicos, 155. «Entre el hombre que inventa y la máquina que funciona existe una relación de isodinamismo [...] De hecho, la verdadera relación analógica se da entre el funcionamiento mental del hombre y el funcionamiento físico de la máquina. Estos dos funcionamientos son paralelos, no en la vida corriente sino en la invención.»

181. Ibid.

182. Ibid., 207. 


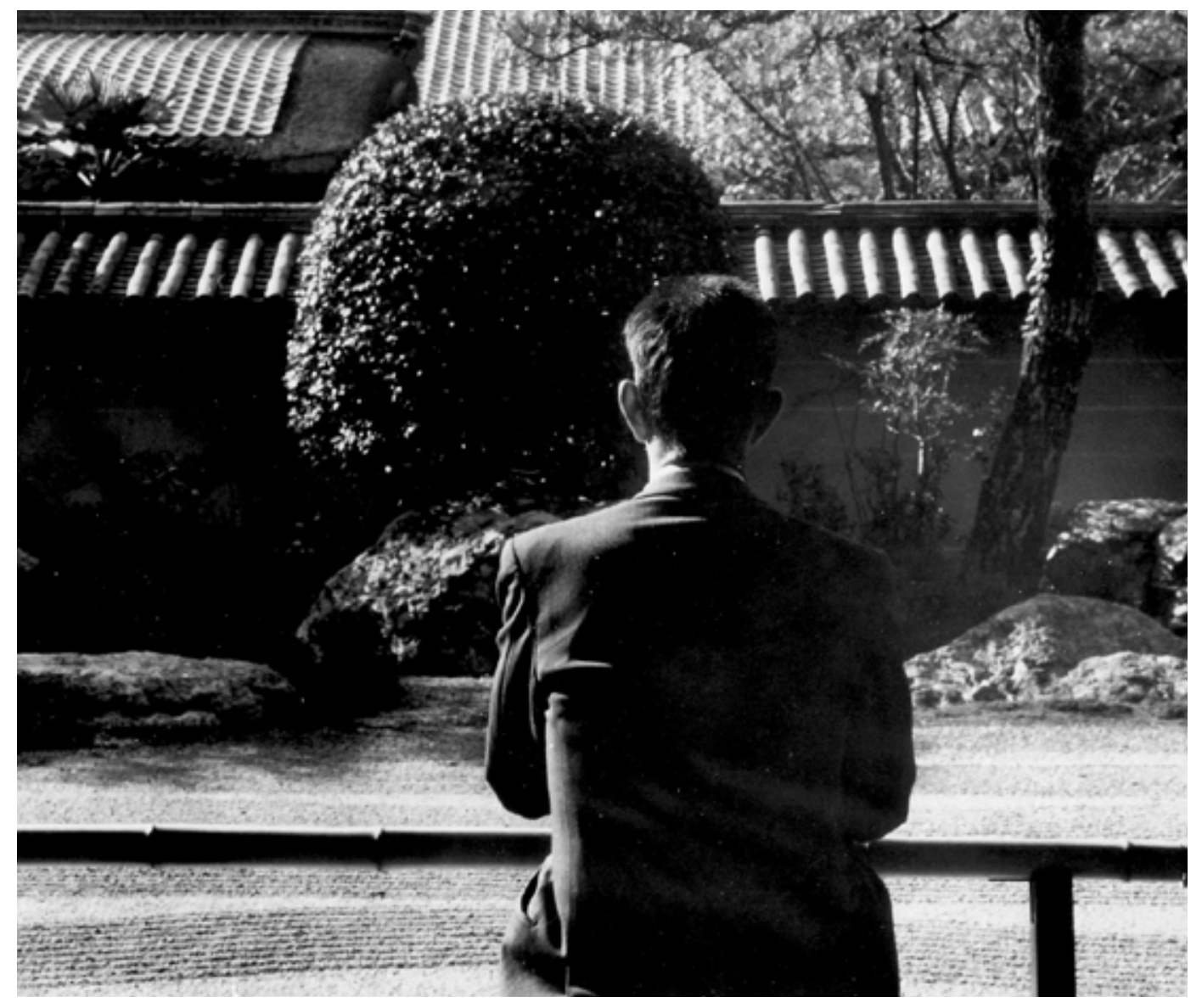

Figura 62. John Cage en Japón (1962) 


\title{
CAPÍTUlo 2. VÉRTiCES Y DiAgONALES: INTERACCIONES EN LAS TRAYECTORIAS Y EL PENSAMIENTO DE JOHN Cage, Juan Navarro Baldeweg y Gilles Deleuze (1939-1989)
}

\author{
Because sound vanishes into air and past time, the history of listening must be constructed \\ from the narratives of myth and fiction, 'silent' arts such as painting, the resonance of \\ architecture, auditory artefacts and nature. In such contexts, sound often functions as a \\ metaphor for mystical revelation, instability, forbidden desires, disorder, formlessness, \\ the supernatural, for the breaking of social taboos, the unknown, unconscious and extra- \\ human. ${ }^{1}$

\section{Toop. Sinester Resonance}

La exposición Für Augen und Ohren: Von der Spieluhr zum akustischen Environment ${ }^{2}$, organizada por la Akademie der Künste de Berlin en 1980, sirvió como altavoz para las diferentes prácticas artísticas que, congregadas bajo la etiqueta de arte sonoro, habían consolidado el empleo del sonido como medio de expresión estética. Según René Block³, comisario de la exposición, el propósito de la muestra era plantear mediante objetos, instalaciones y performances ${ }^{4}$ las

1. David Toop, «Prelude: Distant Music (on the contemplation of listening)», en Sinister Resonance: The Mediumship of the Listener, Edición: 1 (Continuum, 2010), xv.

2. Für Augen und Ohren: Von der Spieluhr zum akustischen Environment. Objekte - Installationen - Performances. Akademie der Künste, Berlin. 20 de enero - 02 de marzo de 1980.

3. René Block es galerista, editor de arte, coleccionista y comisario de arte.

4. La exposición contó con obras de David Tudor, Bernhard Leitner, Robert Rauschenberg, Allan Kaprow, Erik 
siguientes cuestiones fundamentales: «¿cómo abordan el espacio los compositores? ¿Cómo se desarrolla la escritura de las partituras hasta devenir un lenguaje visual propio? ¿Cómo han investigado los compositores desde principios del siglo XX nuevos sistemas sonoros y cómo han construido nuevos instrumentos en el marco del futurismo, el dadaísmo o a título individual? Y viceversa, ¿cómo han comprendido y empleado los artistas visuales el sonido como material nuevo, cómo han descubierto el sonido como ensanchamiento del espacio?» ${ }^{5}$

El catálogo de la exposición comienza con un esquema que muestra la evolución del arte sonoro $^{6}$ desde Pitágoras hasta los movimientos experimentales de la segunda mitad del siglo XX. En el conjunto de elementos gráficos que componen el diagrama, el nombre del compositor John Cage destaca sobre el resto. Cage, al ser el gran condensador de la modernización de la percepción auditiva en el siglo XX, aglutina alianzas tanto con artistas plásticos como con las corrientes musicales modernistas y futuristas que impulsaron los compositores y artistas sonoros Luigi Russolo, Edgard Varèse, George Antheil o Henry Cowell. ${ }^{7}$ La situación espaciotemporal de Cage en la historia del arte, coincidente con la irrupción de la tecnología sonora, lo convirtió en un personaje polifacético que puso en práctica todos los modos de escucha para generar estructuras reflexivas y abiertas, en las que el espacio, el paisaje y el medio ambiente se conjugaban en un mismo ejercicio creativo. El interés por lo inusual, por lo que no se ve o no se escucha, se desarrolló entonces mediante nuevas expresiones artísticas con el fin de encontrar la presencia estructural y estética del sonido en el espacio. ${ }^{8}$

La obra de John Cage (1912-1992) impulsa la construcción de una historia de la escucha en la que las artes silenciosas (arquitectura, literatura, pintura...) permiten el abandono definitivo de las certidumbres adquiridas en favor de la experimentación. Los pasos docentes de Cage en Chicago y las cartas entre John Cage y el compositor Pierre Boulez inician un recorrido que atraviesa la historia del arte, la arquitectura y la filosofía en los años en los que el interés por el sonido del entorno evolucionó hasta formalizar el concepto paisaje sonoro. Las investigaciones ligadas al signo y al reconocimiento sensible del entorno de György Kepes en el Massachusetts Institute of Technology, las obras sonoras realizadas por Maryanne Amacher y Juan Navarro

Satie o John Cage, entre otros.

5. Fundació Joan Miró, ¿Arte sonoro? (Barcelona: Fundació Joan Miró, 2019), 70.

6. Réne Block et al., Für Augen und Ohren. Von der Spieluhr zum akustischen Environment. Objekte - Installationen - Performances, 1. edition (Akademie der Künste Berlin, 1980), 6.

7. Cfr. Branden Wayne Joseph, Experimentations: John Cage in music, art, and architecture, First edition (New York ; London: Bloomsbury Academic, 2016), 40.

8. Cfr. Brandon LaBelle, Background noise: perspectives on sound art, Second edition (New York: Bloomsbury Academic, 2015), 52. 


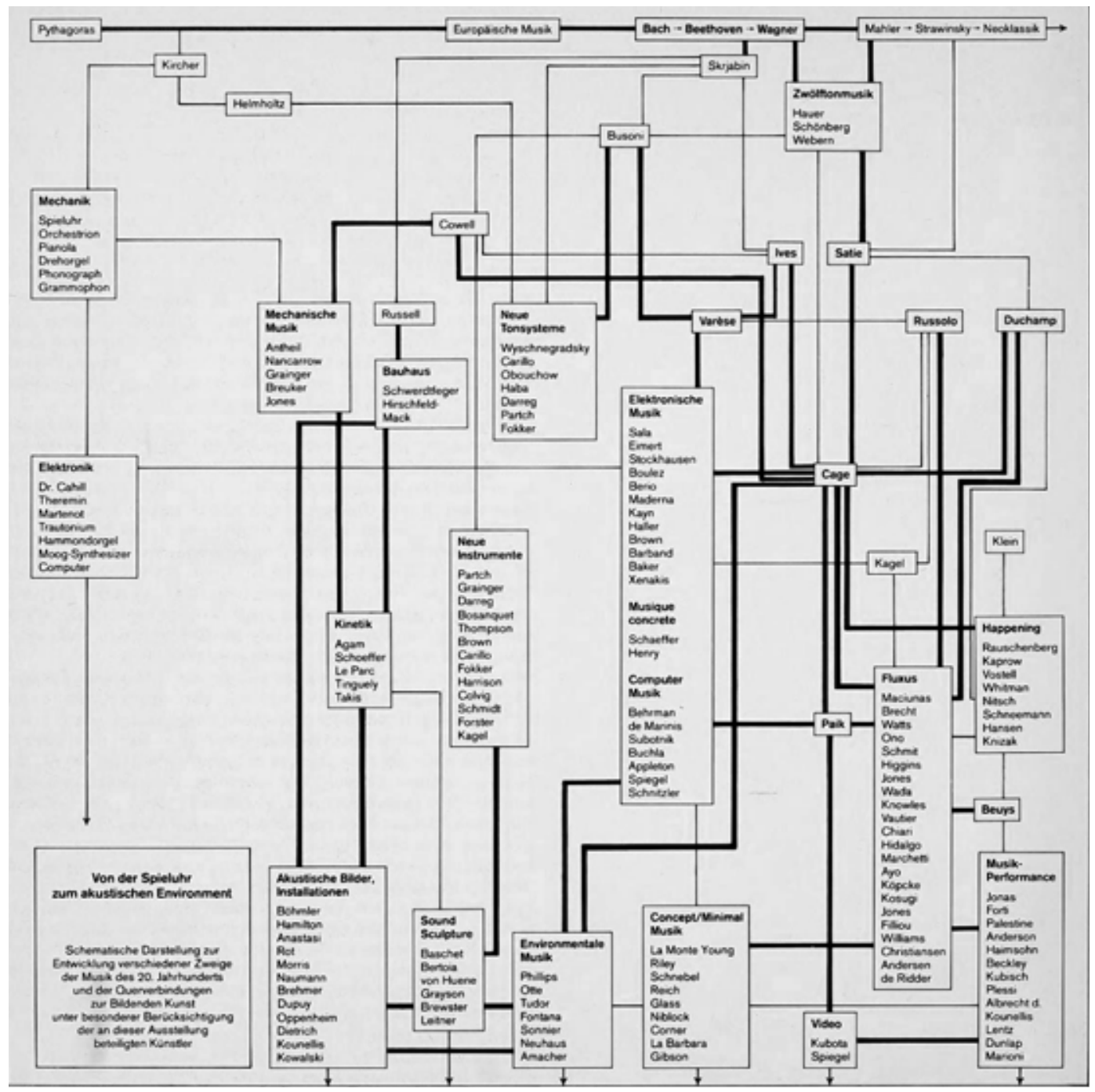

Figura 63. Esquema de la evolución del arte sonoro desde Pitágoras hasta 1980 


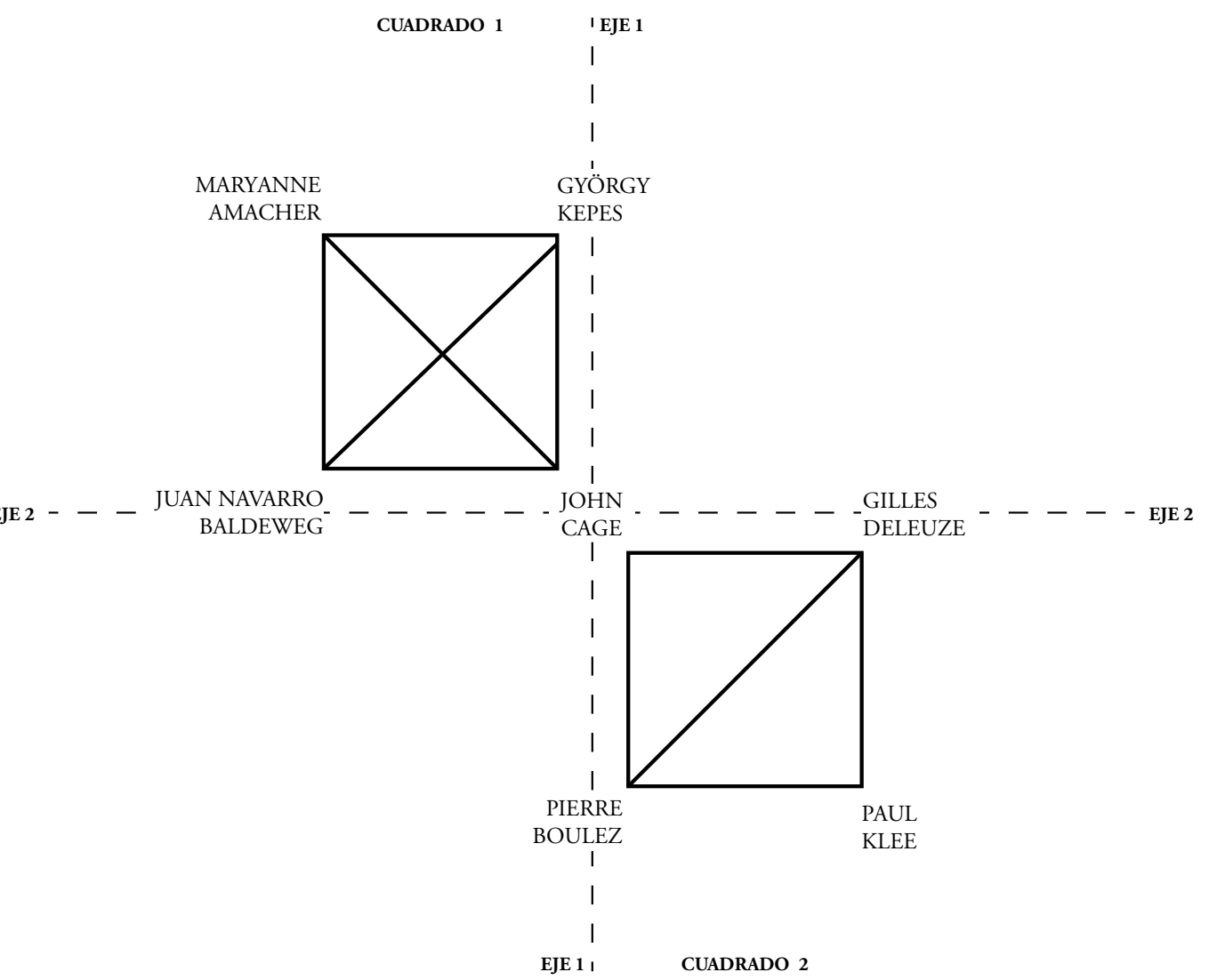

Figura 64. Mecanismo de anclaje 
Baldeweg en el Center for Advanced Visual Studies, y los ensayos sobre música y sonido de Gilles Deleuze y Pierre Boulez, establecen las paradas en el recorrido.

Puesto que una cronología no filtrada de este período sería inabarcable, se ha optado por recurrir a un mecanismo de anclaje para su desarrollo. Un plano cartesiano en el que se sitúan dos cuadrados. Cada elemento del plano (dos ejes y dos cuadrados), cubre un período específico comprendido entre 1939 y 1989 que contiene los acontecimientos y obras que justifican la pertinencia de la selección de la obra de John Cage, Juan Navarro Baldeweg y Gilles Deleuze para el desarrollo de esta investigación. Se ordenará la exposición siguiendo un orden cronológico.

\section{Eje i. I939-I96 I: John CAge, Pierre Boulez y György Kepes}

My father was an inventor. He was able to find solutions for problems of various kinds, in the fields of electrical engineering, medicine, submarine travel, seeing through fog, and travel in space without the use of fuel. He told me that if someone says "can't" that shows you what to do. He also told me that my mother was always right even when she was wrong. ${ }^{9}$

\section{J. CAGE. An Autobiographical Statement}

No es extraño que, con sus antecedentes, Schönberg considerase a su alumno John Cage como un 'inventor genial' ${ }^{10}$. Tras pasar su infancia y primera juventud en California, Cage realizó en 1930 un viaje por Europa que le llevó por París, Mallorca y Berlín. Tras volver a Estados Unidos y asistir a las clases de Schönberg en California, fue nombrado compositor para las clases de danza de Bonnie Bird en la Cornish School de Seattle. La necesidad de incorporar percusión en la música que componía para las coreografías de Bird, activó el ingenio de Cage. Colocando objetos entre las cuerdas convirtió su piano en un instrumento de percusión. Nacía así el piano preparado.

Siguiendo la doctrina Zen y siempre a la vanguardia en el empleo de los últimos avances

9. John Cage, «An Autobiographical Statement», accedido 18 de noviembre de 2019, https://www.johncage.org/ autobiographical_statement.html.

10. «Someone asked Schoenberg about his American pupils, whether he'd had any that were interesting, and Schoenberg's first reply was to say there were no interesting pupils, but then he smiled and said, "There was one," and he named me. Then he said, "Of course he's not a composer, but he's an inventor -of genius." " Richard Kostelanetz y John Cage, Conversing with Cage (Psychology Press, 2003), 6. 
técnicos, Cage comenzó a componer piezas mezclando sonidos acústicos con sonidos amplificados. Gracias a sus experimentos en la estación de radio de la Cornish School, en sus primeros ańos ${ }^{11}$ compone tres de sus cinco Paisajes imaginados. Estas piezas 'electroacústicas' compuestas entre 1939 y 1952, surgen de una interpretación libre de la idea de Erik Satie de realizar transposiciones sonoras de procesos derivados de las artes plásticas. ${ }^{12}$

Tras estas primeras experiencias, Cage iniciará la década de los cuarenta en Chicago y la terminará en París. En cada ciudad, respectivamente, cruzará su trayectoria con la del artista György Kepes y con el compositor Pierre Boulez. A través de los encuentros, correspondencia y entrevistas que mantuvo con ambos, Cage dará forma a sus primeras intuiciones sobre el entorno sonoro y los procesos de composición aleatorios que marcarán su obra posterior.

\section{i937-I94I: John Cage y György Kepes en la Escuela de diseño de Chicago}

En los años en los que Cage se encontraba en la Escuela de Cornish, paralelamente, el artista László Moholy-Nagy se convertía en el director de la llamada Nueva Bauhaus en Chicago. The New Bauhaus: American School of Design, comenzó a impartir sus clases en octubre de 1937, siguiendo un plan de estudios muy similar al de la Bauhaus alemana que incorporaba, además, clases impartidas por profesores de la Universidad de Chicago. Más tarde, en febrero de 1939, Moholy-Nagy abrió su propia escuela, The School of Design, también en Chicago. El centro desarrolló un importante programa de talleres y conferencias impartidas por profesores y estudiantes de la Nueva Bauhaus -como Geörgy Kepes- y por profesionales invitados, entre los que se encontraba John Cage. ${ }^{13}$

György Kepes (1906-2001), pintor y fotógrafo de origen húngaro, había tenido contacto previamente con la Bauhaus alemana a través de su compatriota Moholy-Nagy. Él fue quien le propuso dirigir el departamento de 'Luz y color' ${ }^{14}$ en la nueva escuela. Kepes emigró entonces a Estados Unidos, poco antes del comienzo de la Segunda Guerra Mundial, y se estableció en

11. Se identifican como primeras obras de John Cage las comprendidas entre 1930 (primeras composiciones en Mallorca) hasta 1948 (cuando es invitado a participar en la Black Mountain College).

12. Cfr. Javier Maderuelo Raso, La idea de espacio en la arquitectura y el arte contemporáneos, 1960-1989(Ediciones AKAL, 2008), 247-48.

13. «Moholy-Nagy Foundation», accedido 12 de febrero de 2020, https://moholy-nagy.org/teaching/.

14. Gyorgy Kepes, Marjorie Supovitz, y James R. Killian, Gyorgy Kepes: The MIT Years 1945-1977, Edición: New edition (Cambridge, Mass: MIT Press, 1978), 10. 

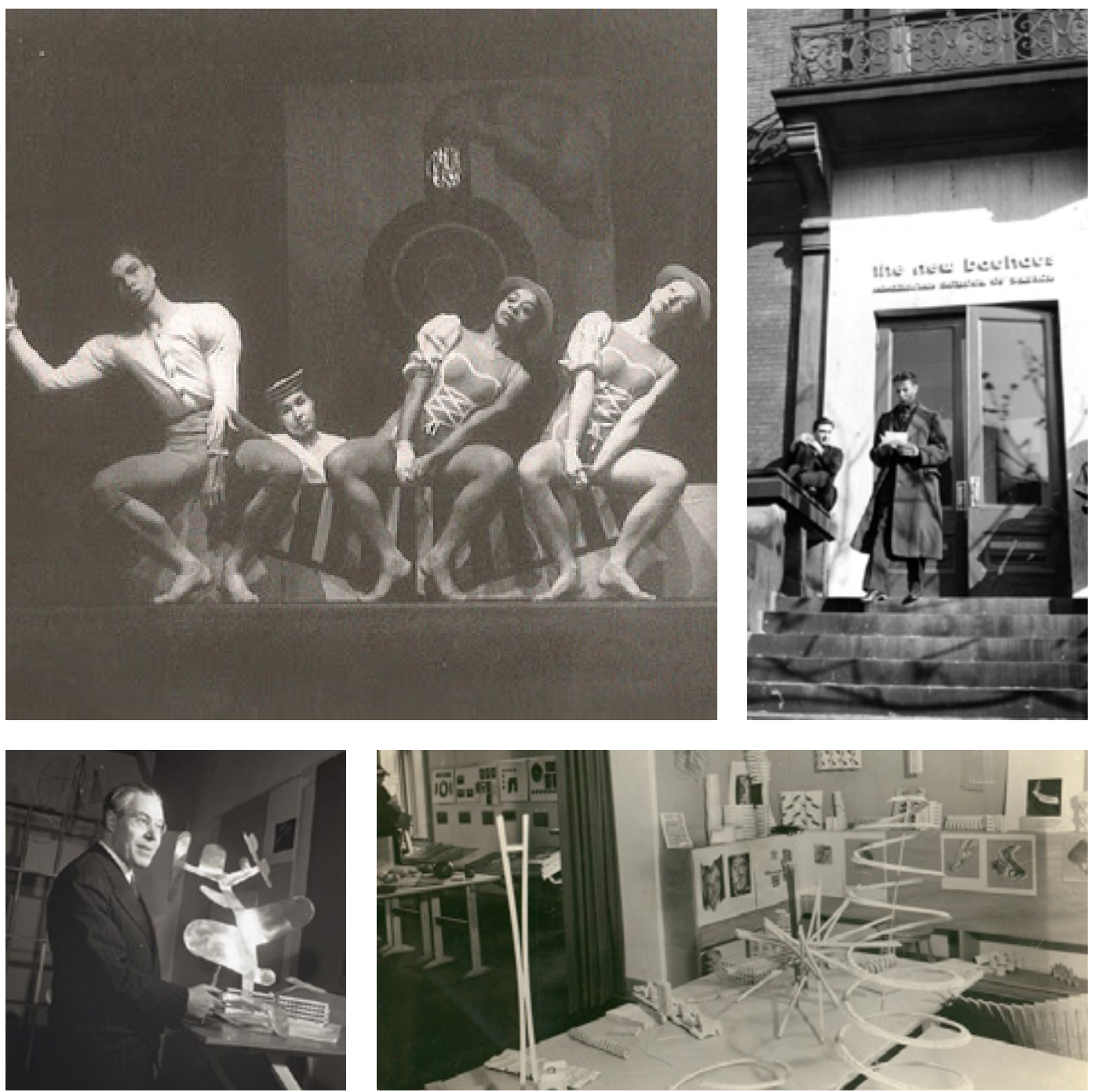

Figura 65. Merce Cunningham, Bonnie Bird, Syvilla Fort, y Dorothy Hermann en la Cornish School (1938) Figura 66. Vista exterior de la Nueva Bauhaus, Chicago (1937/39) Figura 67. László Moholy-Nagy en el Institute of Design, Chicago (1946).

Figura 68. Exposición de los trabajos de los estudiantes del curso preliminar de la Nueva Bauhaus, Chicago (1938). 
Chicago para trabajar como profesor en la Nueva Bauhaus. Unos años más tarde, en septiembre de 1941, e invitado igualmente por Moholy-Nagy ${ }^{15}$, John Cage se mudó a Chicago para impartir un curso sobre experimentación sonora ${ }^{16}$ en la Escuela de Diseño ${ }^{17}$.

La coincidencia de John Cage y György Kepes en la Escuela de Diseño de Chicago supone un primer punto común en las vidas de ambos. La influencia que Moholy-Nagy y su libro The New Vision supuso para los dos artistas ${ }^{18}$, les llevó a compartir experiencias ${ }^{19}$ e ideas años después de nuevo en Chicago.

i 949: El viaje a París. Primer contacto de John Cage con Pierre Boulez

Tras estrenar la obra In a Landscape en 1948, Cage recibirá la Beca Guggenheim con la que viajará junto a Merce Cunningham a Europa. ${ }^{20}$ En la primavera de 1949, John Cage llegó a Paris, y siguiendo la sugerencia que le había propuesto su amigo Virgil Thomson, fue a conocer a Pierre Boulez. Allí nació una amistad entre ambos, mutuamente influyente, que quedó reflejada en las cartas que se cruzaron hasta $1954 .{ }^{21}$ Aunque su personalidad era muy

15. En una carta dirigida a Peter Yates, fechada el 12 de diciembre de 1940, Cage cuenta el interés que MoholyNagy tiene en él: «Moholy-Nagy begged me to come to Chicago. Funds also necessary. In looking for support, I made many new contacts, learned a lot. For one thing became acquinted with new technological advances, including the possibilities of film and film editing, enabling a composer to compose directly without the use of any musical instrument». John Cage, The Selected Letters of John Cage (Wesleyan University Press, 2016), 50.

16. Sobre el contenido del curso experimental impartido, ver Jeffrey Saletnik, «László Moholy-Nagy, John Cage Und Die Kreative Dynamik», en John Cage Und... Bildender Künstler - Einflüsse, Anregungen., ed. Wulf Herzogenrath (Berlin: Akademie der Künste, 2012), 66, https://www.academia.edu/13108047/

17. Mientras estaba en la Escuela de Diseño, Cage enseñó también en la Universidad de Chicago, acompañando clases de baile dirigidas por May Manning, y dio importantes actuaciones tanto en la Universidad de Chicago como en el Club de Artes de Chicago. Cage, The Selected Letters of John Cage, 52.

18. Cfr. Branden Wayne Joseph, Experimentations: John Cage in music, art, and architecture, First edition (New York ; London: Bloomsbury Academic, 2016), 39.

19. «Kepes poseía una casa, un bungalow, en Cape Cod, hecha por su compatriota y amigo Marcel Breuer. Allí fuimos un verano mi mujer, Pepa, y yo para pasar un día, bañándonos en el lago al pie de la casa. [...] Cuando ya nos íbamos, Kepes nos pidió que firmáramos en el libro de visitas. En él había una cantidad de rúbricas de figuras extraordinarias, Walter Gropius, Merce Cunningham, John Cage, Alvar Aalto, Sert...y otros muchos.» Cfr. Juan Navarro Baldeweg, Escritos, 1. ed, Pre-textos. Ensayo 1449 (Valencia: Pre-Textos, 2017), 278.; M. Aurora Fernandez Rodriguez y Luis Andrés de Fontcuberta Rueda, «Marcel Breuer y el sueño de la cabaña americana», RA. Revista Arquitectura, n. ${ }^{\circ} 14$ (junio de 2012): 51-60, http://www.unav.edu/web/escuela-tecnica-superior-dearquitectura/colecciones.

20. Llorenç Barber y Círculo de Bellas Artes (Madrid), John Cage (Madrid: Círculo de Bellas Artes, 1985), 28.

21. Pierre Boulez y John Cage, The Boulez-Cage Correspondence (Cambridge University Press, 1995). 
diferente $^{22}$, comenzaron su relación unidos por la dificultad de sus circunstancias intelectuales ${ }^{23}$, ayudándose el uno al otro a promocionar su obra. Boulez introdujo a Cage al público europeo y Cage hizo lo mismo con Boulez en Estados Unidos.

Dearest Mother and Dad:

Things are progressing very well with the giving of concerts. Pierre Boulez, the composer I admire most here, introduces me to everyone, painters poets, critics, musicians, and arranges the private concerts which I am about to give.... Boulez is crazy about my music, and I about his. That is very pleasant. In fact everything is unbelievably delightful. ${ }^{24}$

Aunque en los comienzos de su relación compartían una preocupación común por los mismos aspectos musicales como la organización rítmica o la relatividad de las escalas tradicionales, la deriva hacia el azar que tomó Cage en los años cincuenta motivó la divergencia de sus caminos ${ }^{25}$. Tras su estancia en París, Cage volvió a California y Boulez continuó su carrera por Europa, pero extendieron su relación epistolar -considerada una de las relaciones intelectuales más ricas de la historia de la música- durante cinco años más.

La inquietud y el dinamismo constante de John Cage contrastan con la concentración y precisión de Pierre Boulez. El desarrollo paralelo de sus trayectorias como músicos (ambos empleando la tecnología, las referencias a la poesía, conectando artistas y pensadores de todos los campos), enriqueció, gracias a su labor, no solo la música, sino el estudio del sonido en general. ${ }^{26}$ Cage y Boulez son los dos puntos de anclaje de una bisagra que hace posible la

22. Como describe Alex Ross en El ruido eterno, la personalidad de Cage era una mezcla de excentricidad y sofisticación capaz de tensar su música entre la violencia y la delicadeza, mientras que Boulez era temido en sus primeros ańos por sus artículos mordaces y su genio temperamental. Alex Ross, El ruido eterno escuchar al siglo XX a través de su música (Barcelona: Círculo de Lectores, 2009), 445-60.

23. En la carta de John Cage a Boulez del día 17 de junio de 1950, encontramos el desánimo y la lectura ácida del contexto musical de la américa de los cincuenta: «Since knowing you, our music sounds feeble to me. In truth, it is only you who interests me». Pierre Boulez y John Cage, «The Americans», October. The MIT Press 65 (Summer de 1993): 63, https://doi.org/10.2307/778763.

24. Cage, The Selected Letters of John Cage, 103.

25. «Las cartas de Boulez, dirá, me interesaban prodigiosamente, ¡me atrevo a esperar que las mías no le hayan sido indiferentes! Pero Boulez rechazó toda idea de admitir el azar. Eso no entraba en sus perspectivas». Barber y Círculo de Bellas Artes (Madrid), John Cage, 28.

26. La huella de Moholy-Nagy se mantuvo en la experimentación sonora durante años, y su impulso contribuyó a crear los primeros laboratorios de sonido en Europa: «During the 1950s, electronic music production studios located within the infrastructure of European national radio stations provided precisely the type of laboratory research environments that Moholy-Nagy proposed in 1922. The studios most often referenced within the context of a history of European 20th-century experimental music are the WDR studio for electronic music in Cologne, Germany, where Karlheinz Stockhausen carried out his early research; the Paris Radiodiffusion Française studios, where Pierre Schaeffer developed Musique Concrète on magnetic tape; and the RAI Studio of Phonology in Milan, Italy. Rarely, however, does the Electroacoustic Music Studio of HEAR, located in Moholy-Nagy's native 
conexión entre lo abstracto y lo concreto. Juntos, aunque separados, trazaron el camino que permite explorar el tiempo y el espacio desde su representación.

I945-1956: De los nuevos paisajes a la forma urbana. Geörgy Kepes y John Cage EN EL MIT

En 1947, György Kepes fue invitado a establecer el programa Visual Design in New Materials and Methods of Design en la reconvertida Bauhaus americana. En aquel año, la escuela pasó a ser parte del Massachusetts Institute of Technology. A partir de entonces y hasta el año 1952, influenciado por el contacto continuo con ingenieros y científicos en el MIT, Kepes recopila una serie de imágenes que conformarán la exposición The New Landscape (M. Hayden Gallery, 1951) y la publicación The New Landscape in Art and Science (1956). ${ }^{27}$

As its title implies, the book is a landscape. Or, more correctly, it is the first sketch of a new landscape which seems to me rich in promise, a landscape I am moved by and have confidence in. ${ }^{28}$

Con el fin de enseñar a ver a los nuevos estudiantes de arquitectura, The New Landscape persigue el propósito de aumentar la capacidad de entender el mundo, apreciar su riqueza y hacer frente a sus problemas. ${ }^{29}$ Empleando el paisaje como metáfora, Kepes presenta el panorama científico y artístico de los años cincuenta en un proyecto «concebido para ser visto más que leído» ${ }^{30}$. El libro, ligado a la exposición homónima, aporta una visión multidisciplinar de los valores y problemas provocados por la conjunción del arte y la ciencia, principales constituyentes del media $a r t^{31}$, compaginando la información gráfica con una colección de

country, receive this kind of attention, despite the important work and research into electronic sound carried out at a time when Hungary was living under Soviet rule.» Zach Layton, "Moholy-Nagy and "Optical Sound" at the Guggenheim», Guggenheim (blog), 18 de julio de 2016, https://www.guggenheim.org/blogs/checklist/moholynagy-and-optical-sound-at-the-guggenheim.

27. Kepes, Supovitz, y Killian, Gyorgy Kepes, 12-13.

28. Gyorgy Kepes, The New Landscape in Art and Science (Academy Editions Ltd, 1956), 17.

29. Cfr. Ibid., 19-20.

30. Ibid., 17. "This book is meant to be looked at more than read. It is a picture book, arranged to bring attention to a newly emerged aspect of nature, hitherto invisible but now revealed by science and technology. The "text" of the book is nor its message. Primarily, a body of material is presented, rather than scientific information or esthetic theory. The material is organized to help the reader to see, with the hope that he will grasp significant connections for himself. »

31. Amplia investigación realizada por Ángela Juarranz Serrano, «La construcción del medio : hacia la mediación disciplinar como laboratorio de arquitectura (1967-2017)» (phd, E.T.S. Arquitectura (UPM), 2019), http:// 
697071
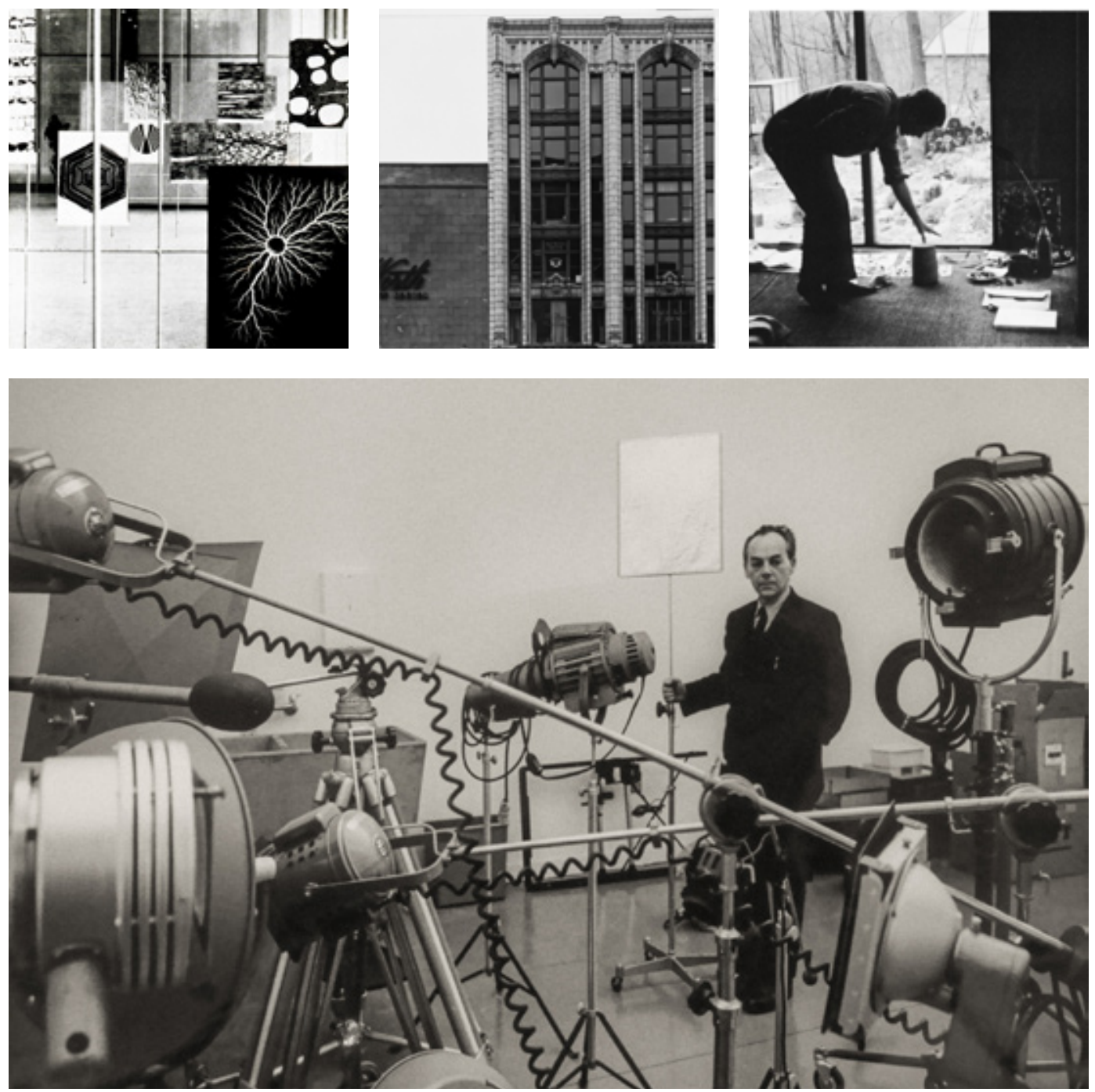

Figura 69. György Kepes, The New Landscape (1951)

Figura 70. Urban Form seminar. South Facades, Boylston Street, Former Berkeley Building, Montgomery-Frost Co. (1954-1959)

Figura 71. John Cage en su apartamento. William-Cage House (1956)

Figura 72. György Kepes en el Center for Advanced Visual Studies (CAVS) del MIT, Cambridge, Massachusetts (1967) 
ensayos. Naum Gabo, Richard J. Neutra, Fernand Léger, S. Giedion o Walter Gropius, entre otros, reflexionan sobre el paisaje industrial, el paisaje interior y exterior, la compresión del evento en el tiempo, la modulación de las señales, la analogía y la metáfora...todo el contenido, visual y ensayístico, convierten a The New Landscape en una obra completa que muestra el contexto académico, científico y artístico de una época en el que, paralelamente, la música electrónica y las artes digitales comenzaban a traspasar los límites de todos los géneros establecidos. Como ya sucediera a principio de siglo tras la Primera Guerra Mundial, la inquietud de la postguerra y las nuevas herramientas surgidas del impulso técnico derivado de la Segunda Guerra Mundial, dirigió la atención intelectual a la unión entre ciencia y arte, incentivando el estudio de los medios capaces de aumentar la experiencia sensorial:

Man explored his environment with his senses and learned about its form and textures; work and reflection revealed in nature, innate order and susceptibility to human organizing, bringing him a feeling of confidence and power. Sense experiences bring intimacy with nature, awareness of its patterns and the ability to enjoy the natural world. Out of the sensible richness of his environment, man built himself and image, a picture of nature as the great mother - the universal source of life and strength - and of the natural world as a garden - a refuge from stress and the living source of a human life. He sensed form-patterns in nature the sun, the moon, a face, an ear of wheat, the shadow of a tree, and used them to break down his isolation within himself. Stored in memory, recreated by imagination, they built a feeling of being connected with the physical environment and with other human beings. ${ }^{32}$

La construcción de una imagen de la naturaleza basada en la apreciación de patrones sensibles lleva a Kepes a realizar una cartografía de los medios para identificar las posibilidades que la ciencia podía ofrecer al arte. Las nuevas herramientas científicas de la primera mitad del siglo XX, permitían una modulación de las señales ${ }^{33} \mathrm{y}$ una amplificación de la percepción que aumentaban y 'disciplinaban' la sensibilidad racional hacia el entorno como nunca antes se había conseguido. Si bien las tesis de György Kepes fueron formuladas desde una perspectiva visual, su investigación refuerza y fundamenta, asimismo, algunos aspectos perceptivos también involucrados en la representación del sonido, como son la transformación de señales y la estructura de la experiencia sensible.

Kepes defiende que la formación de imágenes como una acción básica tanto para la ciencia

oa.upm.es/53902/.

32. Kepes, The New Landscape in Art and Science, 18.

33. Sobre la modulación de señales, ver Ibid., 172-73. 
como para el arte. En un nivel complejo, entre las imágenes que provienen del arte y las que tienen su origen en la ciencia, puede existir una correspondencia estructural. ${ }^{34}$ Este pensamiento nos devuelve a las transducciones implicadas en el proceso de construcción de la imagen del sonido $^{35}$, donde lo científico y lo artístico crean en su interacción una experiencia que conlleva la comprensión, tanto objetiva como poética, de las estructuras de la realidad:

Art begins when they recreate sense patterns, using sounds and images to preserve past experiences and to enrich the present. These recreate sense patterns are used for communication; sounds heard are transformed into music and speech, forms seen are transformed into pictures and writing. The effort to recreate and preserve sense experience lays the basis for the symbolic structure of communication. Science, art and social communication are superstructure built with the material of primary sense experience. And man's emotional life -his experience of pleasure and pain, of order and chaos- is similarly anchored in the sensed field..$^{36}$

Al igual que Tratado de objetos musicales de Pierre Schaeffer, The New Landscape investiga sobre la transformación de patrones en sus análogos estructurales a través de la modulación de señales ${ }^{37}$. Para ejemplificar esta transformación en el campo sonoro, Kepes emplea, entre otros ejemplos, la imagen de la transducción gráfica de unos ladridos de perro obtenida en los laboratorios Bell y las huellas de una frecuencia sonora conseguida en el laboratorio del MIT. ${ }^{38}$

La investigación llevada a cabo para The New Landscape se solapó en sus últimos años con el seminario Urban Form, un proyecto que comenzó en 1954 en el Center for Urban and Regional Studies del Massachusetts Institute of Technology. Dirigido por Kevin Lynch y György Kepes, el seminario tenía como objetivo estudiar la forma de la ciudad durante cinco años, y constituyó para Lynch la base de las teorías sobre planificación urbana discutidas en su

\footnotetext{
34. Ibid., 22. «Image-making is basic for art. It is basic for science, too, defining goals, delimiting fields for study and providing sense models which anticipate the corresponding fields for study and providing sense models which anticipate the corresponding scientific statements of order relations. On the image-making level, the difference between pre-scientific and pre-artistic perception of order is a difference of attitude, an attention to structure, on the one hand, to the felt quality of experience, on the other. There is no need for theses attitudes to exclude each other. Structures can be understood and qualities felt in a single, balanced perception order, in an experience which has characteristic of scientific and artistic activities both. This balance is also possible in complex levels; one and the same set of created symbols can evoke an intense emotional response to the richness of its sensed patterns and convey tan idea if logical structure.»

35. Ver Capítulo 1. Apartado 1.5.Vías de representación del sonido del paisaje.

36. Kepes, The New Landscape in Art and Science, 103.

37. Ibid., 173.

38. Ibid., 175.
} 
libro The Image of the City ${ }^{39}$.

Uno de los encuentros llevados a cabo para preparar el contenido del seminario consistió en una entrevista de Kepes y Lynch a John Cage. ${ }^{40}$ Este encuentro vuelve a conectar a Kepes y a Cage tras coincidir en la escuela de Moholy-Nagy trece años antes. Kepes y Lynch, al considerar la ciudad una experiencia fundamentalmente rítmica, plantean la posibilidad de diseñar el entorno urbano desde un enfoque sonoro, y se preguntan si los sonidos de la ciudad podrían controlarse y utilizarse para diseñar espacios urbanos agradables. En sus respuestas, Cage sostiene la idea de que una diversidad de sonidos es favorable y posible gracias a que en su experiencia confluyen el lugar, el movimiento y la tecnología:

Modern painting helps to make people aware of the city environment, even the most banal parts. Interest in sounds has the same effect, it introduces people to their environment. Interest in sounds has brought about a development in music; that of magnetic tape which can record any sound produced. One can also work directly with the machine, recording synthetic sounds and also the sounds of the city. Sounds alter in character when recorded from different places, i.e., rather than having musicians at one spot, one can have a situation in which sounds come from various directions or go continuously from low to high with respect to all their characteristics. This is a field situation rather than a series of discrete steps. Harmony in music did not arise from the physics of sound as was always assumed, but from convention. In the field situation one must take care not to set up discrete choices again. There are possibly six categories for sound: 1- city sounds; 2 - country sounds; 3 - synthetic sounds; 4- manually produced sounds; 5 -vocal or wind sounds; 6- sounds so quiet they have to be magnified to be in concert with others. ${ }^{41}$

Cage defiende en este encuentro el sonido como medio para conocer el entorno en profundidad, y por ello aboga por el disfrute de la incertidumbre y la aleatoriedad natural que aporta la complejidad del mundo frente a la idea de control de los sonidos urbanos propuesta por Lynch y Kepes, ya que todos los sonidos son para él una experiencia enriquecedora. Finalmente, la entrevista desemboca en la discusión del 'ritmo'. Un concepto que, para Cage, dada la revolución tecnológica de la época, se encontraba en un momento cambiante, pues consideraba que cada evento desarrollaba su propio ritmo. Así, Cage propugna la idea de continuidad frente a la fragmentación del tiempo, y aporta su visión de la música silenciada

39. Kevin Lynch (1919-1984). Urbanista. Entre los diferentes investigadores con los que trabajó, Lynch reconoce en el prefacio del libro la profunda influencia que Kepes tuvo en sus trabajos sobre planeamiento urbano. Cfr. Kevin Lynch, The Image of the City (Cambridge, Mass.: MIT Press, 1964).

40. Además, entrevistaron a James T. Farrell y Andreas Feiniger en tres ocasiones. Cfr. Charissa N. Terranova, Art as Organism: Biology and the Evolution of the Digital Image (Bloomsbury Publishing, 2015), 143.

41. Gyorgy Kepes, «Urban Form Seminar», 1954, http://dome.mit.edu/handle/1721.3/35673. 
para favorecer y ensalzar la escucha de los sonidos del entorno frente a la composición clásica.

Este segundo encuentro entre Cage y Kepes demuestra el interés por la exploración del entorno desde el sonido que, progresivamente, irá perfilando el camino hacia el paisaje sonoro a través de las corrientes artísticas de los años sesenta.

\section{I96I: Ritmo Eтc.}

György Kepes, siguiendo su método de investigación multidisciplinar, procedió a organizar una serie de seminarios para estudiantes de arquitectura sobre temas de interés común para científicos y artistas. Bajo un enfoque esencialmente estructuralista ${ }^{42}$, los seminarios dieron lugar a una colección de libros titulada Vision + Value, formada por siete volúmenes. En 1961, Kepes invita a John Cage a escribir un artículo en uno de los libros de la serie, Module, Proportion, Symmetry, Rhythm ${ }^{43}$, para el cual Cage aportará el ensayo Ritmo Etc.:

Traté de imaginar dónde había podido encontrar Kepes esa lista de temas (y por qué había pensado en pedirle a un músico que hablara de cuestiones referentes a la visión). Como vivía al lado de un aficionado a la arquitectura que estaba profundamente impresionado por Le Corbusier, caí en la cuenta y pensé que las palabras podían haber salido del libro de Le Corbusier, El Modulor. Corrí a la casa de al lado, cogí el libro, lo abrí. Efectivamente allí estaban todas las palabras, además de una explicación del amor de Le Corbusier por la música, todo lo cual me aclaró por qué a Kepes se le había ocurrido escribir a un músico. ${ }^{44}$

Influenciado por su amigo y compañero en la Black Mountain College, Paul Williams ${ }^{45}$, Cage utilizó su Cartridge Music ${ }^{46}$ para escribir un texto cuyas reglas internas de composición se

42. Ver Kepes, Supovitz, y Killian, Gyorgy Kepes, 13.

43. György Kepes, ed., Module, Proportion, Symmetry, Rhythm, First Printing edition, Vision + Value (New York: George Braziller, 1966).

44. Se ha trabajado con la versión traducida al castellano por Carmen Pardo en John Cage et al., Escritos al oído (Murcia: Colegio Oficial de Aparejadores y Arquitectos Técnicos de la región de Murcia : Consejería de Educación y Cultura de la Región de Murcia : Fundación CajaMurcia, 2007), 115-33.

45. Arquitecto, alumno de la Black Mountain College. Ver «Architecture at Black Mountain College», accedido 11 de junio de 2020, https://blackmountaincollegeproject.org

46. Cage hace referencia a su obra Cartdrige Music (1960). Mediante el uso del 'cartucho' en el que se inserta la aguja del tocadiscos (cartdrige), Cage propone en una serie de instrucciones colocar bajo el cartucho todo tipo de objetos y amplificarlos. Todos los sonidos deben ser amplificados y controlados por el intérprete o intérpretes. A cada intérprete se le otorgan veinte hojas numeradas en las que aparecen formas irregulares y cuatro transparencias (una con puntos, otra con círculos, otra con un círculo marcado como un cronómetro, y la última con una línea curva punteada, con un círculo en un extremo). Estas transparencias se superponen a una de las 20 hojas. Cada intérprete 
generaron mediante el azar:

O sea que llegué a instrucciones como la siguiente: de la línea 24 a la línea 57 , cuenta una historia que sea relevante para la proporción, habla de una idea acerca del ritmo, continúa esto con una idea que no tenga nada que ver con el equilibrio. ${ }^{47}$

En los párrafos 'libres' de Ritmo Etc. aparecen sentencias ligadas a la experiencia artística de Cage sobre las estructuras rítmicas macro-microscópicas, la posición central del sujeto en la percepción del acontecimiento, la relación de los espacios interiores con el espacio exterior ${ }^{48} y$ finalmente, sobre la estructura:

Lo que cambió la cuestión radicalmente fue la disposición a dejar de trabajar antes de que la estructura estuviera acabada. Después de eso ya no hubo ninguna estructura fija: solamente partes en cualquier cantidad, superposición y duración. El sentido del tiempo cambió. Ahora él dice: La permeabilidad del espacio con el sonido. ${ }^{49}$

Las reflexiones de Ritmo Etc. reflejan la influencia que los principios estéticos de la arquitectura del Gatehill Community ${ }^{50}$, a la que Cage se mudó en 1954. El vidrio ${ }^{51}$ representa para Cage la continuidad con el entorno, la permeabilidad y la contemplación del silencio frente a la fragmentación y la medida que impone el Modulor.

Esta tercera intersección entre Cage y Kepes cierra un período de transición en el que la ruptura con los modos de composición tradicionales y la ampliación de la percepción mediante el uso de cintas magnéticas, permiten interpretar el entorno como una estructura de fuerzas sensibles en las que el sonido se convierte en un medio para su estudio.

tendrá una partitura distinta. Este mismo procedimiento fue utilizado para crear este texto. «John Cage Complete Works», accedido 22 de abril de 2019, https://www.johncage.org/

47. Cage et al., Escritos al oido, 114.

48. «Y cuando llegue lo que aún no ha sido escuchado, jpodremos decir más o menos de lo que ahora acerca de la unidad y su relación con el todo? En el interior de ese espacio, abierto y sin embargo lleno como un plato que rebosa con sonidos a la vez suaves y aterradores, que suceden en puntos impredecibles no sólo del tiempo sino también por todo el espacio.» Ibid., 122.

49. Ibid., 125.

50. Cfr. Joseph, Experimentations, 120.

51. «Cuanto más vidrio, mejor, digo yo.» Cage et al., Escritos al oído, 123. 


\section{Cuadrado i. i967-i975: Maryanne Amacher, John Cage, György Kepes y Juan Navarro Baldeweg}

En el libro An Anthology ${ }^{52}$ (1963), el músico Henry Flynt acuñó la expresión 'arte conceptual' ${ }^{53}$ para denominar al 'arte' cuyo material es la relación entre los conceptos y el lenguaje. En su ensayo, Flynt se plantea qué cualidades son las que permiten identificar como arte al 'arte conceptual' y para ello, comienza a estudiar los antecedentes de los que proviene esta práctica: las matemáticas y las 'artes estructurales' (como la música o las artes visuales).

Moviéndose en el terreno musical, Flynt toma como ejemplos de 'arte estructural' el fenómeno musical de la fuga y la música serial, que ejemplifican a su vez los tipos de arte estructural que pueden encontrarse de acuerdo con la manera en la que se aprecia la estructura. En el caso de una fuga, escribe Flynt, el oyente es consciente de su estructura al escucharla. Es decir, encuentra una serie de relaciones mientras se produce simultáneamente la escucha de la pieza. Por el contrario, en la música serial, no es posible encontrar la estructura pues, según Flynt, esta solo permite ser analizada. Flynt, con sus ejemplos, ensalza la independencia de la estructura del medio a través del cual este se 'expresa'.

Desligando la estructura de la materialidad, el espacio del tiempo, el año 1961 inaugura el comienzo de la expansión de las artes ${ }^{54}$. Fue entonces cuando la relación entre materia y objeto evoluciona y trasciende la imagen estática para descubrir la experiencia, el evento y la instalación, en las que el arte mismo es la existencia de un proceso ${ }^{55}$. Esta circunstancia, trasladada al campo del arte sonoro, como explica Brandon laBelle, lleva la atención al espacio en el cual operan las fuerzas del propio espacio en el que se produce una instalación. Por tanto, el sonido se convierte al mismo tiempo en consecuencia y causa de una transformación del

52. Colección de partituras, poesía, y otros trabajos de vanguardia recopilados por George Maciunas. Muchos de los artistas que se incluyen en la recopilación (George Brecht, Dick Higgins, Alan Kaprow...) habían sido alumnos de Cage en la New School for Social Research. Ver capítulo tercero. Apartado 3.2. Paritura-evento.

53. Henry Flynt, «Concept art», en An Anthology, ed. La Monte Young y Jackson Mac Low (New York: Jackson Mac Low and La Monte Young, 1963). La primera versión del texto data de 1961. Cfr. "Essay: Concept Art», accedido 11 de junio de 2020, http://www.henryflynt.org/aesthetics/conart.html.

54. Expresión tomada del título de la exposición; \pm I96I La expansión de las artes, 19 de junio -28 de octubre de 2013. Museo Nacional Centro de Arte Reina Sofía, Madrid.

55. Cfr. Robert Morris, «Some Notes on the Phenomenology of Making: The Search for the Motivated.», Artforum, April. "What I wish to point out here is that the entire enterprise of art making provides the ground for finding the limits and possibilities of certain kinds of behavior and that this behavior of production itself is distinct and has become so expanded and visible that it has extended the entire profile of art. This extended profile is composed of a complex of interactions involving factors of bodily possibility, the nature of materials and physical laws, the temporal dimensions of process and perception, as well as resultant static images» 
espacio. $^{56}$

Con el desarrollo de las instalaciones, los happenings y los eventos a finales de los años sesenta, el sonido se refuerza como elemento espacial y ambiental a través de la instalación sonora. El espacio dejó de ser un objeto estático para convertirse en un instrumento vivo en relación directa con la arquitectura y el entorno. Gracias a las cintas magnéticas y a los micrófonos, fue posible desplazar sonidos de un lugar a otro, o mezclar el sonido de muchos lugares en uno solo creando una narrativa a partir de elementos dispares. Así, las conexiones relacionales y asociativas de la estructura sonora de un lugar se unificaban en la escucha empleando el sonido como medio artístico.

Las obras de artistas sonoros como Annea Lockwood, Bill Fontana, La Monte Young, Max Neuhaus, Maryanne Amacher o Bernhard Leitner centran su atención en un lugar concreto para crear situaciones a partir del sonido encontrado en un localización específica, natural o urbana. Los artistas se interesan entonces por el paisaje, que deja de ser representado como un objeto para constituirse como proceso artístico. De esta forma, el 'paisaje' se deconstruye (land-scape), y la acción creativa que se materializa en y con un paisaje, uniendo el cuerpo y el entorno natural en una misma experiencia estética, se bautiza como Land-art. En paralelo a la revolución provocada por los artistas Landart surgen, de la mano de la difusión generalizada de la tecnología sonora, la ecología acústica y las geografias sonoras a principios de los años setenta del siglo XX..$^{57}$ Estos movimientos emplearán los sonidos grabados de entornos naturales para hacer composiciones musicales o estudios acústicos. Así, progresivamente, la locución 'entorno sonoro' fue sustituida por el neologismo Soundscape.

En esta etapa, Geörgy Kepes y John Cage se unirán de nuevo a través de los artistas Maryanne Amacher y Juan Navarro Baldeweg, alumnos en el Center for Advanced Visual Studies (CAVS). La convergencia de los cuatro desvela el entendimiento estructural de un entorno dinámico a través del sonido.

56. Brandon LaBelle, Background noise: perspectives on sound art, Second edition (New York: Bloomsbury Academic, 2015), 51

57. Alan Licht, Sound art: beyond music, between categories (New York, N.Y: Rizzoli International Publications, 2007), 124. "Conceptual artist Les Levine has written "environment art can have no beginnings or endings" and likewise the sound artists sought the elimination of time. That the first generation of sound artists (...) emerged in the "60s and early '70s at the same time as the Earthworks and Lands artists cannot simply be coincidental. While Descartes may have thought that sound originates in the human ear, the invention of microphones and tape recorders proved, through the recording signal transferred to tape, that sound was most certainly an external phenomenon, as well as a universal and elemental force, like earth, light, water, or air.» 
i 967: Inicio de la Serie City-LinkS de Maryanne Amacher

Influenciados por las primeras obras de John Cage y el acceso a técnicas de grabación y reproducción 'domesticas', la generación de 'artistas sonoros' posterior a Pierre Schaeffer encontró en la acción de separar el sonido de su fuente de emisión un motivo estético. ${ }^{58}$ En el empleo de esta técnica destacó Maryanne Amacher (1938-2009), compositora estadounidense pionera en realizar instalaciones sonoras a gran escala. Su pensamiento y sus obras anticiparon la cultura de la hiperconexión contemporánea, el arte digital, la ecología acústica, y la interacción creativa entre arquitectura y sonido. Alumna de Stockhausen, Amacher colaboró con el coreógrafo Merce Cunningham y con el compositor John Cage, para quien creó un sonido de tormenta para su obra multimedia Lecture on the Weather. Durante más de treinta años trabajó en instalaciones de sonido en las que abordó la relación entre sonido y espacio, recurriendo a la experimentación con elementos arquitectónicos y con sistemas de amplificación y captación del ruido ambiental.

Entre 1967 y 1981, Maryanne Amacher produjo City-Links, un conjunto de veintidós proyectos en los que, conectando micrófonos dispuestos en lugares distantes y usando líneas telefónicas analógicas de frecuencia modulada, trabajó con el desplazamiento virtual del sonido de un espacio en tiempo real. Empleando esta técnica, hasta su estudio (o hasta museos como el Museo de Arte Contemporáneo de Chicago o la Hayden Gallery del MIT) llegaban los sonidos de centro de Buffalo, del puerto de Boston o del río Mississippi ${ }^{59}$ :

In my first sound works I developed the idea of sonic telepresence, pioneering the use of telecommunication in sound installations. In the telelink installations for "CITYLINKS" \#1-22 (1967-) the sounds from one or more remote environment (in a city, or in several cities) are transmitted in real-time to the exhibition space, as an ongoing sonic environment. I create the "CITY-LINKS" installations using real-time telelinks, transmitting the sounds from microphones which I place at the remote locations. [...]. The adventure is in receiving live sonic spaces from more than one location at the same time - the tower, the ocean, the abandoned mill. Remote sounding environments enter our local spaces and become part of our rooms. I created these works with many different

58. En paralelo a los no lugares sonoros, Robert Smithson plantea la visualidad de lo abstracto a través del sonido, repasando el recorrido de los transductores históricos (Edison, Scott, Bell...). Smithson concluye que el problema de la visión es, realmente, un problema lingüístico. Cfr. Robert Smithson, «The Artist as Site-seer; or, a Dintorphic Essay (1966-1967)», en Robert Smithson, the collected writings (Berkeley: University of California Press, 1996), 34045.

59. «Maryanne Amacher», accedido 15 de abril de 2019, http://act.mit.edu/cavs/person/ KuSTdtevcHYwcJtGmADnN9. 


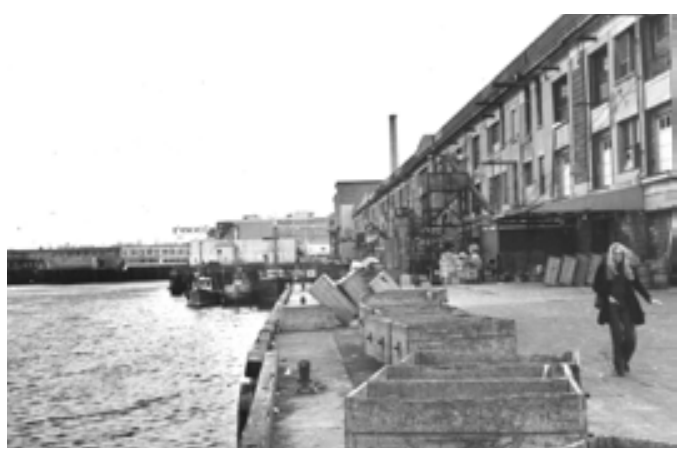

1) Pier 6, Boston Harbor

been receiving sound from 2. at Pier 6, Boston Harbor - acoustic space of this it CAvs where I listen to during time of sounding is installed, transmitting om the harbor. I hear the out being physically pre. lows for observations to din many conditions not ecording: hearing not tereis previpuatly con-

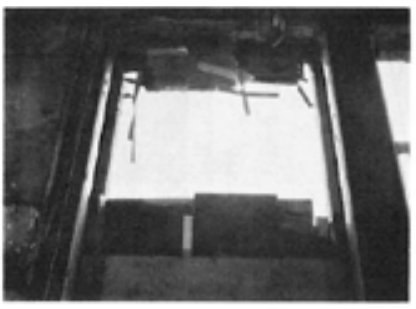

bringing interpretaticn to bringing in or than hearing by being it space while working. iming. impl cations about fuestioning the relevancy $x$, of present notion of esstur physical context tial mental constraints itating only the more rabits of tutoperception. pace over an extended g changing subjective nditions, letting place g subliminal impressions Cemaior concentrations otal of resonant tone in to is a frequency between
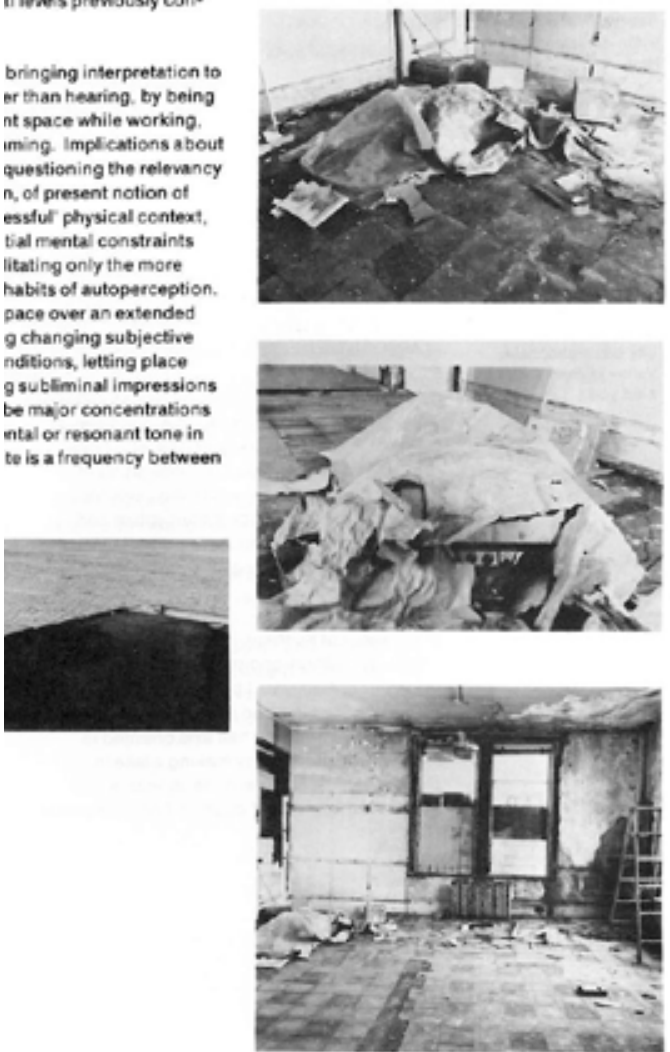

Figuras 73-74. Fotografía de Maryanne Amacher comprobando un micrófono en el puerto de Boston para su proyecto City Links (1974).

Figura 75. Publicación del proyecto City Links en Arttransition, CAVS, MIT (1975). 
sonic environments, harbors, steel mills, stone towers, flour milles, factories, airports, rivers, open fields, utility companies, and with musicians "on location." In my installations I was particularly interested in the experience of "syncronicity" - hearing spaces distant from each other at the same time-which we do not experience in our lives. Very often quite remarkable sonic events would all of a sudden occur at the same moment of time! I developed different ideas for each installation. ${ }^{60}$

El resultado de los proyectos City-Links son espacios virtuales únicos, donde dos o más lugares concurren en un único punto al mismo tiempo ${ }^{61}$. Persiguiendo el diálogo del sonido con la arquitectura, la espacialidad, y las situaciones ambientales, Maryanne Amacher concibe los sonidos del entorno como un instrumento para constituir un paisaje sonoro mental. Durante la escucha de la obra, Amacher describe que existe una doble lectura simultánea que involucra tres lugares. Por un lado, se escucha un lugar específico, se revelan los eventos sonoros de un lugar en un segundo emplazamiento que contiene sus propios sonidos; mientras que, al mismo tiempo, el sujeto que escucha es consciente de la existencia de un desplazamiento de un lugar para ubicarlo en otro, formando un tercero desplazado. En las obras de Amacher, el sonido se convierte tanto en una parte de la experiencia auditiva como en el material con el que construir un nuevo lugar. El oyente experimenta una intensificación de la experiencia que va más allá de la identificación de una situación ambiental, volviendo próximo lo lejano, convirtiendo el instante en duración, y los espacios públicos en privados. ${ }^{62}$

La dislocación basada en la esquizofonía, en la separación del sonido de su fuente original, planteaba la posibilidad de trascender el entendimiento del Soundscape más allá de la mera grabación de sonidos para subrayar su naturaleza espacial y 'medioambiental'. La tecnología hacía posible sumar los sonidos de dos o más lugares desplazados que al superponerse, crean un no lugar o, más bien, un lugar propio de cada sujeto. Otros artistas, como Bill Fontana ${ }^{63}$,

60. Documento que Amacher empleaba para sus presentaciones y publicaciones. Archivo Ars Electronica Maryanne Amacher, «CV Maryanne Amacher», s. f., https://calls.ars.electronica.art/media/ assets/14006af3fe7bec64d189b3f4a8bc2002.pdf. Verificado con la Fundación Maryanne Amacher.

61. John Cage explicará estos espacios en su entrevista con Daniel Charles: «D.C - Así, por un lado, las obras invaden el espacio, lo envuelven, y, por otro, el espacio viene de vuelta "en" las obras, se infiltra en el interior de las obras mismas. ; J.C: - Y, además, hay un espacio como consecuencia de la superposición de las obras, que acumulan sus espacios. Finalmente, no se trata de un espacio único: hay varios espacios, que tienden a multiplicarse unos por los otros.» John Cage, Para los pájaros (Alias, 2013), 161.

62. Cfr, LaBelle, Background noise, 197-99.

63. En sus obras, Fontanta no solo disloca el lugar, sino que también desplaza el tiempo. Bill Fontana (1949 -) es un artista estadounidense conocido internacionalmente por su trabajo experimental con el sonido. Discípulo de Cage y contemporáneo a Schaffer, considera el entorno físico como una fuente viva de información musical, con cualidades estéticas que pueden evocar imágenes visuales. Desde 1976, Fontana ha creado instalaciones de sonido en las que traslada el sonido ambiental de un lugar alejado del centro urbano hasta un emplazamiento específico 
usarán esta técnica para criticar las posiciones de la ecología acústica de Schafer y plantear la recodificación de un lugar a través de los sonidos que se producían en él en el pasado.

Los trabajos de Amacher, reconocida como una de las primeras artistas en emplear estrategias 'deformativas' del espacio junto con Westerkamp, Neuhaus y Leitner, impulsó una corriente de interés hacia el sonido ambiental y la ecología acústica que, unos años más tarde, se tradujo en el neologismo Soundscape en el World Soundscape Project iniciado por M. Schafer en 1970.

i 97 I-i 975: Centre for AdVAnCed Visual Studies. Punto de encuentro de G. Kepes, M. Amacher y J. Navarro Baldeweg

En 1967, György Kepes funda el Center for Advanced Visual Studies (CAVS) en el Massachusetts Institute of Technology. Un lugar en el que, rememorando el espíritu de la Bauhaus, artistas, científicos e ingenieros colaborarían en proyectos a gran escala en los que experimentasen con el entorno y los nuevos medios. ${ }^{64} \mathrm{El}$ centro tenía como objetivo conocer las posibilidades que podía ofrecer el empleo de las nuevas tecnologías como medio artístico, promover el interés por la escala urbana, incorporar en las propuestas los procesos y fuerzas naturales del territorio (la luz, el viento, el agua...), y, en definitiva, incentivar tanto la intensificación del mundo sensitivo infraindividual como el desarrollo de redes de comunicación

de la ciudad. Su propósito es agudizar la percepción del paisaje auditivo y sumergirse en la escucha de lo invisible, y explotar así la capacidad del sonido para obtener imágenes visuales a través de la memoria y el conocimiento, creando una tensión causada por la contradicción de lo que se oye y lo que no se ve. Ejemplo de este tipo de obras es Distant Trains (1984), una escultura de sonido que se instaló en el gran campo vacío de la que había sido una de las estaciones de tren más transitadas de Europa antes de la guerra, el Anhalter Bahnhof de Berlín. Una serie de altavoces fueron enterrados en el lugar donde se encontraba la estación. Al mismo tiempo, se colocaron ocho micrófonos en la estación de Colonia, una de las estaciones de tren más concurridas de Europa, reproduciéndose en Berlin, a tiempo real, los sonidos de la estación de trenes. El espacio acústico de Anhalter fue reconstruido cuarenta ańos después de su destrucción durante los bombardeos de la Segunda Guerra Mundial mediante el sonido de la actividad de la estación de Colonia, situada a 600 kilómetros y 45 años de distancia. Este tipo de obras de Fontana sirven para convocar regiones físicas e imaginarias donde los pensamientos discurren fácilmente, para atraer horizontes entrecruzados del mundo que nos envuelve y atraviesa. Mediante la conexión de dos entornos físicos separados a través de la escucha permanente, los micrófonos instalados en una ubicación transmiten su continuo de sonido resultante a otra ubicación, donde se pueden escuchar, permanentemente, como una superposición permeable al espacio visual. Aunque no se incluyen en la investigación, dado que queda fuera del marco temporal acotado, los documentos originales de la obra (memoria, planos, correspondencia, presupuestos...) han sido consultados presencialmente en el archivo del DAAD de Berlin. «DAAD Artists-in-Berlin Program», www.daad.de, accedido 11 de junio de 2020, https://www.daad.de/.Ver también: «Bill Fontana, essay, Sound As Virtual Image», accedido 15 de mayo de 2018, http://resoundings.org/Pages/sound\%20As\%20Virtual\%20Image.html.

64. Kepes, Supovitz, y Killian, Gyorgy Kepes, 13. 
recíproca entre el individuo y el medio ambiente. ${ }^{65}$

Maryanne Amacher, tras su paso por la Universidad de Illinois, ingresará como residente ${ }^{66}$ del CAVS en 1972, donde coincidirá con el arquitecto y pintor español Juan Navarro Baldeweg ${ }^{67}$ (1939- ). Becado por la Fundación Juan March e invitado por György Kepes, Navarro se había incorporado como becario de investigación del centro un año antes. Ambos reconocerán en sus biografías lo importante y fructífera que fue aquella etapa de sus vidas ${ }^{68}$, pues la visión global y multidisciplinar de Kepes conseguiría consolidar las intuiciones que tanto Navarro como Amacher habían alcanzado en sus primeros proyectos plásticos y sonoros.

Especialmente interesados en la arquitectura de la información, las estructuras dinámicas, la realidad virtual, la tele-tecnología e internet, Navarro y Amacher formaron parte de la comunidad de becarios que trabajaron en grupo e individualmente para alcanzar los objetivos del CAVS en sus proyectos. Las piezas de sombras, luz, magnetismo, tiempo y sonido de Juan Navarro Baldeweg recibirán la influencia del pensamiento sonoro de Amacher. ${ }^{69}$ Ambos colaborarán juntos en proyectos grupales del centro, como el proyecto del puerto de Boston, en el que una serie de propuestas sobre lugares específicos debían aumentar la experiencia urbana y la conciencia ecológica de sus habitantes.

Una de esas propuestas fue la instalación sonora Tone and Place (Work1) Pier 6, Boston Harbor realizada por Maryanne Amacher. Enmarcada dentro de su proyecto City-links, Amacher colocó un micrófono en una habitación frente al océano Atlántico en la lonja de Nueva Inglaterra (en el puerto de Boston), que transmitía el sonido del puerto hasta su estudio en el CAVS. Durante tres años, desde noviembre de 1973 y hasta 1976, Amacher pudo escuchar el espacio distante del puerto de Boston 'en directo' desde Chicago. Como describe en la memoria del proyecto ${ }^{70}$, escuchar día a día el espacio sin estar físicamente presente en el lugar, le permitió realizar observaciones a largo plazo que las grabaciones in situ no pueden aportar. El desplazamiento y la distancia posibilitan otro tipo de conclusiones que no son posibles cuando el oyente se encuentra inmerso en el espacio:

65. «CAVS History», accedido 22 de febrero de 2020, http://bit.ly/1p2RADq.

66. Residencia en el CAVS desde 1972hasta 1975.

67. Residencia en el CAVS desde 1971 hasta 1975.

68. Ver Navarro Baldeweg, Escritos, 277.; y «Ars Electronica Archiv», accedido 20 de febrero de 2020, http:// archive.aec.at/.

69. Ver capítulo 3. Apartado 3.3. Surtidores de signos.

70. CAVS, «Tone and Place (Work1) Pier 6, Boston Harbor», ed. Massachusetts Institute of Technology, Arttransition, 1975, 73, http://act.mit.edu/cavs/item/CAVS_Arttransition?image=884c09f1e98e. 

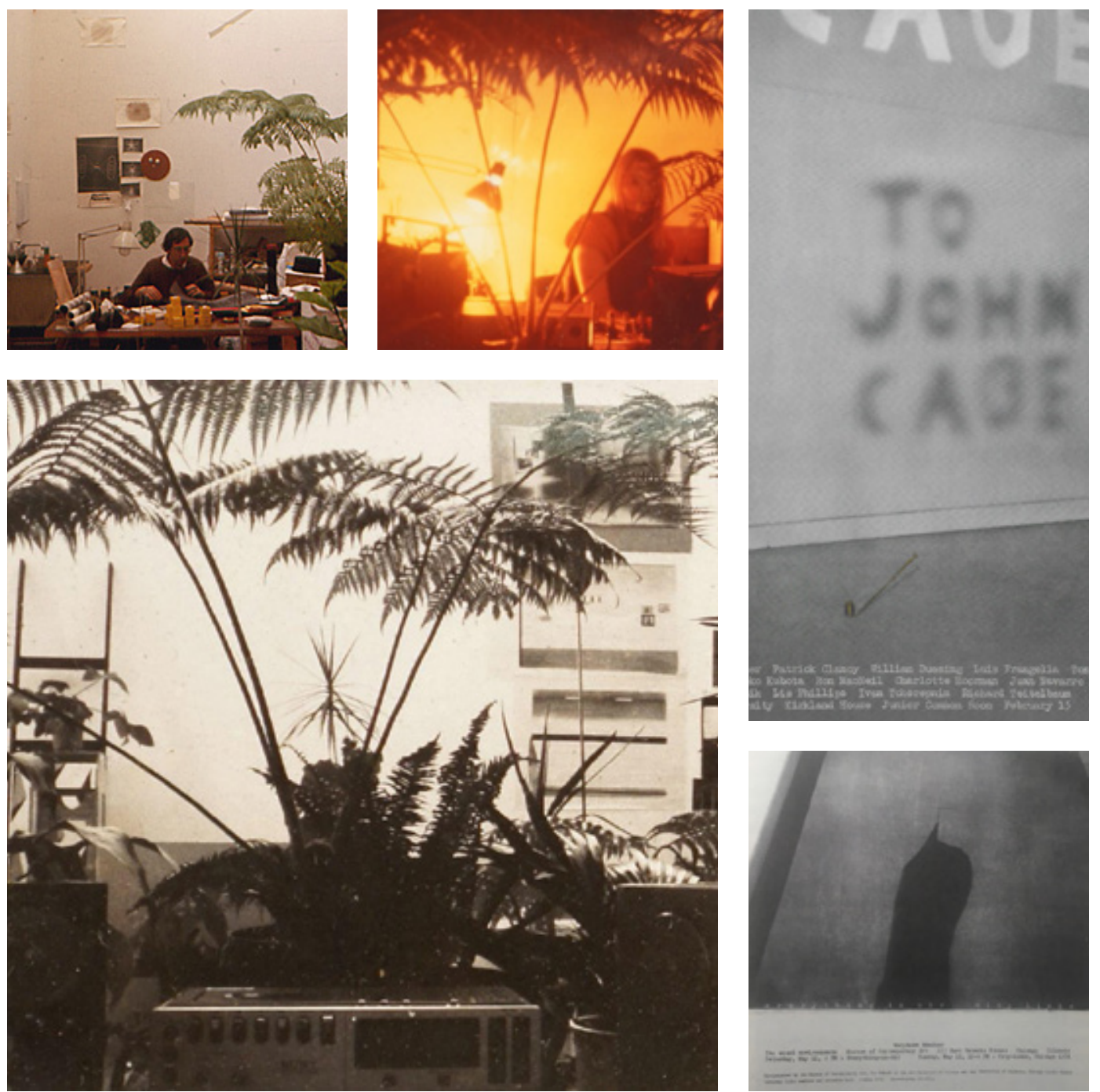

Figura 76. Juan Navarro en su estudio del Center for Advanced Visual Studies, MIT

Figura 77. Maryanne Amacher en el Center for Advanced Visual Studies, MIT

Figura 78. Juan Navarro Baldeweg, To John Cage. Cartel para concierto homenaje a John Cage (1974)

Figura 79. Estudio de Maryanne Amacher en el Center for Advanced Visual Studies, MIT

Figura 80. Juan Navarro Baldeweg, cartel para el concierto de Maryanne Amacher Everything in the air, city links (1974). 
The work has been in bringing interpretation to perceptual levels, other that hearing, by being present with the distant space while working, sleeping, talking, dreaming. Implications about tone of place appear, questioning the relevancy to essential perception, of present notion of distance, carrying 'stressful' physical context, with perhaps unessential mental constraints which seem to be facilitating only the more compulsive 'thought' habits of autoperception. 'Hearing' the distance space over an extended period of time, noticing changing subjective and environmental conditions, letting place sink in -ways of letting subliminal impressions surface- continue to be major concentrations in the work. Fundamental or resonant tone in the air of the harbor site is a frequency between 91 and 93 hz. $^{71}$

La incorporación de la noción de distancia, el espacio de la distancia descubierto a través del sonido del entorno, hace especialmente relevante la obra de Maryanne Amacher. Sus instalaciones se desarrollan en un período clave en el que el 'entorno acústico' progresivamente se transforma en 'paisaje sonoro'. Los desplazamientos sonoros de Amacher convirtieron el sonido de los lugares en un instrumento, y sus procedimientos sustentaron un modelo para investigar la profundidad acústica y la dimensión espacial de un lugar a través del sonido.

Además de los proyectos y exposiciones, Amacher y Navarro impartieron en el MIT junto a otros dos artistas del centro, Scott Fisher y Luis Frangella, el seminario titulado 'Live' Space ${ }^{72}$ durante el curso 74-75. El objetivo del mismo era investigar «exploraciones intersensoriales entre la visión estereoscópica y la dimensión auditiva» ${ }^{73}$. Como describe la memoria del curso, se trataba de explorar el 'espacio vivo' mediante la observación y la reproducción, de descubrir cómo la percepción a lo largo del tiempo hace próximo y lejano al mismo tiempo el sonido del entorno. Las After images, las resonancias psicológicas, la sintonización del cuerpo y del medio ambiente, la composición de imágenes mentales del espacio en el que se sumerge el oyente,

71. Ibid.

72. Mi agradecimiento a The Maryanne Amacher Foundation, quienes me facilitaron la documentación del simposio 'Live'Space: Maryanne Amacher at the Center for Advanced Visual Studies MIT. (Laboratorios Bell, NJ, Marzo 2018), y confrontaron la documentación empleada en este estudio. Bill Dietz, «maryanne.amacher.foundation@ blankforms.org», 25 de febrero de 2020. «The Maryanne Amacher Foundation - Blank Forms», accedido 20 de febrero de 2020, https://blankforms.org/the-maryanne-amacher-foundation/.

73. Contenidos del curso: «Cross-sensory explorations between stereo vision and auditory dimension. The making of stereo visual spaces for interior and outdoor environments. Exchange of 'live' space conditions through observation and reproduction. Perception over time -approach and disappearance of what is sounding in the environment. After images, physiological resonances. Tuning to the body, to the environment. Acoustic spaces of felt sound phenomena, experienced either subliminally, or making recognizably direct physical resonance to the body. Composite mental images of immersion space, as in stereo vision; direct physiological experience of an acoustic space, as distinguished from the perception of an acoustic space, aurally, as 'image' - patterns within air.» "Academic course catalog, MIT Center for Advanced Visual Studies, fall semester 1974», 6, accedido 21 de febrero de 2020, http://act.mit.edu/cavs/item/cavs_coursecat_F74?image=4260b3c06f7b. 
el reconocimiento de la resonancia física en el cuerpo, la 'auralidad como imagen'...todos los temas desarrollados en el curso tendrán una gran influencia en la obra posterior y los escritos teóricos de Juan Navarro Baldeweg, pues muchas de sus piezas incorporarán, de forma inversa, lo sonoro en lo visual.

Muestra de ello son dos piezas de sombra que Juan Navarro crea para dos conciertos en los que participaba Maryanne Amacher:

En una ocasión me encargó un póster para una de sus presentaciones musicales en Chicago. Dado que estaba entonces trabajando en un libro de sombras, pensé que el cartel podía ser una página de uno de estos libros de sombras. En la imagen vemos la sombra de una mano escribiendo una T: se ve la T dibujada y la sombra del brazo. Es una figura ambigua que orienta y precisa algo su definición al venir junto a la expresión escrita everything in air, city links, el título del concierto. De modo que la imagen de la letra T se asocia a algo que sobrevuela un territorio como un pequeño avión con una cola de humo. El cartel aludía a esa mancha espacial ilimitada, al transporte aéreo de una información sonora capaz de viajar entre ciudades distantes. ${ }^{74}$

El segundo cartel es otra pieza de sombra titulada To John Cage, realizada en febrero de 1974 para un concierto homenaje a John Cage en la Kirkland House de la Universidad de Harvard ${ }^{75}$. La fotografía de la sombra arrojada que produce sobre la pared el título escrito (To John Cage) con letras recortadas manualmente y colocadas sobre un cristal, buscaba la interposición del cuerpo humano como elemento de activación de la obra. ${ }^{76}$

Tanto los carteles como las piezas o surtidores de signos de Juan Navarro Baldeweg desarrollados en su etapa en el CAVS ${ }^{77}$, demuestran el efecto que los aspectos sonoros tuvieron en su obra plástica. La influencia recíproca entre Navarro y Amacher no se limita sólo a sus respectivas piezas y obras, sino que forma parte de la historia de la transgresión de la expresión artística sonora, pues fueron pioneros -arropados por Kepes-, en enfatizar el transvase de estructuras de un lenguaje espacial, propio del sonido, al de la imagen, y viceversa.

74. Navarro Baldeweg, Escritos, 288-90.

75. Programa del concierto en el archivo de la Fundación Bonotto: «Advertising flyer for the concert at Harvard University, Kirkland House. Black offset on white paper, 28 x 21.6 cm.», 1974, Fondazione Bonotto, https://www. fondazionebonotto.org/.

76. Ignacio Moreno, Dibujos mentales: Principios del universo creativo de Juan Navarro Baldeweg, Edición: 1 (Madrid: Ediciones Asimétricas, 2017), 181.

77. Ver capítulo tercero, apartado 3.3. Surtidores de signos. 


\section{I975: LECTURE ON THE WEATHER. AMACher, Cage y la eCOlogía aCÚstica}

En 1975, John Cage invita a Maryanne Amacher a componer una atmósfera de tormenta para su composición multimedia Lecture on the Weather, basada en los diarios de H. Thoreau. Luis Frangella, también alumno del CAVS, produjo la película que acompañaría la tercera parte de la obra durante su interpretación. La partitura del prefacio se compuso colocando dibujos de Thoreau sobre doce líneas de pentagramas musicales que sirven de notación gráfica para los músicos. Los dibujos de cada pentagrama están dispuestos en la estructura 5-7-5 características de un poema Haiku.

La actuación comienza con la lectura del prefacio de Cage. En él, expresa su consternación con las instituciones del gobierno americano ${ }^{78}$. A continuación, doce personas leen fragmentos de texto extraídos de los escritos de Henry David Thoreau. En la primera parte de la pieza, la lectura se acompańa de sonidos de brisa; en la segunda parte, de sonidos de lluvia; en la tercera y última parte, las luces del espacio se atenúan hasta la oscuridad, y los intérpretes están acompañados tanto por la película de Frangella como por los sonidos de truenos de Amacher.

Lecture on the Weather se enmarca dentro de las obras ecologicas de John Cage. Precedida por Etcétera (1973), en la que Cage incorporaba sonidos del exterior en la interpretación de la pieza en la sala, estas obras coinciden con los intereses de Amacher al incorporar el sonido 'en vivo' de un lugar a sus composiciones. Amacher creó también el entorno sonoro que acompañará otras obras como Empty Words, basada en Walden de Thoreau, o Close Up, una obra sonora para el ballet de Cunningham. La incorporación de los sonidos del entorno a la 'música' caracteriza estas obras en las que el sonido del exterior se convierte tanto en una parte de la experiencia como en el material con el que se realiza la composición. ${ }^{79}$

En paralelo y de la mano de M. Schafer se inicia en Canadá la ecología acústica, que promueve la escucha activa y la cultura de la sensibilidad hacia los sonidos de un lugar. A diferencia de las obras de Amacher, Neuhaus o Cage, que trabajan con el sonido de un lugar geográfico delimitado y específico, la ecología acústica sitúa el sonido en relación con la ecología del planeta. ${ }^{80}$ Es decir, entiende el sonido como un componente físico más, medible y modificable, desde una visión científica. El uso de la palabra 'ecología' tiene, por tanto, un sentido diferente

78. El prefacio es un discurso completamente actual en el que se hacen referencias constantes a la gestión de los recursos y al cambio climático. "JOHN CAGE: Lecture on the Weather - STREAMING MUSEUM», accedido 17 de noviembre de 2019, http://streamingmuseum.org/john-cage-lecture-on-the-weather/.

79. Amacher, «CV Maryanne Amacher».

80. Cfr. LaBelle, Background noise, 297-99. 

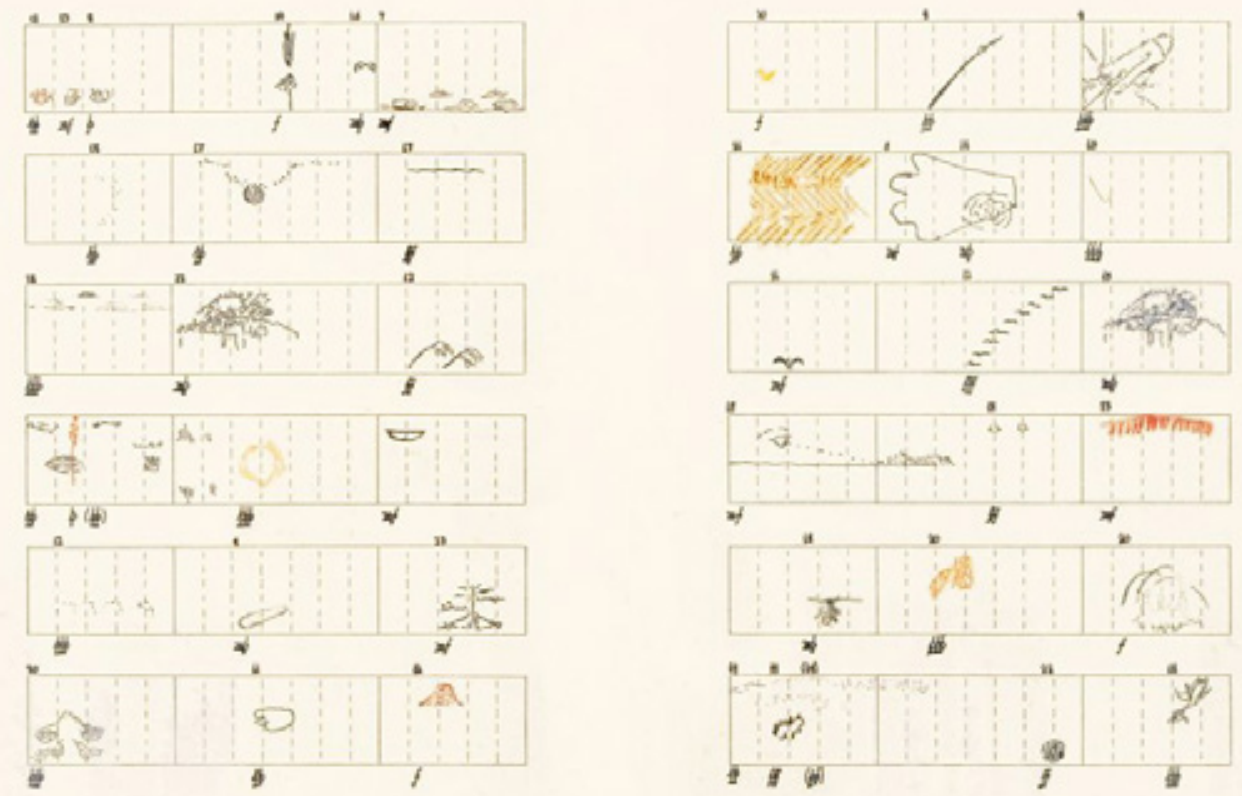

Figura 81. John Cage, Score without Parts (40 Drawings by Thoreau): Twelve Haiku (1978) 
en cada uno de los casos. La ecología acústica promovida por Schafer, pretende recopilar grabaciones de los sonidos del mundo con el fin de catalogarlo, de generar un archivo de sonidos grabados in situ. En el caso de las obras ecológicas de Cage, el sonido de un lugar tiene la capacidad, al incorporarse a una pieza, de producir transformaciones en el espacio de la escucha. El calificativo 'ecológico' hace referencia, en el primer caso, a la procedencia natural de los sonidos que se captan con medios de grabación. Pero, en el caso de Amacher y Cage, existe una complejidad mayor en el significado del término al incorporar la dimensión espacial que un sonido 'ambiental' produce al escucharlo.$^{81}$ Las obras ecológicas tratan de demostrar que el entorno acústico es algo más que una instantánea, y que el sonido sirve para situar al oyente dentro de una intensificación de la experiencia inmediata, más allá de su enfoque ambiental. ${ }^{82}$

\section{Cuadrado 2. I977-I989: Gilles Deleuze, Pierre Boulez, Paul Klee y John CAge}

La filosofía, el arte y la ciencia mantienen relaciones de mutua resonancia, relaciones de intercambio, pero por razones intrínsecas en cada caso. Unos repercuten en otros en función de su evolución propia. En este sentido, hay que considerar el arte, la ciencia y la filosofía como líneas melódicas ajenas unas a otras, pero que no dejan de interferirse. En este contexto, la filosofía no tiene ningún seudoprimado reflexivo ni, en consecuencia, ninguna inferioridad creativa. Crear conceptos no es menos difícil que crear nuevas combinaciones visuales, sonoras o nuevas funciones científicas. ${ }^{83}$

\section{G. Deleuze. Conversaciones}

Al igual que en Estados Unidos, la atracción por el estructuralismo y la semiótica en Europa fue decayendo para ser sustituida a finales de los años sesenta por lo que se denominó post-estructuralismo. Tras los acontecimientos de mayo de 1968, una nueva generación de filósofos franceses (Derrida, Foucault, Deleuze, Nancy, Lyotard...entre otros) construyen el

81. «El aspecto de la naturaleza del que hoy tenemos idea -y esa idea es casi penosa- es le de que nosotros, como especie humana, hemos puesto en peligro la naturaleza. Hemos actuado contra ella, nos hemos rebelado contra su existencia. En consecuencia,, hoy debemos preocuparnos por devolverle el sitio que le es propio. Y la naturaleza no consiste en una separación del agua y el aire, del cielo y de la tierra, etcétera, sino en un "trabajo-conjunto", o un "juego-conjunto" de esos elementos. Es lo que llamamos ecología. La música, tal como la concibo, es ecología. Podría llegar más lejos y decir: ES ecología.» Cage, Para los pájaros, 289.

82. LaBelle, Background noise, 197-99.

83. Gilles Deleuze, Conversaciones, trad. José Luis Pardo Torio, Edición: 1 (Valencia: Editorial Pre-Textos, 1995), 199. 
pensamiento moderno en el que confluyen el arte, la filosofía y la ciencia.

Siguiendo la estela de la tradición acusmática francesa, en 1970 el presidente de la República Georges Pompidou crea el Institut de Recherche et Coordination Acoustique/Musique IRCAM $^{84}$. Un centro de creación musical y laboratorio acústico de música electrónica asociado al Centro Nacional de Arte y Cultura Pompidou que se inauguró en 1977 bajo la dirección de Pierre Boulez. El IRCAM fue uno de los primeros centros que fusionó la investigación sonora, la composición musical y la acústica espacial en un edificio que marcó un hito técnico, pues cuenta con espacios de dimensiones variables, como el Espace de projection, con techos y paredes móviles. ${ }^{85}$

El IRCAM será el primer lugar de encuentro entre el filósofo Gilles Deleuze (1925-1995) y el compositor Pierre Boulez (1925-2016). Admiradores el uno de la obra del otro, la influencia del pensamiento de Boulez en Deleuze quedó registrado en las constantes alusiones hacia el músico que aparecen en sus escritos ${ }^{86}$. Tanto la filosofía de Gilles Deleuze -en solitario o junto con Félix Guattari- como la obra de Boulez estuvieron influenciadas por numerosos artistas como Mallarmé, Joyce, Proust o Messiaen. John Cage también es mencionado por ambos, a menudo empleado como ejemplo para explicar el silencio y la ruptura con los modelos de música tradicionales. Además, tanto Boulez como Deleuze reconocieron su profunda admiración por el artista Paul Klee, sirviéndose de su obra para explicar a través de ella sus teorías.

Las líneas melódicas a las que hacía referencia Deleuze en la cita que abre este apartado, forman los lados y diagonales de la tercera figura que compone el plano cartesiano de referencia que sirve de guía en este capítulo. Un cuadrado en el que la diagonal entre Deleuze y Boulez estructura el pensamiento sobre el tiempo y su representación, y donde aparece por primera vez en este recorrido histórico el concepto paisaje sonoro formulado desde las variables temporales que contiene. Se considerarán una serie de encuentros que ligaron personal e intelectualmente a Gilles Deleuze y Pierre Boulez: el curso Sobre la música (1977) de Gilles Deleuze, el seminario Le Temps Musical (1978), el ensayo Ocupar sin contar: Boulez, Proust y el tiempo (1986) y el libro Le Pays Fertile (1989). Los cuatro puntos se exponen cronológicamente para visibilizar el progreso de la influencia mutua que compartieron Boulez y Deleuze.

84. «IRCAM», accedido 19 de marzo de 2019, https://www.ircam.fr

85. Proyecto de Richard Rogers y Renzo Piano. 1971-1977 (construcción del edificio de los laboratorios). Cfr. Rogers Stirk Harbour + Partners + redbox, «IRCAM - Rogers Stirk Harbour + Partners», accedido 11 de junio de 2020, https://www.rsh-p.com/projects/ircam/.; «RPBW - Ircam», accedido 11 de junio de 2020, http://www.rpbw. $\mathrm{com} /$ project/ircam.

86. Entre ellos: Conversaciones, El pliegue, Leibniz y el Barroco, Foucault, Mil Mesetas y ¿Qué es la filosofía? 
i977: Sobre la música. Seminario de Gilles Deleuze en la Universidad de VINCENNES

Entre 1970 y 1987, Gilles Deleuze formó parte del claustro de la Universidad experimental de Vincennes, una institución creada tras los disturbios intelectuales y pedagógicos que siguieron la estela de Mayo del 68.

Como describe en su texto Cómo puede la filosofía servir a los matemáticos e incluso a los músicos, incluso y sobre todo cuando no trata de música ni de matemáticas ${ }^{87}$, Vincennes apostaba por la democratización y la apertura al conocimiento. ${ }^{88}$ Un profesor de filosofía podía tener como alumnos a matemáticos, músicos o historiadores, pues aunque la materia impartida no les pudiera ser familiar, la audiencia acudía en busca de la apropiación del conocimiento ajeno. Una circunstancia en sintonía con el proceder de Deleuze, quien consideraba que «la enseñanza de la filosofía se orienta directamente a la cuestión de saber cómo puede la filosofía servir a los matemáticos, a los músicos, etc., incluso y sobre todo cuando no trata de música ni de matemáticas» ${ }^{89}$.

En 1977 Deleuze impartió el curso titulado Sobre la música en la Universidad de Vincennes. En él, a través de las preguntas de su amigo y compositor Richard Pinhas ${ }^{90}$, planteaba una serie de cuestiones centradas en el concepto de tiempo que, partiendo del dominio musical, desembocaban en problemas comunes a otras disciplinas. En aquellos años, en los que se encontraba dando forma su libro Mil Mesetas junto a Félix Guattari, Deleuze se interesa principalmente por la diferenciación entre el tiempo pulsado y el tiempo no pulsado. Dos expresiones que toma directamente de las teorías de Pierre Boulez presentadas en el libro Pensar la música hoy.

Años antes, en 1961, Pierre Boulez había impartido una serie de conferencias en la escuela de Darmstadt con la intención de ser publicadas. De ahí surgió Pensar la música hoy, donde Boulez quería promover una teoría de la serie generalizada aplicable a otros ámbitos, no solo

87. Gilles Deleuze, Dos regimenes de locos. Textos y entrevistas (Valencia: Editorial Pre-Textos, 2008), 157-58.

88. Para Deleuze "una clase es una especie de materia en movimiento musical, donde cada grupo toma lo que le conviene. Todo no conviene a cualquiera. Un curso es emoción. Si no hay emoción, no hay inteligencia, ningún interés, no hay nada". Abecedario de Deleuze, citado por François Dosse y Sandra Garzonio, Gilles Deleuze y Félix Guattari: Biografía cruzada (Buenos Aires [etc.: Fondo de Cultura Económica, 2009), 459.

89. Deleuze, Dos regimenes de locos. Textos y entrevistas, 157.

90. Richard Pinhas es músico y compositor francés. Amigo cercano de Deleuze, transcribió sus cursos y conferencias en la página webdeleze.com, que recoge textos inéditos, como el curso Sobre la música de 1977. Tras contactar con él por correo electrónico, certificó la autoría de las traducciones en francés. Los cursos, a partir de 1978, se encuentran en el registro de la TGB de París, pero las cintas de 1977 no se conservan. 
al musical, y fijó su empeño en definir «las características del universo sonoro sobre el que ésta [teoría] ha de regir» ${ }^{91}$. Boulez consideraba que el pensamiento musical de la época debía revisar los tipos de espacio y de tiempo que se utilizaban en la música de la segunda mitad del siglo XX. Para ello tendrían que romper la rigidez clásica que primaba en estos aspectos y promover una variabilidad de los espacios que fuera acorde a la complejidad de las estructuras y a los avances técnicos que los nuevos movimientos traían consigo. Motivado por este fin, Boulez definirá el espacio liso y el espacio estriado ${ }^{92}$, y de forma análoga y respectiva, el tiempo pulsado y el tiempo amorfo. La diferencia fundamental entre el tiempo pulsado o estriado y el tiempo amorfo o liso es el producto resultante de su variación en el tiempo. ${ }^{93} \mathrm{Si}$, en relación con el tiempo cronométrico, se aumentan el número de pulsaciones, de cortes en él mismo, en consecuencia se incrementa la densidad del tiempo. Por tanto, el tiempo estriado es susceptible a la aceleración o a la deceleración cuando se altera su medida. Sin embargo, el tiempo amorfo no se mide en distancias, sino en la intensidad de los acontecimientos que suceden en él. O lo que es equivalente, se medirá según su índice de ocupación.

91. Pierre Boulez, Pensar la música hoy (Murcia: Colegio Oficial de Aparejadores y Arquitectos Técnicos de la Región de Murcia : Consejería de Educación y Cultura de la Región de Murcia : Fundación Cajamurcia, 2009), 125.

92. Boulez parte del estudio de las variables del espacio sonoro: a) la complejidad y densidad de la estructura; b) el encadenamiento, la repartición o superposición de los fenómenos sonoros, que permitirán diferenciar o no los intervalos; c) la velocidad (y en consecuencia, el tiempo), con el que se desarrollan las figuras; d) La proporción de intervalos entre sí. La cuestión del intervalo, de la medida, resulta fundamental para definir dos tipos de espacio: los espacios lisos y los estriados. El espacio liso es el punto de partida. Explicado desde la metáfora, el espacio liso es equiparable a un cielo sin estrellas. Una dimensión donde no existen referencias de medida, donde la percepción no encuentra el principio o el final, pero cuyo crecimiento y movilidad es posible a través de fuerzas. Si al espacio liso se le impone una medida, una serie de cortes, el espacio se convierte en estriado, y por tanto, la percepción puede captar intervalos, ritmos y distancias. En función de los cortes que se precisen en una superficie idealmente lisa, un espacio estriado puede convertirse en liso y viceversa. Uno y otro se refunden en el recorrido continuo. Como explica Boulez: «basta con disponer en un espacio liso intervalos que observen proporciones sensiblemente iguales para que el oído los conduzca a un espacio estriado; del mismo modo, empleemos intervalos muy poco semejantes, en proporciones, en un espacio estriado, la percepción los desvinculará de su temperamento, para instalarlos en un espacio liso: hay en los dos casos pregnancia de la disposición, del accidente, con relación al principio organizador.» La discusión sobre la precisión del intervalo y el corte viene impulsada por el desarrollo de la experimentación en magnetófonos y la posibilidad de mezclar sonidos en un "laboratorio de sonido". Debido a ello, Boulez (recordemos que era matemático) lleva la teoría al límite literal, más próximo a la tendencia hacia el infinito de las indeterminaciones y el cálculo diferencial aplicado a lo audible. Hasta cierto punto, se cuestiona la validez práctica de este pensamiento, dado que la percepción limitada a un cierto rango de frecuencias del oído humano no nos permite diferenciar entre un tono y otro variado ligeramente en un laboratorio. Por ello, los escritos de Boulez deben leerse desde la abstracción, el análisis y la imaginación.

93. El tiempo pulsado lo equipara con la superficie estriada (las estructuras de la duración se referirán al tiempo cronométrico, en función de un sistema de marcas o de referencias que pueden ser a su vez regulares o irregulares); mientras que el tiempo amorfo lo identifica con una superficie lisa (no se refiere a un tiempo cronométrico, sino a las duraciones). 
Tomando como base el tiempo estriado y amorfo de Pierre Boulez, Deleuze plantea en el curso Sobre la música de Vincennes el problema del tiempo en la música, diferenciando entre el tiempo pulsado y el tiempo no-pulsado ${ }^{94}$, y explica la diferencia entre ambos a través de la idea de 'territorio':

Cronos, Aión, es una noción que tiene toda una historia en la historia de la filosofía. Cronos, de manera general es el tiempo cronológico, como dicen los griegos, Cronos es el número del movimiento; Aión también es el tiempo, pero es un tiempo menos simple de comprender. El tiempo pulsado es del orden de Cronos, nuestra pregunta en general es: ¿̨hay otro tiempo? Por ejemplo el tiempo no pulsado, [...]. Propongo volver a partir de la noción misma de pulsación para que intentemos tener un tiempo de partida claro. Si intento decir que un tiempo es pulsado, no es evidentemente su periodicidad: hay pulsaciones irregulares. No es, entonces, a nivel de una regularidad cronométrica que podría definir el tiempo pulsado o Cronos. [...], yo identifico Cronos y tiempo pulsado, entonces Cronos no es la regularidad, no es la periodicidad. [...]Me propongo decir que usted tiene un tiempo pulsado cuando usted se encuentra siempre frente a tres coordenadas. Basta que haya una de las tres. Un tiempo pulsado, siempre es un tiempo territorializado, regular o no, es el número del movimiento del paso que marca un territorio: jrecorro mi territorio! Puedo recorrerlo de mil maneras, no forzosamente en un ritmo regular. Cada vez que recorro o frecuento un territorio, cada vez que asigno un territorio como mío, me apropio de un tiempo pulsado, o pulso un tiempo. Yo diría que la forma musical más simple del tiempo pulsado, no es el metrónomo, no es una cronometría cualquiera, es el ritornelo, a saber esa cosa que no es todavía música, el pequeño ritornelo. El ritornelo del niño, puede tener un ritmo relativamente complejo, puede tener una metronomía, una metrología irregular, es tiempo pulsado porque es fundamentalmente la manera como una forma sonora, por simple que sea, marca un territorio. Cada vez que haya marcaje de un territorio hay pulsación del tiempo. El catastro es una pulsación del tiempo. ${ }^{95}$

Materializando la imagen del espacio ligado al tiempo pulsado, Deleuze desvela los principios que conformarán junto a Guattari el ensayo del Ritornelo ${ }^{96}$, y al igual que Boulez juega con el repliegue constante de lo liso y lo estriado, Deleuze hará lo mismo con las operaciones de territorialización y desterritorialización ${ }^{97}$. Cómo convertir un tiempo pulsado en no pulsado será

94. Deleuze no toma literalmente los términos de Boulez, pues sustituye el tiempo amorfo o liso por lo que considera un nuevo tiempo, el no-pulsado.

95.Sesiones de marzo de 1977. Transcripciones y traducciones en: «Webdeleuze», accedido 26 de febrero de 2020, https://www.webdeleuze.com/textes/184.

96. Gilles Deleuze y Félix Guattari, Mil mesetas: capitalismo y esquizofrenia, 5. ed, Pre-Textos Ensayo 94 (Valencia: Pre-Textos, 2002), 317-58.

97. Ver capítulo tercero, apartado 3.5. Ritornelo. 
otro de los puntos que desarrolle en este curso:

$\mathrm{Si}$, a partir de una forma de fuertes propiedades intrínsecas, usted arranca partículas informales, que sólo tienen entre ellas relaciones de velocidad y lentitud, de movimiento y de reposo, usted ha arrancado al tiempo pulsado un tiempo no pulsado. ¿Quién hace algo así? Hace un momento yo decía que es el músico quien desterritorializa el ritornelo, él hace tiempo no pulsado desde ese momento, y sin embargo conserva el tiempo pulsado. ¿Quién arranca partículas de una forma? Inmediatamente digo que los físicos, ellos no hacen más que eso con sus máquinas, [...]: fabrican tiempo no pulsado. ¿Qué es un ciclotrón? Digo jocosamente que no tengo ni idea. ¿Qué son esas máquinas? Son máquinas de arrancar partículas que sólo tienen velocidades diferenciales, al punto que a ese nivel particular, no llamaremos a eso velocidades, las palabras serán otras, pero no es nuestro asunto, ellos arrancan a las formas físicas partículas que sólo tienen relaciones cinemáticas, cuánticas, la palabra es tan bonita, y que se definen por velocidades, velocidades extremadamente complejas. Un físico pasa su tiempo haciendo eso. ${ }^{98}$

El curso terminará haciendo referencia a John Cage y a Pierre Boulez para tratar de definir el silencio. Frente a la no-definición de Cage ${ }^{99}$, para quien el silencio es el entorno, Deleuze sí considera posible su definición como un elemento creador que forma parte de la máquina musical $^{100}$. El entorno es, para Deleuze, el afuera de la máquina, donde no existe el silencio ${ }^{101}$. Dos visiones, una por abolición y otra por incorporación, que llamará la atención de uno de los asistentes al curso: el sobrino de Pierre Boulez ${ }^{102}$. A través de él, Boulez contactará con Deleuze para proponerle participar en el seminario sobre el tiempo que se celebraría en el IRCAM al ańo siguiente.

\section{8. «Webdeleuze». \\ 99. Ver nota 50. Capítulo segundo. \\ 100. Ver capítulo tercero, apartado 3.5. Ritornelo.}

101. En torno a la cuestión del silencio planteada en el curso de Vincennes, Deleuze le contesta a su asistente haciendo referencia a Boulez: «En el movimiento de la territorialidad tenemos el ritornelo, con el ruido del entorno, en la máquina musical tienes todo tipo de elementos en relaciones variables, y uno de los productos de esos procesos de desterritorialización, es el silencio. Para responder a la pregunta: ¿podemos definirlo, o no?. Yo no diría ni como Richard, ni como tu, yo diría que se puede definir perfectamente el silencio, pero solo al interior de la máquina musical. En el texto de Boulez que citas, la tendencia a la abolición es plenamente un componente de la máquina musical y una tendencia a la abolición de otra naturaleza sería completamente diferente, no tendría ninguna relación con esta abolición muy especial que es la abolición sonora. Entonces, para Boulez, esta abolición forma parte, íntegramente, de la máquina musical.» «Webdeleuze».

102. "It was after his return to Paris in 1977 that Boulez first came into contact with Deleuze, though the auspices of his nephew, who attended the philosopher's seminar at Vincennes. Boulez recalls how Deleuze approached him, with a view to participating in the IRCAM seminar on 'Time', which he [Boulez] was organizing in 1978.» Edward Campbell, Boulez, music and philosophy, Music in the twentieth century 27 (New York: Cambridge University Press, 2010), 141-42. 
I978: El Seminario Le TempS musical. Deleuze, Boulez y el paisaje sonoro

En febrero de 1978, Pierre Boulez organizó en el IRCAM un taller titulado Le temps musical, que consistió en cinco sesiones públicas -en las que él mismo analizaba pasajes y fragmentos específicos de cinco obras ${ }^{103}$, y un debate de clausura para doscientos asistentes ${ }^{104}$. Este último encuentro sirvió para recapitular las ideas sugeridas en las reuniones de planificación previas a la realización del taller ${ }^{105}$ por cuatro compositores ligados al IRCAM (Gerald Bennett, Luciano Berio, Michel Decoust y Jean-Claude Risset) y tres filósofos (Roland Barthes, Gilles Deleuze y Michel Foucault).

Deleuze, impulsado por el espíritu transdisciplinar de Vincennes y ante la convocatoria de expertos ajenos al mundo musical, inicia su disertación preguntándose ¿Por qué nosotros, que no somos músicos? Su intervención le sirve para continuar perfilando sus inquietudes personales ${ }^{106}$ sobre el tiempo musical, anteriormente esbozadas en el seminario Sobre la música. Dejando las obras seleccionadas por Boulez en un segundo plano, Deleuze vuelve a preguntarse en qué consiste el tiempo no pulsado. En su respuesta ofrecerá una lectura del concepto paisaje sonoro de gran trascendencia para esta investigación, pues rompe con la definición 'ecológica' dominada por el término 'entorno' y empleada hasta ese momento con mayor frecuencia:

Hay cierto tipo de individuación que no remite a un sujeto [Moi], ni si quiera a una combinación de forma y materia. Un paisaje, un acontecimiento, una hora del día, una vida o un fragmento de vida...proceden de otro modo. Tengo la impresión de que el problema de la individuación en música, que sin duda es muy complicado, pertenece más

103. Obras seleccionadas: Concierto de cámara de György Ligeti, Diálogo del viento y el mar de Claude Debussy, Modes de valeur et d'intensité de Olivier Messiaen, A Mirror on Which to Dwell de Elliott Carter y su propia obra Éclat. «Sons Dessus Dessous \#18 - Musical Time», accedido 16 de marzo de 2019, https://www.ircam.fr/article/ detail/sons-dessus-dessous-18-le-temps-musical/. Sobre las cinco obras, apuntará Deleuze: «En el caso concreto del ciclo escogido por Boulez, el perfil particular del tiempo no pretendía en absoluto agotar la cuestión del tiempo musical en general. Se veía cómo, a partir de un tiempo pulsado, se liberaba una especie de tiempo no pulsado, incluso aunque este tiempo no pulsado se convirtiese en una nueva forma de pulsación.» Deleuze, Dos regímenes de locos. Textos y entrevistas, 149.

104. Cfr. Campbell, Boulez, music and philosophy, 139.

105. La sesión se encuentra en internet dividida en tres partes. Además, existen múltiples transcripciones de la misma. Se ha trabajado con la versión en castellano publicada en Gilles Deleuze, "Hacer audibles fuerzas que en sí mismas no lo son», en Dos regímenes de locos. Textos y entrevistas (Valencia: Editorial Pre-Textos, 2008), 149-52.

106. La intervención de Deleuze resulta ser controvertida. Los asistentes, en su mayoría jóvenes, interrumpen a Deleuze y se quejan de la poca claridad del discurso. No logran entender nada. Boulez les recrimina su 'ignorancia' y Deleuze continúa leyendo su ensayo. La lectura del curso Sobre la música, resulta fundamental para entender las cuestiones de fondo abordadas en Le temps musical por Deleuze, al igual que ambos encuentros son necesarios para interpretar del Ritornelo. 

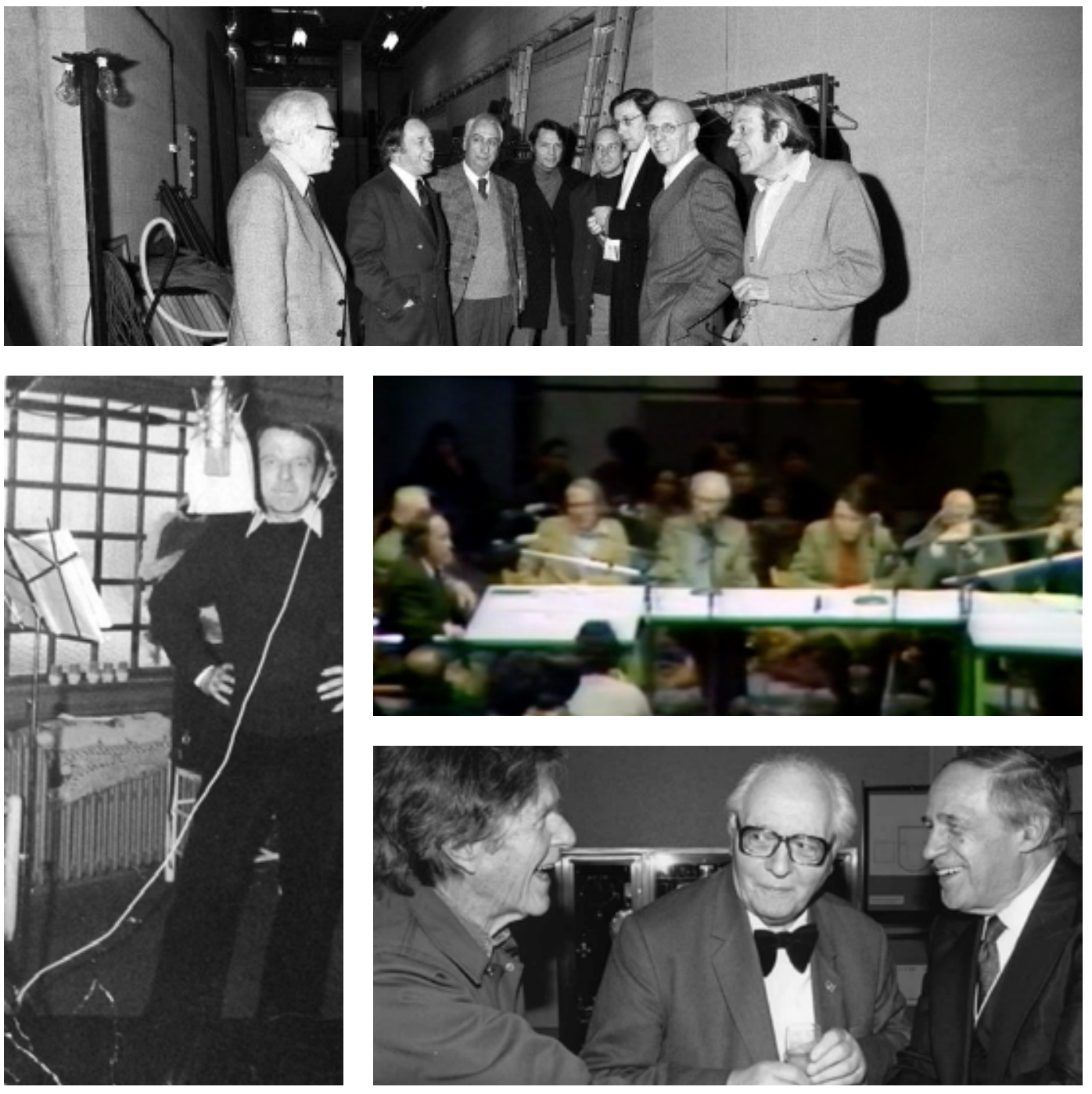

Figura 82. Seminario Le temps musical. De izquierda a derecha: Elliott Carter, Pierre Boulez, Roland Barthes, JeanClaude Risset, Gerald Bennett, Michel Decoust, Michel Foucault, Gilles Deleuze. París, 23 de febrero de 1978 Figura 83. Le temps musical. 23 de febrero de 1978. Fotograma de la sesión Figura 84. Gilles Deleuze durante la grabación del tema Le Voyageur del grupo Schizo (1972)

Figura 85. John Cage, Olivier Messiaen y Pierre Boulez en el Festival de música contemporánea de Huddersfield (1989) 
bien a este tipo secundario de individuaciones paradójicas ${ }^{107}$.

Para entender la complejidad del tiempo no pulsado, Deleuze describe la relación que pueden establecer un paisaje, un color y un personaje de una ópera con el sonido. Tres realidades no musicales que en su estado natural se encuentran regidas por el tiempo cronológico (el tiempo pulsado). El sonido, por asociación o por sinestesia, puede establecer una relación de correspondencia con una imagen, de tal forma que es capaz de evocar un paisaje, un color, o en el caso concreto de las óperas de Wagner, puede asociarse a un personaje. Los tres casos ejemplifican una relación materia-forma donde la materia (el sonido, la música) se convierte en forma (un paisaje, un color o un personaje), en base a una jerarquía construida desde lo simple hasta alcanzar lo complejo a través de una escucha.

El incremento de la complejidad del material sonoro que Deleuze aprecia en obras electroacústicas como Éclat de Boulez o en Dialogue du vent et de la mer de Debussy, le llevan a pensar que esa nueva complejidad permite hacer que fuerzas que aparentemente no son sonoras (como el tiempo, la duración o la intensidad), llegan a sonar o hacerse audibles gracias al material que las transforma en apreciables. ${ }^{108}$ En consecuencia, en todo ese mundo de sonidos complejos, el par 'simple' materia-forma es sustituido por el par 'complejo' material-fuerza, el tiempo pulsado se transforma en tiempo no pulsado, y el paisaje, los colores y los personajes de Wagner se convierten respectivamente en paisajes sonoros, colores audibles y personajes rítmicos a través del sonido.

Como advierte Deleuze, para aclarar la complejidad de la transformación, en el caso del paisaje sonoro «no se trata de que un sonido remita a un paisaje sino de que la propia música implica un paisaje estrictamente sonoro que le es interior» ${ }^{109}$. Sucede lo mismo con los colores o los personajes de la ópera:

Podemos considerar ciertos motivos asociados con un personaje exterior, pero los motivos de Wagner no se conforman con asociarse a un personaje exterior sino que se transforman, tienen una vida autónoma en un tiempo flotante y no pulsado en el que llegan a ser ellos

107. Deleuze, «Hacer audibles fuerzas que en sí mismas no lo son», 150.

108. Un ejemplo de la aplicación práctica de esta teoría es el estudio de los agujeros negros a través del sonido de la astrofísica Janna Levin. Aunque resultase imposible (pues la propagación sonora sería inviable en el espacio), Levin recrea mediante el sonido la hipotética muerte de un agujero negro en el Cosmos o el momento en el que un agujero negro engulle a otro. Este modelo ayuda a entender (y a visualizar) tanto la acción en sí, como la intensidad y la velocidad de la misma. Janna Levin, Janna Levin: El Sonido Del Universo, accedido 3 de mayo de 2020, https://www. ted.com/talks/janna_levin_the_sound_the_universe_makes?language=es.; Janna Levin, Black Hole Blues, Edición: Reprint (New York: Random House USA, 2017).

109. Deleuze, Dos regímenes de locos. Textos y entrevistas, 151. 
mismo, por sí mismos, personajes interiores a la música. ${ }^{110}$

$\mathrm{Al}$ igual que en la ponencia de Vincennes, donde tomaba el ejemplo del ciclotrón, Deleuze acude ahora a otra disciplina ajena a la filosofía y a la música para entender las velocidades y fuerzas del tiempo no pulsado y explica cómo los biólogos se enfrentan a un problema análogo cuando estudian la hererocronía de la evolución. En biología se perciben cambios físicos que no son cronológicos, sino que están ligados a los ritmos y a la velocidad con la que se producen esos cambios. Esto le lleva a Deleuze a pensar la música en términos moleculares, y asume que el tiempo pulsado implica magnitudes como la velocidad, la intensidad, las frecuencias y los cambios de ritmo implícitos en una fuerza:

Entonces, la música ya no es solamente cosa de los músicos, en la medida en que el sonido ya no es su elemento exclusivo y fundamental. Su elemento es el conjunto de las fuerzas no sonoras que el material sonoro elaborado por el compositor llega a hacer perceptibles, de tal manera que incluso podrán percibirse las diferencias entre esas fuerzas, todo el juego diferencial de sus fuerzas. ${ }^{111}$

El desplazamiento de la música a la física justifica la pregunta inicial con la que Deleuze comenzaba su discurso para concluir defendiendo el abandono del par materia-forma en la música y en todos los dominios. Deleuze propone en su discurso dejar de pensar en términos de materia y forma, dejar de creer en la jerarquía que parte de lo simple para llegar a lo complejo, y abrir una vía de entendimiento de lo complejo desde lo complejo para hacer sensibles, audibles o pensables unas fuerzas que de suyo no lo son. Se trata de un pensamiento imposible, que en su mención al paisaje, desvela cómo a través del sonido puede superarse la evocación a la forma y entender así que es el propio sonido el que puede contener un paisaje. El paisaje sonoro se convierte entonces en un 'material complejo' que requiere un 'pensamiento complejo', de una escucha diferente, más profunda, que es entendimiento.

Las ideas musicales desarrolladas por Deleuze en los seminarios Sobre la música y Le temps musical, se concretarán finalmente en el ensayo del Ritornelo, publicado en 1980 en su obra Mil Mesetas, escrita conjuntamente con Félix Guattari.

110. Ibid.

111. Ibid., 151-52. 
i 986: OCUPAR SIN CONTAR: BOULEZ, PROUST Y EL TIEMPO

Unos años más tarde, en 1986, con motivo de la conmemoración del sexagésimo cumpleaños de Boulez, Deleuze contribuirá a la antología titulada Éclat/Boulez ${ }^{12}$ con un ensayo titulado Ocupar sin contar: Boulez, Proust y el Tiempo. Este breve ensayo, al mismo tiempo que resume los postulados de Boulez, evidencia la influencia y admiración que se profesaron mutuamente. El compositor señaló que su artículo sobre Wagner El tiempo re-explorado ${ }^{113}$ fue el punto de partida para las reflexiones del filósofo sobre el tiempo musical ${ }^{114}$ y que fue más tarde cuando surgió una conexión entre ellos ${ }^{115}$. Mediante la descripción de la relación de Boulez con Proust, Deleuze reincide en el análisis de los tiempos pulsado y no pulsado para lograr una mayor precisión en la definición de sus características:

Hay que entender la velocidad y las variaciones de velocidad. Los bloques de duración. Los bloques de duración "comportan velocidades y lentitudes, aumentos y disminuciones, sumas y restas, son inseparables de relaciones métricas y cronométricas que definen visibilidades, conmensurabilidades, proporcionalidades: la "pulsación" es un mínimo común múltiplo (o un múltiplo simple), y el "tempo" es la inscripción de cierto número de unidades en un tiempo determinado. Es un espacio-tiempo estriado, un tiempo pulsado, puesto que las rupturas son determinables en él, es decir, son de tipo racional (primer aspecto del continuo), y las medidas, sean regulares $o$ no, se determinan como magnitudes entre rupturas. [...]. Pero de lo estriado se desprende a su vez un espacio-tiempo liso o no pulsado, que ya no se remite a la cronometría más que de forma global: las rupturas son en él indeterminadas, de tipo irracional, y las medidas son sustituidas por distancias y proximidades indescomponibles que expresan la densidad o la rareza de lo que aparece (reparto estadístico de los acontecimientos). Un índice de ocupación sustituye al índice de velocidad. Aquí es donde se ocupa sin contar para ocupar ${ }^{116}$.

Deleuze vuelve a las conferencias recogidas en Pensar la música hoy, y profundiza en el problema de la percepción y la memoria. El problema del arte y la creación, escribe Deleuze, es la percepción, y al ser la música pura presencia ${ }^{117}$, esta reclama una percepción ampliada:

Ampliar la percepción quiere decir hacer sensibles, sonoras (o visibles), fuerzas

112. Pierre Boulez, Pierre boulez eclats (Paris: Editions du Centre Pompidou, 1992).

113. Le Temps re-cherché se publicó en el libro-programa del festival de Beirut de 1976. Cfr. Pierre Boulez, Orientations: Collected Writings (Harvard University Press, 1990), 260.

114. Cfr. Edward Campbell, Music After Deleuze (A\&C Black, 2013), 171.

115. Cfr. Campbell, Boulez, music and philosophy, 142.

116. Deleuze, Dos regímenes de locos. Textos y entrevistas, 265.

117. Ibid., 266. 
ordinariamente imperceptibles. Sin duda, esas fuerzas no necesariamente son el tiempo, pero se entrecruzan y se unen con las del tiempo. "El tiempo, que normalmente no es visible..." Percibimos fácil y, a veces, dolorosamente lo que está en el tiempo, percibimos también la forma, las unidades y relaciones de la cronometría, pero no el tiempo como fuerza, el tiempo mismo, "un poco de tiempo en estado puro". Hacer del sonido el intermediario que hace sensible el tiempo, que hace perceptibles los Números del tiempo, organizar el material para captar las fuerzas del tiempo y hacerlo sonoro. ${ }^{118}$

Ocupar sin contar remarca la función del sonido como revelador de fuerzas y el papel del músico como la máquina que "captura y hace sensibles las fuerzas del tiempo».

\section{9: Le pays fertile. Consideraciones musicales sobre la obra de Paul Klee por Pierre Boulez}

El último punto de este cuadrado centra su atención en Le pays fertile (1989), el libro que recopila las conferencias que impartió el compositor francés Pierre Boulez en el Centro Pompidou con motivo de la exposición Klee et la Musique ${ }^{119}$ (1985). En ella se expusieron algunas de las obras del pintor Paul Klee (1879-1940) desarrolladas siguiendo ciertos 'valores del sonido' (módulo, timbre, tono, ritmo, movimiento...).

El interés de Boulez por Klee proviene de la relación entre música y pintura que estableció el artista suizo. Mientras otros se limitaban a hacer una 'traducción' gráfica, Klee intentó aplicar las riquezas de la música a otros modelos de expresión, estudiando y transportando las estructuras que pertenecen a un orden invisible y transitorio (el de la música y el sonido), a otro visible y concreto (el de la pintura y el dibujo). Boulez corroboró sus propias ideas estudiando las clases, experimentos visuales, dibujos y esquemas de Paul Klee, quien, según Boulez, no tenía una visión servil de la música, sino que buscaba cierta objetividad en la expresión de la misma.

D'autres peintres ont tenté ce genre de «traduction » graphique de la musique [...]. Mais s'agit-il pour Klee de parvenir à une simple "traduction" ? Non point, c'est bien plutôt une tentative c'appliquer les richesses de la musique à un autre mode d'expression, d'étudier et

118. Ibid., 268.

119. Exposición Klee et la musique, 10 de octubre de 1985 - 1 de enero de 1986. Centre Georges Pompidou, Paris; y Paul Klee und dir Musik, Schirn-Kusthalle Frankfurt, 14 de junio- 17 de agosto de 1986. Collectif, Klee et la Musique -Catalogue Exposition - Centre Georges Pompidou, Musée National d'Art Moderne - Paris - 1985 (Paris: Editions du Centre Pompidou, 1992).; Bettina Zeller et al., Paul Klee und die Musik (Berlin: Nicolaische Verlagsbuchhandlung, 1986). 
de transposer ses structures. ${ }^{120}$

Los análisis gráficos que realiza Klee del pensamiento y los medios de escritura de Bach ${ }^{121}$ o Mozart advierten de la peligrosa relación que se establece habitualmente entre el ojo y el oído. La tendencia a quedar seducido por el interés estético ${ }^{122}$ puede llevar a la banalización del proceso de transducción de un lenguaje en otro, pues, como señala Boulez, una línea melódica puede dar como resultado una transcripción visual bella, pero a la inversa, «una admirable curva traducida en notas podrá darnos una línea melódica banal.» ${ }^{123}$

On le voit, Klee ne s'attache nullement à établir un parallélisme strict, qui a d'ailleurs de très limitations, entre le monde des sons et celui de la vue. Si quelque leçon doit être apprise de lui, c'est que les deux mondes ont leur spécificité et que la relation entre eux peut être seulement de nature structurale. ${ }^{124}$

Boulez expone en su discurso varias situaciones espacio-temporales que deben considerarse en el estudio de la transducción de estructuras sonoras. Se destacan cuatro casos, considerados relevantes para la representación del concepto paisaje sonoro: la movilidad de la escucha, la perspectiva múltiple, la representación de las fuerzas y la correspondencia entre el espaciotiempo sonoro y el pictórico.

\section{Movilidad de la escucha}

Boulez rescata los elaborados fondos de algunos cuadros de Klee con el fin de explicar la movilidad del espacio que provoca el sonido. Boulez toma como ejemplo Wald bei G, obra que se descompone en dos elementos: un fondo informe y una figura precisa dibujada en línea negra sobre él. Si se elimina el dibujo a línea del primer plano del cuadro, aparecen tras él cientos de matices luminosos sin una direccionalidad evidente, incapaces de fijar la atención

120. Pierre Boulez, Le pays fertile: Paul Klee (Paris: Gallimard, 1989), 36. "Otros pintores lo que hacen es una "traducción" gráfica de la música [...] ¿pero se trata para Klee de una simple traducción? No es así, es más bien un intento de aplicar las riquezas de la música a otros modelos de expresión, de estudiar y trasportar estructuras.» Traducción de la autora.

121. Klee tiene un intento de transcripción de una de las sonatas para violín de Bach. Es, en este contexto, una transposición gráfica literal. Ibid., 56.

122. Cfr. Ibid., 97-98.

123. Ibid., 53. Traducción de la autora.

124. Ibid., 38, 44. "Como podemos ver, Klee no atribuye ninguna importancia al establecimiento de un paralelismo estricto, que también tiene limitaciones muy fuertes, entre el mundo del sonido y el de la vista. Si hay alguna lección que aprender de él, es que los dos mundos tienen su especificidad, y que la relación entre ellos puede ser solo de naturaleza estructural.»Traducción de la autora. 

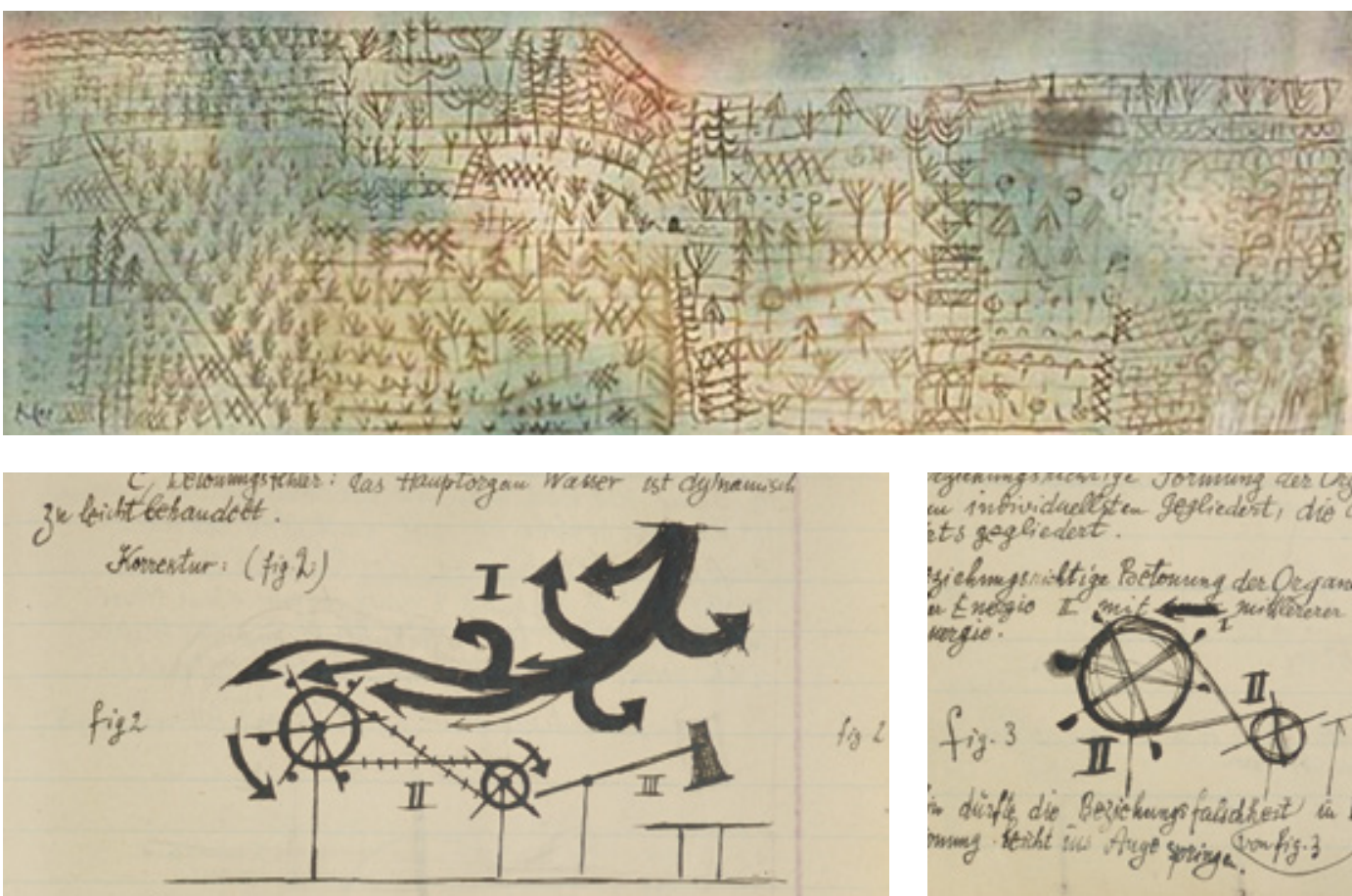

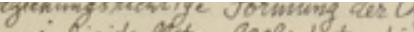
un invidueltstem gegliedest, die its gegliedert.

Gichneys ittige Retoreng der Oegan Exeyio 1 mit

argie:

fig. 3

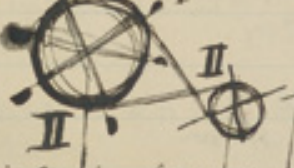

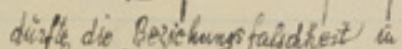

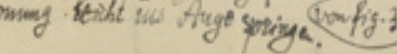

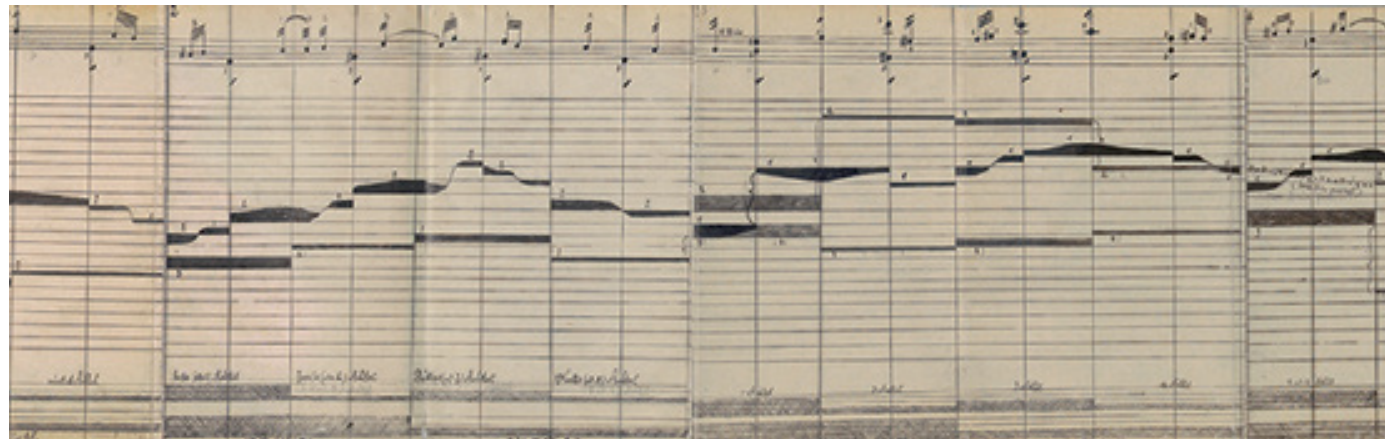

Figura 86. Paul Klee. Wald bai G(1925)

Figuras 87-88. Paul Klee. El molino de agua. Curso del 27 de febrero de 1922, p. 89

Figura 89. Paul Klee. representación gráfica de los primeros compases del Adagio de la sexta sonata para violín y clavicordio, BWV 1019/4, de Johann Sebastian Bach. Curso del 16 de enero de 1922, p. 53 
del espectador en un único foco. Un fenómenos equiparable, dirá Boulez, a lo que ofrece una nube en su constante movimiento en el cielo:

Quand in regarde un nuage, le regard épouse et suit la mobilité du nuage, mais devant un fond de Klee la mobilité est dépendante de la façon dont on le regarde, qui fait que l'espace s'oriente ou se désoriente au gré de ce que veut celui qui regarde. ${ }^{125}$

En contraposición a la multiplicidad fluctuante del fondo, Klee dibuja un trazo negro preciso sobre él. Una forma que moviliza la visión en una única dirección. El aprendizaje que Boulez desprende de estas obras fondo-figura, es que la música cambia de apariencia según el instante, lo que impide su entendimiento como algo fijo. Lo que Klee logra plásticamente, Boulez intenta reproducirlo en su música, siendo consciente de que el oído se encuentra en un punto fijo y que es el sonido lo que le va a permitir una movilidad virtual. Esta idea la equipara al fondo orquestal sobre el que se introduce el solo de un instrumento a un volumen mayor. ${ }^{126}$ De forma análoga, la inmersión en un paisaje supone la apreciación de una nube de estímulos, y es el sujeto quien procesando la potencia de los sonidos, la proximidad o la familiaridad con su tono, selecciona los impulsos sonoros predominantes, dibujando una percepción única en cada instante. ${ }^{127}$

\section{Percepción de las fuerzas}

Boulez destaca la capacidad analítica de Paul Klee basándose en los esquemas pedagógicos que realizó en la Bauhaus, la mayoría publicados en Das bildnerische Denken. ${ }^{128}$ En ellos, Klee no copia la naturaleza, sino que busca su estructura a través del dibujo. Boulez rescata el esquema del funcionamiento del molino de agua para mostrar cómo simboliza Klee los movimientos y la dinámica del artefacto mediante el empleo de flechas que indican fuerzas, direcciones e intensidades. ${ }^{129}$

Tanto en los esquemas como las obras pertenecientes al periodo de cuadros con flechas, Klee

125. Ibid., 166. «Cuando miramos una nube, la mirada espera y sigue su movimiento, pero delante de un fondo de Klee, la movilidad depende de la forma como miremos, que hace que el espacio se oriente o se desoriente en función de lo que queramos ver.» Traducción de la autora.

126. Ibid., 168.

127. Parte de este capítulo ha sido publicado como avance de la investigación. Ver Covadonga Blasco Veganzones, «Sobre la dimensión sonora del paisaje. La representación del "paisaje sonoro" a través de intermediarios espaciales", Constelaciones: Revista de arquitectura de la Universidad CEU San Pablo, n. 6 (2018): 63-74.

128. Ver recopilación de esquemas en Paul Klee, Pädagogisches Skizzenbuch, Faks.-Nachdr., 3. Aufl., Neue Bauhausbücher (Mainz [etc.]: F. Kupferberg, 1981).

129. Análisis de este esquema en Boulez, Le pays fertile, 151-53. 
fija una función dinámica en la inmovilidad del dibujo, representando «una estructura en la que pueden mostrarse las tendencias autónomas de procesos morfológicos abiertos» y elaborando, como observa Navarro Baldeweg, «una casuística de auténticas epifanías de mundos posibles, coherentes con unos principios físicos y orgánicos de su invención» ${ }^{130}$.

Los esquemas pedagógicos de Paul Klee abstraen el funcionamiento de una estructura espacial compleja (desde el movimiento de músculos y huesos, hasta la relación de la Tierra con el Universo) para convertirlas en estructuras puramente lineales. Klee genera así un modelo de comportamiento dinámico, un espacio que hace posible otros espacios.

\section{Perspectiva múltiple}

El desarrollo del multi-perspectivismo de Klee dentro de las artes visuales fue consecuencia de la aplicación de sus conocimientos musicales ${ }^{131}$ a la pintura. Motivado por ello, quiso alcanzar la idea de polifonía gráficamente expresando varias dimensiones lineales simultáneamente. Los dibujos y pinturas polifónicas y perspectivistas de Klee se conciben con la intención explícita de proporcionar a la vista la multiplicidad captada por el oído en la polifonía de la música tradicional. ${ }^{132}$

Boulez repara de nuevo en los estudios pedagógicos de Klee e investiga sobre la perspectiva en sus estudios visuales. Como describe Boulez, Klee propone a sus alumnos imaginar un juego de perspectivas múltiples, de perspectivas que se desplazan según un punto del cuadro en el que se sitúa un observador imaginario. Combinando operaciones de superposición de planos horizontales y verticales posicionados en diferentes niveles, Klee convierte la perspectiva tradicional (estática y con un punto de fuga), en múltiple y dinámica, transformando el espacio fijo en un espacio móvil en tres dimensiones. Klee enseña a sus alumnos cómo la modificación de la altura del ojo del espectador, o de las proporciones entre altura y horizonte, consiguen convertir un centro fijo en un centro que se desplaza por el espacio del dibujo. ${ }^{133}$

Ejemplo de esta técnica es Zimmerperspective mit Einwohnern ${ }^{134}$ (1921), en el que se

130. Navarro Baldeweg, Escritos, 41.

131. El padre de Paul Klee era profesor de música, y su madre había estudiado canto. A los siete años, Paul Klee comenzó a tocar el violín y tocó música de cámara durante toda su vida. Su mujer, Lily era pianista. «El universo musical de Paul Klee, con motivo de la exposición "Paul Klee: maestro de la Bauhaus":» (Fundación Juan March, abril de 2013), http://www.march.es/musica/musica.asp.

132. Campbell, Boulez, music and philosophy, 211.

133. Boulez, Le pays fertile, 55,64.

134. Perspectiva una habitación con sus habitantes. 


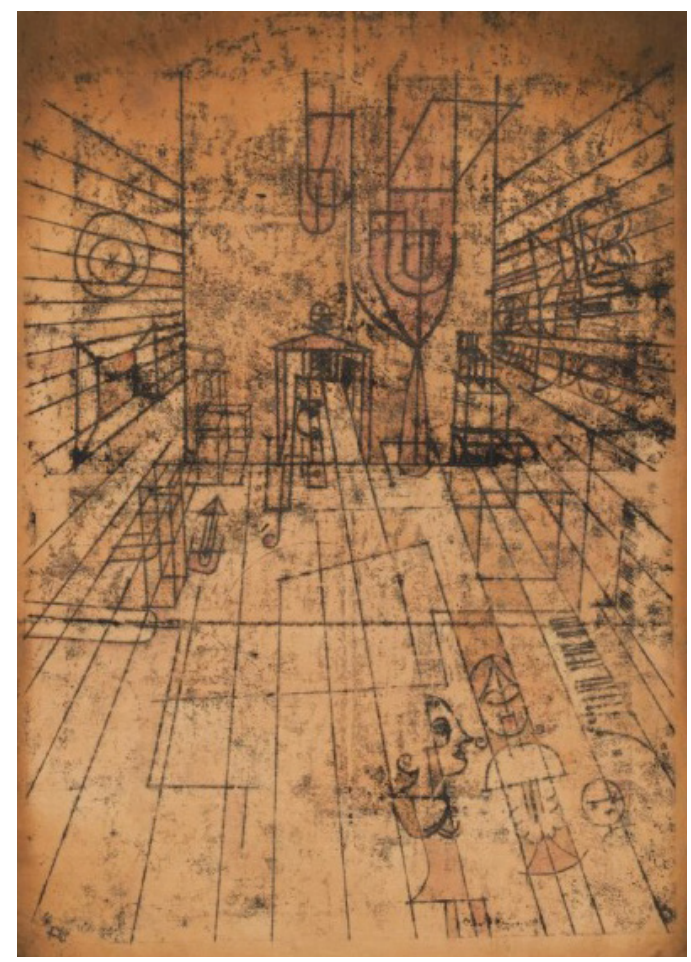

Figura 90. Paul Klee, Zimmerperspective mit Einwohnern (1921) 
superponen verticalidad y horizontalidad, dando como resultado una representación conjunta del espacio y del movimiento. Para Boulez, este mismo principio puede encontrase de forma equivalente en la música, sobre todo en la orquestal, en la que un mismo objeto musical se ofrece desde diversas perspectivas sonoras, dando lugar al tejido acústico armónico en el que se producen cambios de sentido y de tiempo. Pensando inversamente en cómo puede escribirse la música para obtener una perspectiva múltiple a través del sonido, Boulez rememora las partituras de Schönberg o Debussy. 'Dibujos' que define como espacio - temporales, puesto que en ellos se superponen el tiempo y un objeto auditivo o acústico en el espacio. ${ }^{135}$

\section{Tiempo y espacio en la música y la pintura.}

Impossible de ne pas citer la célèbre phrase de Wagner dans Parsifal: « Der Raum wird hier zur Zeit» [sic] (L'espace ici devient temps). Les deux notions que recouvrent ces termes sont-elles comparables? Suffit-il de changer de paramètre pour tirer les mêmes conclusions $s^{\prime}$ agissant de musique ou de peinture? ${ }^{136}$

Boulez vuelve a revisar el tiempo liso y estriado sosteniéndose en la pintura de Klee para abordar el gran problema al que se enfrenta el músico: la confusión del espacio y el tiempo. ${ }^{137}$ Tiempo y espacio, dice Boulez, podrán organizarse de forma análoga, haciendo irregular la pulsación (en el caso del tiempo) o el módulo ( en el caso del espacio) con el fin de desorientar la percepción. Ese reparto irregular de divisiones no funciona igual en lo sonoro que en lo gráfico, y la forma de percibir espacio y tiempo, por lo tanto, contiene más diferencias que similitudes.

Cuando se observa un cuadro, se perciben de un vistazo sus límites y su totalidad ${ }^{138}$. En música, sin embargo, la percepción del tiempo y del módulo, está fundamentada en un instante que no puede ser renovado. Si bien la vista permite apreciar el espacio global de un cuadro, en música la visión global solo será posible cuando una obra termina; es el instante, o al menos,

135. Boulez, Le pays fertile, 72.

136. Ibid., 102. «Es imposible no citar la célebre frase de Wagner en Parsifal: "Der Raum wird hier zur Zeit” (el espacio aquí deviene tiempo) ¿Las dos nociones que envuelven estos términos son comparables? ¿Basta cambiar de parámetro para ofrecer las mismas conclusiones sobre la música o la pintura?» Traducción del autor. La frase que cierra la escena uno del acto primero de Parsifal, en todas las obras consultadas, es "zum Raum wird hier die Zeit.", por lo que la transcripción de Boulez da lugar a una interpretación inversa ("el espacio se convierte en tiempo", en lugar de "el tiempo se convierte en espacio"). La traducción de la frase en español puede encontrarse, a propósito del análisis de las sinfonías de Mahler, en Eugenio Trías, El canto de las sirenas: argumentos musicales, Serie Ensayo (Barcelona: Galaxia Gutenberg : Círculo de Lectores, 2007), 412.

137. Boulez, Le pays fertile, 102.

138. Ibid., 84-86. 
la relación de un instante con otro instante lo que realmente se aprecia. En consecuencia, como deduce Boulez, «la reconstrucción de la obra en su globalidad es una reconstrucción imaginaria.[...]. La síntesis solo puede hacerse después virtualmente.» ${ }^{139}$

La reconstrucción virtual de un todo reclama, por tanto, el empleo de la memoria auditiva, aquella que interviene en la percepción de la música y que está vinculada al instante. Si frente a un cuadro, los tiempos de reflexión son los propios de quien mira, marcados por el sujeto de forma activa, escuchar una pieza de música se produce en un tiempo pasivo, en el que solo si el sujeto conoce la pieza previamente, puede lograr un reconocimiento de la globalidad antes de que termine la obra. Esta memoria retroactiva que desencadena una globalización virtual previa, permite una reconstitución totalmente provisional que se anula o modifica gracias a la escucha. El oyente va así de reconstrucción en reconstrucción, y el conocimiento en profundidad de la obra facilita la continuidad de estas reconstrucciones esporádicas. ${ }^{140}$

Para Boulez, tiempo y espacio no desempeñan las mismas funciones ni tienen las mismas propiedades en la música que en la pintura. Pueden ser similares, pero a la vez ser totalmente diferentes. La noción de tiempo en música es de sentido único, hacia delante en el tiempo. No podemos regresar al sonido anterior cuando se produce, lo que hace que la espacialidad provocada en cada instante sea única. Por el contrario, el tiempo en la pintura es multidireccional. Desde un punto estático, la obra completa se percibe en un instante, ocupado por todas las direcciones. ${ }^{141}$

En découvrant pour la première fois l'aquarelle de Klee, en la regardant, j'y ai constaté une démarche similaire, tendant à la dépersonnalisation du créateur, à son anonymat. Le titre : À la limite du pays fertile, aurait en effet tout à fait convenu car l'extrême rigidité des procédés employés pouvait très bien mener à l'infertilité. [...].

Cette ouvre de Klee est demeurée pour moi un tableau-symbole. Si l'on n’a pas su éviter l'écueil qu'est l'obéissance à un désir de structuration sans poétique, c'est-à-dire si la structuration devient trop forte et contraint la poétique à n'être qu'inexistante, on se situe, oui, à la limite du pays fertile, mais du côté de l'infertilité. Au contraire, si la structure force l'imagination à entrer dans une nouvelle poétique, alors, on est, en effet, en pays

139. Ibid., 87.

140. Ibid., 110-11.

141. Ibid., 110. 
fertile. $^{142}$

Las reflexiones de Boulez en Le pays fertile, son un alegato en contra de la simplificación $\mathrm{y}$ de las correspondencias ingenuas que habitualmente se plantean entre música y pintura. El mayor aprendizaje que obtiene Boulez de Klee es la profundidad de su método pedagógico, en el que el pensamiento y la invención aplicados a sus investigaciones, se van transformando a lo largo de toda su trayectoria profesional. De él extrae un principio: solo si nos alejamos de la situación familiar, de los conocimientos previos, será posible capturar mejor una situación dada, transformarla, reflexionar fundamentalmente sobre los poderes de la expresión y, en definitiva, orientar la imaginación sobre la poética. ${ }^{143}$

\section{Eje 2. I939-I989: Juan Navarro Baldeweg, John Cage y Gilles DeleuZe}

Equidistante a la fecha inicial (1939) y final (1989) que limita la deriva desarrollada en este capítulo, se encuentra Proust y los signos (1964). Un ensayo en el que Deleuze deseaba hacer valer la reflexión filosófica en terrenos apartados por la tradición académica como la literatura. ${ }^{144}$ En él, realiza un análisis de la novela de Marcel Proust En busca del tiempo perdido, queriendo demostrar el alcance filosófico de la obra.

Aprender concierne esencialmente a los signos. Los signos son el objeto de un aprendizaje temporal y no de un saber abstracto. Aprender es, en primer lugar, considerar una materia, un objeto, un ser, como si emitiera signos por descifrar, por interpretar. ${ }^{145}$

El análisis de los múltiples signos que Deleuze encuentra a lo largo de En busca del tiempo perdido le conducen a describir las propiedades y características del signo y profundizar en el

142. Ibid., 175. «Cuando descubrí la acuarela de Klee, cuando la miré, noté un proceso similar, tendiente a la despersonalización del creador, a su anonimato. El título: En la frontera de la tierra fértil, habría sido muy apropiado porque la extrema rigidez de los procedimientos utilizados podría muy bien conducir a la infertilidad. [...]. Esa obra de Klee ha permanecido en mí como un cuadro simbólico. Si no hemos sido capaces de evitar el escollo de obedecer a un deseo de estructuración sin poética, es decir, si la estructuración se hace demasiado fuerte y obliga a la poética a ser inexistente, nos encontramos, así, en la frontera de la tierra fértil, pero del lado de la infertilidad. Al contrario, si la estructura obliga a la imaginación a entrar en una nueva poética, entonces estamos, de hecho, en tierra fértil.» Traducción de la autora.

143. Ibid., 148.

144. Cfr. Dosse y Garzonio, Gilles Deleuze y Félix Guattari, 163.

145. Gilles Deleuze, Prousty los signos (Barcelona: Editorial Anagrama S.A., 1995), 12. 
papel que este desempeña en el proceso de aprendizaje. Deleuze, en base a su estudio, defenderá que solo cuando se interpretan o descifran los signos sensibles emitidos por las personas, los objetos o las materias, se aprende ${ }^{146}$ y se fuerza al pensamiento, pues pensar es «interpretar, explicar, desarrollar, descifrar y traducir un signo» ${ }^{147}$. En la cadena de aprendizaje producida por y mediante los signos, tienen el mismo valor tanto la sensibilidad que logra captar el signo como tal, como la inteligencia, la memoria o la imaginación (es decir, el pensamiento puro) que explican su sentido y su esencia. ${ }^{148}$

El signo sensible se basa, por tanto, en un sistema de redesignación, en el que la percepción del signo remite a su vez a una esencia ideal del mismo que se encuentra previamente encarnada en su sentido material. Todos los signos, concluirá Deleuze, convergen en el arte, y todos los aprendizajes, por las vías más diversas, son a su vez aprendizajes inconscientes del arte mismo. ${ }^{149}$

La influencia de la lectura de aquel libro de Deleuze en los ańos setenta me ayudó a encauzar el trabajo de índole artístico que realizaba en mi estancia en el Center for Advanced Visual Studies del Insituto Tecnológico de Massachusetts, invitado por su director Gyorgy Kepes, [...]. A partir de un signo desencadenante se iniciaba una escalada de manifestaciones que estimulaban la imaginación o el pensamiento o algún tipo de acción creativa en un proceso de desciframiento cuyo sentido último se iría desvelando. Así que la lectura de aquel libro de Deleuze avaló un trabajar casi a ciegas pero con un principio sustentante: sensibilizarse a los signos, abrirse confiadamente a ciertas señales en el medio físico que se presentan espontáneamente o que, por algún motivo, dejan de ser inadvertidas. ${ }^{150}$

La importancia de la lectura de Proust y los signos para Juan Navarro Baldeweg, convierte a este ensayo en el eslabón que une al arquitecto directamente con Gilles Deleuze. En los mismo años, el volumen de la serie Visual + Value dirigido por Geörgy Kepes, Signs, Image, Symbol (1966) desentrañaría las relaciones y diferencias entre signo y símbolo en un periodo marcado por los estudios semióticos. Algunos artículos incluidos en la recopilación como el de Rudolf Arnheim, Image and Thought, muestran su proximidad al conocimiento a través de los signos defendidos por Deleuze:

146. Ibid., 13.

147. Ibid., 180.

148. Ibid., 183.

149. Ibid., 22.

150. Juan Navarro Baldeweg, «Surtidor de signos», Prólogo a Dibujos Mentales: Principios del universo creativo de Juan Navarro Baldeweg, de Ignacio Moreno (Madrid: Ediciones Asimétricas, 2017), 11. 
Thinking is concerned with the objects and events of the world we know. Therefore, when thinking takes place, these objects and events must be present and acted upon. When they are bodily present we can perceive them, think them, handle them. The handling is inseparably related to the thinking. Thoughtful exploring involves handling. We actually think with our hands when we are dealing with objects.

When the objects are not physically present, they are represented indirectly by what we remember and know about them. In what shape do memory and knowledge deliver the needed facts? Experiences deposit images, and these images are handled as though they were the originals themselves. ${ }^{151}$

Rudolf Arnheim (1904-2007) apuesta por la creación de objetos para pensar, y explica cómo un evento, al ser reducido a su representación en formas abstractas, implica que configuraciones o sucesos espaciales sin ninguna referencia directa al inventario de imágenes del mundo físico se concreten en una forma tangible. ${ }^{152}$ Arnheim explica, en otras palabras, el proceso de redesignación de los signos que definía Deleuze: las experiencias crean las imágenes, y estas imágenes se manejan como un objeto original.

En línea con este pensamiento, el sonido del paisaje (entendido como signo sensible que emite un entorno), moviliza y fuerza la imaginación, la memoria y la inteligencia para crear su representación y, en consecuencia, poder ser pensado. Si bien el signo forma parte del mundo físico, la palabra conforma el símbolo bajo el cual se designa y especifica una familia de signos sensibles del mismo tipo. Se forma entonces el concepto 'paisaje sonoro', dando paso a un mundo propio, subjetivo y personal, que transforma el mundo físico (el del signo) en 'virtual' (el del símbolo) $)^{153}$.

El recorrido que une a Gilles Deleuze, Juan Navarro Baldeweg y John Cage a través de las referencias al sonido y al paisaje que existen en sus reflexiones y obras, muestra además cómo los términos con los que se designaba la relación entre sonido y entorno fueron variando

151. Rudolf Arnheim, «Image and Thought», en Sign Image Symbol, ed. György Kepes, 1st edition (New York: Braziller, 1966).

152. Ibid., 74 .

153. En el primer artículo que abre la publicación, Lawrence K. Frank explica la diferencia entre signo y símbolo a través de las palabras de Ernst Cassier: «Symbols - in the proper sense of this term - cannot be reduced to mere signs. Signals and symbols belong to two different universes of discourse: a signal is a part of the physical world of being: a symbol is a part of the human world meaning. Signals are operators; symbols are designators. " Mediante esta diferenciación, Frank sostiene que los grupos sociales crean un mundo como representación, transformando el mundo real en un 'mundo virtual'. Ernst Cassirer, An Essay on Man: An Introduction to a Philosophy of Human Culture, Edición: Reprint (New Haven, CT: Yale University Press, 1962), 32, citado en Lawrence K. Frank, "The World as a Communication Network», en Sign Image Symbol, ed. György Kepes, 1st edition (New York: Braziller, 1966), 3. 
progresivamente hasta consolidarse en el neologismo Soundscape. El arte, impulsado por la semiótica y la tecnología en los años sesenta y setenta del siglo XX, conformó el concepto paisaje sonoro mediante la unión de tres unidades abstractas: signo sonoro, espacio y tiempo. Cage, pionero en el uso del término paisaje y de la tecnología en la composición musical, emplea la expresión 'entorno sonoro' en su discurso durante los ańos cincuenta, como demuestra la entrevista que realizaron al compositor Kepes y Lynch en el MIT ${ }^{154}$. Seguidamente, en los años sesenta, el interés por el entorno, el estructuralismo desprendido del arte conceptual y el Environmental Art, además de fundar la base de los propósitos del Center for Advanced Visual Studies de Geörgy Kepes, dieron paso al Landart y a la 'invención' de la palabra 'Soundscape' que, en los últimos años del periodo de estudio, emplea en su discurso Gilles Deleuze.

Además de la evolución del lenguaje, las obras de Cage, Navarro y Deleuze son a su vez ejemplo de tres enfoques diferentes desde los que abordar la representación del paisaje sonoro. Durante los años cuarenta y cincuenta, la obra musical de Cage explorará el entorno a través del sonido del mismo, a través de la experimentación con la tecnología y el lenguaje. Sus partituras son el intermediario que da lugar a un espacio mediante el sonido (algo similar a lo que Boulez encontraba en las partituras de Messiaen y Debussy). Juan Navarro, inmerso en las corrientes conceptuales y semióticas del arte de finales de los sesenta, busca la objetualización del signo sonoro mediante la fabricación de objetos. Por último, la visión temporal del paisaje sonoro de Deleuze apuesta por la virtualización de la imagen del paisaje, unos pocos ańos antes de la invención de la realidad virtual en la década de los ochenta.

Deleuze, en Prousty los signos, advierte que «nunca aprendemos actuando como alguien, sino actuando con alguien» ${ }^{155}$. Geörgy Kepes, Maryanne Amacher y Pierre Boulez, constituyen los anclajes que permiten urdir la red de conexiones personales que vinculan a Cage, Navarro y Deleuze en un estudio relativo al paisaje sonoro. El campo fértil de influencias que crearon entre todos, da lugar a la presentación de una mirada específica sobre la representación del concepto, donde la conjunción de tres puntos de vista procedentes de diferentes disciplinas aporta y abre nuevas perspectivas sobre el objeto de estudio. La unión de un compositor, un arquitecto y un filósofo evidencia que existe una ósmosis entre disciplinas que da como resultado un perfil común a una época dada, y que los medios empleados para la representación de un concepto sonoro, aunque diferentes en su forma y naturaleza, coinciden en un nivel profundo.

154. Ver en este capítulo 1945-1956: De los nuevos paisajes a la forma urbana. Geörgy Kepes y John Cage en el MIT.

155. Deleuze, Proust y los signos, 32. 
El resultado del estudio de las conexiones entre obras, lugares y personas, ha dado lugar a este eje, en el que John Cage, Juan Navarro y Gilles Deleuze quedan unidos por un interés común por la representación del sonido y el espacio, por los aspectos estructurales del arte y por la búsqueda de la despersonalización de la obra. Del análisis de los trabajos de cada autor que quedan dispuestos en el período delimitado en este eje (1939-1989), se extraen las obras que ejemplifican los diferentes instrumentos para la representación del concepto paisaje sonoro presentados en el siguiente capítulo. 


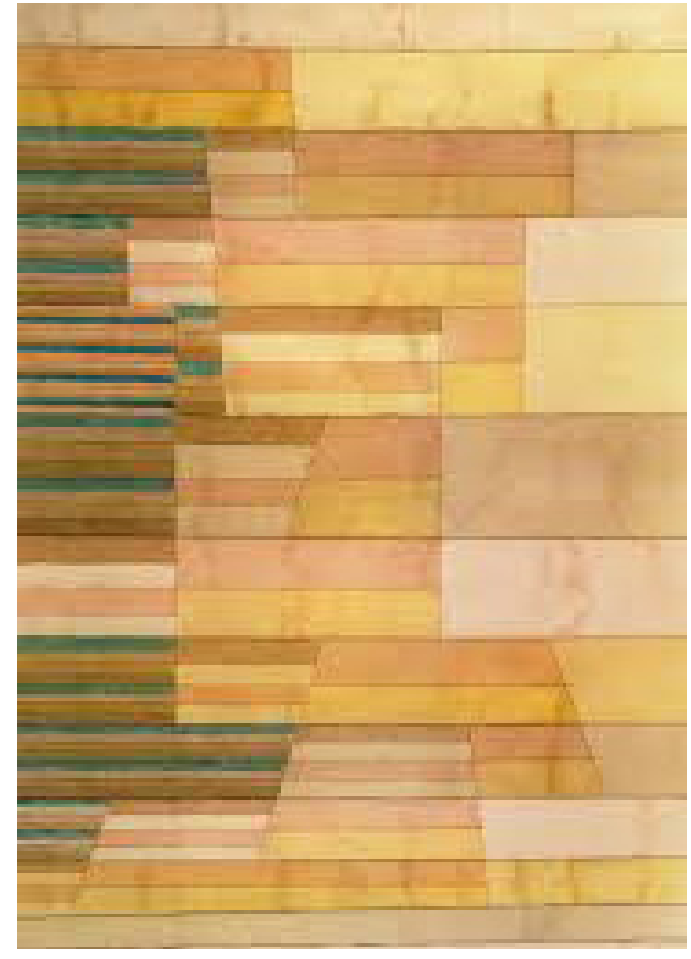

Figura 91. Paul Klee, Monument an der Grenze des Fruchtlandes (1929) 


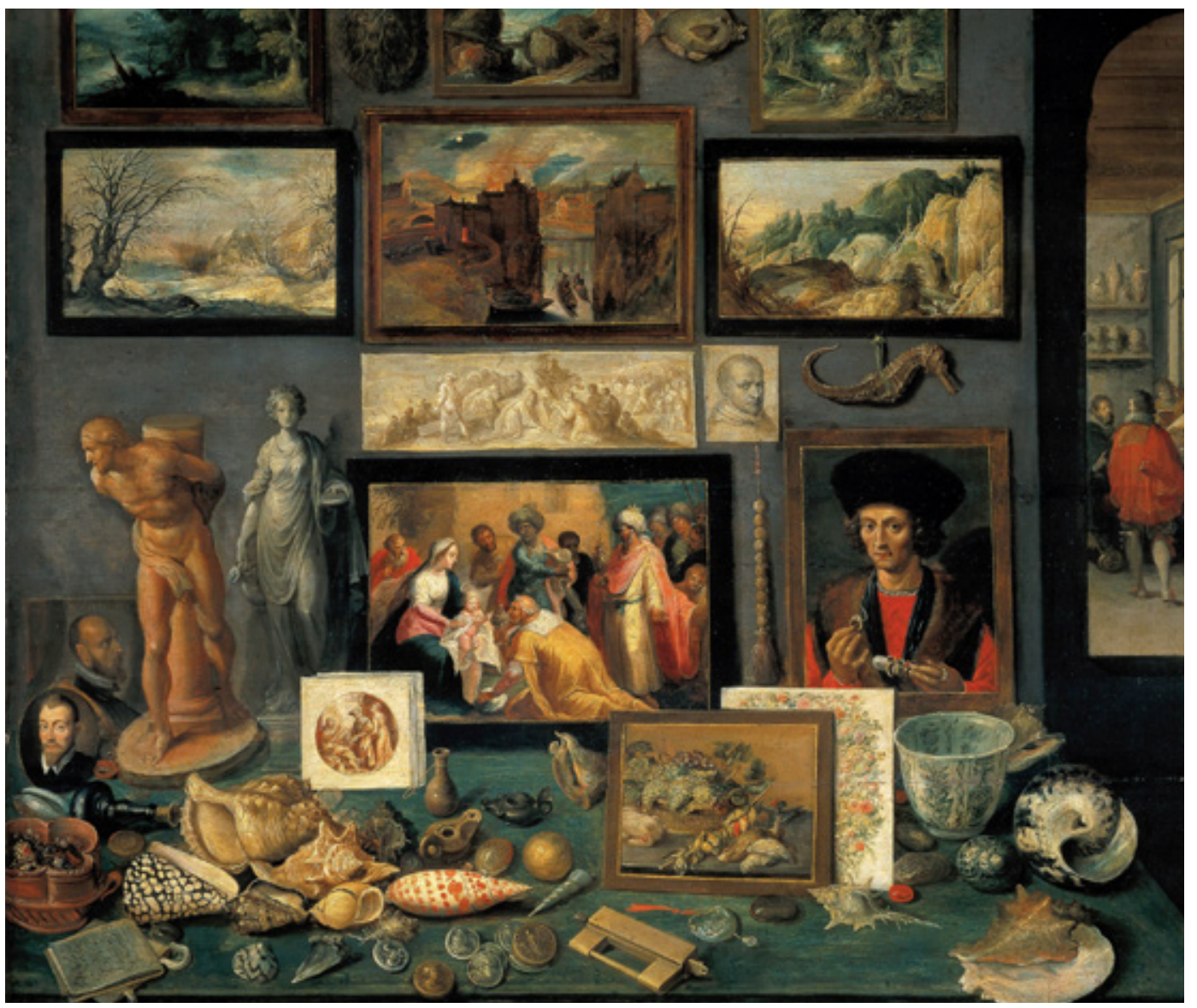

Figura 92. Frans Francken el Joven, Kunstkamer (1636) 


\section{Capítulo 3. Instrumentos PARA La REPRESENTACIÓN DEL CONCEPTO PAISAJE SONORO}

El paisaje entendido como un gabinete de curiosidades es un símil empleado de forma recurrente para explicar la complejidad del término en los estudios teóricos contemporáneos ${ }^{1}$. La disposición estética de una serie de objetos agrupados bajo una temática concreta consigue plasmar en una imagen la disección de lo múltiple contenida en la unidad superior que los congrega. Así, los espectadores y los artífices, juegan a convertirse en artistas que son a su vez intérpretes y autores entregados a los objetos reunidos para comprender mejor un mundo sensible. Una forma de exponer los componentes del paisaje que, en sí misma, conforma un paisaje, o más bien, un metapaisaje.

Aproximar cosas distantes entre sí para provocar conexiones obliga a los cinco sentidos del observador a converger en una sinestesia. El análisis sensorial de los objetos tangibles a través de su proximidad forzada en un espacio común, logra a través de la intensificación perceptiva, imaginativa e intelectual, la compresión de un segmento específico del paisaje al cual están vinculados. ${ }^{2}$

Los instrumentos destinados a desvelar la dimensión sonora del paisaje combinan la tecnología

1. Bajo la influencia del Atlas Mnemosyne de Aby Warburg, la casa museo de John Soane, las cajas de Fluxus o autores como Joseph Cornell o herman de vries, la recopilación y disposición estética de objetos bajo un mismo título es un recurso contemporáneo, plásticamente atractivo que se reinventa constantemente. Ver Günther Vogt y Medea Hoch, Landscape as a Cabinet of Curiosities. In Search of a Position. (Baden; London: Lars Müller : Springer [distributor, 2013).

2. Amplio análisis de esta idea en Barbara Maria Stafford, «Revealing Technologies/ Magical Domains», en Devices of wonder: from the world in a box to images on a screen (Los Angeles, CA: Getty Research Institute, 2001), 1-142. 
sonora con los medios plásticos para representar un concepto desde la interdisciplinariedad. Los diferentes sistemas y expresiones hacen surgir nuevos vínculos al alejarse de sus contextos familiares habituales y ser insertados en un espacio que ofrece la oportunidad creativa de inventar nuevas relaciones. Como explica G. Kepes en The New Landscape for Art and Science:

Instruments bring us fresh knowledge of the world and further control over nature. With instruments we are gradually finding a common denominator in all sensed experience; it is possible to convert sound to sight, space to time, light to form, and interchange phases and events, static and dynamic, sensible and conceptual. Through modulation of signals we extend experience, letting the blind see, the deaf hear. We can introduce new relations into any set of signals -extending, condensing, distorting, magnifying, reducing. ${ }^{3}$

Atendiendo a la evolución histórica del concepto paisaje sonoro, sus modos de representación toman infinitas formas, desde partituras y diagramas acústicos hasta relatos descriptivos. Todos ellos, identificados en esta investigación bajo el nombre genérico de instrumento, funcionan como transductores que quieren hacer visible una parte invisible del paisaje, buscando nuevas relaciones entre sonido, espacio y tiempo.

En el capítulo tercero, las obras 'paisajísticas' del compositor americano John Cage, los ensayos sobre sonido y teorías del territorio formulados por el filósofo Gilles Deleuze, y las piezas sonoras del arquitecto Juan Navarro Baldeweg sirven para ejemplificar cinco tipos de instrumentos posibles para la representación del concepto paisaje sonoro: la tecnología sonora, la partitura-evento, los surtidores de signos, las cajas de resonancia y el ritornelo. El criterio de selección de las obras viene fundamentado por el análisis desarrollado en el capítulo segundo de la tesis, que ligaba a los autores según acontecimientos y reflexiones comunes entrelazadas. Todas las piezas, obras o ensayos elegidos pertenecen al periodo comprendido entre 1939 y 1989.

Cage, Navarro y Deleuze, además de compartir una sensibilidad hacia los signos del entorno, buscan la 'objetividad' en sus obras trabajando en dos direcciones. Por un lado, siguiendo la dirección de la percepción natural, relacionando un signo con el objeto que lo emite. Y por otro, persiguiendo la dirección de la representación, atribuyendo a un objeto el beneficio del signo ${ }^{4}$.

Las etiquetas otorgadas a los instrumentos de este 'gabinete' de curiosidades pretende

3. Gyorgy Kepes, The New Landscape in Art and Science (Academy Editions Ltd, 1956), 173.

4. Remitimos a las palabras de Deleuze que aparecían en la introducción: La inteligencia se interesa por la objetividad, como la percepción por el objeto. Gilles Deleuze, Proust y los signos (Barcelona: Editorial Anagrama S.A., 1995), 39. 
alcanzar una cartografía de variables de instrumentos ${ }^{5}$ que posibilitan la representación del sonido del paisaje o de los aspectos espaciales y estructurales vinculados a él. A partir de una serie de casos, en los que lo visual opera como un vehículo para expresar cualidades no visuales, se concretan perfiles de representación de las fuerzas sonoras captadas en un territorio, o de las estructuras capaces de generar un espacio a través del sonido. Cada uno de ellos es, a su vez, ejemplo de la fusión del conocimiento operativo con el pensamiento sonoro.

El estudio de los instrumentos para la representación del concepto paisaje sonoro profundizan en el conocimiento de las variables semánticas, temporales y espaciales contenidas en ellos, cuestionando los modos de representación de los aspectos sensibles del paisaje. Se valora en cada caso en qué medida se representa un paisaje o, incluso, si el instrumento llega a constituir un paisaje por sí mismo. Un paisaje sin topos ${ }^{6}$ constituido a través del sonido.

\section{I. TECNOLOGÍA SONORA}

Tras un primer contacto con la Europa de las Vanguardias, John Cage abandera el rechazo al dodecafonismo de su maestro Schönberg en aras de la experimentación. La obra de Cage es un reflejo directo y paralelo en el tiempo de la evolución de la tecnología sonora. Sus obras solo pueden entenderse desde la puesta en práctica de los medios de reproducción y grabación del siglo XX, y su filosofía es un intento de teorizar o dar nombre a aquello que inventa. Fiel a sus inquietudes, entre 1939 y 1952, Cage compone la serie Imaginary Landscape. Cinco obras que en catorce ańos, materializan sus intereses, utilizan la tecnología de su época, y desarrollan el pensamiento del mundo de Cage a través del hacer. En ellas experimenta con los instrumentos, la composición, los ritmos y la notación, y lucha por alcanzar la despersonalización de la música y la incorporación del sonido del mundo en el tiempo de la obra.

Atendiendo a los intereses que afronta en cada uno de ellos, los Paisajes imaginados se dividen en dos grupos. Un primer grupo que engloba los paisajes No. 1, No. 2 y No. 3 (1939-

5. «Although visual qualities can emerge out of the performance of these kinds of practices, since every perceptual object is inevitably the result of an intimate connection between synesthetic and kinesthetic activities, focus on aural varieties of environmental inquiry and exclusion of visual terminology facilitate the imaginative constitution of a coherent meshwork of radically sensuous, emotional presence.». Alex Arteaga y Boris Hassenstein, Architecture Without Walls (Errant Bodies Press, 2016), 4.cado y un marimbala urbanismo y la ciudad en como las primeras del g

6. Javier Maderuelo Raso, La idea de espacio en la arquitectura y el arte contemporáneos, 1960-1989 (Ediciones AKAL, 2008), 247-48. 
1942), en los que Cage experimenta con los ritmos y la manipulación de los instrumentos; y un segundo grupo, formado por los paisajes No. 4 y No. 5 (1951-1952), donde pone en práctica la composición aleatoria y el uso de las indicaciones del libro de las mutaciones, el I Ching. Algunos de ellos son, además, ejemplo de experimentación en el campo de la notación musical.

En 1939, y poniendo en práctica su $C r e d 0^{7}$, Cage crea la primera obra electroacústica jamás compuesta ${ }^{8}$ : Imaginary Landscape No. 1. La obra, titulada Hilarious Dance Concert, fue compuesta para una coreografía de Bonnie Bird en la escuela Cornish, y la música para la primera actuación se realizó en el estudio de radio de la escuela. ${ }^{9}$ Con esta obra nace la electrónica en vivo, un método de creación musical en el que el sonido es ordenado y manipulado en el mismo momento del concierto. ${ }^{10}$ Este tipo de obras suponen una reinvención de la práctica musical clásica a través de un inmersión en el sonido manipulado que permitían las primeras mesas de mezclas. Con Imginary Landscape No. 1, Cage articula lo que se convertiría en la fuerza impulsora del discurso estético de la inmediatez y la apertura hacia las circunstancias incontrolables. ${ }^{11}$

7. El texto Credo de John Cage se extrae de una charla ofrecida en un encuentro de la sociedad de arte de Seattle, organizado por Bonnie Bird en 1937. Es un alegato a favor de la libertad de creación, apología del ruido y la experimentación sonora: «Dondequiera que estemos, lo que oímos más frecuentemente es ruido. Cuando lo ignoramos, no molesta. Cuando lo escuchamos, lo encontramos fascinante. El sonido de un camión a cincuenta millas por hora. La estática entre emisoras. La lluvia. Queremos capturar y controlar estos sonidos, y usarlos no como efectos sonoros sino como instrumentos musicales. Modificar con palabras propias: Los métodos actuales de composición, especialmente los que usan la armonía y su referencia a las medidas particulares del campo del sonido, resultarán inadecuados para el compositor, que se encontrará frente al campo entero del sonido. Se descubrirán nuevos métodos, que mantendrán una relación definitiva con el sistema de doce tonos de Schoenberg y con los métodos actuales de escritura para la música de percusión y con cualquier de los métodos que están libres del concepto de un tono fundamental. Si la palabra "música" se considera sagrada y reservada para los instrumentos de los siglos dieciocho y diecinueve, podemos sustituirla por otro término más significativo: organización de sonido. Deben crearse centro de música experimental. Los medios fotoeléctricos, magnéticos y mecánicos para la reproducción sintética de música serán explorados. Mientras que, en el pasado, el punto de desacuerdo estaba situado entre la disonancia y la consonancia, en el futuro, estará entre el ruido y los llamados sonidos musicales.» John Cage, «El futuro de la música: Credo», en Escritos al oído, Arquitectura 38 (Murcia: Colegio Oficial de Aparejadores y Arquitectos Técnicos de la región de Murcia, 2007), 51.

8. Llorenç Barber y Círculo de Bellas Artes (Madrid), John Cage (Madrid: Círculo de Bellas Artes, 1985), 17.Esta afirmación de Llorenç, es discutible. Otros autores consideran que la primera obra electoracústica fue Pini di Roma de Ottorino Respighi (1924), que utiliza sonidos de aves pregrabados. En el archivo oficial de obras de Cage, describen las dos obras como las primeras del género.

9. Paul Cox, «Cage's Credo: The Discovery of New Imaginary Landscapes of Sound», programa del disco JOHN CAGE: The Works for Percussion 1, vol. 229 (NY: Mode Records, N.Y), http://media.dramonline.org/content/notes/ mode/mo229.pdf.

10. En contraste a las formas de música electrónica de los ańos cuarenta, entendidas como una pieza cerrada -un objeto que en lugar de interpretarse en un momento simultáneo entre orquesta y espectadores se presenta como grabaciones totalmente terminadas en una cinta magnética-, Cage no renuncia a la interpretación con su electrónica en vivo. Cfr. Barber y Círculo de Bellas Artes (Madrid), John Cage, 17.

11. Sobre la notación y la interpretación de Imaginary Landscape No1 Cfr. Michael Nyman, Música Experimental: 


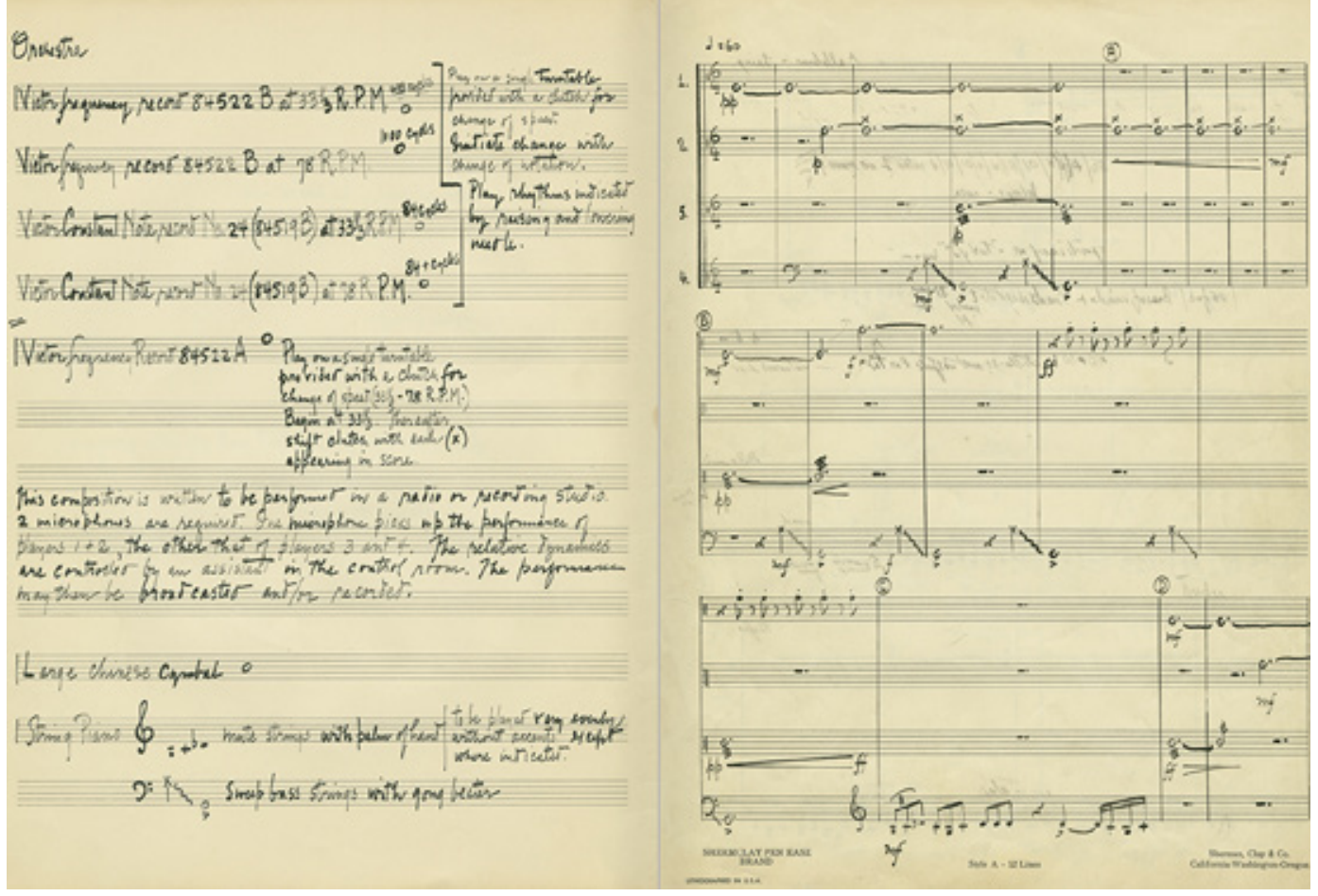

Figura 93. John Cage, Imaginary Landscape No. 1, páginas 2 y 3 (1939) 
Independientemente de si la representación de un espacio se hace explícita o no en el momento en el que se produce (algo que sí ocurre en una sala de conciertos, por ejemplo, al ver lo que está sonando), las grabaciones sonoras contienen información del espacio donde se realizan. Cuando los espacios se descontextualizan sonoramente mediante el procesamiento de sonido, como hace Cage en Imginary Landscape No. 1, la incorporación de señales acústicas genera nuevas dimensiones que densifican y multiplican la espacialidad del lugar en el que se produce la escucha.

Además de promulgar el uso de la tecnología en la nueva música, Cage reconoce en su Credo que los métodos de composición basados en la armonía y las medidas particulares del campo de la música, resultarían inadecuados para los nuevos compositores de la época, pues estos manejaban el campo entero del sonido. ${ }^{12}$ La música concreta empleaba los sonidos grabados como instrumentos, dando como resultado una ordenación secuencial de efectos hasta alcanzar un todo cerrado. ${ }^{13}$ Por el contrario, los Imaginary Landscape no se conciben siguiendo una secuencia temporal, sino como un bloque de tiempo ${ }^{14}$ en el que las longitudes de tiempo resultaban ser la mezcla de una duración con la dimensión espacial.

Con Imaginary Landscape No. 1, Cage comienza a emplear las estructuras ritmicas. Estas construcciones, cuyo origen se encuentra en las composiciones para coreografías o performances, definen la base de toda la música de percusión de Cage desde 1939 en adelante. En la conferencia autobiográfica de 1948 A composer's Confession ${ }^{15}$, Cage recalca las dos razones por las que las estructuras rítmicas se convirtieron en la base de su música. La primera razón fue el trabajo con bailarines -Cage escribiría el acompañamiento para danza después de que la coreografía estuviera completada, después de que los bailarines le dieran las 'medidas' del baile-; y la segunda, la naturaleza de los sonidos de percusión con los que trabajaba. Como consecuencia de la previa observación de la naturaleza de los sonidos, Cage estableció la duración como base de la estructura de sus composiciones. La naturaleza física de los materiales con los que estaba tratando (el baile y la percusión), le llevaron, en consecuencia, a la concepción del

De John Cage en adelante (Documenta Universitaria, 2006), 76; James Pritchett, The Music of John Cage (Cambridge University Press, 1996), 20; William Fetterman, John Cage's Theatre Pieces (Routledge, 2012), 5-6.

12. Cage, «El futuro de la música: Credo», 54.

13. Cfr. David Grubbs, Records ruin the landscape: John Cage, the sixties, and sound recording (Durham: Duke University Press, 2014), 59.

14. Ver apartado 3.5. Ritornelo.

15. John Cage, "A composer's confession", Making the Right Choices: A John Cage Centennial Celebration, accedido 13 de junio de 2020, https://www.nws.edu/JohnCage/AComposersConfession.html. 
ritmo estructural. ${ }^{16}$

El método de composición de las estructuras rítmicas tenía su origen en las frases de longitud arbitraria que le marcaban los bailarines. Después Cage realizaba los arreglos de las longitudes, y agrupaba las frases en unidades más grandes (en secciones). Este último principio de organización de la composición en dos niveles de jerarquía de ritmo estructural -la frase y la sección- fue lo que Cage llamó micro-macrocosmic rhythm structure, un dispositivo que fue de inmensa importancia en su trabajo. ${ }^{17}$

Siguiendo este mecanismo, Cage compone Imaginary Landscape No. 2, del cual se encuentran dos versiones. La primera (1940) fue compuesta para una danza -sobre árboles- para Bird ${ }^{18}$ que, posteriormente, en el año 1942, se modificó para incluir elementos 'eléctricos'. En esta obra los instrumentos de percusión -latas, una caracola, un bombo, un gong de agua, una papelera de metal...- se combinan con una bobina de cable amplificado y el rugido de un león.

En 1942, John Cage se muda a Nueva York. Influenciado por Mark Tobey, comenzará a interesarse por la apreciación del entorno urbano ${ }^{19}$. En ese mismo año también compone Imaginary Landscape No. $3^{20}$.

Entre el paisaje No.3 (1942) y el No.4 (1951) incurre otro paisaje, In a Landscape, obra estrenada en el Black Mountain College el 20 de agosto de 1948. El sonido de la composición, suave y meditativo, nada tiene que ver con la percusión de los paisajes imaginados 1, 2 y 3 . La importancia de In a Landscape radica en su estructura. Cage vuelve a emplear la estructura micro-macrocósmica para componer esta pieza, de tal forma que la proporción que las grandes secciones de la obra tienen con respecto al todo, es igual a la relación que las pequeñas secciones guardan con respecto a las grandes en la que está integrada. Es decir, esta pieza tiene 15 secciones

\footnotetext{
16. Pritchett, The Music of John Cage, 13-15.

17. Ibid., 14.

18. Paul Cox, «Cage's Credo: The Discovery of New Imaginary Landscapes of Sound», programa del disco JOHN CAGE: The Works for Percussion 1, vol. 229 (NY: Mode Records, N.Y), http://media.dramonline.org/content/notes/ mode/mo229.pdf.

19. Branden Wayne Joseph, Experimentations: John Cage in music, art, and architecture, First edition (New York ; London: Bloomsbury Academic, 2016), 58. Años más tarde, volverá a compartir sus intereses sobre urbanismo y la ciudad con Kevin Lynch y Geörgy Kepes en el Urban form Seminar del MIT.

20. «In contrast to the irony of the second Landscape, the Imaginary Landscape No. 3, written shortly before the second in February 1942, is a more direct expression of Cage's feelings about the war, which he later described in an interview: "When the Second World War came along, I talked to myself, what do I think of the Second World War? Well, I think it's lousy. So I wrote a piece, Imaginary Landscape No. 3, which is perfectly hideous.» Cox y Percussion Group Cincinnati, «Cage’s Credo: The Discovery of New Imaginary Landscapes of Sound».
} 
de compases, y cada subsección se halla formada por tres frases de 5, 7 y 3 compases ${ }^{21}$.

En Imaginary Landscape No. 4 (1951), Cage comienza a intuir la necesidad de alejarse como compositor de las obras que produce, y confía en las acciones de azar y aleatoriedad las decisiones de forma. Para ello empleó el I Ching para configurar superposiciones, tiempos, duraciones, sonidos y dinámicas. Cage tenía como objetivo borrar toda voluntad del autor en la obra:

It is thus possible to make a musical composition the continuity of which is free of individual taste and memory (psychology) and also of the literature and "traditions" of the art. The sounds enter the time-space centered within themselves, unimpeded by service to any abstraction, their 360 degrees of circumference free for an infinitive play of interpretation. $^{22}$

Finalmente, Imaginary Landscape No. 5, (1952) es una pieza collage compuesta por fragmentos de discos de larga duración grabados en cinta. El magnetófono entraba en los años cincuenta en el escenario musical, y la música podía componerse entonces como una película ${ }^{23}$. La partitura de esta composición seguía, a la manera iniciada por Morton Feldman, los nuevos medios de expresión de la música. ${ }^{24}$ Volviendo a la visión del tiempo como duración, como medida de longitud, la partitura especificaba la longitud de los tramos de cinta magnética que debían emplearse para interpretarla. Cage dibujó ocho bandas (pistas) sobre un papel milimetrado donde cada cuadrado correspondía a tres pulgadas de cinta magnética. Como consecuencia del empleo del I Ching para su composición, aunque la duración y la amplitud se anotan en la partitura, no hay indicación de qué grabaciones (o qué tipo de grabaciones)

21. Barber y Círculo de Bellas Artes (Madrid), John Cage, 25.

22. John Cage, «To Describe the Process of Composition Used in "Music of Changes" and "Imaginary Landscape No. 4"”, en Silence: Lectures and Writings, Repr (London: Marion Boyars, 1999), 59.

23. «Aunque Arnold Shönberg, desde los primeros ańos de la década de 1910, había abierto un camino a la modernidad de la música con el dodecafonismo, que ideó en paralelo a la abstracción expresionista de Kandinsky, la crisis de la música y sus lenguajes no se generalizó hasta que en los años inmediatos al fin de la Segunda Guerra mundial el compositor Pierre Schaeffer propuso un nuevo universo sonoro al incorporar los sonidos no musicales, es decir, lo que habitualmente se llaman ruidos, al repertorio de la música. Esto fue posible gracias al desarrollo que experimentó durante la guerra el magnetófono de cintas. Este instrumento permitía grabar y manipular cualquier tipo de sonido captado por medio de un micrófono y reproducirlo después con gran fidelidad o deformarlo con procedimientos como alterar la velocidad de lectura o invertir el sentido de la cinta. Por su parte, la cinta magnetofónica permitía la aplicación de las mismas técnicas de montaje que la película cinematográfica, [...]. El magnetófono, al hacer surgir los sonidos a través de un altavoz, tanto si estos eran voces, música o ruidos ocasionales, puso estos tres tipos de sonidos, que culturalmente habían permanecido segregados, en un mismo plano de igualdad.»Javier Maderuelo, «Música gráfica», Arte y Parte, julio de 2015, 36.

24. Cfr. David Cline, The Graph Music of Morton Feldman (Cambridge University Press, 2016), 36. 


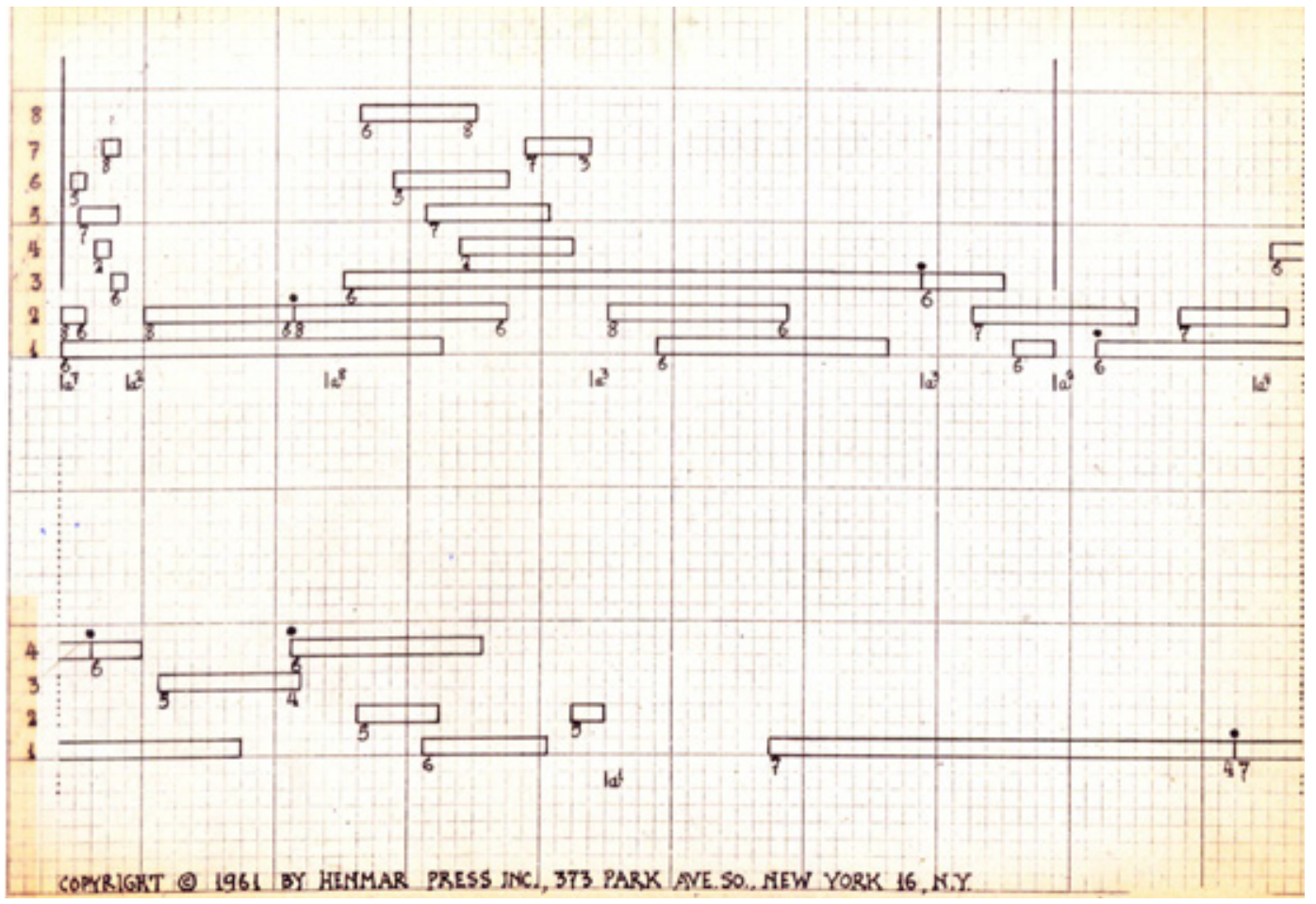

Figura 94. John Cage, Imaginary Landscape No. 5 (1952) 
deben usarse ${ }^{25}$.

De composiciones como el último Paisaje imaginado de Cage, surgen las artes visuales electrónicas. En ellas, la expresión artística superaba los límites de todos los géneros establecidos, y la tecnología se empleaba como un medio que, de una manera experimental, permitía que la interdisciplinariedad se convierta en un proceso de autorreflexión al mismo tiempo que incitaba una nueva experiencia sensorial. ${ }^{26}$ La nueva escritura musical dejaba de ser gráfica para convertirse en auditiva, y la partitura, arrastrada por la electrónica, se convierte en un manual de instrucciones concebido con la claridad inherente a la ciencia y a la técnica. ${ }^{27}$

- ¿Por qué se llamaron Imaginary Landscape estas primeras obras?

- No es un paisaje físico. Es un término reservado para las nuevas tecnologías. Es un paisaje en el futuro. Es como si utilizaras la tecnología para despegar del suelo e ir como Alicia a través del espejo. ${ }^{28}$

Cuando Alicia traspasa el espejo y observa la habitación de la chimenea desde el otro lado, se da cuenta de que todo los objetos del lado imaginario que podían verse desde la habitación 'real' eran comunes y poco interesantes. Pero todos aquellos objetos situados en ángulos muertos o bien ocultos a la vista, hasta ese momento desconocidos para Alicia, eran atractivos y diferentes. ${ }^{29}$ En los paisajes imaginados, como le confiesa Cage al escritor Richard Kostelanetz, la palabra paisaje no denota un paisaje, sino el medio de su existencia. Cage, situado al otro lado del espejo, construye mediante la tecnología sonora la parte 'imaginaria' de estas obras a través de procesos esquizofónicos y acusmáticos en los que la representación y presentación de lo heterogéneo se produce de forma simultanea.

Where does Cage's metaphor of a Sonic landscape fit with another term that sprung up in its take - the "soundscape"? The term "soundscape" tends to be used to refer to both the distribution of sounds in a given space (with the implication that this space is defined or described in the perceiving of the sounds it contains), as well as any sonic representation of space. It is an aural view of an environment as well as a mediated representation of an

25. Cage utilizó principalmente grabaciones de jazz.

26. Dieter Daniels y Barbara U. Schmidt, eds., Artists as inventors, inventors as artists (Ostfildern, Germany: Hatje Cantz, 2008), 10.

27. Maderuelo, «Música gráfica», 38.

28. John Cage y Richard Kostelanetz, «A Conversation about Radio», The Musical Quarterly 72, n. ${ }^{\circ}$ No. 2: 218, accedido 20 de noviembre de 2019, https://www.jstor.org/stable/948120?seq=1\#page_scan_tab_contents.

29. Lewis Carroll y Lewis Carroll, Alice's adventures in Wonderland: and, Through the looking-glass and what Alice found there, The Modern Library Classics (New York: Modern Library, 2002), 125. 
environment. ${ }^{30}$

Como defiende David Grubbs en su estudio sobre la relación entre Cage y la tecnología sonora, las piezas Imaginary Landscape constituyen una representación de espacios heterogéneos, 'imaginarios', ya sea mediante la superposición de grabaciones múltiples y diversas o mediante la discontinuidad de la edición. ${ }^{31}$ En ellas se destaca la naturaleza mediada de la reproducción del sonido, empleando la palabra paisaje como metáfora para identificar el proceso mediador, múltiple y heterogéneo con el que análogamente se construye el concepto paisaje.

Como advierte Nelson Goodman, «La denotación es el núcleo de la representación y no depende de la semejanza» ${ }^{32}$. Al igual que un cuadro de pintura paisajística denota un paisaje, la palabra designa lo que representa ${ }^{33}$ a través de un código de signos alfabéticos sin adoptar la forma de lo representado, y de la misma manera que el ojo está condicionado por su propio pasado, las palabras son también objeto de prejuicio. Tras el estudio del uso de la palabra 'paisaje' que John Cage hace a lo largo de su obra ${ }^{34}$, se desprende que las composiciones tituladas Imaginary Landscape emplean la palabra paisaje para denotar, mediante una metáfora, un proceso de composición múltiple ligado a la tecnología.

El uso recurrente de la palabra 'paisaje' en estas composiciones ha hecho que se le otorgue a Cage el mérito de la reincorporación del paisaje al arte en los años cuarenta. Este hecho ha sido, más bien, una consecuencia no pretendida (o malentendida a posteriori) pues, como respondía Cage ante la pregunta de Kostelanetz en su conversación sobre la radio, Cage era consciente de que sus paisajes no hacían referencia a paisajes físicos, no buscaban una representación más o menos subjetiva y evocadora de la atmósfera de un lugar, sino que la palabra 'paisaje' denota los medios. En los Imaginary Landscape, el medio (la palabra paisaje) son los medios. En estas composiciones, Cage aborda y pone en práctica -supuestamente de forma inconsciente- una serie de estrategias que dan sentido al enfoque estructural del concepto paisaje sonoro.

30. Grubbs, Records ruin the landscape, 56.

31. Ibid.

32. Nelson Goodman, Los lenguajes del arte: aproximación a la teoría de los simbolos (Barcelona: Paidós, 2010), 21.

33. Según Goodman, «La forma más ingenua de entender la representación podría formularse diciendo que una cosa (a) representa a otra (b) en tanto que (a) se asemeja a (b)». La semejanza, a diferencia de la representación, es reflexiva -(a) se asemeja a (b) tanto como (b) a (a)-. Ibid., 19-20.

34. Se distinguen tres etapas en las que la representación del concepto 'paisaje' evoluciona de forma diferente en la trayectoria de Cage. La primera, correspondiente a sus obras iniciales (1939-1952) donde se incluyen Imaginary Landscape (1, 2, 3, 4 y 5) e In a Landscape; una segunda etapa (1952-1962), en la que predominan los eventos y el deslizamiento hacia la actitud pasiva-activa y la despersonalización (con 4’33” y las clases de composición en NY); y por último, la etapa (1962-1983), en la que se encuentran las obras de música ecologica, entre ellas Lecture on the Weather. 
A raíz de las manifestaciones artísticas de Cage nace el paisaje sonoro, aunque no se designe bajo la palabra Soundscape hasta los años setenta. Bajo la intuición de titular a estas composiciones como paisajes imaginados, no solo se identifica la idea de multiplicidad en la metáfora, sino otras muchas características propias de la formación del concepto paisaje que van más allá de su imagen, como la estructura micro-macrocósmica ${ }^{35}$, o la trascripción sonora a partir de un hecho visible, físico y dinámico como son la danza y la percusión. Estos tres componentes (estructura, representación y proceso de formación) permiten establecer una analogía entre los procesos de formación de los paisajes imaginados y la formación del concepto paisaje que nada tiene que ver con la semejanza entre imágenes.

Cage emplea el sonido como disparador para proyectar al oyente a un plano que va más allá de lo representativo. La re-presentación impulsará a una retórica de la audición que, progresivamente, junto con el desarrollo de las corrientes conceptuales del arte, permitirá que la música se desprenda de ella misma y el sonido pueda, independientemente, utilizarse como herramienta para la descripción y representación de espacios y estructuras del entorno. ${ }^{36}$

\subsection{Partitura-evento}

Todo sonido oído a la mayor distancia posible produce uno y el mismo efecto: una vibración de la lira universal, así como la atmósfera intermedia forma una lejana ondulación de tierra que interesa a la mirada por su tinte azul. Llegaba hasta mí en este caso una melodía que el aire había pulsado y que había conversado con cada hoja y aguja de los bosques, esa porción de sonido que los elementos habían aceptado, modulado y prolongado con ecos de valle en valle. El eco es, hasta cierto punto, un sonido original, y de ahí su magia y encanto. No es sólo la repetición de lo que era digno de repetirse en la campana, sino en parte la voz del bosque, las mismas palabras y notas triviales cantadas por una ninfa. ${ }^{37}$

H. D. Thoreau. Walden

35. Ver Capítulo primero, apartado 1.2.2. El Stimmung o la visión sonora del mundo.

36. «Cage's work, his procedures and ideas, underscores sound not only as a musical medium but as a trigger for directing attention not so much beyond interpretation but toward the context in which interpretation must always take place.» Brandon LaBelle, Background noise: perspectives on sound art, Second edition (New York: Bloomsbury Academic, 2015), 5.

37. Henry David Thoreau, Walden, Edición: 1 (Madrid: Errata Naturae, 2013), 168. En 1846, tras un año apartado del mundo viviendo en la cabańa que había construido, Henry David Thoreau comenzó a escribir Walden (1854), el relato autobiográfico de su vida aislada en los bosques con el que quiso dar respuesta a cuáles son los recursos mínimos necesarios para vivir. 
La influencia de H. D. Thoreau (1817-1862) en el compositor americano John Cage, proviene de su interés por la literatura. Admirador de la riqueza y la complejidad de las obras de Gertrude Stein y James Joyce, Cage encontró materializado en la obra de Thoreau uno de sus mayores anhelos: la desaparición del autor en la obra. «Thoreau sólo desaba una cosa: ver y escuchar el mundo que le rodeaba. Y se interesó por la escritura, y aspiró a encontrar un tipo de escritura que permitiera a los otros no ver y entender cómo lo había hecho él, sino ver lo que él había visto y escuchar lo que él había escuchado " ${ }^{38}$. Un manera propia de escribir, dice Cage, que cada vez se aleja más de la experiencia personal del autor, para acercarlo a la experiencia. Un alejamiento en busca de la anulación de la subjetividad.

Despersonalizar la música supone un proceso de reconversión en el que el compositor se convierte en cartógrafo ${ }^{39}$, dejando la música libre de su gusto personal. El paisaje implica una componente espacial ineludible cuya representación mediante el dibujo o la cartografía dan como resultado un producto que acoge diversas lecturas. Al igual que en la música, el sistema de notación de una partitura constituye un lenguaje universal, entendible por aquellos que saben leer ese lenguaje, pero cuya interpretación, tal y como ocurre con la ejecución de dos edificios con los mismos planos, nunca será igual cuando la realizan dos individuos diferentes.

Nelson Goodman (1906-1998), en Los lenguajes del arte $e^{40}$, explora el papel intermediario que puede desempeñar un plano o una partitura. Ambos constituyen una transición entre algo que puede reproducirse al mismo tiempo que provoca una acción única cuando se ejecuta su notación. El lenguaje musical se transforma según las necesidades de quienes se comunican por medio de él, y la evolución de la notación musical manifiesta cómo se han rebasado las necesidades comunicativas para convertir la partitura en un acontecimiento gráfico y plástico que contiene "paralelismos con el mundo de la poesía visual y con ciertos aspectos de la pintura.» ${ }^{41}$ La aparición de nuevos instrumentos electrónicos invalidó la condición universal

38. John Cage, Para los pájaros (Alias, 2013), 295.

39. Calificativo asignado por Barber y Círculo de Bellas Artes (Madrid), John Cage, 30. Reforzado por las palabras de Javier Maderuelo, «del descubrimiento de lo gráfico y lo espacial por parte de los músicos y de la capacidad de experimentar con lo gráfico, lo dibujísitico, lo poético, lo cromático..., dando origen a un nuevo tipo de partitura híbrida que absorbe los recursos de la confección de planos, collages, mapas, pinturas expresionistas, esquemas técnicos o que incluyen la imagen fotográfica como estímulos sinestésicos para la creación sonora.» Maderuelo, «Música gráfica», 37.

40. Los lenguajes del arte ( $1^{\mathrm{a}}$ ed. 1968) de Nelson Goodman, obra enmarcada en el auge de los estudios semióticos y la lingüística estructural de los 60 y 70 del siglo XX. Goodman consideraba estos estudios incompletos si no abordaban el examen de los sistemas de símbolos no verbales, desde la representación pictórica hasta la notación musical. Cage le sirvió de ejemplo por su rompedora forma de proceder. Goodman, Los lenguajes del arte, 13-15.

41. Maderuelo, «Música gráfica», 33. 
del pentagrama como sistema de notación, y los compositores recurrieron a otros medios de expresión gráfica.

El desprendimiento progresivo del $Y o$ y la apertura hacia el sonido del entorno marcarán los métodos de notación de la música de Cage, libre de memoria, gustos personales y de tradiciones. Todo el proceso de captación, selección, montaje, manipulación, edición y reproducción de los sonidos y las cintas magnetofónicas desemboca en anotaciones e instrucciones para los nuevos intérpretes que, dada su formación técnica, no necesariamente conocen el lenguaje musical tradicional. Ese alejamiento de la música e incursión de los 'no músicos' en el campo sonoro, generó un lenguaje para la definición de procesos, operaciones, tiempos...una descripción de la producción o transducción de efectos sonoros que es, en definitiva, la representación 'verbal' de la acción que crea o representa un acontecimiento sonoro. Así, el paisaje pasará a concebirse como un fenómeno no verbal que queda inscrito en un discurso ${ }^{42}$

La cuestión que nos interesa en realidad es si es posible que, a través de un sistema de notación, la obra de pintura o grabado quede liberada de su dependencia de un autor en particular o de un lugar, fecha o modo de reproducción. ¿¿Sería teóricamente posible escribir una partitura que definiera la obra de pintura, o un grabado, de tal forma que objetos producidos por otros medios (diferentes por ejemplo, de la plancha original), pudieran subordinarse a la partitura y contar como ejemplos equivalentes de la obra? Es decir, ¿podría la institución de un sistema de notación hacer que la pintura o el grabado pasaran de ser un arte autográfico en convertirse en alográfico? ${ }^{33}$

En las conversaciones recogidas en el libro Para los pájaros, el filósofo Daniel Charles hace referencia al libro de Goodman para preguntarle a John Cage sobre la representación del tiempo en sus partituras. ${ }^{44}$ Cage, en su respuesta, afirma que «el tiempo está más allá de los relojes», y diferencia las tres operaciones que caben dentro de una obra: escribir, interpretar y escuchar. Para Cage, si al escribir el compositor impone una medida de tiempo determinado, el oyente no capta el tiempo del compositor, sino el que ofrece el 'ejecutante' de la partitura cuando la lee. El 'ejecutante' no leerá el tiempo, sino una medida de tiempo.

Defensor del instante y la vivencia, Cage consideraba que la interpretación de una composición era una experiencia única, irrepetible, y que la grabación de las mismas equivalía a una postal que aporta un conocimiento pasado de algo, una imagen estática, mientras que

42. Cfr. Michael Jakob, What is landscape? Ediz. illustrata (List, 2018), 17.

43. Goodman, Los lenguajes del arte, 180. Ver Capítulo 1. Apartado 1.4.4. Articulaciones de la representación.

44. Cage, Para los pájaros, 155-57. 
la acción remite a algo futuro, dinámico e ilimitado. En tono irónico, y más allá del empleo de la metáfora del paisaje imaginario en sus obras electrónicas, Cage afirmaba que tanto las grabaciones como las postales «arruinan el paisaje» ${ }^{45}$, pues destruyen la experiencia real del entorno.

En la pieza 'silenciosa' 4’33” (1952), John Cage dirige su atención a los tres aspectos fundamentales necesarios para que exista cualquier obra: escribir, interpretar y escuchar. En 4'33", la exploración de la estructura, del tiempo en la partitura y del cambio de rol del público -de oyente pasivo a intérprete activo-, llevaron a Cage a un punto de inflexión a partir del cual el silencio pasó a definirse como el inevitable lleno producido por los sonidos del entorno. La obra, precedente de la ecología acústica ${ }^{46}$, fue escrita en el verano de 1952 después de que Cage regresara a la ciudad de Nueva York desde el Black Mountain College. Allí trabajó como profesor y compositor y coincidió con otros artistas de diversas disciplinas, como Robert Rauschenberg, quien en 1951 realizó en la misma Black Mountain sus Pinturas Blancas, de gran influencia para la concepción de la partitura de 433”.47

La primera interpretación de la pieza 4’33” la realizó en 1952 el pianista David Tudor en el festival de Woodstock, N.Y. La apertura y cierre de la tapa del piano indicaban el comienzo

45. Esta afirmación se encuentra primero en la conferencia sobre composición Indeterminacy: «A performance of a composition which is indeterminate of its performance is necessarily unique. It cannot be repeated. [...]. A recording of such work has no more value tan a postcard; it provides a knoledge of something that happened, whereas the action was a non-knowledge of something that had not yet happened. " John Cage, Silence: Lectures and Writings, Repr (London: Marion Boyars, 1999), 39. En la entrevista de Daniel Charles encontramos la afirmación de Grubbs: «D.C.—Los discos a su juicio, no son más que tarjetas postales...; J.C. — Que arruinan el paisaje.» Cage, Para los pájaros, 50.

46. Sobre la ecología en Cage y su relación con las obras silenciosas: «D.C.-_iA fin de cuentas, no habría que hipnotizarse tampoco con la música sistemática, constituida, que se superpone a la naturaleza o a los elementos? J.C. —¿Usted quiere decir que la música siempre deviene, que siempre se convierte en alguna cosa, y que no es necesaria porque esa cosa ya existe? D.C.—Usted puede tomarlo así. Pensaba en sus piezas de silencio. ¿o son superfluas, puesto que los ruidos de la naturaleza ya existen? J.C. - El aspecto de la naturaleza del que hoy tenemos idea -y esa idea es casi penosa- es el de que nosotros, como especie humana, hemos puesto en peligro la naturaleza. Hemos actuado contra ella, nos hemos rebelado contra su existencia. En consecuencia, hoy debemos preocuparnos por devolverle el sitio que le es propio. Y la naturaleza no consiste en una separación del agua y el aire, del cielo y la tierra, etcétera, sino en un "trabajo-conjunto", o un "juego-conjunto" de esos elementos. Es lo que llamamos ecología. La música, tal y como la concibo, es ecológica. Podría llegar más lejos y decir: ES ecología.» Cage, Para los pájaros, 288-89.

47. «Cage observed that the monochrome surfaces of the White Paintings, uninflected by gestural brushstrokes, reflected changes in light and shadows in their surrounding environment. Cage identified these works as the inspiration for his signature "silent" composition 4'33" (1952).» "The Black Mountain Years: Experiments and Collaborations», Robert Rauschenberg Foundation, 17 de agosto de 2016, https://www.rauschenbergfoundation. org/art/lightboxes/black-mountain-years-experiments-and-collaborations. 

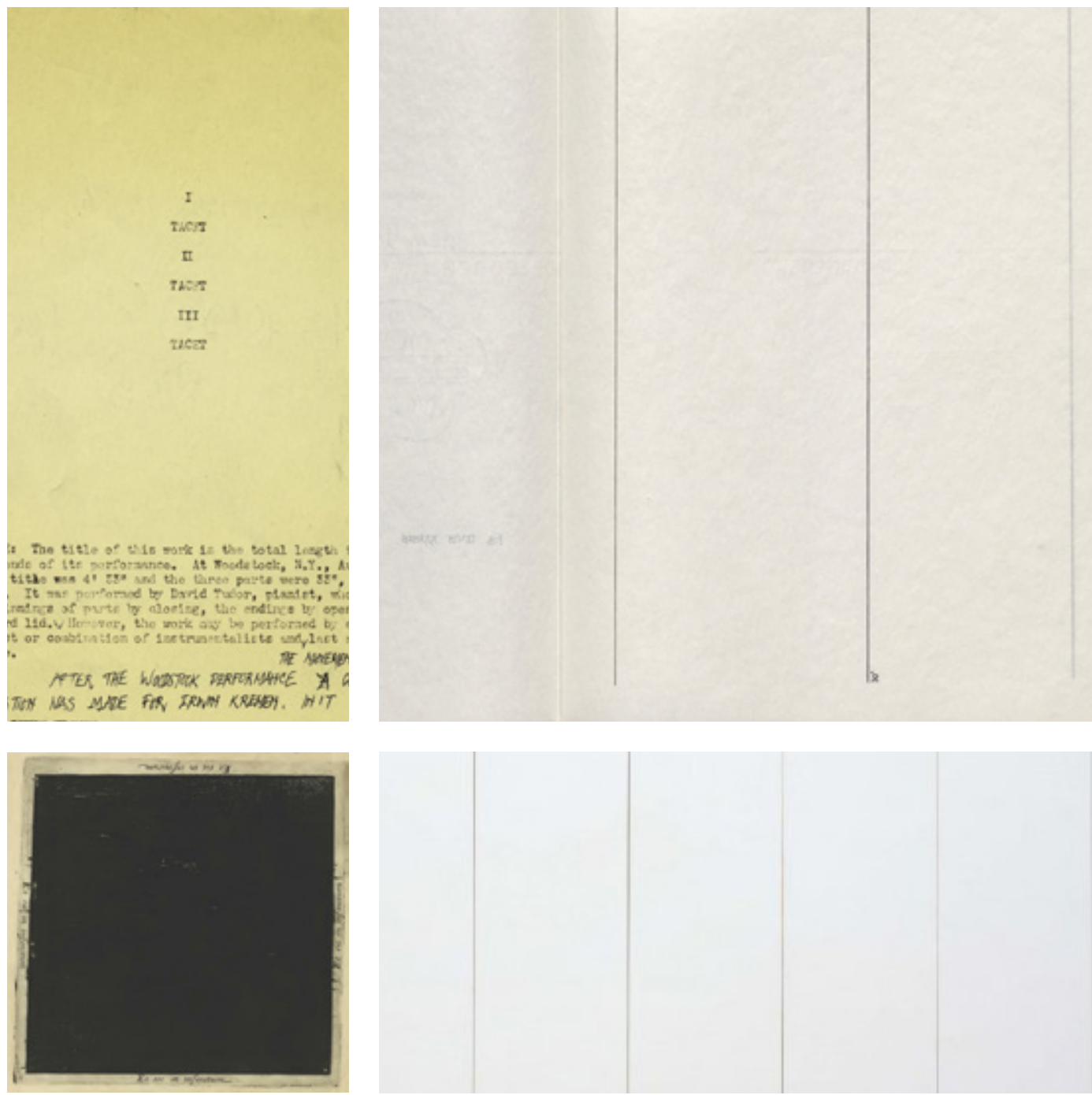

9798

Figura 95. John Cage, versión mecanografiada de 4'33" (Tacet) (1960)

Figura 96. John Cage, 4'33": For Any Inst[r]ument or Combination of Instruments. Graphic score in proportional notation (1953)

Figura 97. Robert Fludd, Et sic in infinitum (1617)

Figura 98. Robert Rauschenberg, White Painting [seven panel] (1951) 
y el final de cada una de las tres partes en que se divide la obra. Así describe Calvin Tomkins ${ }^{48}$ la actuación de aquel día:

In the Woodstock hall, which was wide open to the woods art he back, attentive listeners could hear during the first movement the sound of wind in the trees; during the second, there was a patter of raindrops on the roof; during the third, the audience took over and added its own perplexed mutterings to the other "sounds not intended" by the composer. Wether this was a case of art imitating nature or nature imitating art is perhaps an open question. ${ }^{49}$

La partitura de 433" fue evolucionando a lo largo de los ańos. La original que interpretó Tudor (1952), era un papel de música clásico, con pentagramas pero sin notas. La lectura del tiempo de esta pieza con el sistema tradicional era complicada, por lo que Cage realizó un segundo manuscrito con motivo del cumpleaños de su amigo, el artista americano Irwin Kremen (manuscrito de Kremen, 1953). En ella, cada movimiento fue delimitado dibujando una línea vertical, y cada segundo correspondía a un octavo de pulgada medida en el papel. Una tercera versión, la más conocida, convierte la expresión gráfica en instrucciones mecanografiadas que enumeran los tres movimientos con números romanos acompañados por un texto en el que explica qué debe hacer el músico ${ }^{50}$ para interpretar la obra. ${ }^{51}$

La partitura 'en blanco' de Cage supone un ejemplo más de representación de la dualidad vacío/lleno que describe un proceso sin principio ni fin, logrando sustituir una postura egocentrista por otra cosmocentrista basada en la congregación de una multiplicidad de centros que provienen del exterior del hombre. Una idea desarrollada en otros ejemplos como la cartografía del infinito Robert Fludd ${ }^{52}$ o el mapa de La Caza del Snark ${ }^{53}$ de Lewis Carroll. 4'33”

48. Escritor y crítico de The New Yorker magazine.

49. Calvin Tomkins, The Bride and the Bachelors | Five Masters of the Avant-Garde. [Expanded Ed.] (New York: Viking Press, 1968), 119.

50. Transcripción de las instrucciones del manuscrito: «NOTE: The title of this work is the total length in minutes and seconds of its performance. At Woodstock, N.Y., August 29, 1952, the title was 4'33" and the three parts were 33", 2'40", and 1'20". It was performed by David Tudor, pianist, who indicated the beginnings of parts by closing, the endings by opening, the keyboard lid. However, the work may be performed by (any) instrumentalist or combination of instrumentalists and last any length of time.» Dieter Daniels y Inke Arns, eds., Sounds like Silence: John Cage, 4'33": Silence Today: 1912, 1952, 2012 (Leipzig: Spector, 2012), 129.

51. Ibid., 26.

52. Para hacer más entendible el conocimiento del universo, la primera imagen de la enciclopedia de Robert Fludd corresponde a un inquietante cuadrado negro enmarcado por un espacio blanco, en el que puede leerse la inscripción "Et sic in infinitum" (así hasta el infinito) ocupando el lugar habitual de los cuatro puntos cardinales. La visión cósmica de Fludd comienza entonces con una maravillosa representación de lo desconocido, donde el caos primordial es representado por una masa indefinida negra que se extiende al infinito.

53. En el mapa que el capitán del barco encargado de atrapar aquel animal mitológico entregó a tripulación para 
es el germen de una nueva notación en la que el compositor no construye objetos cerrados, sino que abre procesos.

Unos años después de la composición de 4’33”, John Cage impartió una docena de cursos sobre 'composición experimental' en la New School for Social Research, de Nueva York entre 1956 y $1960 .^{54}$ A sus clases asistían compositores, coreógrafos, actores, poetas y artistas plásticos a los que alentó a probar nuevos materiales y estrategias de azar para la composición, como el empleo de objetos encontrados o la planificación de acciones. Muchos de sus alumnos, al no ser profesionales de la música, expresaban sus propuestas por medio de palabras, signos o gráficos. De esta manera, cualquier elemento gráfico u objeto físico se convertía en un signo susceptible de ser interpretado sonoramente. ${ }^{55}$ Las clases de Cage fueron determinantes para muchos de sus alumnos como Allan Kaprow, Yoko Ono, o George Brecht, quienes acabarían siendo integrantes del movimiento Fluxus.

George Brecht (1926-2008), químico de profesión e hijo de músico ${ }^{56}$, aprendió de Cage los procedimientos para generar partituras musicales mediante procedimientos aleatorios y a apreciar el sonido del entorno como ready-made auditivo ${ }^{57}$. Sumando estos conocimientos, y continuando el camino iniciado por la obra 4'33', Brecht desarrolla las partituras-evento:

In composing music, the composer permits an experience by arranging a situation within which sound arises. If a musical score (sound score) prepares a musical (sound) situation, the event-score prepares one for events in all dimensions...

Rather than an image of a concrete moment in life, it is a signal preparing one for the moment itself.

Event scores prepare one for an event to happen in one's own now. ${ }^{58}$

Las partituras-evento, en contraposición a la tarjeta postal que mencionaba Cage, rechazan

la expedición estaban contenidas todas las rutas posibles, y los marineros, felices, comprobaron que todos eran capaces de interpretar aquel mapa.

54. Joseph, Experimentations, 133

55. Maderuelo, «Música gráfica», 40.

56. Influencias musicales en su obra explicadas por George Brecht. Cfr. George Brecht et al., eds., George Brecht, events: eine Heterospektive ; [anlässlich der gleichnamigen Ausstellung im Museum Ludwig, Köln, 17. September 2005 - 8. Januar 2006 und im MACBA Museu d'Art Contemporani de Barcelona, 25. Mai - 3. September 2006] (Köln: König, 2005), 238.

57. Sobre la importancia del readymade en la obra de Brecht: «The link between Cage's sound and Duchamp's readymade is crucial and would be extraordinary important for Brecht's work. The question of the relationship of the readymade to photography would be picked up almost decade later in Conceptual Art, as would be the distinction between "readymade structure" and "readymade content".» Ibid., 52.

58. George Brecht, "Events (Assembled Notes)," unpublished manuscript, (1961). George Brecht Notebool vii, March-June 1961, citado en Ibid., 16. 
la imagen estática para proyectar un momento. Las numerosas partituras de Brecht reducen a unas simples líneas una acción -sonora o no-, sintetizando la estructura del espacio y el tiempo de una obra según el modelo bergsoniano del acto en el que «la percepción dispone del espacio en la exacta proporción en que la acción dispone del tiempo" ${ }^{59}$. Las tarjetas de instrucciones para cada evento reflejan el pensamiento o la acción que involucra al espectador con el espacio y con los objetos que tiene a su alrededor. El resultado es la producción de un campo abierto a la experiencia en el que el autor desaparece en el momento en el que un 'ejecutor' realiza la acción descrita.

Los Happenings y Environmments de finales de los años cincuenta vertieron las ideas de John Cage en el contexto visual a través de la representación performativa. En el año 1959, maestro y alumno realizaron dos obras de 'acción', Water-Walk y Drip Music, respectivamente, que sirvieron para explorar los límites que surgen en la interacción entre el espacio, el cuerpo, los objetos y el sonido.

Water-Walk, de John Cage, fue estrenada en el programa de televisión italiano Lascia o Raddoppia? La obra consistía en una performance de tres minutos de duración que concibió siguiendo sus técnicas basadas en el azar. La partitura consta de varias partes: una lista de treinta y cuatro objetos relacionados principalmente con el agua (una bañera, peces de juguete, una olla a presión, cubitos de hielo, un pato de goma, etc), un plano que muestra la ubicación de los instrumentos y de los objetos que se han de utilizar, tres páginas con una línea de tiempo de un minuto cada una que contiene las descripciones, la duración, y una lista de anotaciones pictográficas sobre algunas de las acciones a realizar en el orden propuesto. ${ }^{60}$

Fluxus seguirá el ejemplo de Cage y dará un paso más en la síntesis y depuración de sus performances. En contraposición al exceso y redundancia de información de Water-Walk, George Brecht plantea en sus partituras-evento una configuración espacial cerrada, pero de resultado impredecible. Brecht aísla el acontecimiento y lo proyecta en una actuación que llamó 'evento'. Empleando la partitura como mediador. El 'evento' da nombre al espacio entre el 'ejecutante' y el 'observador' o 'recibidor' del acto, designando un campo abierto a la experiencia. ${ }^{61}$

Mediante unas simples indicaciones, Drip Music (1959) de George Brecht, indica un evento

59. «Cualquiera que sea esa relación, cualquiera sea pues la naturaleza íntima de la percepción, se puede afirmar que la amplitud de la percepción mide exactamente la indeterminación de la acción consecutiva, y en consecuencia enuncuar esta ley: la percepción dispone del espacio en la exacta proporción enque la acción dispone del tiempo.» Henri Bergson, Materia y memoria: ensayo sobre la relación del cuerpo con el espiritu (Buenos Aires: Cactus, 2010), 47.

60. Fetterman, John Cage's Theatre Pieces, 32-36.

61. Cfr. Brecht et al., George Brecht, events, 18. 

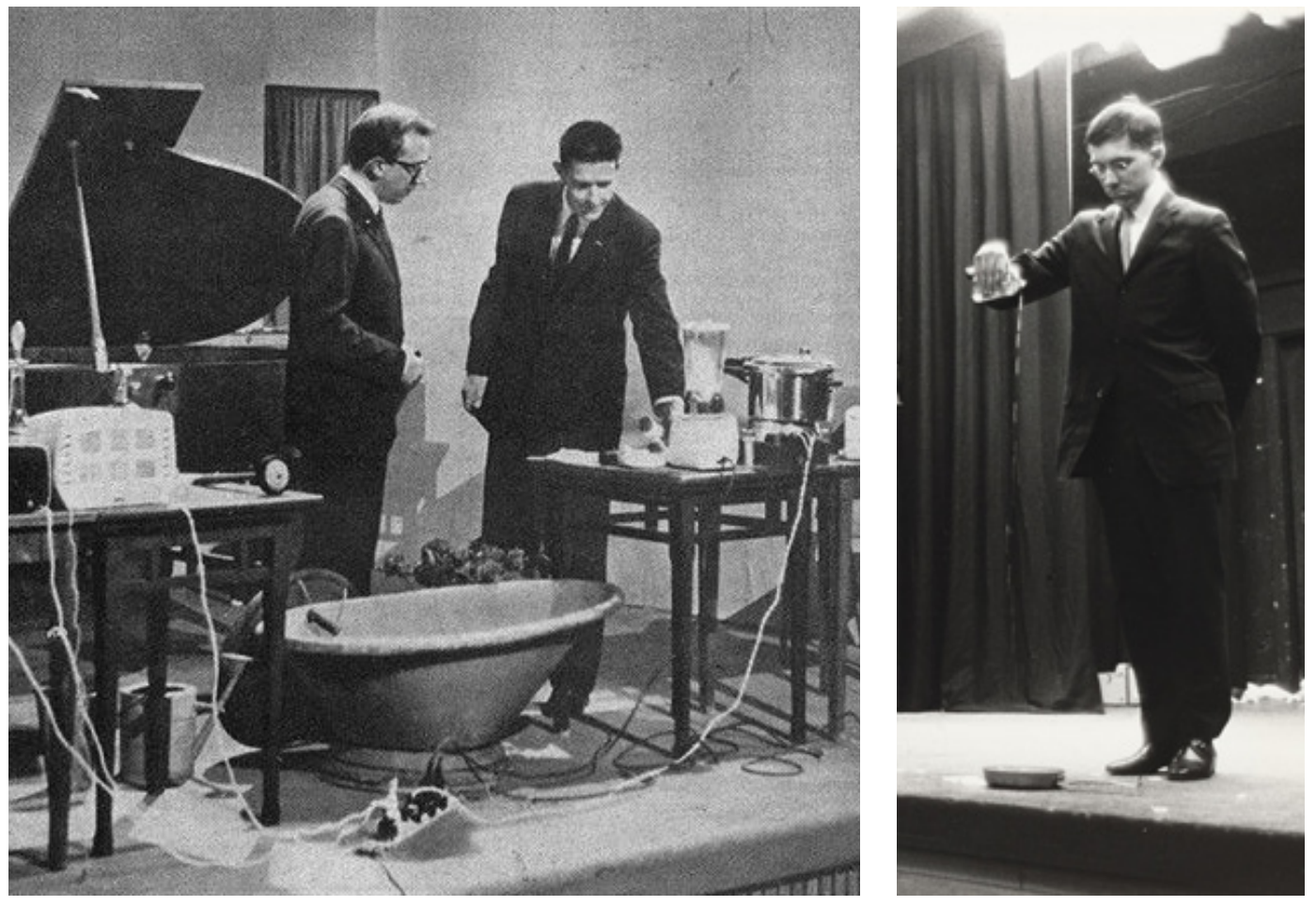

Figura 99. John Cage interpretando Water-Walk (1959)

Figura 100. George Maciunas interpretrando Drip Music en Amsterdam (1963). Foto: Oscar Van Alphen 
sonoro infraleve ${ }^{62}$. El goteo del agua en un cuenco vacío que va llenándose lentamente, dirige a la audiencia hacia la percepción misma. Brecht sitúa la música y el evento auditivo dentro de la imaginación del lector u oyente, y llega al sonido a través de la sugerencia, mediante la imagen sonora que denota el lenguaje, apoyándose en la escritura.

Un último ejemplo de cómo la influencia de Cage impulsó formas experimentales de tratamiento del sonido del entorno y su representación lo encontramos en el músico francés Luc Ferrari (1929-2005). Discípulo de Varèse y Schaeffer, Ferrari coincidió con Cage en el año 1958 durante la celebración del Internationale Ferienkurse für Neue Musik de Darmstadt, convirtiéndose en su mayor referente. Su obra Presque Rien $n^{o} 1$, le lever du jour au bord de la mer (1967-70), se sitúa al inicio de la normalización del término Soundscape en el ámbito de la de música concreta post-Schaefferiana. Este trabajo, -el primero de cinco obras tituladas Presque Rien, haciendo una serie análoga a los Paisajes imaginados de Cage-, recoge los sonidos grabados mediante un micrófono colocado en una ventana frente al mar durante su estancia en Vela Luka, un pequeño pueblo de pescadores de Croacia. ${ }^{63} \mathrm{La}$ obra toma los sonidos del exterior, el murmullo aleatorio y ambiental de la vida cotidiana del puerto, y los procesa para componer una 'imagen sonora idealizada' ${ }^{64}$. Una vez alcanzada la 'imagen ideal' de veintiún minutos de duración, Ferrari transcribió en un papel milimetrado las duraciones de cada uno de las 'acciones' que van apareciendo en la secuencia. ${ }^{65}$

Este tipo de notaciones espacio-temporales, entre la narración y el objeto artístico, sustituyen la música por un diálogo entre los oyentes y el entorno que hace desaparecer de forma inmediata al autor de la obra. Las partituras-evento no sólo se limitan a recoger acciones pasadas asociadas al sonido del paisaje (como hace Ferrari), sino que pueden funcionar de la misma forma que lo hace un plano, proyectando una acción sonora delimitada por un marco perceptivo. En este segundo caso, las partituras se convierten en vehículos de la experiencia del

62. «The infra-thin of sound is situated at the divergence between sound and what remains of it, that is to say its trace. The infra-thin is what persists of the sonorous when we take again the audible, constituting, in short, an imperceptible. The trace stands in an intimate relation to that from which it emanates. [...] The infra-thin is an absent presence, a residue of presence that marks and actualizes the difference, as minuscule as it may be, between what has been and what persists, at the point where the trace draws out a presence to the point of disappearance. The notion of the infra-thin is positioned dialectically between contact and the attenuation of contact, between the present and the evaporated. This is why the sound of the trousers is not itself infra-thin, but signals the infra-thin.» Francois J. Bonnet, The Order of Sounds: A Sonorous Archipelago (Oxford: Urbanomic Media Ltd, 2016), 32; Cfr. Marcel Duchamp, Escritos: Duchamp del signo, seguido de notas (Barcelona: Galaxia Gutenberg [etc, 2012), 21-25.

63. Luc Ferrari, Presque rien no. 1: le lever du jour au bord de la mer: auvre sur support audio: cycle Presque rien, 1st edition (Paris: Maison Ona, 2018).

64. Grubbs, Records ruin the landscape, 61-62.

65. Ferrari, Presque rien no. 1. 

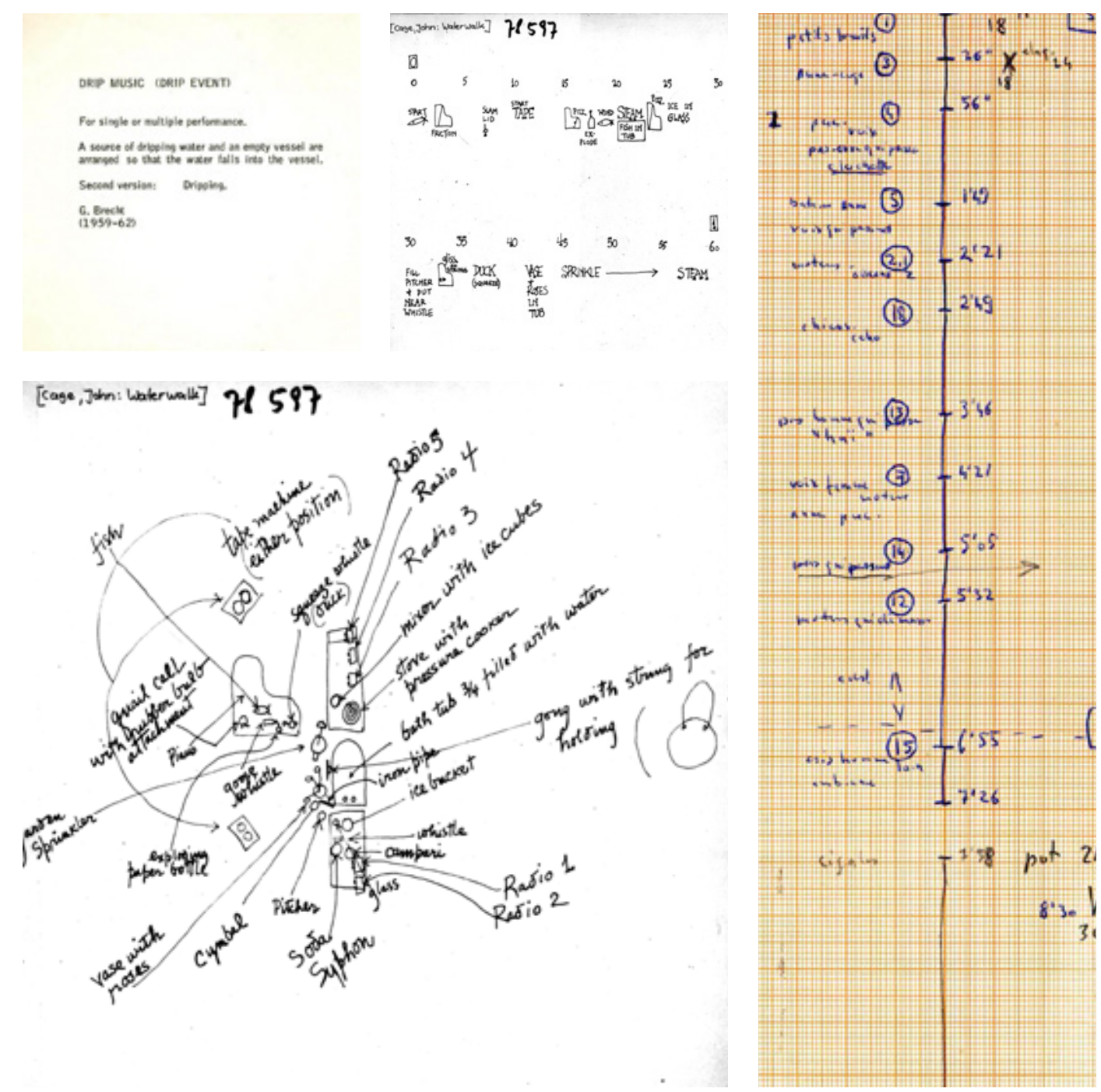

101102

103104

Figura 101. George Brecht, Drip Music (1959)

Figuras 102-103. John Cage, Water Walk (1959)

Figura 104. Luc Ferrari, Presque rien no.1 (1970) 
paisaje o en estimulantes de la imaginación del espectador.

Por tanto, las partituras-evento pueden ser instrumentos tanto generadores como representativos. Si la acción descrita inaugura un proceso abierto pero delimitado por una serie de reglas -como hacen Cage o Brecht-, la partitura genera un espacio en un instante determinado; $\mathrm{Si}$, por el contrario, describe un espacio a través del sonido como hace Ferrari, la partitura y su resultado serán una fotografía de los sonidos que ocurren en un determinado instante y lugar, convirtiéndose la reproducción en un objeto.

\subsection{Surtidores de Signos}

Tras un primer encuentro en el apartamento de Yoko Ono, el artista Robert Morris (19312018) escribió una carta ${ }^{66}$ a John Cage en la que le presentaba algunas de sus autodenominadas 'máquinas' como The Performer Switch, Clock, The Plus and Minus Box o Box with the Sound of its Own Making. Esta última pieza consistía en una caja de madera cúbica con un altavoz oculto en su interior que amplifica la grabación de los sonidos recogidos durante las tres horas y media que duró el proceso de construcción de la misma. En su escucha se aprecian golpes de martillo, sierras cortando maderas, objetos que caen... la obra hace presente el proceso pasado que dio origen al resultado que se ve.

Una de las primeras personas que vio Box with the Sound of its Own Making (1961) en el estudio neoyorquino de Morris fue John Cage, quien sentado frente a la caja, escuchó la grabación durante tres horas ${ }^{67}$. La tecnología, al igual que en los paisajes imaginarios, desempeña el papel de intermediario entre lo real (la presencia de la caja) y el pasado (las imágenes mentales que evocan los sonidos del interior de la caja). De esta forma, «haciendo explícita la presencia de la caja como forma material a través de la repetición de su propia construcción» ${ }^{68}$, se produce una tensión entre realidad y experiencia de la realidad. Si la realidad impone una caja, la experiencia de la realidad se compone de dos, pues aunque no se vea, el sonido construye una segunda caja virtual mediante la narración sonora de los procesos pasados que contiene. La caja de Morris construye una duración a través del sonido que, al igual que lo hace el paisaje,

66. Carta del 27 de febrero de 1961, Robert Morris, «Letters to John Cage», October 81 (1997): 71, https://doi. org/10.2307/779019.

67. «Box with the Sound of Its Own Making», The Seattle Art Museum, accedido 13 de junio de 2020, http:// localhost/objects/11616/box-with-the-sound-of-its-own-making;

68. LaBelle, Background noise, 84. 
formula el problema de la representación y la experiencia sirviéndose de la escucha activa como herramienta.

Las clases de composición experimental de Cage en Nueva York fueron el germen del colectivo internacional de artistas de neo-vanguardia Fluxus. ${ }^{69}$ Fundado por el artista y diseñador lituano-americano George Maciunas en 1962, Fluxus acogía bajo su nombre una serie de festivales, acciones y publicaciones que con rapidez extendieron por Europa, América y Japón las prácticas cageanas $^{70}$. En sus comienzos, en un esfuerzo por categorizar las prácticas artísticas de Fluxus, Maciunas correlaciona en un esquema «las 'máquinas artísticas', las 'máquinas musicales' y los 'entornos sonoros' en una categoría en la que parece incluirlo todo, desde Jean Tinguely y el arte cinético hasta la música en cinta magnetofónica y los dispositivos electrónicos generadores de sonido $»^{71}$. Desarrolladas en paralelo a las performance e instalaciones sonoras, las denominadas por Maciunas como 'máquinas poéticas', suponían otra forma de entender el cuerpo y el entorno a través de objetos. Este tipo de máquinas, desarrolladas en paralelo a un interés creciente por la semiótica, alentó un cambio en la manera de pensar el sonido a través de los objetos.

Según la filósofa y teórica literaria Julia Kristeva, la semiótica, como ciencia que estudia los signos, tiene el propósito de hallar el lenguaje adecuado para describir el objeto-signo (gesto, sonido, icono, etc.), sin considerarse dicho hallazgo como un proceso terminado, sino como una construcción que se encuentra en constante evaluación y replanteamiento. ${ }^{72}$ Compuesto por el significante y el significado, el signo reproduce «la diferencia entre lo sensible y lo inteligible, y con ello, la metafísica en su totalidad. ${ }^{73} \mathrm{El}$ sonido, entendido como el signo que nos desplaza hacia la metafísica de aquello que lo emite -como ejemplifica la caja de Morrisrevela un modelo de transformación y entendimiento en el que la palabra, el signo y el símbolo quedan unidos por un proceso que parte de la percepción y termina en la expresión.

69. Natilee Harren, Fluxus Forms: Scores, Multiples, and the Eternal Network (University of Chicago Press, 2020),

70. «En España el eco de FLUXUS será ZAJ, que aglutinará en torno a Juan Hidalgo una serie de fantásticas actividades de raíz estrictamente cageiana.» Barber y Círculo de Bellas Artes (Madrid), John Cage, 59.

71. Liz Kotz, «Máquinas Poéticas», en \pm 1961. La Expansión de Las Artes (Madrid: Museo Nacional Centro de Arte Reina Sofía, 2013), 60.

72. Cfr. Ruth Nayibe Cárdenas Soler y Dennys Martínez Chaparro, «El paisaje sonoro, una aproximación teórica desde la semiótica», Revista de Investigación Desarrollo e Innovación: RIDI 5, n. 2 (Enero-Junio) (2015): 129-40.

73. Patricio Marchant, «Introducción: Presencia y escritura», en Tiempo y presencia, de Jacques Derrida (Santiago, Chile: Eds. Universidad Diego Portales, 2015), 15. 

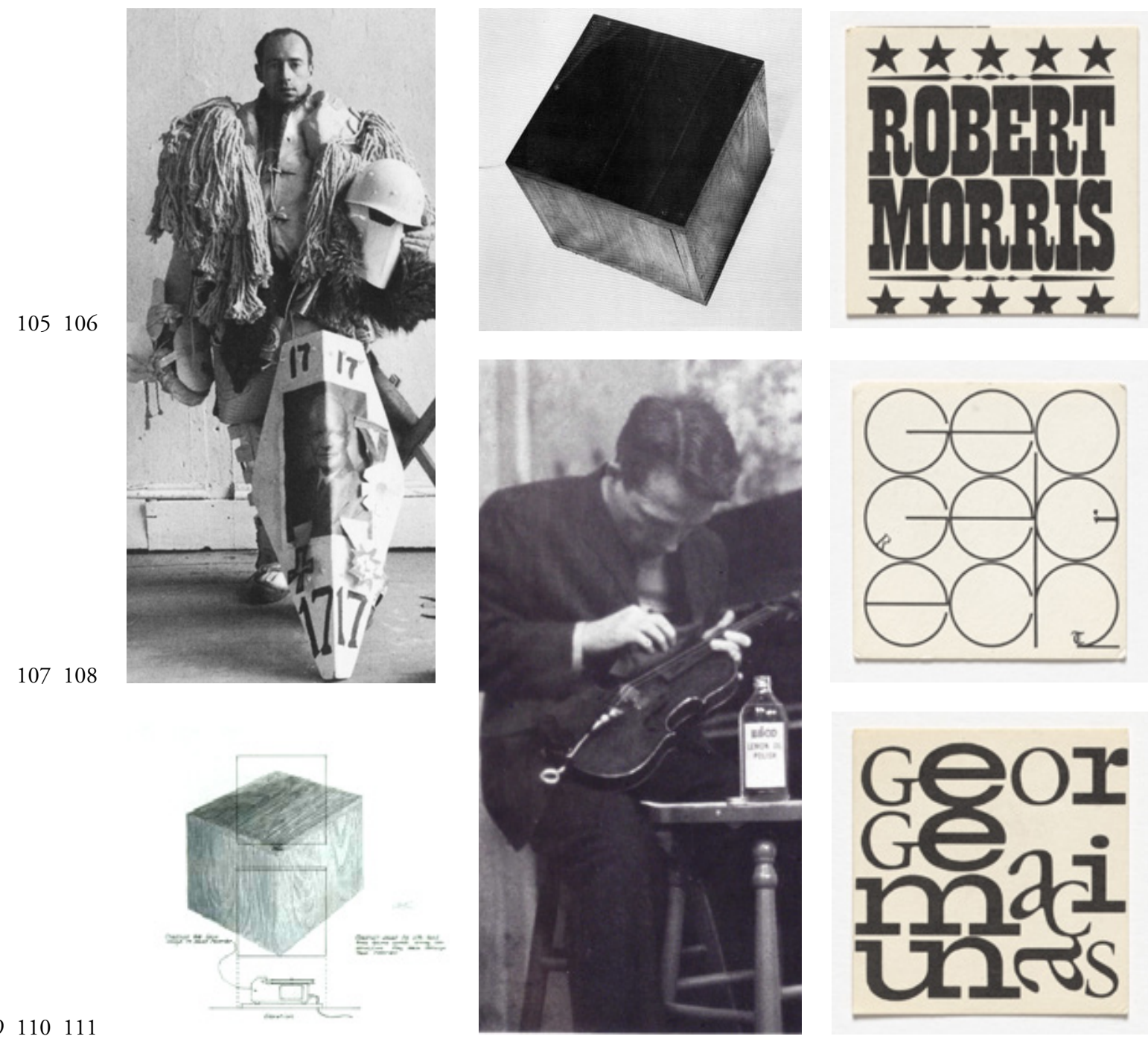

Figura 105. Robert Morris, Box with the Sound of Its Own Making (1961)

Figura 106. George Maciunas, Name card for Robert Morris (1964)

Figura 107. Robert Morris in costume for War (1963)

Figura 108. George Maciunas, Name card for George Brecht (1964)

Figura 109. Robert Morris, Dibujos para Box with the Sound of Its Own Making (1965)

Figura 110. George Brecht interpretando Solo for Violin (1964). Foto: George Maciunas

Figura 111. George Maciunas, Name card for George Maciunas (1964) 
A finales de los sesenta, autores como A. Kondratrov ${ }^{74} \mathrm{o}$ artistas como Juan Navarro Baldeweg consideraron la estrecha relación que la semiótica comenzó a establecer con la cibernética. Bajo la influencia de las posibilidades que aportaban las nuevas herramientas informáticas, el hombre, al animal o la máquina se consideraban como «un dispositivo cibernético que realiza operaciones sobre diversos sistemas de señales y textos». ${ }^{75}$

Gran parte de mi trabajo ha consistido precisamente en activar signos, por medios artísticos diversos y en diferentes órdenes del contexto físico, capaces de desencadenar estímulos sensoriales y provocar percepciones de soldadura de nuestro ser y el entorno. ${ }^{76}$

El universo plástico de Juan Navarro Baldeweg posiciona la triada sujeto, objeto y mundo en una red de puntos clave en forma de piezas. Desarrolladas a partir de las energías presentes en un espacio y un tiempo concretos, sus piezas son surtidores de signos que fuerzan a pensar emitiendo señales. A través de ellas, el sujeto percibe un mundo esencial filtrado a través de objetos que avanzan en el conocimiento de la representación de lo invisible en un proceso de investigación que, además, es artístico. Algunas de sus piezas sonoras sugieren inquietudes premonitorias de la obsolescencia de la tecnología ante la acumulación de información digital. Obras que desde el sonido, en su condición de parámetro fugaz en constante creación y destrucción, cuestionan el registro y la representación del entorno mediante la creación de analogías perceptivas. Algunas de sus piezas más conocidas surgen del sentir de la estructura sonora de un espacio. Así, obras que finalmente se enmarcan en el campo visual, como $L a$ columna y el peso, tienen su origen en el planteamiento de la condición vibratoria y sonora del mundo y su sentir en el cuerpo. En otros casos, sus piezas sonoras sugieren inquietudes que toman actualmente pleno sentido como el Transductor luz-sonido.

\subsection{TRANSDUCTOR LUZ-SONIDO (I970-7I)}

Durante el curso 69-70, Juan Navarro Baldeweg recibe una beca para realizar un trabajo de investigación en el Centro de Cálculo de la Universidad de Madrid con el título, Aplicaciones de la teoría de autómatas en arquitectura y urbanismo. El trabajo tenía como objetivo investigar sobre las posibles aplicaciones del cálculo automático y los ordenadores en la enseñanza, el

74. (1937-1993) Lingüista, biólogo y escritor ruso.

75. A. Kondratov, Sounds and Signs (Central Books Ltd, 1969), 11. Traducción de la autora.

76. Juan Navarro Baldeweg, Escritos, 1. ed, Pre-textos. Ensayo 1449 (Valencia: Pre-Textos, 2017), 235. 
arte y la arquitectura. ${ }^{77}$ Parte de los resultados se publicaron en una texto titulado Arquitectura Informática ${ }^{78}$, publicado en 1972 en la revista Arquitectura. El texto recoge los resultados de la construcción y aplicación práctica de un modelo experimental concebido para demostrar los planteamientos teóricos de la emergente arquitectura de la información.

Para Navarro, los nuevos medios de comunicación darían lugar a una nueva manera de ser arquitecto cuya función principal sería atender a los problemas y necesidades surgidos de la manipulación de la información. De forma premonitoria, Navarro afirma que «la inserción humana en los procesos de la creación, transmisión y asimilación de la información en el trabajo, en el papel social desarrollado por cada individuo y en el ocio privado y colectivo caracterizará una calidad de vida ${ }^{79}$ y, bajo esta premisa, define la existencia de un entorno informático en el cual se vive y opera.

Los factores clásicos que intervienen en la comunicación (el emisor, el medio de transmisión, el receptor, el sistema de referencia, el código, el lenguaje y el mensaje) se analizan desde varias perspectivas. Comenzando por el enfoque semiótico, el discurso de Arquitectura Informática desarrolla las nociones básicas de la formación de la imagen mental a través de símbolos. Las palabras de Navarro sustentan el esquema que muestra las vías de representación del concepto paisaje sonoro en el primer capítulo de la tesis, en el que partiendo del sonido del paisaje como signo inicial, se desencadena un proceso de transducciones entre el interior y el exterior del sujeto que desemboca en la producción individual de imágenes mentales, verbales o materiales ligadas al sonido:

El fenómeno lingüístico dirigirá también nuestra atención al sistema nervioso humano, a las relaciones, por conexiones neuro-atómicas que van de lo sensorial a lo motórico; y al modo en que se realiza la simbolización, o sea, sobre la facilidad de la mente humana para interiorizar y almacenar "imágenes" o "patterns" codificados neurológicos del mundo exterior. Estas y otras observaciones dirigen la mirada hacia lo que rotularíamos como dominio interno del lenguaje. Hay también un dominio externo. Aún cuando el material a tratar por el arquitecto informático no parece tan tangible como otras entidades físicas habitualmente manejadas se incorporan físicamente. Para comenzar, el espacio, por tanto un elemento arquitectónico reconocido, juega un papel importantísimo. Esto es bien evidente en los medios de transmisión artificial, cada uno con su alcance espacial, con una

77. Ignacio Moreno, Dibujos mentales: Principios del universo creativo de Juan Navarro Baldeweg, Edición: 1 (Madrid: Ediciones Asimétricas, 2017), 116.

78. Juan Navarro Baldeweg, "Arquitectura informática», ed. Colegio Oficial de Arquitectos de Madrid, Arquitectura, n. ${ }^{\circ}{ }^{\circ} 161$ (mayo de 1972): 16-19.

79. Ibid., 16. 

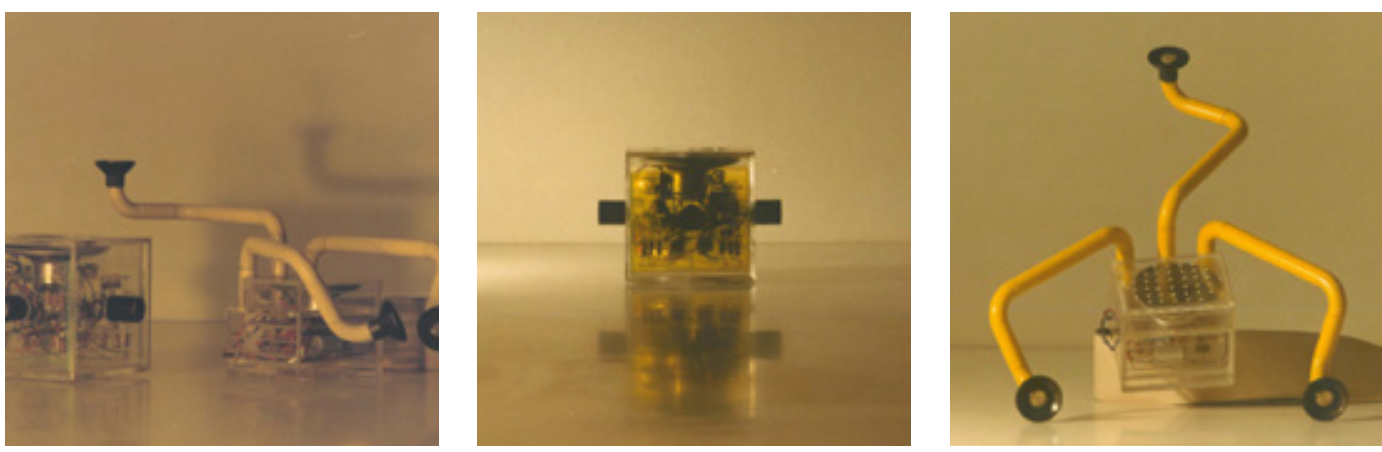

112113114
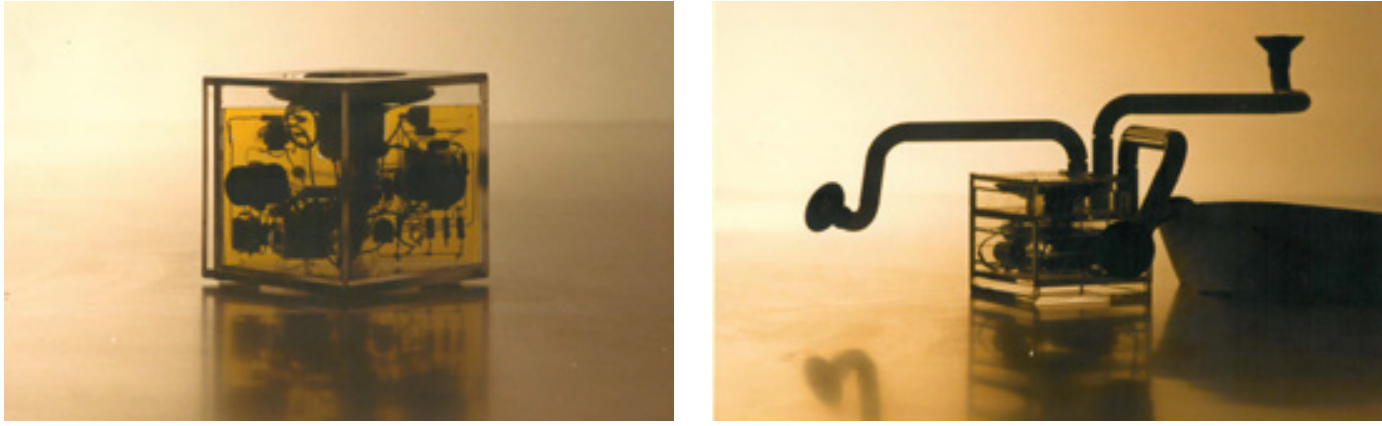

115116
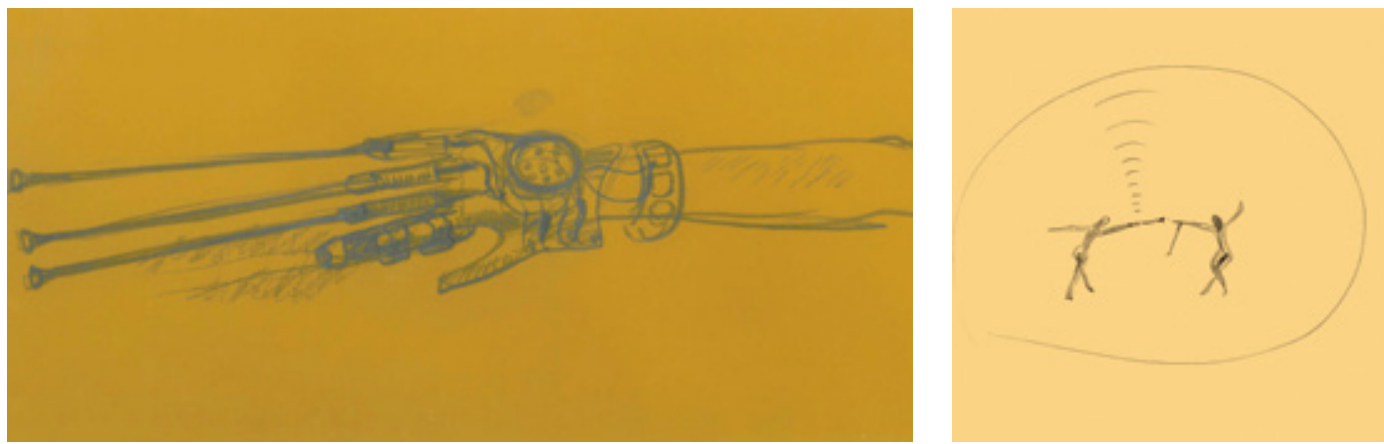

Figuras 112-116. Juan Navarro Baldeweg, Arquitectura Informática. Transductor luz-sonido (1970-1971) Figura 117. Juan Navarro Baldeweg, Arquitectura Informática. Croquis para el emisor de luz (1970-1971)

Figura 118. Juan Navarro Baldeweg, Arquitectura Informática. Dibujo para explicar el funcionamiento del sistema (1970-1971). 
órbitas asociadas a las potencias del emisor-receptor. Pero aún en las modalidades naturales, biológicas puras, se manifiesta la estructura de una geometría subyacente. De acuerdo con la variedad de enlaces o vínculos interindividuales existen espacios visuales, auditivos, táctiles, olfativos y termales. ${ }^{80}$

Con el fin de ilustrar lo que puede llegar a ser la arquitectura concebida en términos de uso y la disposición de mecanismos de tratamiento de la información, al igual que hace Lanier con el khane en sus conferencias, Juan Navarro toma el sonido para explicar realidades inmateriales del universo informático, y encuentra en un instrumento transductor de seńales el medio para ejemplificar la conversión sensorial de un estímulo exterior al interior y viceversa.

El modelo experimental construido, el ISOFO (integrador social óptico-fónico-óptico), constaba de dos partes: un transductor luz-sonido acoplado a un cinturón que, al igual que el optófono d'Albe ${ }^{81}$, era sensible a la luz traduciendo impresiones lumínicas en notas musicales $\mathrm{u}$ oscilaciones de frecuencia variable; y una linterna con la que cada participante realizaba el vínculo óptico desde la distancia con los transductores.

El juego de interacciones personales es coordinable para alcanzar ciertas metas -rítmicas, sonoras- integrales resultantes de la acción a dúo o múltiple y la del grupo entero. Las posiciones mutuas, así como los movimientos del cuerpo y de los miembros, sirven para producir una cadena de momentos fónicos. La interacción entre los participantes con metas comunes sirve para conjuntar y adaptar las actividades conformando un sistema unitario. ${ }^{82}$

Los vínculos fónicos, extraorgánicos, conectan las vibraciones producidas desde cada transductor con el oído de cada participante, integrándose los sonidos producidos en el medio aéreo que los envuelve. Navarro emplea, como Boulez, la imagen de la nube $e^{83}$ para describir la agrupación de sonidos producidos por unos o por otros, desmontando la unidireccionalidad predominante en los sistemas de información. Así, el ISOFO se convertía en un instrumento capaz de producir información que, al mismo tiempo, era destruida y respondida al unísono por toda la comunidad. En otras palabras, Navarro convierte a cada participante en músico y bailarín al mismo tiempo empleando el tacto a distancia de la luz y el sonido, tal y como insinúa

80. Ibid.

81. Ver Capítulo primero, apartado 1.3.1. Procesos de conversión de señales: auscultación, transducción y reproducción.

82. Navarro Baldeweg, «Arquitectura informática», 18.

83. Ver Capítulo segundo, apartado 1989. Le pays fertile: Consideraciones musicales sobre la obre de Paul Klee por Pierre Boulez. 
el montaje de 'la japonesa'. Una idea de continuidad entre el cuerpo del instrumentistas y su instrumento resuena con el Paukenspieler (1940) de Paul Klee, en el que el cuerpo del timbalero aparece fusionado con su timbal.

Según se interprete, una máquina técnica compleja como el ISOFO en un instrumento musical, en el sentido pleno de la expresión. Como máquina de producir signos, el Transductor luz-sonido ${ }^{84}$ fuerza a pensar, al mismo tiempo que incorpora las condiciones del gesto del instrumentalista, pues es simultáneamente «semiótico (significa algo), epistémico (depende de los conocimientos aportados por una sensibilidad táctilo- auditivo-cinestésica) y ergonómico (realiza un auténtico trabajo)» 85

Al considerar holísticamente el grupo o la colectividad que conforma el sistema, le caracterizaremos también como un elemento activo con entradas, salidas y estados internos. Interpretaríamos las entradas y salidas como los vínculos que van desde las partes al todo y del todo a las partes, por medio del ruido producido y oído, respectivamente. La sucesión de estados fónicos define la línea de estados internos del grupo. ${ }^{86}$

Distancia, territorio, direccionalidad de la información, aspectos temporales... El Transductor luz-sonido de Juan Navarro y las consideraciones en torno al mismo, remiten directamente a los fundamentos de esta investigación. El ISOFO es capaz de crear 'imágenes' individualmente y proporcionar un universo externo de dimensiones múltiples. Alejado de referencias naturalistas, Baldeweg construye un artefacto que media entre el sujeto y el entorno para crear y representar al mismo tiempo un espacio dinámico, efímero y cambiante.

\subsubsection{LA COLUMNA Y EL PESO (1972)}

La obra que el pintor y arquitecto Juan Navarro Baldeweg desarrolló entre 1971 y 1975, durante su estancia en el CAVS, supone una aportación, directa aunque distanciada, al arte sonoro español de la época. ${ }^{87}$ Los dos trabajos de esta etapa que se han visto en el capítulo

84. El Transductor luz-sonido forma parte del conjunto Sounding Mirror o Espejo sonoro (1970-1972), que incluye dibujos, esquemas de los circuitos electrónicos, collages...Espejo sonoro fue también presentado en el CAVS. Desde 2017 forma parte de la colección del Centre Pompidou de París.

85. Bernard Sève, El instrumento musical: un estudio filosófico, 2018, 88.

86. Navarro Baldeweg, «Arquitectura informática», 18.

87. Así lo demuestra la incorporación de su obra en la exposición Escuchar con los ojos. Arte sonoro en España, 1961-2016 (Fundación Juan March, 14 de octubre de 2016 - 15 de enero de 2017). Ver Escuchar con los ojos. Arte sonoro en España, 1961-2016, Edición: 1 (Madrid: Fundación Juan March, 2016), 224-27. 

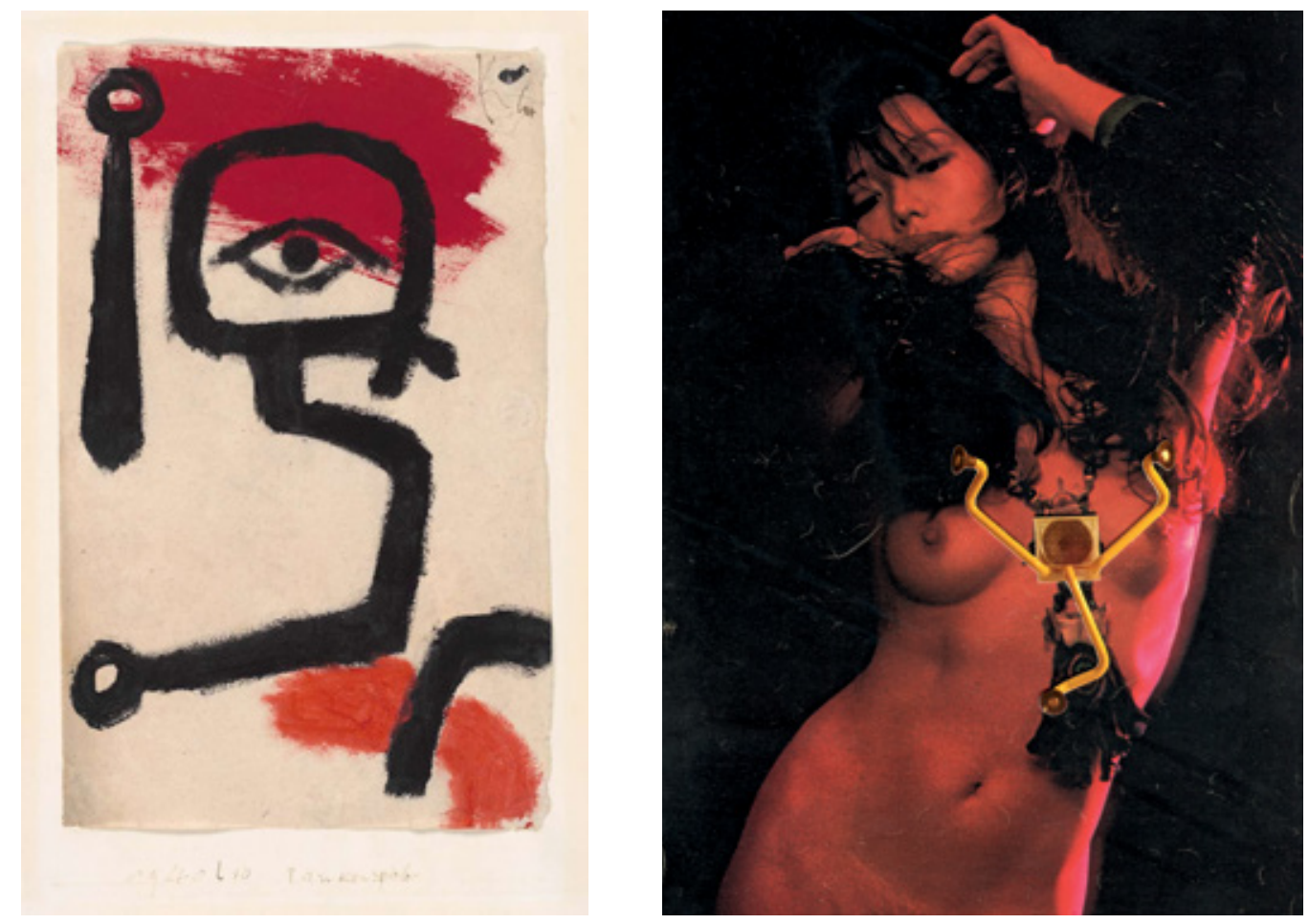

Figura 119. Paul Klee, Paukenspieler (1940)

Figura 120. Juan Navarro Baldeweg, Arquitectura Informática. Fotomontaje (1979-1971) 
segundo, los carteles que diseñó para Maryanne Amacher y para un homenaje colectivo a John Cage en la Kirkland House de Harvard, son muestra del trabajo colaborativo entre compañeros de distintas disciplinas artísticas en el MIT. Algunas de las piezas más conocidas de Juan Navarro surgen del sentir de la estructura sonora de un espacio. Así, obras que se enmarcan en el campo visual y gravitatorio, como La columna y el peso o Partitura, tienen su origen en el planteamiento de la condición vibratoria del mundo y su sentir en el cuerpo, algo que le llevó a considerar las superficies arquitectónicas como membranas o tímpanos-transmisores de las vibraciones latentes. ${ }^{88}$

Alguien dijo que podríamos leer o reproducir en la superficie de la pintura el sonido de la habitación en que se produjo, descubrir a través del análisis de esa superficie el sonido en su huella impresa cuando el óleo aún está húmedo. Por ejemplo, podríamos teóricamente conocer la conversación que tuvo Leonardo con la Gioconda. Habría que crear unos filtros finísimos para distinguir las voces que habrían dejado esa huella...finalmente uno desearía hacer que las cosas fueran nítidas absolutamente. ${ }^{89}$

Los finísimos filtros que sugería Juan Navarro Baldeweg para conocer las conversaciones de Da Vinci justifican la elección de los surtidores de signos como instrumentos para la representación del concepto paisaje sonoro. Máquinas poéticas que permiten hacer visible la estructura de la dimensión sonora de un entorno partiendo del estudio de las condiciones espaciales que la contienen o provocan. Trabajando en esta misma dirección, François J. Bonnet desarrolla la investigación The Order of Sounds, donde a través del discurso contemporáneo sobre el sonido, revisa nociones clave como el silencio y la escucha reducida a través de Deleuze, Nancy, Adorno y Simondon. La búsqueda del grafismo de la escucha, no desde el oído, sino desde dentro de la estructura misma del sonido, marca la diferencia entre traza y huella sonora:

Even before materializing or becoming a signal, the sonorous -sound-in order to be, must leave a trace. Like a parasite, in order to exist it first of all needs a host. [...] it does not fix sound-all it can do is to reactualize it on demand, which is something entirely different. Without itself being presence, the trace draws sound toward a regime of permanence that is located upstream of any process of 'conservation'. It is the manifestation of sound, the 'both suprasensible and sensible' halo surrounding it, affirming and activating its existence. $^{90}$ Arquitectos de Madrid, Arquitectura, n. ${ }^{\circ} 274$ (octubre de 1988): 116.

90. Bonnet, The Order of Sounds, 7. 
La traza sonora es un infraleve, una 'presencia ausente' que marca la diferencia entre lo que ha sido y lo que persiste, en el punto en que la traza dibuja una presencia hasta el punto de desaparecer. ${ }^{91}$ Las descripciones de Bonnet fundamentan un enfoque duchampiano de la escucha donde huella y traza se diferencia en su materialidad. Mientras que el sonido adquiere una materialidad tangible a través de la huella, la traza supera al sonido. El eco y la memoria sonora son trazas, caminos inmateriales sobre los que el sonido se hace audible, un camino previo al signo sonoro que enfatiza la íntima relación que existe entre un sonido y aquello de lo que emana.

Las piezas invitan a deshacer expectativas y ver de un modo nuevo. Se produce una oscilación mental, un cuestionamiento entre recuerdo y novedad y eso favorece el encuentro con la dimensión inadvertida, la gravitación que pasa a protagonizar la escena. La imagen aparentemente estática es huella de una acción que transcurre ahí mismo. Se puede oír el murmullo de una interna inquietud energética. El objeto es transitivo en ese horizonte de interpretación, actúa en él. ${ }^{92}$

La pieza La columna y el peso, realizada en CAVS en 1972, es una herramienta precisa que provoca una mirada sonora. Tal y como la describe Juan Navarro, aunque se trata de una pieza silenciosa, «estimula el entendimiento de las bases físicas del sonido que se oculta en las propias vibraciones del espacio a las que hay que abrir nuevos sentidos. ${ }^{93}$ Las acciones asociadas a la obra La columna y el peso (1972), la disposición de un peso junto a una columna y su fotografía, tienen un origen musical..$^{94}$ Juan Navarro consideró la transmisión de vibraciones del forjado sobre el que reposaba el peso e imaginaba el suelo como una membrana vibratoria. El peso es el elemento que evidencia materialmente las vibraciones, creando un área de afección que varía en función de la distancia marcada entre el peso y los elementos estructurales del edificio-como la columna frente a la que se encuentra-.

Con una intención similar, Partitura (1973) es otra pieza de gravedad posterior que constituye una analogía visual de la transmisión del sonido a través del aire y los elementos arquitectónicos. ${ }^{95}$ Los dos cimbales en suspensión que componen la obra rastrean la traza del sonido mediante el movimiento ligero que induce el aire de la sala. Su disposición próxima

91. Ibid., 32.

92. Juan Navarro Baldeweg, Una caja de resonancia (Valencia, Spain: Editorial Pre-Textos, 2008), 23.

93. Memoria de trabajos del MIT. No publicada. Citado en Moreno, Dibujos mentales, 328.

94. Navarro Baldeweg, Escritos, 288.

95. En la cartela descriptiva de esta pieza, expuesta en el CAVS en 1973: «Score: A Physical and visual analogy; sound conducting walls, floors and air vibrations.» Citado en Moreno, Dibujos mentales, 193. 
induce una tensión que activa el potencial sonoro del espacio mediante una imagen mental. Para reflejar la transmisión de vibraciones por el suelo, bajo los cimbales ${ }^{96}$ se dibujaron unas líneas blancas que se alejan progresivamente de ellos, al igual que hace una onda sonora que pierde intensidad a medida que se aleja de su fuente de emisión. Los pesos situados sobre cada línea vuelven a ser activadores de la idea del suelo-membrana en vibración. Ambas obras son el preludio de una arquitectura entendida como caja de resonancia.

\subsubsection{ARADO (1975)}

Arado (1975), a veces también denominada Muerte, es una pieza realizada en los últimos años de estancia de Juan Navarro en Estados Unidos que expresa un sentimiento de añoranza de España. Esta pieza se basa en el efecto que produce la asociación y la forma de exponer los elementos que la componen, es decir, lo que Navarro denomina display ${ }^{97}$. Ocho discos de lija colocados junto a un tocadiscos llevan inscritos las palabras 'vencejo', 'ataúd', 'sombra', 'virgen', 'copa' o 'cigarro'. Junto a ellos, se dispone una fotografía ${ }^{98}$ de la estepa castellana con un par de mulos y un hombre arando de fondo.

La intención de Navarro con Arado es conectar las ideas auditivas, visuales y táctiles. Inducir el sonido de un paisaje desde el silencio empleando analogías perceptivas. ${ }^{99}$ La pieza incita una escucha a escala a partir de la materialidad de los objetos y las imágenes que la componen.

La pieza, basada en el poema de Antonio Machado Muerte de Abel Martín, contiene de forma implícita la narración de los acontecimientos que se describen en el poema. Los discos de

96. Se trata de una activación sonora desde la vista, como hace también en Hacia una constitución poética del año en curso de 1980. En esta colaboración en el libro de Álvaro Pombo, la simetría de los dos cimbales (uno en cada página) provocan un "sonido" metálico al cerrar las páginas del libro. Alvaro Pombo, Hacia una constitución poética del año en curso (Barcelona: La Gaya Ciencia, 1980).

97. «Así que cabe pensar en maneras de componer con elementos existentes y lograr transformaciones del ser del conjunto por su forma de presentarse, de agruparse. Tales operaciones caracterizan un tipo de arte que no es sino simple display. En definitiva, se trata de reciclar no sólo en un sentido físico sino sobre todo en el plano de los significados. El "menos es más" tendrá que generalizarse ampliando su territorio referencial para comprender tal tipo de estrategia.» Navarro Baldeweg, Escritos, 208.

98. También existe una dimensión simbólica y poética de la fotografía: «Castilla que también estaba representado con la imagen del arado de fondo, era una condensación de lo que es la vida, que es pasar medio destruyendo la naturaleza para sacar los frutos de ella, y todo ello es un símbolo puramente vital. Y el arrastre que se produce es como un arado, que los fenómenos de la vida son una especie de arado con su sonido particular.» Juan Navarro Baldeweg, Conversación con Juan Navarro Baldeweg, entrevistado por Covadonga Blasco Veganzones, 4 de junio de 2017.

99. Escuchar con los ojos. Arte sonoro en España, 1961-2016, 226-27. 

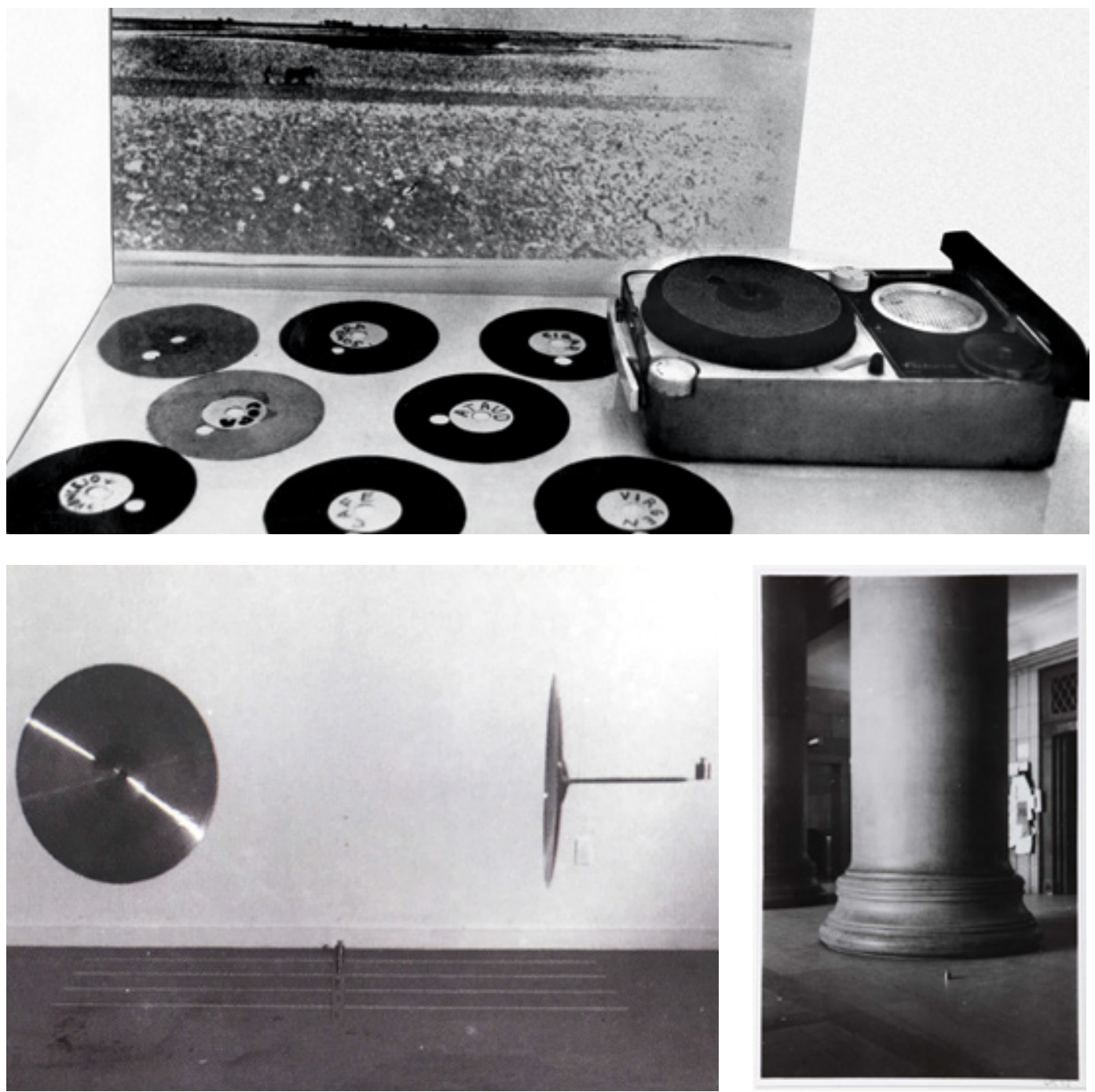

Figura 121. Juan Navarro Baldeweg, Arado (1975)

Figura 122. Juan Navarro Baldeweg, Partitura (1973)

Figura 123. Juan Navarro Baldeweg, La columna y el peso (1972) 
lija no solo se asocian al sonido de la tierra al arar, sino que la sutileza del cambio de grosor del grano de su textura se corresponde al 'peso auditivo' de las palabras ${ }^{100}$ escritas en cada uno de ellos. Así, haciendo sonar el disco con el grano más fino, diferenciado por la palabra 'vencejo', al moverlo bajo la aguja como proponía Rilke con la calavera ${ }^{101}$, Navarro encuentra el silbar de los pájaros que inundan la plaza del poema de Machado. Según el extenso análisis de las piezas de Juan Navarro Baldeweg realizado por Ignacio Moreno ${ }^{102}$, los discos representan, además, la idea de circularidad en movimiento que Juan Navarro seguirá analizando en los vencejos de sus pinturas y piezas.

Entonces vemos que la percepción necesita de la representación y sospecho que no existe percepción sin un paralelo y simultáneo trabajo de representación. Ver y dibujar son la huella y contrahuella en la escalera de la percepción y existencia del mundo. Vemos a partir de una cadena de réplicas y reconocimientos. Reconocimos algo que ya se ha fijado en otros momentos como imagen idéntica o parecida. Las imágenes nuevas son producto de una combinatoria, son fertilizadas por asociación. ${ }^{103}$

Los surtidores de signos de Juan Navarro Baldeweg certifican que la representación del concepto paisaje sonoro va más allá de la sonoridad. En la percepción directa de un fenómeno sonoro, el sujeto obtiene una información, unas reglas que crean un mundo al mismo tiempo que lo representan. Los 'filtros perceptivos', 'máquinas' o, en el lenguaje de Juan Navarro Baldeweg, surtidores de signos fuerzan a aflorar las experiencias acumuladas del sujeto en el momento de la percepción del objeto sensible. ${ }^{104}$ Lejos de ser una abstracción de lo que se ve

100. Navarro Baldeweg, Conversación con Juan Navarro Baldeweg.

101. Ver Estado de la cuestión en Fundamentos, apartado i. Breve historia de la representación del sonido del paisaje hasta la Segunda Guerra Mundial.

102. Moreno, Dibujos mentales.

103. Navarro Baldeweg, Una caja de resonancia, 28.

104. En su texto La copa de cristal, Baldeweg describe el papel intermediario entre el hombre y la percepción del paisaje que juega este sencillo objeto, el cual garantiza el paisaje del mirar al ver. 'La copa de cristal' constituye un ejemplo más de instrumento para la representación. «La copa de cristal tallado o esmaltado posee un doble carácter. Tenemos, por un lado, la escena representada en el vaso o en la copa que fue fruto de una mirada curiosa y que fue registrada como imagen y, por otro, está el campo actual de experiencias que afecta tanto a la copa como a su entorno. Entre medias queda el sentimiento de un botín ya consolidado y de una posibilidad en la extensión de la posesión. Habitualmente nuestro vínculo óptico con las cosas es despreocupado, desatento, carente de intencionalidad. Sin embardo, la copa, con su representación, que es residuo de lo real y además es realidad viva, posee una capacidad desencadenante de nuevas incursiones visuales y de una intensificación de la percepción. Propicia procesos de fijación y adquisición figurativa: entre la copa con sus figurillas en el espacio y el propio espacio se desencadena una estimulación mutua como el juego en la conjunción de dos troncos. [...] La conjunción 
(o se oye), los surtidores de signos resultan ser una mediación para ver aquello que no se percibe a simple vista (u oído).

En el proceso de realización de una obra de arte se generan signos espontáneos que también hay que descifrar; se estimulan decisiones a tiempo real y se pone en funcionamiento una rueda de percepciones, pensamientos y actuaciones sin descanso. El arte, tanto como obra como proceso o tarea, está sumido en una efervescente actividad dígnica y podemos decir que se comporta cual vivo surtidor de signos. ${ }^{105}$

Juan Navarro demuestra cómo la invención de piezas para la lectura de signos permite decodificar señales pre-lingüísticas, y la escucha activa, sentida y lógica, conducen al instrumento decodificador que permite representar para ver, y viceversa. En el proceso de ideación y fabricación de los surtidores, el objeto trasciende el límite de la utilidad y pasa a convertirse en pieza de arte, pues solo a través del arte, como defenderá Gilles Deleuze, se revelan las esencias, $y$ una vez que se manifiestan, ejercen su actuación en otros campos. ${ }^{106}$

\subsection{Cajas De Resonancia}

¿Orfeo? Es, en nuestra humanidad cambiante, el deseo de oír y ser oído; el poder de vivir y crear en la sonoridad; es el símbolo soberbio de nuestra huida más allá de los elementos pringosos y zafios de nuestras sensaciones arqueanas compuestas de vista y amasadas de tacto...Lógicamente nunca existió el Orfeo-individuo, sino sólo poderes órficos, cuyo apogeo, en nuestra humanidad actual, nos permite concebir el mundo tal que así: una sustancia sonora de la que procede toda una serie de atributos que otrora preponderaban: ¡la extensión! ¡El movimiento! ¡Aquello que se veía, aquello que se tocaba! ${ }^{107}$

\section{SEgalen. En un mundo sonoro}

El médico y arqueólogo Victor Segalen, publicó en 1907 un breve relato en la revista Le

\footnotetext{
de ambos estados y capacidades de reversibilidad -objeto o depósito vivo de imágenes- ahuyentan el miedo a lo desconocido porque la aparente facilidad de ese tránsito borra las fronteras entre las representaciones y la realidad. [...] Su función es similar en esto a la de un cuadro en la pared que absorbe, seduce y fija la mirada, pero también es ejemplo y guía de todo mirar. Induce y enseña a ver. Garantiza el paisaje del mirar al ver.» Ibid., 17-18.

105. Juan Navarro Baldeweg, «Surtidor de signos», en Dibujos Mentales: Principios del universo creativo de Juan Navarro Baldeweg, de Ignacio Moreno (Madrid: Ediciones Asimétricas, 2017), 12.

106. Deleuze, Proust y los signos, 49.

107. Victor Segalen, En un mundo sonoro ; Entrevistas con Debussy (Segovia: La Uńa Rota, 2018), 40.
} 
Mercure de France que narraba la vida de un físico que deseaba vivir en un mundo únicamente sonoro. Al borde de la locura, el protagonista transforma una habitación de su casa en una caja de resonancia, llena de resonadores y lámparas de hidrógeno que convertían el espacio en una cámara vibrante que permitía oír cualquier sonido. El inventor de los resonadores que describe Segalen en su relato, el físico y filósofo alemán Hermann von Helmholtz (18211894), había ampliado pocos años antes el modelo de la percepción sensorial al añadirle una dimensión 'psíquica' a los sentidos. Defendió la naturaleza interpretativa del signo sonoro ${ }^{108}$ y la correspondencia entre la realidad y su representación a través de lenguajes sensibles. Para Helmholtz, una magnitud espacial debe representarse mediante una magnitud espacial ${ }^{109}$, aunque el espacio de la realidad y la representación puedan tener distinta naturaleza. Los artistas eran para él los encargados de superar la transcripción literal de magnitudes para encontrar una traducción entre escalas sensitivas diferentes. ${ }^{110}$

Los principios formulados por Helmholtz sirven de base para justificar la pertenencia del empleo de instrumentos para la representación del paisaje. Para ello será necesario un transvase sensitivo entre la naturaleza aural del espacio de uno y la visualidad de las formas que caracteriza al otro para superar la divergencia de la naturaleza del espacio que contiene cada realidad. Un artista, arquitecto o creador, siguiendo las ideas de Helmholtz, será quien plantee el medio para su transvase sensitivo, de tal forma que los parámetros que caracterizan a la arquitectura y al paisaje (gráficos, visuales y estáticos), se correspondan con los del sonido (efímeros, dinámicos y móviles).

Siguiendo las mismas inquietudes, en 1912, cuando el famoso Bösendorfer-Saal de Viena iba a ser demolido, el arquitecto Adolf Loos (1870-1933) escribió un ensayo titulado El misterio de la acústica. Un alegato en defensa del edificio en el que afirmaba que las salas de conciertos, similares a los violines de madera, absorben la música que se toca en ellas a través de la estructura molecular de sus materiales de construcción:

Have our ears changed? No, it is the material the hall is made from that has changed.

For forty years the material has absorbed good music and has been impregnated with the

108. Para Helmholtz, los sentidos identifican los signos del mundo exterior mediante una interpretación basada en la experiencia vital. No encuentra el signo en el sonido, sino en la interpretación producida en la percepción. Cfr. David Novak y Matt Sakakeeny, eds., Keywords in sound (Durham ; London: Duke University Press, 2015), 179.

109. Cfr. Hermann von Helmholtz, Science and Culture: Popular and Philosophical Essays (University of Chicago Press, 1995), 166-67.

110. «What he (the artist) has to give is not a mere transcript of the object, but a translation of his impression into another scale of sensitiveness, which belongs to a different degree of impressibility of the observing eye, in which the organ speaks a very different dialect in responding to the impressions of the outer world.» Ibid., 291. 
sound of Philharmonic and the voices of our singers. These are mysterious changes in molecular structure which until now have only been observed in the wood violins are made of. ${ }^{11}$

Esta comunicación invisible entre el sonido y los materiales es lo que hace, según Loos, que algunos edificios sean mejores acústicamente, no dependiendo su acústica de la forma, sino de la música (buena o mala) que tuviera lugar en ellos. Este tipo de reflexión, sin fundamento científico pero llena de intencionalidad, pone del revés la relación entre sonido y arquitectura, siempre dominada por esta última al tratarse como contenedor independiente del contenido. Partiendo de la anécdota de Loos, ¿cómo puede el sonido conformar una forma o una visiónsonora?

Si atendemos a las reflexiones de Boulez a través de la obra de Klee en Le pays fertile, existe una arquitectura que mantiene una correspondencia estructural profunda con la música, y donde las deducciones del campo visual pueden ser traducidas a un mundo de sonidos. La arquitectura sonora $^{112}$ no es aquella que se lee musicalmente, sino la que contiene un desarrollo estructural que induce una suerte de sinestesia musical. Como apunta Boulez, las villas de Klee contienen un desarrollo orgánico de simetrías y ritmos que se traducen en formas comunes a ambos mundos. ${ }^{113}$ Asimismo, al igual que en la música clásica basada en esquemas repetitivos es posible 'presentir' la estructura global de la pieza antes de que suene, en la arquitectura clásica, basada en fuertes ritmos y simetrías muy marcadas, también es posible prever las partes ocultas de un edificio sin siquiera verlas. ${ }^{114}$

Boulez encuentra también una condición sonora en los cuadros de Klee realizados mediante texturas de pequeńos puntos, más o menos densos, que ocupan el espacio mediante impulsos

111. „Haben sich unsere ohren geändert? Nein, das material, aus dem der saal besteht, hat sich geändert. Das material hat durch vierzig jahre immer gute musik eingesogen und wurde mit den klängen unserer philharmoniker und den stimmen unserer sänger imprägniert. Das sind mysteriöse molekularveränderungen, die wir bisher nur am holze der geige beobachten konnten“. Adolf Loos, «Das Mysterium der Akustik», en Trotzdem, 1900-1930 (Wien: Brenner-Verlag, 1931), 116-17. Cfr. Traducción al inglés en Florence Feiereisen y Alexandra Merley Hill, Germany in the Loud Twentieth Century: An Introduction (Oxford University Press, USA, 2012), 65-66.

112. En un enfoque más sonoro que gráfico, el empleo del sonido para determinar un espacio o modificar su experiencia mediante variaciones de intensidad, ritmo o velocidad del sonido, fue bautizado como arquitectura sonora por el artista Bernhard Leitner en 1971 en pleno apogeo del arte sonoro, pero experimentado de forma intuitiva mucho antes por Le Corbusier en el Pabellón Philips. El pabellón, en el que se dispusieron más de 400 altavoces, era contenedor y expresión del sonido al mismo tiempo. Cfr. Bernhard Leitner, «Sound Architecture», Artforum, marzo de 1971.; Sobre el pabellón Philips y la arquitectura acústica, ver Susana Moreno Soriano, Arquitectura y música en el siglo XX (Madrid: Fundación Caja de Arquitectos, 2008).

113. Pierre Boulez, Le pays fertile: Paul Klee (Paris: Gallimard, 1989), 112.

114. Ibid., 117-19. 

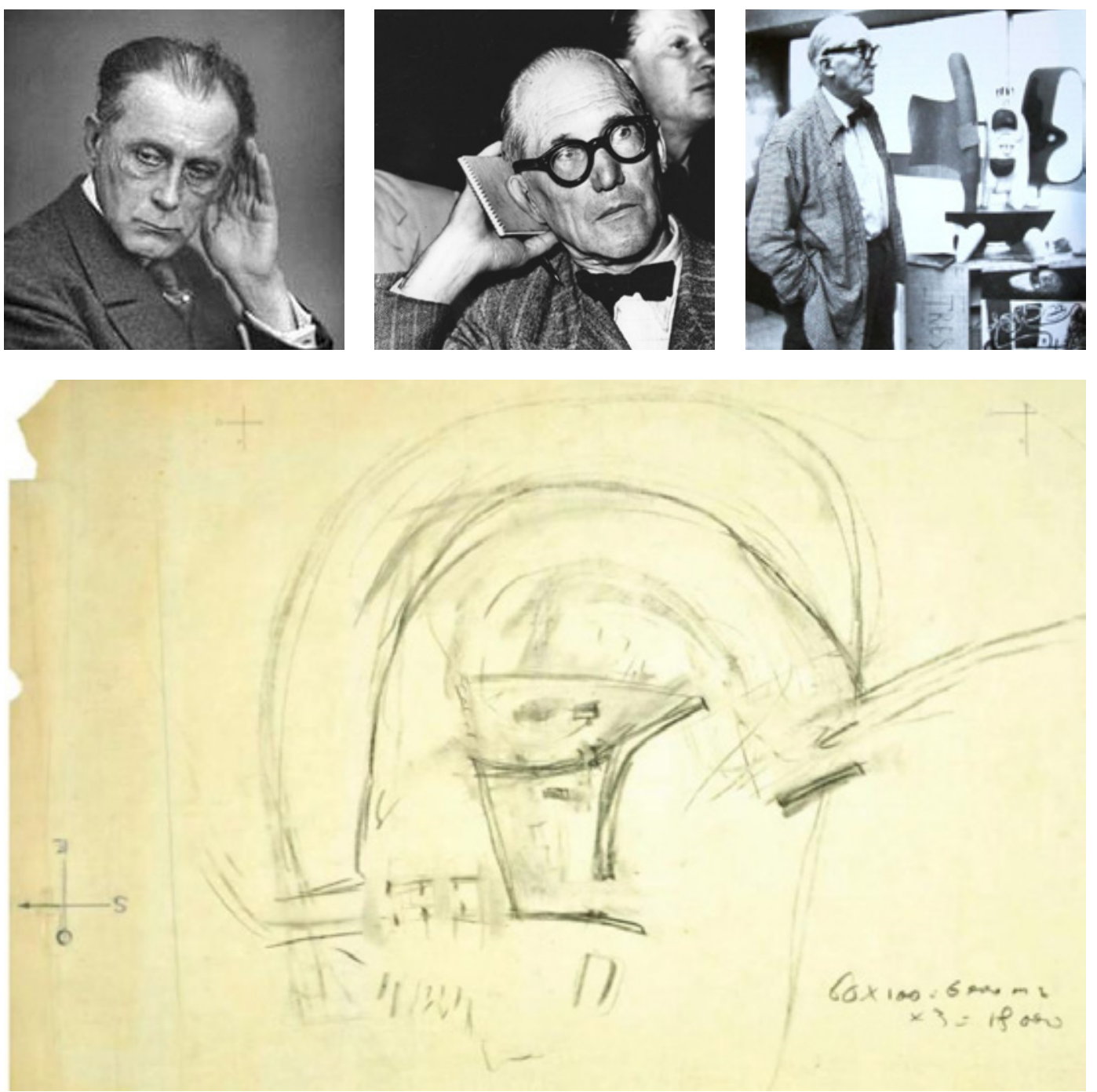

Figura 124. Adolf Loos

Figura 125. Le Corbusier (1951)

Figura 126. Le Corbusier frente a la escultura Ozon II

Figura 127. Croquis para la capilla de Ronchamp (1950) 
de color o ritmos de la misma manera que las pulsaciones ocupan el tiempo en la música. ${ }^{115}$ Por medio de la inducción sinestésica, como lo denominará Juan Navarro Baldeweg, el arquitecto o el pintor es capaz de crear con el ornamento, según la simetría y el ritmo, «la ilusión de una pulsación espacial» ${ }^{116}$ que induce una vibración o un murmullo:

Al impregnarse lo espacial de una aparente condición temporal, se libera una dinámica forzada de itinerarios visuales en el campo óptico del observador. Esas capacidades o potencias de la simetría están profundamente arraigadas en cualquier cultura y sirven para que lo que nos rodea, aun lo inerte o inmóvil, en rigor, dance, se invista de la vitalidad propia de un baile acompasado. ${ }^{117}$

La capilla de Notre Dame du Haut (Ronchamp, 1954) de Le Corbusier (1887-1965) es un ejemplo bien conocido que manifiesta cómo la consideración de la estructura del sonido del paisaje en un proyecto es capaz de amplificar y dar sentido a la forma arquitectónica:

Les recherches plastiques de Le Corbusier l'avaient conduit à la perception d'une "intervention de nature acoustique dan le domaine des formes". Une mathématique, une géométrie, une physique implacables peuvent et doivent auner les formes offertes à l'œil; leur concordance, leur récurrence, leur interdépendance, et l'esprit de corps ou de famille qui les unir conduisent à l'expression architecturale, phénomène, dit-il, aussi-souple, aussi subtil, aussi exact, aussi implacable que celui l'acoustique... On commença donc par une acoustique paysagiste, prenant les quatre horizons à témoin [...]. On créa des formes pour répondre à ces horizons, pour les accueillir. ${ }^{118}$

Las características formas receptivas de la capilla, como las describiría el escritor John Berger, «capturan, de alguna manera, las vibraciones, lo que llega hasta ellas del paisaje circundante, que atraen o reciben dentro de ellas el mundo que las rodea ${ }^{119}$. Las formas acústicas ${ }^{120}$ que configuran su geometría eran, según Le Corbusier, «una respuesta a una psico-fisiología de la sensación» ${ }^{121}$ derivadas de la serie de esculturas en madera $O z o n$ que realizó en los años cuarenta. Si bien, en última instancia y como afirma Keneth Frampton, Ronchamp es «una

115. Ibid., 29.

116. Navarro Baldeweg, Escritos, 242.

117. Ibid.

118. Le Corbusier, Euvre complète. Vol. 5: 1946 - 1952, 11., reimpresión de la primera ed. 1953 (Basel: Birkhäuser, 1999), 72.

119. John Berger, Cuatro horizontes, Edición: 1 (Barcelona: Editorial Gustavo Gili, S.L., 2015), 40-41.

120. Amplia investigación en la tesis doctoral de Jaime Coll López, «Le Corbusier : la forma acústica» (Ph.D. Thesis, Universitat Politècnica de Catalunya, 1994), http://www.tdx.cat/handle/10803/482045.

121. Le Corbusier, Euvre complète. Bd. 5, 72. 
de tales esculturas, sutilmente transformada en edificio» ${ }^{122}$, Ronchamp es también un ejemplo de arquitectura intermediaria entre el hombre y el paisaje nacida de la implicación directa del arquitecto con el sonido del entorno ${ }^{123}$.

Durante unos años, empujado por las experiencias plásticas en el CAVS , Juan Navarro Baldeweg trabajó en la idea de "concebir la arquitectura como instrumento, como caja de resonancia» ${ }^{124}$. Juan Navarro investiga como artista disfrazado de arquitecto a través de herramientas polimórficas coherentes a su método personal de proyectar. A veces pintura, otras escultura o arquitectura, sus surtidores de signos resuenan con el método que Le Corbusier empleó en Ronchamp, utilizando el arte para encontrar y sentir las «estructuras que están presentes, dejar que manifiesten su ley según su diversa naturaleza y descubrir las formas en las que pueden cristalizar.» ${ }^{125}$

La aplicación de los surtidores de signos al proyecto de arquitectura asegura un conocimiento profundo y sensible del mundo y, en consecuencia, una relación natural entre el individuo y el paisaje. Desarrolladas a partir de las energías presentes en un espacio y un tiempo concretos, las piezas de Juan Navarro Baldeweg son instrumentos que no solo funcionan como receptores de señales, sino que ellas mismas emiten señales que fuerzan al pensamiento. A través de ellas, desde la percepción pura, el sujeto percibe un mundo esencial filtrado a través de objetos que, como los dibujos de Klee, avanzan en el conocimiento de la representación de lo invisible en un proceso de investigación que, además, es artístico.

La fabricación de objetos para desmaterializar el potencial de los eventos, acciones, ideas inherentes al espacio forman parte del método de proyectar la arquitectura de Juan Navarro Baldeweg. En sus proyectos practica una investigación paralela y simultánea que genera versiones en diferentes géneros artísticos de una misma idea que termina aglutinándose finalmente en la arquitectura. ${ }^{126} \mathrm{~A}$ través de estas creaciones, Navarro consigue amplificar los vínculos existentes entre el hombre y su entorno, manifiestando «un mundo físico subyacente que es una envoltura

122. Kenneth Frampton, Le Corbusier (Ediciones AKAL, 2001), 136.

123. Otro ejemplo similar, el Memorial en honor al padre Donosti, capuchino y musicólogo (Agińa, 1957) de Jorge Oteiza y Luis Vallet, emplea la arquitectura como herramienta para amplificar el sonido del paisaje. Tal y como se describe en la memoria del proyecto «la forma paraboidal adoptada para dar forma a la capilla de Agińa, condensa y resume todos los sonidos y músicas de la naturaleza vasca, como lo hiciera el gran musicólogo [...].» Luis Vallet y Jorge Oteyza (sic), «Memorial en honor del al Padre Donosti (sic), Capuchino y musicólogo», Munibe. Grupo de Ciencias Naturales Aranzadi. Suplemento de Ciencias Naturales del Boletín de la Real Sociedad Vascongada de Amigos del País., Año IX (1957), Cuaderno 3º.

124. Navarro Baldeweg, Escritos, 288.

125. Sobejano, Nieto, y Mata, «Arquitectura», 121.

126. Navarro Baldeweg, Conversación con Juan Navarro Baldeweg. 
de un ser humano genérico» ${ }^{127}$. Cada una de sus piezas cristaliza la idea de que «la arquitectura es también una caja de resonancia no sólo en relación a la gravedad sino también a otras muchas fuerzas y energías» ${ }^{128}$.

Muchos aspectos de nuestro medio físico pasan inadvertidos, desvinculados de nuestro sentir, en aparente inexistencia, alejados o desvaídos. Una tarea siempre pendiente consistirá precisamente en liberar señales en ese medio que nos alerten de su compañía para hacérnoslo presente y conmovedor; que lo ordinario se transfigure y parezca extraordinario, que sintamos extrańeza ante lo familiar y que nuestro cuerpo se abra y se entreteja en ese hábitat que de pronto nos atrae por el acontecer de una súbita exaltación. ${ }^{129}$

El objetivo esencial de la arquitectura, según Navarro, será siempre dirigir la mirada creativa al medio físico natural para hacer presente lo preexistente, a la naturaleza que nos envuelve y nos permite estar frente a ella, y al mismo tiempo, dentro de ella ${ }^{130}$. Fiel a su método de proyecto, de forma simultánea a los trabajos de construcción de la casa, Navarro construye una pieza que le permite determinar las energías predominantes en el contexto en el que se inserta La Casa de la lluvia (Santander, 1982), obra clave en la formación como arquitecto de Juan Navarro Baldeweg. La casa, una de las primeras obras del arquitecto tras su estancia en el Center for Advanced Visual Studies, debe su concepción y materialización a las investigaciones plásticas mediante las piezas y dibujos que realizó el arquitecto en aquellos mismos años.

La pieza Casa de la lluvia no es una maqueta de la Casa de la lluvia. Es una pieza que pertenece al universo creativo del proyecto, pero que funciona independientemente como pieza artística una vez se desliga de su utilidad como intermediario entre el mundo físico y la obra arquitectónica. En la pieza, el valle de montañas en el que se inserta el proyecto real se traduce en un aljibe, que espera ser llenado. La casa, dispuesta en el centro del vaso de recogida de aguas, se representa como diagrama universal: cuatro paredes y un tejado a dos aguas. En las esquinas del tejado, unos pequeños tubos a modo de gárgolas sobresalen remarcando su presencia, necesaria para que la máquina funcione correctamente. Por último, sobre la casa emerge una nube, en la que cada gota de agua es expulsada desde una posición calculada, buscando a través de una espiral la estructura racional de la lluvia, repartida de manera aleatoria

127. Navarro Baldeweg, Escritos, 298.

128. Ibid., 288, 290.

129. Ibid., 235.

130. «Más allá de los personal, pienso que el anhelo de recuperación de una continuidad del yo y lo circundante, sin otro fin ańadido, fundamenta y alimenta un deseo que es general, socialmente compartido, de hacer obras de índole conectiva, obras que no responden a una necesidad concreta, es decir, sin objetivo utilitario.» Ibid., 235. 

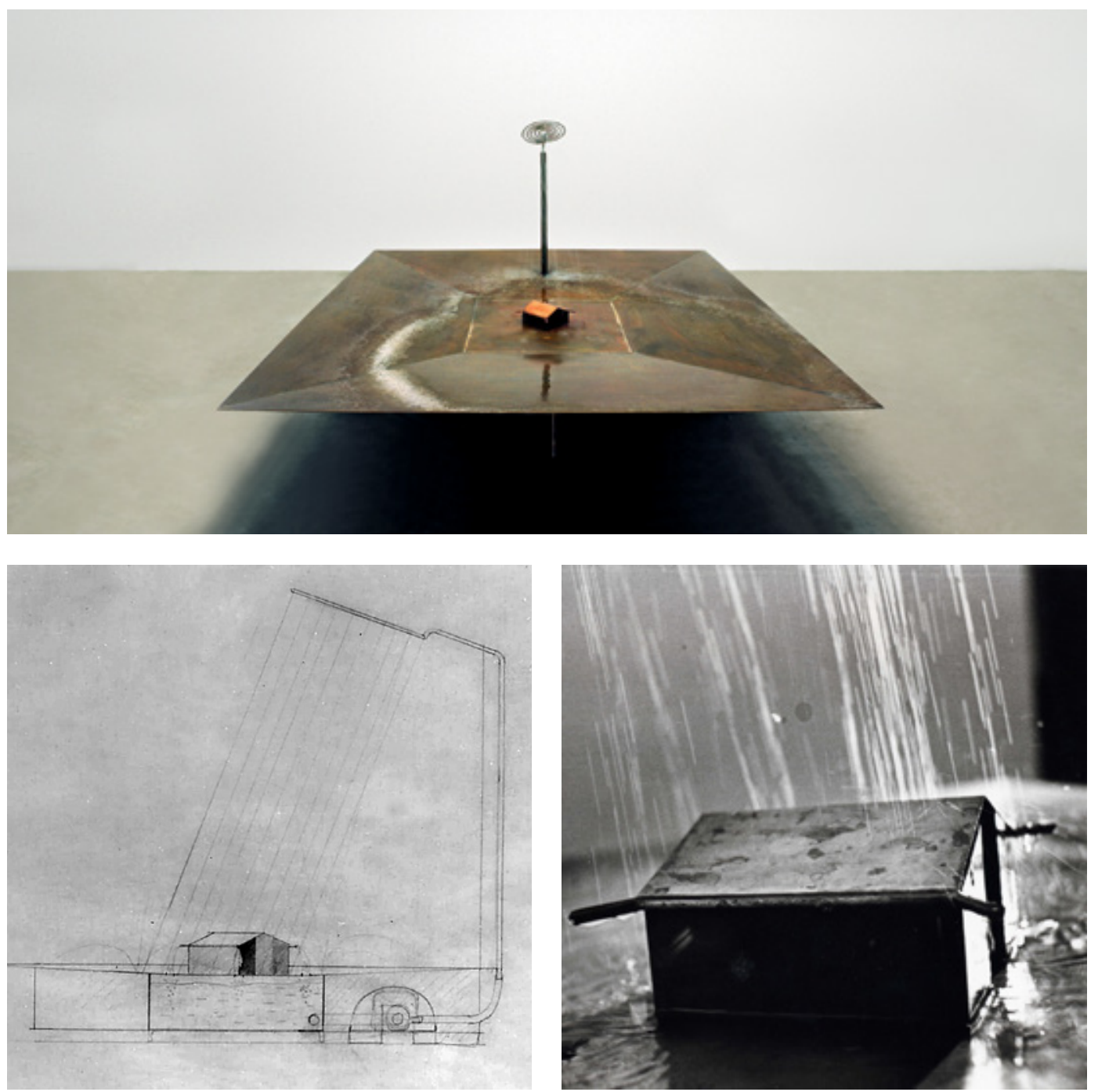

$129 \quad 130$

Figura 128. Juan Navarro Baldeweg, Casa de la lluvia (1978)

Figura 129. Juan Navarro Baldeweg, Dibujo para Casa de la lluvia (1978)

Figura 130. Juan Navarro Baldeweg, Casa de la lluvia (1978) 
y uniforme sobre una superficie.

La puesta en marcha de la pieza supone una narración del proyecto, donde el narrador es el agua, y su precipitación es el acontecimiento que conforma el paisaje. El latón empleado en todos los elementos de la pieza suena al ser golpeado, haciendo legible el discurso. Las gotas de la nube-espiral convierten el tejado de la casa en un tambor, cuyo efecto se traslada, como una homotecia perceptiva, al proyecto real, haciendo de la arquitectura un instrumento tan complejo como una batería.

Navarro describe dos sonidos predominantes ${ }^{131}$ que se perciben en la casa los días de lluvia: el de las gotas que golpean el tejado metálico, y el del agua expulsada violentamente por las gárgolas que coronan las esquinas del proyecto. El paisaje, además de incorporarse en la casa a través de precisos ventanales, entra en el interior 'haciendo ruido', llenando el espacio con el sonido de la lluvia. El paisaje se introduce en este proyecto en el acontecimiento de la lluvia, y para su narración se fabrica un instrumento en el que la realidad interna del objeto deviene mucho más que su simple apariencia. Un resonador de las fuerzas sensibles que direcciona la mirada hacia el evento que define inconscientemente la dimensión sonora de un paisaje concreto.

Este tipo de instrumentos activan los sentidos y el pensamiento, ofrecen la comprensión de nuestra continua transformación del pasado al presente y del presente al futuro. La construcción de un objeto que interpreta y extrae las componentes físicas esenciales que dan lugar al sonido predominante en un paisaje constituyen un modelo de pensamiento basado en el hacer. La pieza Casa de la lluvia constituye, por tanto, un ejemplo de la aplicación del conocimiento operativo de Simondon:

Lo real, para el conocimiento operativo, no precede a la operación de conocimiento; la sigue. Incluso si parece precederla según la experiencia corriente, la sigue según el conocimiento real, pues este conocimiento sólo capta lo real cuando lo ha reconstruido por medio de la manipulación de los elementos. ${ }^{132}$

Como apunta Navarro, el objeto, enfrentado con la realidad deviene mecanismo, limitando lo que es ilimitado en el divagar interpretativo. ${ }^{133}$ En el caso de la pieza desarrollada para $\mathrm{La}$ casa de la lluvia, esta consigue que el proyecto ensalce por sí mismo las componentes sonoras

131. Navarro Baldeweg, Conversación con Juan Navarro Baldeweg.

132. Simondon Gilbert, El modo de existencia de los objetos técnicos (Buenos Aires: Prometeo Libros, 2014), 251.

133. Navarro Baldeweg, Una caja de resonancia, 22. 
naturales que caracterizan el paisaje en el que se inserta. En consecuencia, la identificación como caja de resonancia será válida tanto para la pieza como para la arquitectura, pues la arquitectura se convierte en instrumento y el instrumento en arquitectura. Las prácticas artesanales se erigen como una forma de arquitectura en sí mismas, un acto básico del pensamiento arquitectónico que ayuda a organizar el conocimiento. ${ }^{134}$

\subsection{Ritornelo}

¿qué es un ritornelo? Glass harmonica: el ritornelo es un prisma, un cristal de espaciotiempo. Actúa sobre lo que le rodea, sonido o luz, para extraer de ello vibraciones variadas, descomposiciones, proyecciones y transformaciones. El ritornelo también tiene una función catalítica: no sólo aumentar la velocidad de los intercambios y reacciones en lo que le rodea, sino asegurar interacciones indirectas entre elementos desprovistos de afinidad llamada natural, y formas así masas organizadas. ${ }^{135}$

\section{G. Deleuze y F. Guattari. Mil Mesetas}

Conocido por inventar las lentes bifocales o el pararrayos, Benjamin Franklin (1706-1790) también ideó un instrumento musical, el Glass harmonica o armónica de cristal. Franklin, gran aficionado a la música, proyectó en 1761 un artilugio basado en los juegos de copas que había conocido durante sus viajes por Europa. Varios cuencos de vidrio de diferentes tamańos, dimensionados cuidadosamente para producir diferentes tonos, se encajaban en un eje formando un cono de cristal que giraba mediante un pedal. Cuando el músico deslizaba sus dedos humedecidos sobre los bordes de los cuencos giratorios, se obtenían diferentes notas musicales envueltas en un característico sonido vibratorio y agudo que llegaba a producir, según los expertos de la época, trastornos mentales. ${ }^{136}$

Este complejo instrumento musical sirve como cierre de Del ritornelo, capítulo del libro Mil Mesetas (1980) en el que Gilles Deleuze y Félix Guattari desarrollaron el concepto homónimo.

134. «Pottery-making gave man thought models of form and substance, permanence and change. The framework of thinking the grew from craft practices became an organizer of knowledge. Building up a vessel from rings of clay is a form of architecture, a basic act of architectonic thinking.» Cfr. Kepes, The New Landscape in Art and Science, 42.

135. Gilles Deleuze y Félix Guattari, Milmesetas: capitalismo y esquizofrenia, 5. ed, Pre-Textos Ensayo 94 (Valencia: Pre-Textos, 2002), 351.

136. Kaitlyn Duling, Benjamin Franklin: Inventor and Founding Father (Cavendish Square Publishing, LLC, 2019), 73. 


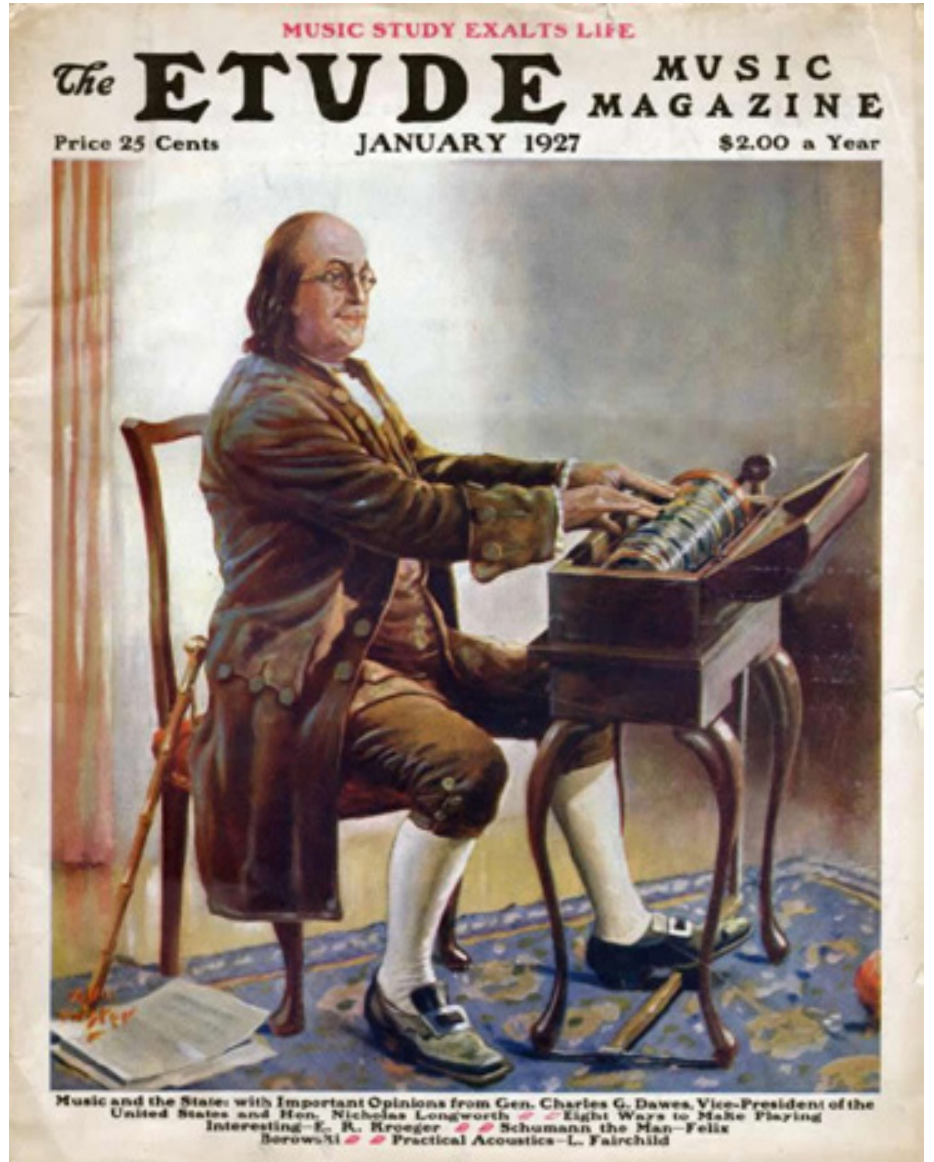

Figura 131. Portada de la revista The Etude (enero, 1927). Benjamin Franklin tocando la armónica de cristal. 
El símil entre el concepto y el instrumento de Franklin cierra un camino que comienza en la sencillez de la canción de un niño y culmina con la identificación del ritornelo como pieza de una máquina -el devenir-, que como advierte Anne Sauvagnargues ${ }^{137}$, debemos entender «no como un objeto técnico que podemos sostener en nuestras manos y encender y hacer funcionar con un botón, una palanca, un torniquete o una pantalla», sino como un concepto filosófico operativo que explica cómo las tres componentes sobre las que interviene (materia, cuerpo y mente) «pueden funcionar juntas mientras permanecen heterogéneas» ${ }^{138}$. Partiendo de esta última consideración, el ritornelo se perfila como un instrumento más para la representación del concepto paisaje sonoro, capaz de hacer emerger, mediante la expresividad del ritmo, la imagen del sonido.

Aunque no es fácil distinguir entre lo que pertenece a Deleuze y lo que pertenece a Guattari, el término ritornelo fue formulado por primera vez por Félix Guattari (1930-1992) en su obra L' inconscient machinique en 1979. Guattari, que a su vez toma la expresión de Lacan ${ }^{139}$, utiliza este término para abordar los problemas del tiempo según los diversos modos rítmicos de temporalización ${ }^{140}$.

Deleuze, quien con anterioridad había citado el ritornelo de Guattari en el curso de Vincennes de 1977 y en el seminario Le temps musical organizado por el IRCAM en $1978^{141}$, incorpora a la explicación del concepto las consideraciones sobre el tiempo de Pierre Boulez registradas en Pensar la música hoy. La distinción entre el 'tiempo pulsado' característico de la música basada en los valores clásicos, y el 'tiempo no pulsado', propio de la música flotante y maquínica ${ }^{142} \mathrm{de}$ las obras electrónicas, remite a los modos de temporalidad clásicos Cronos (tiempo de la medida que desarrolla una forma y determina un sujeto) y Aiôn (tiempo indefinido del acontecimiento) respectivamente. La exploración del tiempo en la música conduce a Deleuze y Guattari a la relación tiempo-movimiento:

Algunos músicos modernos oponen al plan trascendente de la organización, que supuestamente ha dominado toda la música clásica occidental, un plan sonoro inmanente, siempre dado con lo que da, que permite percibir lo imperceptible, y que ya solo contiene

137. Filósofa francesa especialista en la obra de Deleuze.

138. Anne Sauvagnargues et al., Artmachines: Deleuze, Guattari, Simondon (Edinburgh: Edinburgh University Press, 2016), 190.

139. Cfr. Ibid., 129.

140. Cfr. Ibid., 125.

141. Ver capítulo segundo, aparatado 1978: El seminario Le temps musical. Deleuze, Boulez y el paisaje sonoro.

142. Cfr. Deleuze y Guattari, Mil mesetas, 265. 
velocidades y lentitudes diferenciales en una especie de chapoteo molecular: la obra de arte debe señalar los segundos, las décimas, las centésimas de segundo. O más bien se trata de una liberación del tiempo, Aiôn, tiempo no pulsado para una música flotante, como dice Boulez, música electrónica en la que las formas son sustituidas por puras modificaciones de velocidad. John Cage es sin duda el primero que ha desplegado lo más perfectamente posible ese plano fijo sonoro que afirma un proceso frente a toda estructura y génesis, un tiempo flotante frente al tiempo pulsado o el tempo, una experimentación frente a toda interpretación, y en el que tanto el silencio como el reposo sonoro señalan el estado absoluto del movimiento. ${ }^{143}$

Al igual que la geografía, nos dirán Deleuze y Guattari, el paisaje no es sólo físico y humano, sino también una forma mental. ${ }^{144}$ Partiendo de esta premisa, los paisajes melódicos o sonoros presentes en Del Ritornelo se forjan como consecuencia de la confluencia de tres agentes: el ritmo que remite a un cambio de medio, el devenir ${ }^{145}$ que permite la transcodificación de los medios; y el cristal, que en última instancia, determina la construcción de una estética de lo virtual $^{146}$ de la que el paisaje sonoro forma parte.

\subsection{RITMO, TERRITORIO Y AGENCIAMIENTO}

En un sentido general, se denomina ritornelo a todo conjunto de materias de expresión que traza un territorio, y que se desarrolla en motivos territoriales, en paisajes territoriales (hay ritornelos motrices, gestuales, ópticos, etc.). En un sentido restringido, se habla de ritornelo cuando el agenciamiento es sonoro o está "dominado" por el sonido. ${ }^{147}$

Con el objetivo de cuestionar la relación del hombre con el mundo, Mil mesetas despliega una serie de conceptos operatorios (rizoma, ritornelo, máquina, territorio, devenir, agenciamiento...) que forman una 'mecanosfera' ${ }^{148}$. El concepto ritornelo, basado en la transformación de cualidades funcionales en componentes expresivas, no se ajusta a una definición única,

143. Ibid., 270.

144. «La geografía no se limita a proporcionar a la forma histórica una materia y unos lugares variables. No sólo es física y humana, sino mental, como el paisaje.» Gilles Deleuze y Félix Guattari, ¿Qué es la filosofía? (Barcelona: Círculo de lectores, 1995), 96-97.

145. Deleuze y Guattari, Mil mesetas, 350.

146. Cfr. François Dosse y Sandra Garzonio, Gilles Deleuze y Félix Guattari: Biografía cruzada (Buenos Aires [etc.: Fondo de Cultura Económica, 2009), 579.

147. Deleuze y Guattari, Mil mesetas, 328-29.

148. Dosse y Garzonio, Gilles Deleuze y Félix Guattari, 316. 
sino que a medida que Deleuze y Guattari van desarrollando el concepto, su complejidad y riqueza aumentan al mismo tiempo que precisan sus características, dando como resultado un concepto poliédrico del que se conocen muchas caras. Para ajustar su aplicación al campo de estudio de esta investigación, es necesario abordar otros dos conceptos inherentes al mismo: el agenciamiento y el territorio.

El concepto agenciamiento es muy amplio. De forma simplificada, se establece que designa "la puesta en relación de un conjunto de relaciones materiales con un régimen de signos correspondiente» ${ }^{149}$. Los agenciamientos, además, se definen a su vez por materias de expresión ${ }^{150}$, lo que da lugar a la existencia de muchos tipos de agenciamiento (territoriales, animales, sonoros...). Analizando la cita que abre este epígrafe, en la restricción del uso del concepto ritornelo al agenciamiento sonoro, encontramos la pertinencia de su estudio en esta investigación, pues dicho agenciamiento tiene que ver con actos de discernimiento de los que se obtiene como resultado «un nuevo "aspecto" producido por la imbricación de lo semiótico y de lo material, ${ }^{151}$. El ritornelo aporta, en consecuencia, una apertura en la que encontrar nuevos aspectos en la relación entre el valor semiótico del paisaje sonoro, y la expresión material que nos conduce hasta su representación.

Además de ser un agenciamiento propiamente sonoro, el ritornelo es también un agenciamiento territorial, lo que implica, en palabras de Deleuze y Guattari, una consolidación ${ }^{152}$ del medio ${ }^{153}$ y una descodificación ${ }^{154}$ del código en el que se encuentra codificado ese medio.

La consideración más importante a tener en cuenta para la aplicación del ritornelo como instrumento para la representación del paisaje sonoro es entender a qué hace referencia la palabra ritmo en este contexto. El ritmo, en este caso, no se define como repetición seriada de un elemento, sino como el "paso transcodificado de un medio a otro, comunicación de medio,

149. Ibid., 319.

150. Deleuze y Guattari, Mil mesetas, 341.

151. Ibid.

152. Ibid., 334.

153. «Cada medio es vibratorio, es decir, un bloque de espacio-tiempo constituido por la repetición periódica de la componente. Así, lo viviente tiene un medio exterior que remite a los materiales; un medio interior que remite a los elementos componentes y sustancias compuestas; un medio intermediario, que remite a las membranas y límites; un medio anexionada que remite a las fuentes de energía y a las percepciones-acciones. Cada medio está codificado, y un código se define por la repetición periódica: pero cada código está en perpetuo estado de transcodificación o de transducción. La transcodificación o la transducción es la manera en que un medio sirve de base a otro, o, al contrario, se establece en otro, se disipa o se constituye en el otro.» Ibid., 319-20.

154. Ibid., 340. 
coordinación de espacio-tiempos heterogéneos.» ${ }^{155}$ Esta definición espacio-temporal del ritmo nos lleva al inicio de la investigación, en la que la transducción de las señales acústicas (sonoras) a otro medio (gráfico o sonoro), era la base del proceso de obtención de la imagen del paisaje sonoro. ${ }^{156} \mathrm{El}$ ritmo, por tanto, se halla en el proceso de transcodificación o transducción de señales que permite pasar de un medio visual a otro sonoro y viceversa, construyendo un nuevo plano rítmico o melódico. ${ }^{157}$

Por otro lado, ha de considerarse que el término territorio no significa en este contexto porción de superficie terrestre, sino «un acto que afecta a los medios y a los ritmos, que los "territorializa".» ${ }^{158}$ Si bien el ritmo existe cuando hay un cambio de medio, «hay territorio desde el momento en que hay expresividad de ritmo» ${ }^{159}$. El territorio será, por tanto, una consecuencia del ritmo, «el acto del ritmo devenido expresivo» o, en otras palabras, el territorio sería el efecto del arte ${ }^{160}$.

Como explica Elisabeth Grosz ${ }^{161}$, las artes visuales y sonoras captan la estructura vibratoria de la materia (descodificación del color, el ritmo, el movimiento...) con el fin de delimitar un territorio capaz de transformarse y adquirir una nueva armonía que estabiliza un nuevo plano. El territorio será siempre el encuentro de coordenadas espacio-temporales y cualidades de un medio y un ritmo, mientras que el ritornelo será el modo en que el ritmo replantea o vuelve a formar un territorio. ${ }^{162}$

Para transmitir el funcionamiento del movimiento de entrada y salida (territorrialización ${ }^{163}$

155. Ibid., 320.

156. Ver capítulo primero

157. Cfr. Deleuze y Guattari, Mil mesetas, 321.

158. Ibid.

159. Ibid.

160. Cfr. Ibid., 322.

161. Elizabeth Grosz es Professor of Women's Studies y Literature en la Duke University.

162. E. A. Grosz, Chaos, territory, art: Deleuze and the framing of the earth, The Wellek library lectures in critical theory (New York: Columbia University Press, 2008), 19-20. "The visual and sonorous arts capture something of the vibratory structure of matter itself; they extract color, rhythm, movement from chaos in order to slow down and delimit within it a territory that is capable of undergoing a reshaping and a new harmonics that will give it independence, a plane of stabilization, on which to sustain itself. The refrain is how rhythm stakes out a territory from chaos that resonates with and intensifies the body. Territory is always the coming together both of spatiotemporal coordinates (and thus the possibilities of measurement, precise location, concreteness, actuality) and qualities (which immensurable, indeterminate, virtual, and open-ended), that is, it is the coupling of a milieu and a rhythm. A refrain is the movement by which the qualities of a specific territory or habitat resonate and return to form it as a delimited space, a space contained or bounded but nonetheless always open to chaos from which draws its force.»

163. «Territorializar en Deleuze, como concepto opuesto a desterritorialización, es consolidar los estratos que 
y desterritorialización) que el ritornelo y el territorio realizan constantemente el uno en el otro, Deleuze y Guattari centran parte de su amplio discurso en el arte asociado genuinamente al ritornelo: la música. Deleuze y Guattari estipulan dos tipos ${ }^{164}$ de ritornelo. Un primer tipo, el ritornelo territorial o agenciamiento, y un segundo tipo, basado en la transformación del primero, y cuyo fin es la música:

Es curioso cómo la música no elimina el ritornelo mediocre o malo, o el mal uso del ritornelo, sino que, por el contrario, lo arrastra, o lo utiliza como un trampolín. [...] Más bien habría que mostrar cómo un músico tiene necesidad de un primer tipo de ritornelo, ritornelo territorial o agenciamiento, para transformarlo interiormente, desterritorializarlo, y producir finalmente un ritornelo del segundo tipo, como meta final de la música, ritornelo cósmico de una máquina de sonido. ${ }^{165}$

Solo el trabajo profundo sobre el primer tipo de ritornelo y el devenir del artista creará un ritornelo del segundo tipo. ${ }^{166} \mathrm{El}$ primer tipo se corresponde con la cancioncilla que canturrea un niño para construir un espacio propio de seguridad frente al miedo que le produce la oscuridad (un ejemplo de cómo un aspecto funcional de protección se vuelve expresivo), y el segundo es un desarrollo de ese primer gesto infantil, en el que ya no es el niño quien delimita su espacio mediante la cancioncilla, sino que es la música la que contiene 'a un niño', gracias al devenir-niño del músico. ${ }^{167}$

contienen la potencialidad de las líneas de fuga que producen el concepto segundo. Y ahí aparece la noción de agenciamiento como relación inestable y heterogénea, capaz, aun así de producir metaestabilidad en el devenir.» Juan Miguel Hernández León, «Seminario: Transferencias, proyecto arquitectónico y pensamiento contemporáneo» (MPAA-ETSAM, 2014).

164. Deleuze y Guattari, Mil mesetas, 332, 350. Ritornelos del primer tipo: 1. Los ritornelos territoriales, que buscan, marcan, agencian un territorio; 2. Los ritornelos de funciones territorializados; 3-4. Los ritornelos que reagrupan o reúnen las fuerzas, que dejan de ser terrestres para devenir cósmicos. Ritornelos del segundo tipo: 1 . Los ritornelos de los medios, con dos partes como mínimo, en los que una responde a la otra; 2 . Los ritornelos de lo natal, del territorio, en los que una parte está relacionada con el todo; 3. Ritornelos populares o folclóricos; 4.Los ritornelos molecularizados (el mar, el viento) en relación con fuerzas cósmicas, con el ritornelo-Cosmos (el propio Cosmos es un ritornelo, y el oído también).

165. Ibid., 352.

166. Ibid., 353.

167. Ibid. 


\subsubsection{Devenir-música / Devenir-paisaje}

¿Es posible que la literatura alcance a veces a la pintura, e incluso a la música? ¿y que la pintura alcance a la música? [...] Ningún arte es imitativo, no puede ser imitativo o figurativo: supongamos que un pintor "representa" un pájaro; de hecho, se trata de un devenir-pájaro que sólo puede realizarse en la medida en que el pájaro está a su vez deviniendo otra cosa, pura línea y puro color. Por eso la imitación se destruye por sí solo, en la medida en que el que imita entra sin saberlo en un devenir, que se conjuga sin saberlo con el devenir de aquel que imita. [...] El pintor o el músico no imitan al animal, son ellos los que deviene-animal, al mismo tiempo que el animal deviene lo que ellos querían, en lo más profundo de su armonía con la Naturaleza. ${ }^{168}$

Cantar, componer, pintar o escribir tienen como finalidad desencadenar devenires. ${ }^{169}$ Devenir no es imitar a algo o a alguien ni proporcionar relaciones formales. ${ }^{170} \mathrm{Al}$ igual que el pintor que sufre su propio devenir-pájaro cuando cree representarlo, sumergidos en el problema de la 'representación' del concepto paisaje sonoro, ¿qué ocurre cuando el músico o el pintor tienen como cometido devenir-paisaje?

Devenir-paisaje implica que lo que se deviene devenga tanto como el que deviene ${ }^{171}$, creando un bloque móvil que nunca está en equilibrio. Artesano - paisaje - sonido forman un bloque de devenir ${ }^{172}$ que conjuga las diferentes escalas que contiene cada elemento heterogéneo del bloque. Enfrentándose a un caso similar, Deleuze y Guattari explican el bloque compositormúsica-animal a través de las observaciones de Marcel Moré sobre la música de Mozart ${ }^{173}$, en la que los pájaros se expresan en notas picadas, en gruppeti y apoyaturas. El bloque sonoro del devenir-pájaro hace que, al mismo tiempo, el animal devenga en una sonoridad que no es la suya propia. De igual manera, se fijan en el caso de Hitchcock, quien no reproduce ningún grito de pájaro en su película Los pájaros (1963), sino que produce un sonido electrónico como un campo de intensidades o una ola de vibraciones ${ }^{174}$.

168. Ibid., 303.

169. Ibid., 274.

170. «Devenir es, a partir de las formas que se tiene, del sujeto que se es, de los órganos que se posee o de las funciones que se desempeña, extraer partículas, entre las que se instauran relaciones de movimiento y de reposo, de velocidad y de lentitud, las más próximas a lo que se está deviniendo, y gracias a las cuales se deviene.» Ibid., 275.

171. Ibid., 303.

172. Ibid., 245.

173. Ibid., 302.

174. Ibid., 303. Los efectos sonoros de Los pájaros fueron realizados por Oskar Sala (físico, compositor y pionero de la música digital) con un trautonium, precedente directo de los sintetizadores. Oskar Sala $\bigotimes$ Mixtur-Trautonium $\bigotimes$ 100th Anniversary 2010, accedido 19 de abril de 2020, https://www.youtube.com/watch?v=Hh8-qTjPV9g. 
Mientras que el artista clásico habita los medios, y el romántico los rechaza ${ }^{175}$, es a partir del giro postromántico cuando lo esencial ya no está en las formas y el material (es decir, en la imitación o la semejanza), sino en las fuerzas, en la duración y en las intensidades ${ }^{176}$ :

La materia [en el postromanticismo] ya no era un caos que había que someter y organizar, sino la materia en movimiento de una variación continua. Lo universal había devenido relación, variación. Variación continua de la materia y desarrollo continuo de la forma. A través de los agenciamientos, materia y forma entraban así en una nueva relación: la materia dejaba de ser una materia de contenido para devenir materia de expresión. La forma dejaba de ser un código que dominaba a las fuerzas del caos para devenir fuerza, conjunto de las fuerzas de la tierra. ${ }^{177}$

La sustitución del par materia-forma por el par material-fuerza ${ }^{178}$ constituye el paso a la modernidad, etapa en la que el devenir expresivo del ritmo, el territorio, se libera de la forma y su código propio para determinarse en otra forma. Así, lo que Deleuze y Guattari denominan paisaje melódico ${ }^{179}$, ya no consiste en una melodía asociada a un paisaje, sino en una melodía que crea un paisaje sonoro.

Los sonidos primarios de la naturaleza (el Ur-ritornelo ${ }^{180}$, el ritornelo original del paisaje), no son música -como ya advertía Stravinski ${ }^{181}$. Es el artesano o creador ${ }^{182}$ el que devienepaisaje y consolida el sonido como materia para captar las fuerzas no sonoras o no visibles del paisaje. Mientras que Franz Liszt es, para Deleuze y Guattari, el compositor romántico que interioriza el paisaje sonoro o melódico a través del lied («el arte musical del paisaje, la forma más pictórica de la música, la más impresionista» ${ }^{183}$ ), Edgard Varèse es para ellos el ejemplo de

175. Deleuze toma a Mahler como ejemplo del rechazo romántico (Ver Fundamentos de la investigación, apartado d, i): «Mahler dice que el canto de los pájaros, el color de las flores, el olor de los bosques no bastan para crear la Naturaleza, hace falta el dios Dionisos o el gran Pan. Un Ur-ritornelo de la tierra capta todos los ritornelos territoriales u otros, y todos los de los medios.» Deleuze y Guattari, Mil mesetas, 343.

176. Ibid., 346.

177. Ibid., 344.

178. Ver capítulo segundo. Cuadrado 2. 1978: El seminario Le temps musical. Deleuze, Boulez y el paisaje sonoro.

179. Deleuze y Guattari, Mil mesetas, 324.

180. Ver nota 176 en este capítulo.

181. Ver capítulo primero, apartado 1.3.2. Actitud del sujeto y modos de escucha.

182. «Ser un artesano, no un artista, un creador o un fundador, es la única manera de devenir cósmico.» Deleuze y Guattari, Mil mesetas, 348.

183. Ibid., 325. «El descubrimiento del paisaje verdaderamente melódico y del personaje verdaderamente rítmico señala ese momento del arte en el que éste deja de ser una pintura muda sobre un blasón. [...] La interiorización del paisaje sonoro o melódico puede encontrar su forma ejemplar en Listz no menos que la del personaje rítmico en Wagner. Más generalmente, el lied es el arte musical del paisaje, la forma más pictórica de la música, la más impresionista. Pero los dos polos están tan unidos que, también en el lied, la Naturaleza aparece como personaje 
la modernidad:

Varèse sería ejemplar: una máquina musical de consistencia, una máquina de sonidos (no de reproducirlos), que moleculariza y atomiza, ioniza la materia sonora, y capta una energía cósmica. Si esa máquina debe tener un agenciamiento, ese sería el sintetizador. Uniendo los módulos, los elementos originales de tratamiento, los osciladores, generadores y transformadores, distribuyendo los microintervalos, hace audible el propio proceso sonoro, la producción de ese proceso, y nos pone en relación todavía con otros elementos que rebasan la materia sonora. ${ }^{184}$

La tecnología sonora, génesis del Soundscape, permite de esta manera que un primer ritornelo territorial (Liszt) devenga en un segundo tipo de ritornelo, molecular y cósmico (Varèse). La música creada por los compositores modernos como Boulez o Varèse, moleculariza la materia sonora, de tal forma que captan fuerzas no sonoras como la duración o la intensidad al hacerlas sonoras. ${ }^{185}$

¿Y la pintura? ¿Puede la pintura alcanzar a la música? Para contestar esta pregunta, Deleuze y Guattari transfiguran en el proceso creativo de Paul Klee, «el más músico de los pintores» ${ }^{186}$, la conjugación entre fuerzas del caos, fuerzas terrestres y fuerzas cósmicas que implica el ritornelo.

Según Paul Klee, el artista comienza su proceso creativo con la simple observación de la naturaleza, mirando todos los medios para «captar la huella de la creación en lo creado»; prosigue con un interés por el microscopio, por los cristales, por las moléculas ${ }^{187}$, por los átomos y partículas, por la unidad mínima; y finalmente, termina abriéndose al Cosmos «para captar sus fuerzas en una "obra" ${ }^{188}$. Con medios casi infantiles ${ }^{189}$, Klee capta las fuerzas cósmicas en el material desterritorializado, para 'hacer visible' o captar el Cosmos. Los cuadros de temática sonora de Klee, registran este proceso a partir de gestos simples, desvelando un profundo interés por la captación del tiempo en la pintura:

rítmico de transformaciones infinitas.»

184. Ibid., 347.

185. Cfr. Ibid.

186. Ibid., 301.

187. «El núcleo central del modelo de Deleuze es la tensión entre lo molecular y lo molar, es decir, fuerzas activas y fuerzas reactivas (con la influencia de Nietzsche) en tensión constante. O si se prefiere, lo diferencial y lo unitario.» Hernández León, «Seminario: Transferencias, proyecto arquitectónico y pensamiento contemporáneo».

188. Cfr. Paul Klee, «Filosofía de la creación», en Teoría del arte moderno, Edición: $1^{a}$ ed., $1^{\mathrm{a}}$ imp. (Buenos Aires: Cactus, 2007), 57-61.

189. «Según Klee, basta una línea pura y simple unida a una idea de objeto, y nada más, para "hacer visible” o captar Cosmos.» Deleuze y Guattari, Mil mesetas, 348. 
More and more parallels between music and graphic art force themselves upon consciousness. Yet no analysis is successful. Certainly both arts are temporal; this could be proved easily. At Knirr's they rightly spoke about the presentation of a picture, by which they meant something thoroughly temporal: the expressive motions of the brush, the genesis of the effect. ${ }^{190}$

Aunque Klee se dedica a las artes visuales, el sonido (Klang) está contenido en algunas de sus pinturas como cualidad temporal, planteando visualmente flujos de sonido o polifonías. Algunas de sus obras sugieren inequívocamente valores propios del sonido a través de sus títulos, o introduciendo motivos repetitivos que inducen a la apreciación de un dinamismo estático. En todas ellas, predomina el gesto preciso, cumpliendo así con el requisito único que Deleuze y Guattari exigen para alcanzar la desterritorialización de las materias: la sobriedad ${ }^{191}$.

La obra de Klee corrobora que la expresividad del arte surge en la libertad del código ${ }^{192}$, pensamiento sostenido por Deleuze y Guattari en Del ritornelo. Al igual que ocurría con los ejemplos sonoros, la pintura es una materia de expresión para la interpretación del sonido del paisaje, sino que es el propio medio, la pintura, la que desarrolla el paisaje sonoro o melódico. No hay una determinación a través de la forma, no hay una abstracción, sino una transcodificación del sonido en pintura.

La síntesis de los ejemplos sonoros y visuales seleccionados por Deleuze y Guattari, conduce a la apreciación del devenir como el momento en el que el artista desterritorializa el ritornelo. En ese instante, la coincidencia del espacio-tiempo del sonido y el paisaje coinciden en un territorio, y el material de expresión (pintura o sonido) se convierte en materia molecularizada ${ }^{193}$ que lo desterritorializa. Desde la perspectiva del arte moderno, el paisaje sonoro no necesita formalizarse en su materialidad correspondiente para hacerse legibile, sino estar contenido en la materia en la que se expresa. En consecuencia, el artista no reproduce un paisaje visible, sino que, como decía Klee, lo hace visible.

190. Paul Klee y Felix Klee, The diaries of Paul Klee, 1898-1918 (Berkeley: University of California Press, 1964), 177.

191. «Sobriedad, sobriedad: esa es la condición común para la desterritorialización de las materias, la molecularización del material, la cosmización de las fuerzas.» Deleuze y Guattari, Mil mesetas, 348.

192. Cfr. Ibid., 328.

193. Cfr. Ibid., 346. 


\subsubsection{CRISTAL}

El ritornelo, considerado por Deleuze y Guattari como el mayor aporte que realizaron a la filosofía moderna ${ }^{194}$, es un concepto complejo engendrado a partir de gestos esenciales. Uno de los casos de estudio contenidos en el ensayo Del ritornelo es el comportamiento del pájaro Scenopoeetes dentirostris. Entre las acciones y conceptos explicados a través del pájaro, destaca una observación que, trasladada a los intereses de esta investigación, resulta ser clarividente: «el pájaro se hace visible al mismo tiempo que sonoro» ${ }^{195}$.

El sonido, disparador de la memoria, debe su existencia a su condición espacio-temporal, al dinamismo de las ondas que confluyen con los recuerdos. Por ello, la imagen asociada a un paisaje determinado o un animal definido por su canto, será resultado de un conglomerado de tiempos que lo harán visible en el sonido.

Deleuze y Guattari definían el ritornelo en la cita inicial de este punto como un cristal de espacio-tiempo capaz de actuar sobre lo que le rodea al mismo tiempo que cataliza interacciones entre elementos sin afinidad natural. En dos elementos sin aparente afinidad, como son el sonido y el paisaje, el ritornelo provoca la escisión y el solapamiento simultáneo de dos imágenes durante la escucha activa de un entorno: la imagen del sonido percibido, y la imagen que ese estímulo desencadena en la memoria del sujeto. El resultado de este solape-escisión, siguiendo la lógica deleuziana, se definiría entonces como imagen-cristal:

Cuando digo imagen-cristal tengo una vaga idea en la cabeza...Si hay una imagen mutua, o una imagen donde se produce un intercambio quisiera llamarla imagen-cristal...Diré que una imagen-cristal sería un consolidado de dos imágenes entre las cuales se produce el intercambio. ${ }^{196}$

La imagen-cristal, tan sonora como óptica, proviene del cristal de tiempo -el ritornelo por excelencia-. ${ }^{197}$ Gilles Deleuze hace referencia a la imagen-cristal en los cursos sobre cine que impartió tras la publicación de Mil Mesestas. En ellos explica qué constituye la imagen-cristal:

Lo que constituye a la imagen-cristal es la operación más fundamental del tiempo: como el pasado no se constituye después del presente que él ha sido sino al mismo tiempo, es

194. Gilles Deleuze, Dos regimenes de locos. Textos y entrevistas (Valencia: Editorial Pre-Textos, 2008), 343.

195. Deleuze y Guattari, Mil mesetas, 336.

196. Gilles Deleuze, Cine III. Verdad y tiempo. Potencias de lo falso (CACTUS, 2018), 646.

197.

Gilles Deleuze, Estudios sobre cine (Barcelona: Paidós, 1984), 127. 
preciso que el tiempo se desdoble a cada instante en presente y pasado, diferentes uno y otro por naturaleza o, lo que es equivalente, es preciso que desdoble al presente en dos direcciones heterogéneas, una que se lanza hacia el futuro y otra que cae en el pasado. ${ }^{198}$

Lo que se oye en el cristal, aclara Deleuze, son dos dimensiones del tiempo. Por un lado, la precipitación de los presentes que pasan, y por otro, la elevación o la recaida de los pasados que se conservan ${ }^{199}$. Cada dimensión se convierte en una figura, actual y virtual respectivamente, que son 'imágenes mutuas' ${ }^{200}$. Entre ellas se produce un intercambio que da como resultado una imagen real, pues, para Deleuze, la imagen-cristal no es imaginaria sino virtual, y en consecuencia, real. ${ }^{201}$

Bajo la perspectiva deleuziana el paisaje sonoro se revuelve. Empleando un cristal-tiempo, el ritornelo, se distinguen los paisajes contenidos en el sonido, los paisajes melódicos o sonoros, cuya representación, lejos de interpretarse como una figura imaginaria, es una imagen real que resulta de la coalescencia de dos imágenes asociadas al sonido, una actual y su doble virtual ${ }^{202}$, es decir, una imagen-cristal.

198. Ibid., 113.

199. Ibid., 128.

200. Ibid., 99.

201. Ibid.

202. Ibid., 174-75. 


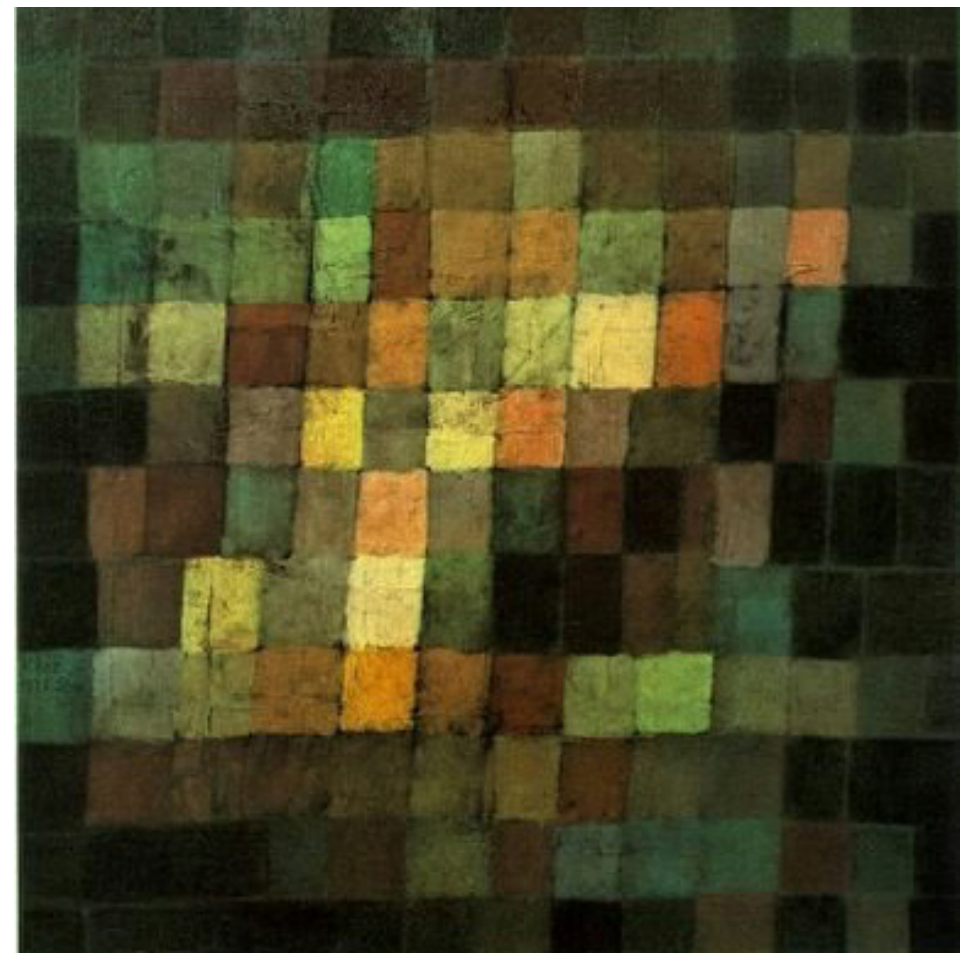

Figura 132. Paul Klee, Alter Klang (1925) 


A MAP OF A SOUND AS A SPACE
A SOUND OF A MAP AS A SPACE
A SPACE OFASOUND AS A MAP
A SOUND OF A SPACE AS A MAP
A MAP OF A SPACE AS A SOUND
A SPACE OF A MAP AS A SOUND




\section{ConClusiones}

\section{COMPROBACIÓN DE LA HIPÓTESIS DE PARTIDA}

Siguiendo el método de investigación planteado, tras el análisis de los procesos de conversión de señales, el estudio de las teorías de la escucha y el establecimiento de las estructuras de percepción, se confirma la hipótesis de la viabilidad de la representación del concepto paisaje sonoro. Las observaciones fenomenológicas y teorías del arte y el sonido de Edmund Husserl, Nelson Goodman, Hans Jonas, Pierre Schaeffer y Gilbert Simondon, sustentan teóricamente la posible figurabilidad o materialización del sonido del paisaje.

La confluencia en el término alemán Stimmung de las dos partes que conforman el concepto objeto de estudio, fundamenta el enfoque sonoro de la representación del paisaje del que parte la investigación. Este hecho es trascendental para la tesis, pues el Stimmung demuestra que la identificación de connotaciones sonoras en la relación que establece el sujeto con su entorno, es mucho más antigua que el Soundscape. Retomando esta visión sensible del paisaje, en la que el cuerpo se conjuga armónicamente con el espacio a través de instrumentos musicales, se justifica la pertinencia de este estudio en el campo de la arquitectura, pues trasladando esta sensibilidad a la práctica, se promueve la proyección de otras arquitecturas denominadas instrumentos que alientan un conocimiento operativo del paisaje.

Siguiendo esta vía de conocimiento, en la que se prioriza el estudio de relaciones analógicas frente a visiones subjetivas y simplistas que consideran la semejanza como horizonte, se rechazan las metáforas empleadas habitualmente en la definición del concepto paisaje sonoro. Con el fin de validar la ampliación del significado del término Soundscape, la tesis se desarrolla desde un posicionamiento a contracorriente que cuestiona los preceptos y definiciones marcados por la 
obra de M. Schafer The Soundscape. Our Sonic Environment and the Tuning of the World, para proponer una actualización de los mismos basada en un transvase de ideas del pensamiento sonoro actual a la teoría estética contemporánea del paisaje.

La secuencia tecnología-arte-filosofía presentada en el cuerpo teórico de la tesis, evidencia cómo la formación del concepto paisaje sonoro es el resultado de un proceso de transferencias entre disciplinas que, empujadas por la precisión de las herramientas de registro y amplificación del sonido, fundaron nuevas ciencias como la ecología acústica. Los artistas generaron nuevas posibilidades de expresión mediante el uso del sonido, lo que provocó la transformación del lenguaje y, en consecuencia, la expresión sonido del entorno se transformó progresivamente en paisaje sonoro en el ámbito musical y artístico.

Paralelamente, la exposición cronológica del contexto disciplinario acotado por las obras de John Cage, Juan Navarro Baldeweg y Gilles Deleuze, muestra la correspondencia directa entre la evolución de los valores estéticos del arte y el sonido, y el desarrollo de la técnica en este campo. Antes de que Schafer acuñase formalmente el neologismo Soundscape, la historia demuestra cómo el concepto paisaje sonoro evolucionó de la mano de la tecnología y las prótesis sensibles que, habiéndose aplicado en los conflictos bélicos, se convirtieron en impulso creativo del arte de vanguardia y de la filosofía de la ciencia y la percepción.

Finalmente, la esquematización del sistema de transducciones concatenadas que transforman y transportan imágenes del sonido en el tiempo, demuestra que el paisaje sonoro puede considerarse tanto un proceso como un objeto. Las vías de representación establecidas por Pierre Schaeffer, directa e indirecta, validan la posibilidad de que la representación del paisaje sonoro pueda ser tanto una visión sonora del entorno, como una representación mediada del mismo. Una circunstancia lógica dado que el paisaje, la estructura superior que contiene al paisaje sonoro, aúna ambas posibilidades de representación.

\section{Aportaciones: El SONIDO COMO MEDiO PARA ESTABLECER UNA ONTOLOGÍA DEL PAISAJE}

¿Qué es lo que el paisaje puede esperar del sonido?

El sonido, entendido como el signo que nos desplaza hacia la metafísica de aquello que lo emite, se revela como medio para profundizar en el conocimiento profundo del ser del paisaje y sus propiedades. Bajo esta lectura, el paisaje sonoro podría considerarse como un metapaisaje, 
es decir, un paisaje que se hace 'visible' trascendiendo la visibilidad de lo físico.

Como John Cage defendía, el sonido es un medio para conocer el entorno en profundidad. $\mathrm{O}$, tomando las palabras de Deleuze, el sonido es el intermediario que hace sensible el tiempo, el intercesor que permite organizar las fuerzas del tiempo y hacerlas sonoras. Aplicado al paisaje, el sonido hace sensibles dimensiones no apreciables a simple vista para hacerlas comprensibles.

Tras el desarrollo de la investigación, se destacan tres aspectos del paisaje que pueden comprenderse mejor a través de una lectura sonora del mismo: la simultaneidad de la experiencia y la representación, la conciencia de la individuación del sujeto y la percepción del tiempo en el paisaje.

\section{I. APRECIACIÓN SENSIBLE DE LA SIMULTANEIDAD DE LA EXPERIENCIA Y LA REPRESENTACIÓN DEL PAISAJE}

El estudio de las imágenes perceptuales, mentales y verbales ligadas al tiempo y al espacio que dan lugar al paisaje sonoro permiten cuestionar, no solo los modos de representación de los aspectos sensibles del paisaje, sino también la estructura y lógica del proceso de formación del concepto. Como se ha visto a lo largo de la investigación, a través de las imágenes asociadas al sonido es posible concretar en una forma los ritmos sensibles inherentes al paisaje, apreciando así las estructuras del entorno. Nos acercamos así al pensamiento abstracto a medida que agudizamos nuestra percepción, y aprendemos, mediante la escucha, a destilar los invariantes que conforman un concepto visual, complejo y cambiante como es el paisaje.

Paisaje y escucha forman cada uno de ellos un plano de significado que, en ambos casos, remite al producto de una reflexión y percepción simultáneas. Esta circunstancia provoca que el resultado de la conjunción de ambos términos sea, por tanto, un retruécano semántico y conceptual que entrelaza lo sentido con el que siente. Entendidos como acciones, en los momentos iniciales de formación de las imágenes asociadas a ambos procesos, se establece entre ellos una analogía dinámica. Es decir, existe un isodinamismo en el proceso de formación de sus respectivos resultados, pues ambos implican, de forma simultánea, la experiencia y la representación de lo que se percibe. Paisaje y escucha podrían entenderse, por tanto, como acciones análogas en el momento de la invención de la imagen asociada a cada uno de ellos.

El paisaje sonoro, además de asumir los enfoques procesal y objetual del paisaje, fija en una imagen un acontecimiento dinámico. La distancia ontológica necesaria para llevar a cabo la abstracción que busca la objetividad de la representación, se ve reforzada, en este caso, por 
la naturaleza autónoma del signo sonoro, recalcando con su percepción la dicotomía entre la experiencia y la representación inherente del paisaje.

\subsection{ConcienCia DE LA INDividuación DEL SUjeto}

El desdoblamiento entre lo que se experimenta y lo que se representa, hace consiente al hombre de sí mismo. El paisaje, producto del intelecto y la sensibilidad, al ser engendrado en la escucha, produce un redoble de subjetividad. Ambas acciones conviven simultáneamente, dando como resultado una paradoja significativa: la experiencia del paisaje es, en primer lugar, una experiencia del yo (sujeto) desde el otro (el sonido del paisaje). El sujeto del paisaje no es uno. Tampoco el otro. Sino un yo que se forma en la conjunción de ambos.

El desarrollo de los medios de grabación y reproducción en el siglo XX, intensificó la experiencia del mundo sensible de cada individuo. El sonido, al igual que el paisaje, sirve como una herramienta que hace consciente al hombre de sí mismo, pues la audición desdibuja el límite entre el interior y el exterior del cuerpo para proyectar una realidad envolvente que da lugar a los espacios propios, a la autoconciencia del propio individuo cuando este se siente sentir.

En consecuencia, el sujeto pertenece al paisaje al mismo tiempo que se posiciona ante él. Esta posición ambigua del sujeto en relación al paisaje, dentro y fuera al mismo tiempo, al ser potenciada por el sonido, produce una resonancia entre cuerpo y entorno. Esta reflexión se alinea con el pensamiento de Deleuze, quien en el seminario Le temps musical, consideraba el paisaje como una forma de individuación.

La escucha del paisaje invita, por tanto, al abandono del ser al mismo tiempo que conforma un vínculo activo con el entorno en mutua sintonía. Es decir, la escucha activa arrastra a devenir paisaje al sujeto a través del sonido del propio paisaje.

\subsection{Percepción del tiempo en el paisaje}

La convivencia de Aión y Cronos convierte el instante del acontecimiento sonoro en duración. La sucesión de transducciones en el tiempo, asaltadas por los recuerdos e imágenes asociadas a estímulos previos registrados en la memoria, transforma el tiempo en un espacio propio que es próximo y lejano al mismo tiempo. El proceso de formación de las imágenes que representan el concepto paisaje sonoro, ejemplifica la paradoja de Parsifal, es decir, la conversión 
del tiempo en espacio.

Las diferencias entre el tiempo pulsado y el tiempo no pulsado exploradas por Pierre Boulez y Gilles Deleuze, conducen al entendimiento del espacio y el tiempo como una unidad, el espaciotiempo (Raumzeit). Si el paisaje sonoro, como exponía Deleuze, es un ejemplo de tiempo no pulsado -un poco de tiempo en estado puro-, las imágenes que sirven para su representación son formas dinámicas moldeadas por un tiempo plástico.

La representación del concepto constituye un corte en el continuo de interacciones entre el interior y el exterior que provocan la alternancia y superposición de dos tiempos, Cronos y Aión. El gesto de la representación (mental o material) supone una ruptura que define la continuidad del tiempo que da forma a la imagen del sonido.

Tanto los instrumentos que simbolizan como aquellos que permiten la representación del paisaje sonoro, conforman un nuevo tipo de tiempo. Fijan un estado del que, o bien aflora la estructura formal de lo percibido a través del sonido, o bien se proyecta con ellos una nueva estructura de percepción. En ambos casos, la característica sonora de lo representado conlleva la consideración del tiempo que, entendido como parámetro generador de forma, produce una alteración en la sintaxis de la expresión paisaje sonoro. El paisaje transmuta en atributo, y el sonido se califica como paisaje, pasando así del paisaje sonoro al sonido paisaje.

\section{Aplicaciones: instrumentos en la docencia de la ARQUITECTURA}

Los patrones lógicos que subyacen en las obras analizadas en el capítulo tercero sirven como modelo para establecer un método de conocimiento creativo basado en la construcción de instrumentos para el estudio de las fuerzas sensibles del paisaje. En ellos, la objetualización del signo sonoro, la fabricación de objetos, artefactos o intermediarios espaciales vinculados al sonido, conlleva una implicación mental y sensorial del constructor con el entorno. Esta acción promueve la exploración de la relación material-fuerza frente a la relación materia-forma.

Se considera que este tipo de instrumentos son una herramienta proyectual de gran valor, hermanada con los experimentos docentes de la AA, la Bartlett School o la Cooper Union que se exponían en los fundamentos de la investigación. Si bien el ser humano será siempre el transductor genuino por excelencia, estos instrumentos constituyen otra forma de conversión de señales que hacen visible una parte invisible del paisaje. 
Desarrolladas en una atmósfera creativa de gran riqueza, las obras vinculadas al paisaje y las fuerzas sensibles de John Cage, Juan Navarro Baldeweg y Gilles Deleuze, abren la reflexión sobre los resultados que pueden obtenerse mediante la ideación y aplicación de los instrumentos al conocimiento del paisaje. El carácter multidisciplinar de los centros e instituciones en los que desarrollaron sus investigaciones, como el CAVS o el IRCAM, hizo posible que el sonido fuera avalado como medio para investigar el espacio y el paisaje. Los cuatro vértices del cuadrado MIT, (Cage, Navarro, Amacher y Kepes) pusieron en práctica las posibilidades de la observación de lo sensible en Estados Unidos, mientras que, paralelamente, la diagonal IRCAM (Deleuze, Boulez) planteaba la teoría de la estructura del sonido en el tiempo y su aplicación en el paisaje y el territorio. John Cage es el electrón que con sus movimientos por París, Chicago y Nueva York, logró difundir todo su espíritu creativo tanto en Europa como en EEUU.

En cada etapa, los artistas, arquitectos y filósofos se han enfrentado al problema fundamental de la representación del espacio-tiempo dinámico empleando diferentes recursos. Tras el análisis de las obras seleccionadas, se observa que cada uno de los autores enfatiza un aspecto concreto de la representación. Así, los enfoques procesal, objetual y virtual, se vinculan, respectivamente, a la obra de Cage, Navarro y Deleuze.

John Cage trata de crear las condiciones que permiten que lo sonidos se identifiquen con el oyente, generando una permeabilidad que busca la objetividad. Las obras firmadas por John Cage son procesos al servicio del oyente en los que el autor desaparece.

La consideración del paisaje como proceso se encuentra en las partituras-evento de Cage y Brecht. Estas generan un campo abierto a la experiencia en el que el autor desaparece en el momento en el que el 'ejecutante' realiza la acción indicada. Tanto los Paisajes imaginados como las partituras-evento constituyen dos maneras de proyectar el espacio que van más allá de lo material, pues son una construcción dinámica en las que la notación espacial despliega todo su sentido. Los Imaginary Landscapes refuerzan, además, la condición atributiva del paisaje, pues alejándose de la semejanza, estas obras son paisaje por su estructura, por la multiplicidad de fuerzas que actúan en ellas y por ser una experiencia individual y múltiple al mismo tiempo. Es decir, son un paisaje sin tierra. Son sonido paisaje.

Los surtidores de signos y cajas de resonancia de Juan Navarro Baldeweg profundizan en el enfoque objetual de la representación del paisaje sonoro. Navarro propone con la construcción de sus piezas un método que obliga al conocimiento de lo físico, la materia, las energías del entorno, y a la interacción del cuerpo con la naturaleza sobre la que se actúa. La obra de Navarro Baldeweg muestra cómo dirigir la mirada creativa al medio físico natural e incorporar 
en la arquitectura las fuerzas preexistentes en el entorno. Sus piezas sonoras lo convierten en una figura clave para comprender, mediante la representación material, el sonido y sus componentes.

Las exploraciones intersensoriales que realiza Navarro a través de objetos obligan a aprender a mirar y a escuchar los signos, por lo que se consideran un método extrapolable a la docencia de proyectos arquitectónicos. Con ellas se desarrolla una forma de pasividad activa que conlleva la implicación de la inteligencia, la memoria y la imaginación en el proyecto de arquitectura. Siguiendo su método, en una primera operación, el arquitecto comprende en el hacer de un instrumento cómo activar el paisaje al aumentar o disminuir homotéticamente las relaciones que incorpora la pieza en su fabricación. De este procedimiento nace una arquitectura sonora que se aleja de lo audible para designar a aquellos edificios que, dada su relación estrecha con el sonido de un lugar, pueden ser calificados como instrumentos en el paisaje. La capilla de Ronchamp o La casa de la lluvia serían ejemplo de ello. También puede considerarse, en una segunda lectura, que las piezas sonoras de Navarro Baldeweg son obras de arte que generan en sí mismas un mundo sonoro, como consigue con la pieza diseñada durante el desarrollo del proyecto de La casa de la lluvia.

Finalmente, la exploración de las componentes espacio-temporales de la representación del sonido desemboca en las imágenes virtuales producidas por el ritornelo de Gilles Deleuze. El ritornelo, haciendo referencia a la imagen móvil de la eternidad de los sonidos de la naturaleza, es la herramienta que sirve para representar el concepto paisaje sonoro sin eludir su complejidad. $\mathrm{Su}$ incorporación en la selección de instrumentos da cuenta de la necesidad del pensamiento abstracto en este campo de estudio con el fin de evidenciar la posibilidad de que exista el paisaje en el sonido. Su estudio supone una apertura en los significados de las palabras básicas del léxico del paisaje sonoro, como 'ritmo' y 'territorio'.

\section{Aperturas: El paisaje virtual}

Paisaje sonoro, dimensión sonora, sonido del paisaje... la traducción de un término forjado en el pensamiento alemán, francés y americano implica que la interpretación del término Soundscape al castellano sea múltiple, pues aunque el sonido de la naturaleza es un lenguaje universal, reflexionar sobre el paisaje y sus componentes sonoros es una tarea siempre influenciada por el lenguaje desde el que se piensa. Lejos de ser un factor negativo, la ambigüedad permite encontrar una brecha en el concepto donde caben la arquitectura y el paisaje. 
Esta anomalía en el lenguaje permite el viraje que despoja a la metáfora paisaje sonoro de su validez indiscutible. En general, existe un problema semántico que tiene su origen en la manera en que se acaban asumiendo las metáforas como verdaderas, sin reparar en que lo sean o no. Pero no siempre lo que se denomina como paisaje sonoro es paisaje. Frente a la representacióncomo paisaje -que reduce significativamente las posibilidades de expresión-, la analogía, la comparación tácita y estructural que implica este proceso, resulta de gran utilidad en el campo de la arquitectura y el paisaje, pues ayuda a abandonar la subjetividad que amenaza el rigor de cualquier estudio.

La relación entre sonido y el mundo informático-virtual patente en las obras sonoras de Juan Navarro o en los discursos de Jaron Lanier, cuestionan la revolución ontológica que produce el mundo digital. De la misma manera que un almacén de ladrillos, no es arquitectura, la recolección de datos conduce a la experiencia alienada que arruina la potencialidad de la experiencia real. Por ello, conscientemente, la investigación no ha profundizado en las herramientas digitales.

Enlazando con la virtualidad de la imagen-cristal deleuzina, los instrumentos analógicos cuestionan la capacidad de manipulación que las herramientas digitales tienen sobre los procesos creativos. En un siguiente estadio, los instrumentos para la representación del concepto paisaje sonoro impulsan a averiguar cuáles son las herramientas que, basadas en la semejanza, presentan la experiencia virtual como experiencia equivalente a la real, pues si el parecido descriptivo se asume como realidad, los sistemas de información anularán la esencia humana de lo sensible. 

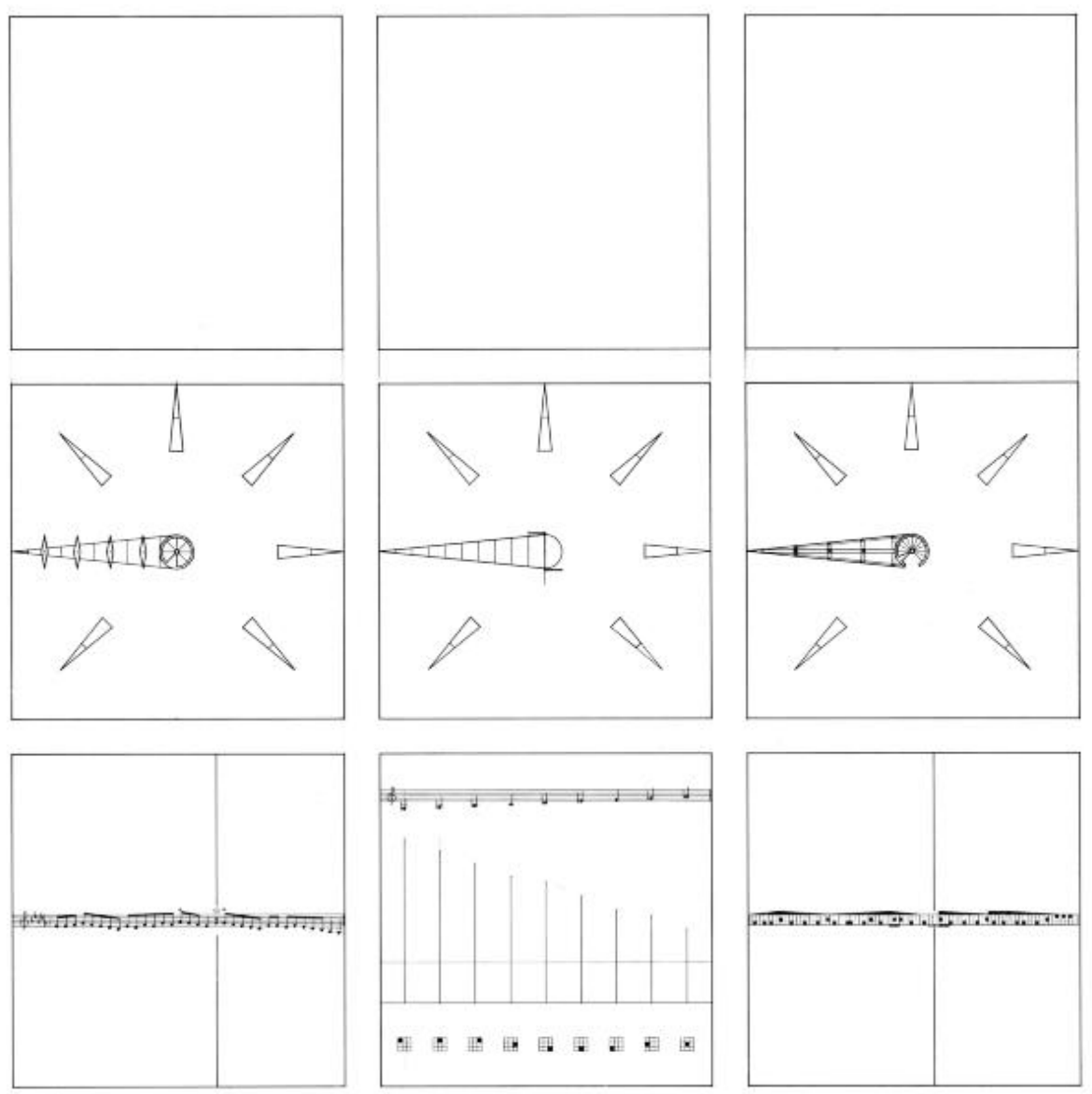

Figura 134. Donald Scott Springer, City of Keyboard, Clock Tower (1990-91) 

ENGLISH

Translations 



\title{
FOREWORD IN THREE PARTS
}

\author{
I. Twittering Machines.
}

Demobilized after the end of World War I, Paul Klee (1879-1940) began to put into practice many of the techniques he had learned as an airplane ${ }^{1}$ painter during the two years he served in the German army. The fabric of the wings or the templates with which he painted the fuselage ${ }^{2}$ formed the reminiscences that later forged the well-known 'trace transfer method' that Klee began to develop from $1919^{3}$ onwards. This system consisted of transferring a line drawing from one paper to another using a third paper which, painted on one side with black oil paint, was interspersed between the other two. To do this, Klee made a first line drawing that he placed on top. He then meticulously traced with a needle the outlines that would be received by the sheet of drawing paper placed under the black painted surface and, once the drawing was transferred, the figures - sometimes accompanied by the inevitable stains produced by the support of the hand on the canvas - were filled with watercolour. The impermeability of the oil allowed the independent coexistence of the defining lines of the main drawing with the water colours that characterised the imprecise and complex backgrounds of many of Paul Klee's paintings.

A reflection of this technique is Die Zwitscher-Maschine (The Tweeting Machine, 1922), one of the paintings that has given rise to the most interpretations in the last century. The title of the work suggests a kind of music box in which, by means of a mechanism activated by a crank, the chirping of four birds perched on a wire can be perceived. The transference technique used in this painting leads us to look for, within the enormous work of the Swiss painter, the line

1. In his diaries, Paul Klee relates his experience in the army between 1916 and 1918 . His incorporation to Flight School 5 as head painter describes it as "one more adventure to prevent war from being so boring". Paul Klee and Felix Klee, The Diaries of Paul Klee, 1898-1918 (Berkeley: University of California Press, 1964), 363-64.

2. The exhibition „Klee in Wartime“, organised by the Paul Klee Centre, focused on the aspects of his work that originated during this time and subsequently influenced his career: „The artist commented on his life as a soldier in his diary and in letters with startlingly ironic detachment. In spite of the terrible events of the war, the years from 1914 until 1918 proved to be a very fertile time for Klee. He discovered new materials, such as the cloth of aeroplane wings, and new tools such as the stencils with which he had to paint aeroplanes. He developed his work further in a formal sense, opened up new subjects and creative media and delved further into those he had already tried out." Zentrum Paul Klee, Bern, Klee in Wartime, December 6, 2017 - June 3, 2018, Zentrum Paul Klee, accessed January 3, 2020, https://www.zpk.org/en/exhibitions/review_0/2017/klee-in-wartime-1563.html.

3. Museum of Modern Art (New York, N.Y.), Paul Klee centennial: prints and transfer drawings: [exhibition] January 8-April 3, 1979, the Museum of Modern Art, New York (The Museum of Modern Art, 1978), 3, www.moma. org/calendar/exhibitions/1825. 
drawing that served as a basis for the final ${ }^{4} d r a w i n g$. As a reference, we find that Klee used a drawing made in 1921, when he was a teacher at the Bauhaus in Weimar: Konzert auf dem Zweig (Concert on the Branch). In it, four birds very similar to those represented in The Tweeting Machine, are perched on a sinuous branch embedded in its right-hand end. The drawing captures the moment when the birds sing. The gestures of the birds - the position of the open beaks, with their tongues stretched out - and the title of the work -concert- make you think of their chirping.

Beyond finding similarities and differences between the figures in the two works, the chronological analysis of the procedures followed to obtain the final image of The Tweeting Machine reveals a logic in Klee's thinking that is of great interest to this research. The passage from one drawing to another, from the concert to the machine, involves the transformation of a scene linked to a natural sound - four birds singing on a tree branch - into a mechanical representation. This transition is analogous to the logical process that decoy builders go through. By observing nature, the craftsman ${ }^{5}$ studies the characteristics of a bird's song and then devises a mechanical system to reproduce a similar sound. Small instruments that arise from the study of nature and that are capable of converting a given moment into a duration.

Establishing a parallelism between the operations implicit in the process of making Klee's painting and the interests of this research, the title Twittering Machines is borrowed to designate, in this thesis, the instruments that serve to represent the concept of soundscape. A concept in which sound, technique and nature converge, just like in the gadget of the four birds.

\section{The REPRESENTATION OF THE SOUNDSCAPE CONCEPT}

On the occasion of the exhibition Staatliches Bauhaus in Weimar 1919-1923, the Bauhaus published its first book in 1923. In addition to showing photographs of the work done by the students in the different workshops, texts signed by all the school's teachers were collected. Among them was Paul Klee, master painter of Bauhaus in those years. His essay Wege des Naturstudiums ${ }^{6}$ proposes extending the modes of knowledge of nature established historically, and explains by means of a diagram the different forms of relationship between the subject and

4. Maurice L. Shapiro, "Klee’s Twittering Machine”, The Art Bulletin Vol.50, n. 1 (March.1968): 67-69, https:// doi.org/10.2307/3048514.

5. The work of French craftsman François Morel stands out in this field. "Quelle est Belle Company", accessed January 3, 2020, https://www.qbc.fr/.

6. Paul Klee, "Wege des Naturstudiums", in Staatliches Bauhaus in Weimar 1919-1923 (Weimar - Munich: Bauhausverlag, 1923), 24-25. 
nature. Beyond the visual relationship between subject and object, Klee proposes transcending any optical relationship by establishing a relationship between them through resonance. This type of linkage would make it possible to synthesize the "outer gaze and inner vision" in a single gesture in order to achieve, in their unity, a knowledge of the inner reality of objects ${ }^{8}$.

Derived from the Latin word resonare, 'resonance' is a term of great importance in the study of natural sciences. Thus, physicists speak of the phenomenon of 'mechanical resonance' when one particle makes another vibrate by subjecting it to an oscillating frequency, astronomers identify resonance when two orbiting bodies exert a regular and periodic gravitational influence on each other, and chemists can speak of various 'resonance structures' in the delocalized electrons of certain molecules?. While the etymological roots of the word are in the acoustic realm, its widespread significance as an 'influence of one body on another' has extended the metaphorical use of the term into the humanities. Until the early 20th century, resonance occupied a predominant position in a vast conceptual terrain, encompassing virtually all European science, art and philosophy that provided a new vision of the role of sound in the West through cultural ${ }^{10}$ practice. A role that has been overlooked by the predominantly visual discourses ${ }^{11}$.

Bearing in mind the architectural nature of the thesis, the aim of the research process was to find the resonance that would allow, on the one hand, to find a spatial link between the different independent subjects that the concept of soundscape brings together, such, as science, philosophy and aesthetic discourse; and on the other hand (keeping Klee's trail in mind), to achieve through his exploration a deep knowledge of the representation of the soundscape concept.

7. Paul Klee, "Vías diversas en el estudio de la naturaleza", in Teoría del arte moderno, 1. ${ }^{a}$ ed.

8. See Klee, "Diverse paths in the study of nature".

9. Cf. Veit Erlmann, "resonance", in Keywords in sound, ed. David Novak and Matt Sakakeeny (Durham; London: Duke University Press, 2015), 173-82.

10. "The disappearance of resonance as a fundamental mechanism of auditory perception did not immediately find a parallel in early 20th century thinking. Quite the opposite: the growing importance of phenomenology in European philosophy following the works of Edmund Husserl, Martin Heidegger and Maurice Merleau-Ponty, as well as the fundamental appreciation that our knowledge of things is inevitably contingent on our experience, seems to have been the basis for the idea of resonance. As Jacques Derrida argues, no one but Heidegger embraced resonance as a cornerstone of the way philosophy can relate to its Other. Heidegger, suggests Derrida, was the first philosopher to reject philosophy's obsession with "absolute belonging", or the difference, represented by the eardrum, between what is proper to oneself and what is the property of the Other. Heidegger's "otophilology" reorganized philosophy by admitting in its disuse a "proven metonymy" of domains previously considered dichotomous" This explanation (translation by the author), seen in Veit Erlmann's essay "resonance" " cited above, is based on the analysis of Jacques Derrida's essay Heidegger's Ear. Jacques Derrida, Politics of Friendship: followed by El oído de Heidegger (Madrid: Trota, 2010).

11. Cf. Erlmann, "resonance”, 176. 
In short, the research reflects the search for a resonance that would facilitate the difficult task imposed by the study of the soundscape: to decipher the correlation between the immateriality of signs and the materiality of things That is, to understand the immateriality of the concept of soundscape through the materiality of its representation. In this process of interpretation, perception has the mission of capturing the sensitive object (the sound), while intelligence has the mission of apprehending the objective meanings of the concept (the construction of the logic of sound). A balance is thus produced in which intelligence is interested in objectivity (in the knowledge of the concept of soundscape) and perception by the object ${ }^{22}$ (by those instruments that allow its representation).

\section{INSTRUMENTS}

The words 'person' and 'personage' come from the term personare, which means 'to resonate through a mask'. The original tragedy mask was understood as a device designed to make the actor ${ }^{13}$ 's voice sound more powerful and audible. The instruments that the title of the thesis presents as a means to achieve the representation of the concept of soundscape, correspond to tools such as masks, capable of serving the image of what is represented.

Three masks, John Cage, Juan Navarro Baldeweg and Gilles Deleuze, whose work distinguishes them as exponents in their respective fields of action, intervene in the three acts that have marked the evolution of the concept: Firstly, they experience the processes of converting the sound of the landscape in its representation into objective forms; secondly, they explore through their works conceptual structures using real supports; and finally, their synergy produces the transgression of classical aesthetic codes.

The three, tangentially united by the artistic and academic contexts in which their paths are inserted, become a whole, connected by the same narrative thread. The approximation of their respective works, tuned in the frequency of landscape and sound, generates a vibration whose maximum oscillation affects, in unison, architecture, music and philosophy.

12. See Gilles Deleuze, Proust y los signos (Barcelona: Editorial Anagrama S.A., 1995), 39.

13. According to the traditional etymology of 'person' the word comes from the Latin personare, which alludes to the mask that the actors used in the theatre to make their voice 'resound'. This mask had a hole at the level of the mouth and gave the voice a penetrating and vibrant sound. So, 'person' would mean first 'mask', 'role of the actor', 'character' and finally 'person'. Alois Walde, Lateinisches etymologisches Wörterbuch, 1910, 578, http://archive.org/ details/Lateinisches-etymologisches-woerterbuch.fr. 


\section{ConClusions}

\section{VERIFICATION OF THE STARTING HYPOTHESIS.}

Following the research method proposed, after the analysis of signal conversion processes, the study of listening theories and the establishment of perception structures, the hypothesis of the viability of the representation of the concept of soundscapeis confirmed. The phenomenological observations and theories of art and sound by Edmund Husserl, Nelson Goodman, Hans Jonas, Pierre Schaeffer and Gilbert Simondon, theoretically support the possible figurability or materialization of landscape sound.

The confluence in the German term Stimmung of the two parts that make up the concept under study, bases the sound approach to the representation of the landscape from which the research starts. This fact is transcendental for the thesis, since the Stimmung shows that the identification of sound connotations in the relationship established by the subject with his/ her environment is much older than the Soundscape. Taking up again this sensitive vision of the landscape, in which the body is harmoniously combined with the space through musical instruments, the relevance of this studio in the field of architecture is justified, as by translating this sensitivity into practice, it promotes the projection of other architectures called instruments, which encourage an operational knowledge of the landscape.

Following this path of knowledge, in which the study of analogical relations is prioritized against subjective and simplistic visions that consider similarity as a horizon, the metaphors usually used in the definition of the concept of soundscapeare rejected. In order to validate the extension of the meaning of the term Soundscape, the thesis develops from a counter-current positioning that questions the precepts and definitions marked by the work of M. Schafer The Soundscape. Our Sonic Environment and the Tuning of the World, to propose an updating of the same based on a transfer of ideas from current sound thinking to contemporary aesthetic theory of landscape.

The technology-art-philosophy sequence presented in the theoretical body of the thesis shows how the formation of the concept of soundscape is the result of a transference process between disciplines that, pushed by the precision of the tools of recording and amplification of sound, founded new sciences such as acousticecology. The artists generated new possibilities of expression through the use of sound, which caused the transformation of language and, consequently, the sound expression of the environment was progressively transformed into a 
sound landscape in the musical and artistic field.

At the same time, the chronological exhibition of the disciplinary context delimited by the works of John Cage, Juan Navarro Baldeweg and Gilles Deleuze, shows the direct correspondence between the evolution of the aesthetic values of art and sound, and the development of technique in this field. Before Schafer formally coined the neologism Soundscape, history shows how the concept of soundscape evolved from the hand of technology and sensitive prostheses which, having been applied in wartime, became the creative impulse of avant-garde art and the philosophy of science and perception.

Finally, the schematization of the system of concatenated transductions that transform and transport images of sound over time shows that soundscape can be considered both a process and an object. The ways of representation established by Pierre Schaeffer, direct and indirect, validate the possibility that the representation of soundscape can be both a sound vision of the environment, and a mediated representation of it. A logical circumstance given that landscape, the superior structure that contains the soundscape, combines both possibilities of representation.

\section{Contributions: Sound as a means to establish an ontology OF THE LANDSCAPE.}

\section{What can the landscape expect from sound?}

Sound, understood as the sign that moves us towards the metaphysics of that which emits it, is revealed as a means to deepen our knowledge of the being of the landscape and its properties. Under this reading, the soundscape could be considered as a meta-landscape, that is, a landscape that becomes 'visible' by transcending the visibility of the physical.

As John Cage advocated, sound is a means of knowing your surroundings in depth. Or, to take Deleuze's words, sound is the intermediary that makes time sensitive, the intercessor that allows the forces of time to be organized and made sound. Applied to the landscape, sound makes sensitive dimensions not perceivable to the naked eye to make them understandable.

Following the development of the research, three aspects of the landscape are highlighted that can be better understood through a sound reading: the simultaneity of experience and representation, the awareness of the individuality of the subject and the perception of time in the landscape. 


\section{I. SENSitive APPRECiation of the SIMUltaneity Of EXPERIENCE AND THE REPRESENTATION OF THE LANDSCAPE.}

The study of perceptual, mental and verbal images linked to time and space that give rise to the soundscape allows us to question not only the modes of representation of the sensitive aspects of the landscape, but also the structure and logic of the process of forming the concept. . As we have seen throughout the research, through the images associated with sound it is possible to specify in a way the sensitive rhythms inherent in the landscape, thus appreciating the structures of the environment. We thus approach abstract thinking as we sharpen our perception, and learn, through listening, to distil the invariants that make up a visual, complex and changing concept such as landscape.

Landscape and listening form each a plane of meaning which, in both cases, refers to the product of simultaneous reflection and perception. This circumstance provokes that the result of the conjunction of both terms is, therefore, a semantic and conceptual pun that interweaves sense with feeling. Understood as actions, in the initial moments of formation of the images associated with both processes, a dynamicanalogy is established between them. In other words, there is an isodynamism in the process of forming their respective results, since both involve, simultaneously, the experience and the representation of what is perceived. Landscape and listening could therefore be understood as analogous actions at the time of the invention of the image associated with each of them.

Soundscape, besides assuming the procedural and objective approaches of the landscape, fixes in an image a dynamic event. The ontological distance necessary to carry out the abstraction that seeks the objectivity of representation is reinforced, in this case, by the autonomous nature of the sound sign, emphasizing with its perception the dichotomy between experience and the inherent representation of the landscape.

\subsection{Awareness of the individuality of the SUbject.}

The split between what is experienced and what is represented makes a human aware of him/herself. The landscape, a product of the intellect and the sensitivity, being generated in listening, produces a redoubling of subjectivity. Both actions coexist simultaneously, resulting in a significant paradox: the experience of the landscape is, first of all, an experience of the self (subject) from the other (the sound of the landscape). The subject of the landscape is not one. Neither the other; but an 'P' that is formed in the conjunction of both. 
The development of recording and reproduction media in the 20th century intensified the experience of the sensitive world of each individual. Sound, like landscape, serves as a tool that makes a person aware of him/herself, since hearing blurs the boundary between the interior and exterior of the body to project an enveloping reality that gives rise to one's own spaces, the self-awareness of the individual when he/she feels.

As a result, the subject belongs to the landscape as it positions itself in front of it. This ambiguous position of the subject in relation to the landscape, both inside and outside at the same time, when enhanced by sound, produces a resonance between body and environment. This reflection is aligned with the thought of Deleuze, who in the seminar Le temps musical, considered the landscape a form of individuation.

Listening to the landscape therefore invites one to abandon one's self and at the same time to form an active bond with the environment in mutual harmony. In other words, active listening drags the subject into becoming a landscape through the sound of the landscape itself.

\subsection{Perception of time in the Landscape.}

The coexistence of Aion and Cronus turns the moment of the sound event into duration. The succession of transductions in time, assailed by memories and images associated with previous stimuli registered in the memory, transforms time into a space of its own that is both near and far at the same time. The process of formation of the images that represent the concept of soundscape, exemplifies the paradox of Parsifal, that is, the conversion of time into space.

The differences between pressed time and unpressed time explored by Pierre Boulez and Gilles Deleuze, lead to the understanding of space and time as a unit, the space-time (Raumzeit). If the soundscape, as Deleuze explained, is an example of unpressed time -a little bit of time in its pure state -, the images that serve for its representation are dynamic forms molded by plastic time.

The representation of the concept constitutes a cut in the continuum of interactions between the interior and the exterior that provoke the alternation and superposition of two times, Cronus and Aion. The gesture of representation (mental or material) implies a break that defines the continuity of time that gives shape to the image of sound.

Both the instruments that they symbolize and those that allow the representation of the soundscape, form a new type of time. They set a state from which either the formal structure of what is perceived through sound emerges, or a new structure of perception is projected with 
them. In both cases, the sound characteristic of what is represented involves the consideration of time which, understood as a shape-generating parameter, produces an alteration in the syntax of the soundscapeexpression. The landscape transmutes into attribute, and the sound is qualified as landscape, thus passing from the sound landscape to landscape sound..

\section{Applications: instruments in the teaCHing of ARCHITECTURE.}

The logical patterns underlying the works analyzed in the third chapter serve as a model for establishing a method of creative knowledge based on the construction of instruments for the study of the sensitive forces of the landscape. In them, the objectification of the sound sign, the manufacture of objects, artifacts or spatial intermediaries linked to sound, entails a mental and sensory involvement of the builder with the environment. This action promotes the exploration of the material-force relationship as opposed to the matter-form relationship.

This type of instrument is considered to be a very valuable design tool, twinned with the teaching experiments of the AA, the Bartlett School or the Cooper Union that were exposed in the foundations of the research. While a human being will always be the genuine transducer par excellence, these instruments are another form of signal conversion that makes an invisible part of the landscape visible.

Developed in a very rich creative atmosphere, the works linked to landscape and the sensitive forces of John Cage, Juan Navarro Baldeweg and Gilles Deleuze, open the reflection on the results that can be obtained through the ideation and application of the instruments to the knowledge of the landscape.. The multidisciplinary character of the centres and institutions in which they developed their research, such as the CAVS or the IRCAM, made it possible for sound to be endorsed as a means of investigating space and landscape. The four vertices of the MITsquare, (Cage, Navarro, Amacher and Kepes) put into practice the possibilities of observing the sensitive in the United States, while, in parallel, the diagonal IRCAM (Deleuze, Boulez) posed the theory of the structure of sound in time and its application in landscape and territory. John Cage is the electron, whom with his movements in Paris, Chicago and New York, managed to spread all his creative spirit both in Europe and in the USA.

At each stage, artists, architects and philosophers have faced the fundamental problem of representing dynamic space-time using different resources. After the analysis of the selected works, it can be seen that each of the authors emphasizes a specific aspect of the performance. Thus, the procedural, object and virtual approaches are linked, respectively, to the work of Cage, Navarro and Deleuze. 
John Cage tries to create the conditions that allow the sounds to be identified with the listener, generating a permeability that seeks objectivity. The works created by John Cage are processes at the service of the listener in which the author disappears.

The consideration of landscape as a process is found in the event scores of Cage and Brecht, which generate an open field of experience in which the author disappears at the moment in which the 'performer' carries out the indicated action. Both the imagined landscapes and the score-events constitute two ways of projecting space that go beyond the material, as they are a dynamic construction in which spatial notation unfolds its full meaning. The Imaginary Landscapes also reinforce the attributive condition of the landscape, since, moving away from similarity, these works are landscape because of their structure, because of the multiplicity of forces acting on them and because they are an individual and multiple experience at the same time. I mean, they are a landless landscape. They are landscape sound.

Juan Navarro Baldeweg's sign fountains and sound boxes deepen the objectual approach to the representation of the soundscape. With the construction of his pieces, Navarro proposes a method that forces knowledge of the physical, the matter, the energies of the environment, and the interaction of the body with the nature on which it acts. Navarro Baldeweg's work shows how to direct the creative gaze to the natural physical environment and incorporate into the architecture the pre-existing forces in the environment. His sound pieces make him a key figure in understanding, through material representation, sound and its components.

The intersensory explorations that Navarro carries out through objects force us to learn to look and listen to signs, which is why they are considered a method that can be extrapolated to the teaching of architectural projects. With them, a form of active passivity is developed that involves intelligence, memory and imagination in the architectural project. Following his method, in a first operation, the architect understands in making an instrument how to activate the landscape by homothetically increasing or decreasing the relations that the piece incorporates in its manufacture. From this procedure a sound architecture is born that moves away from the audible to designate those buildings that, given their close relationship with the sound of a place, can be qualified as instruments in the landscape. Ronchamp's Chapel or The House of Rain would be an example of this. It can also be considered, in a second reading, that Navarro Baldeweg's sound pieces are works of art that generate a world of sound in themselves, as he achieves with the piece designed during the development of the The House of Rain project..

Finally, the exploration of the space-time components of sound representation leads to the virtual images produced by Gilles Deleuze's Ritornello. The Ritornello, referring to the 
moving image of the eternity of nature's sounds, is the tool that serves to represent the concept of soundscape without eluding its complexity. Its incorporation in the selection of instruments shows the need for abstract thinking in this field of study in order to highlight the possibility of the existence of landscape in sound. His study involves an opening up to the meanings of the basic words in the lexicon of soundscapes, such as 'rhythm' and 'territory'.

\section{Openings: The Virtual Landscape.}

Soundscape, sound dimension, sound of the landscape... the translation of a term forged in German, French and American thought implies that the interpretation of the term Soundscape to Spanish is multiple, because although the sound of nature is a universal language, to reflect on the landscape and its sound components is a task always influenced by the language from which one thinks. Far from being a negative factor, ambiguity allows us to find a gap in the concept where architecture and landscape fit.

This anomaly in language allows for a shift that strips the soundscape metaphor of its unquestionable validity. In general, there is a semantic problem that has its origin in the way metaphors are assumed to be true, regardless of whether they are true or not. But what is called a soundscape is not always a landscape. As opposed to representation-as landscape -which significantly reduces the possibilities of expression-, the analogy, the tacit and structural comparison that this process implies, is very useful in the field of architecture and landscape, since it helps to abandon the subjectivity that threatens the rigour of any study.

The relationship between sound and the computer-virtual world, evident in the sound works of Juan Navarro or in the speeches of Jaron Lanier, questions the ontological revolution produced by the digital world. Just as a brick store is not architecture, data collection leads to the alienated experience that ruins the potential of the real experience. That is why, consciously, research has not gone into digital tools in any depth.

Linked to the virtuality of the Deleuzine crystal image, the analogical instruments question the capacity of manipulation that the digital tools have on the creative processes. In a next stage, the instruments for the representation of the concept of soundscape encourage us to find out which are the tools that, based on similarity, present the virtual experience as an experience equivalent to the real one, because if the descriptive similarity is assumed as reality, the information systems will annul the human essence of the sensitive. 

LISTA DE ILUSTRACIONES 

Figura 1 Lewis Carroll, The Hunting of the Snark, 1876. Mapa para la tripulación.

Figura 2 Expedición de Malaspina. Borrador del levantamiento de la costa desde Puerto Mulgrave hasta Cabo Engańo, incluido el Puerto de Desengańo, 1791. Archivo del Museo Naval, Madrid. Fuente: Belén López-Laguna et al., eds., Diseñar América: El trazado español de los Estados Unidos = Designing America: [Spain's impint in the U.S.] (Madrid: Fundación Consejo España-Estados Unidos, 2014), 93.

Figura 3 Quelle est Belle Company. Doce reclamos de pájaros de Europa. (C) Quelle est Belle Company. Fuente: "Quelle est Belle Company», accedido 3 de enero de 2020, https://www. qbc.fr/.

Figura 4 Paul Klee, Die Zwitscher-Maschine, 1922, 15. The Museum of Modern Art, New York. Fuente: «Paul Klee. Twittering Machine (Die Zwitscher-Maschine). 1922 | MoMA», The Museum of Modern Art, accedido 22 de diciembre de 2019, https://www.moma.org/ collection/works/37347.

Figura 5 Paul Klee, Konzert auf dem Zweig, 1921, 188. Zentrum Paul Klee, Bern. (C Zentrum Paul Klee, Bern, Bildarchiv. Fuente: «emuseum - Konzert auf dem Zweig», accedido 22 de diciembre de 2019, http://www.emuseum.zpk.org/

Figura 6 Paul Klee, Actor's Mask, 1924. The Museum of Modern Art, New York. Fuente: «Paul Klee. Actor's Mask. 1924 | MoMA», The Museum of Modern Art, accedido 16 de junio de 2020, https://www.moma.org/collection/works/80094.

Figura 7 Jan Brueghel y Predro Pablo Rubens, El Oido, 1617. Museo del Prado, Madrid. Fuente: «El Oído - Colección», Museo Nacional del Prado, accedido 5 de marzo de 2019, https://www. museodelprado.es/coleccion/obra-de-arte/el-oido/074adedf-40f0-476f-b132-fe450e71e0f3.

\begin{tabular}{|c|c|}
\hline Figura 8 & Pointe du Hoc. Estado actual \\
\hline Figuras 9-10 & Vista aérea del Pointe du Hoc, 1944 \\
\hline Figuras 11-12 & $\begin{array}{l}\text { Covadonga Blasco. Caja del evento sonoro. Planos de ejecución de la caja del evento } \\
\text { sonoro, 2014. Fuente: Covadonga Blasco Veganzones, «La dimensión sonora del paisaje. } \\
\text { Herramientas, modelos y prototipos aplicados para la interpretación del paisaje sonoro } \\
\text { pretérito» (Máster en Proyectos Arquitectónicos Avanzados, E.T.S. Arquitectura (UPM), } \\
\text { 2014), http://oa.upm.es/35474/. }\end{array}$ \\
\hline Figura 13 & $\begin{array}{l}\text { Película de 35-mm. Parte izquierda: registro visual del sonido en el minuto anterior al final } \\
\text { de la Primera Guerra Mundial. Parte derecha: registro después de que las armas dejaran de } \\
\text { disparar a las } 11 \text { a.m. del } 11 \text { de noviembre de 1918.@ imperial war museums. Fuente: Derek } \\
\text { Gregory, «Sounds of War», Geographical Imaginations (blog), } 25 \text { de julio de 2012, https:// } \\
\text { geographicalimaginations.com/2012/07/25/sounds-of-war/. }\end{array}$ \\
\hline Figura 14 & $\begin{array}{l}\text { Sound Rangers del ejército alemán, 1917. Fuente: Derek Gregory, «Sounds of War», } \\
\text { Geographical Imaginations (blog), } 25 \text { de julio de 2012, https:/geographicalimaginations. } \\
\text { com/2012/07/25/sounds-of-war/ }\end{array}$ \\
\hline Figura 15 & $\begin{array}{l}\text { Localizador acústico alemán, 1917. Fuente: «Acoustic Radar. Horn and Wooden Wine Rack } \\
\text { Construction.», accedido } 21 \text { de junio de 2020, http://www.douglas-self.com/MUSEUM/ } \\
\text { COMMS/ear/ear.htm. }\end{array}$ \\
\hline Figura 16 & $\begin{array}{l}\text { Sistema de localización acústica de dos trompas en Bolling Field, USA, 1921. Fuente: } \\
\text { "Aircraft Detection before Radar, 1917-1940», Rare Historical Photos (blog), } 1 \text { de septiembre } \\
\text { de 2016, https://rarehistoricalphotos.com/aircraft-detection-radar-1917-1940/. }\end{array}$ \\
\hline Figura 17 & $\begin{array}{l}\text { Localizador acústico de cuatro cuernos. 1920-30. Fuente: «Acoustic Radar. Horn and } \\
\text { Wooden Wine Rack Construction.» }\end{array}$ \\
\hline Figura 18 & La parábola individual holandesa. 1930-40. Fuente: Ibid. \\
\hline Figura 19 & Espejos acústicos en Kent, Inglaterra. \\
\hline
\end{tabular}




\begin{tabular}{|c|c|}
\hline Figura 20 & $\begin{array}{l}\text { Mapa de barrido de la primera batalla de Passchendaele, Bélgica, 1917. Fuente: «First_ } \\
\text { Battle_of_Passchendaele___barrage_map_(original).jpg }(11231 \times 7796) », \text { accedido } 21 \text { de } \\
\text { junio de 2020, https://upload.wikimedia.org/wikipedia/commons/b/b2/First_Battle_of_ } \\
\text { Passchendaele_-_barrage_map_\%28original\%29.jpg. }\end{array}$ \\
\hline Figura 21 & $\begin{array}{l}\text { Raoul Hausmann. Dibujo que acompañaba a la patente del optófono, 1936. Fuente: } \\
\text { «Optophonic Performance», Le Jeu de Paume, accedido } 21 \text { de junio de 2020, http://www. } \\
\text { jeudepaume.org/index.php?page=article\&idArt=3100. }\end{array}$ \\
\hline Figura 22 & $\begin{array}{l}\text { Isamu Noguchi, Radio Nurse. Fabricado por Zenith Radio Corporation (Chicago, Illinois), } \\
\text { 1937. Fuente: «Isamu Noguchi. Radio Nurse Speaker. } 1937 \text { | MoMA», The Museum of } \\
\text { Modern Art, accedido } 21 \text { de junio de 2020, https://www.moma.org/collection/works/4341. }\end{array}$ \\
\hline Figura 23 & $\begin{array}{l}\text { Isamu Noguchi, Radio Nurse. Fabricado por Zenith Radio Corporation (Chicago, Illinois), } \\
\text { 1937. Fuente:Roger Catlin, «After the Tragic Lindbergh Kidnapping, Artist Isamu Noguchi } \\
\text { Designed the First Baby Monitor», Smithsonian Magazine, accedido } 21 \text { de junio de } \\
\text { 2020, https://www.smithsonianmag.com/smithsonian-institution/after-tragic-lindbergh- } \\
\text { kidnapping-isamu-noguchi-designed-first-baby-monitor-180961454/. }\end{array}$ \\
\hline Figura 24 & $\begin{array}{l}\text { Radio modelo RA248A. Fabricada por Radiola, 1958-59. «Radiola RA248A Radio } \\
\text { Radiola marque, build 1958/1959, } 14 \text { imá», accedido } 21 \text { de junio de 2020, https://www. } \\
\text { radiomuseum.org/r/radiola_radiola_not_known_yet.html. }\end{array}$ \\
\hline Figura 25 & $\begin{array}{l}\text { Aalvar Aalto, Woodberry Poetry Room, 1948. Consola para fonógrafos. Harvard, «Harvard } \\
\text { Art Museums», accedido } 21 \text { de junio de 2020, https://www.harvardartmuseums.org/ } \\
\text { collections/person/24198. }\end{array}$ \\
\hline Figura 26 & $\begin{array}{l}\text { Aalvar Aalto, Woodberry Poetry Room, 1948. Consola para fonógrafos. Planos de ejecución. } \\
\text { Alvar Aalto et al., eds., Aalto and America (New Haven [Conn.] ; London: Yale University } \\
\text { Press, 2012), 252. }\end{array}$ \\
\hline Figuras $27-28$ & $\begin{array}{l}\text { Structures for Sound - Musical Instruments by Francois and Bernard Baschet. MoMA, NY. } \\
\text { 1966. Fuente: Photographic Archive. The Museum of Modern Art Archives, New York. } \\
\text { IN777.1. Photograph by George Cserna. "Structures for Sound - Musical Instruments by } \\
\text { Francois and Bernard Baschet | MoMA», The Museum of Modern Art, accedido } 21 \text { de junio } \\
\text { de 2020, https://www.moma.org/calendar/exhibitions/3475. }\end{array}$ \\
\hline Figura 29 & $\begin{array}{l}\text { Portada del catálogo de la exposición 1962Wiesbaden. FLUXUS1982. Eine kleine Geschichte } \\
\text { von Fluxus in drei Teilen. Wiesbaden, Kassel, Berlin: Berliner Künstlerprogramm des DAAD, } \\
\text { 1982-1983. Fuente: } 1962 \text { WiesbadenFLUXUS1982. Eine kleine Geschichte von Fluxus drei } \\
\text { Teilen., Belines Künstler programm des DAAD (Wiesbaden, Kassel, Berlin, 1983). }\end{array}$ \\
\hline Figuras 30-32 & $\begin{array}{l}\text { Für Augen und Ohren: Von der Spieluhr zum akustischen Environment. Berlin: Akademie } \\
\text { der Künste, 1980. Fuente: Réne Block et al., Für Augen und Ohren. Von der Spieluhr zum } \\
\text { akustischen Environment. Objekte - Installationen - Performances, 1. edition (Akademie der } \\
\text { Künste Berlin, 1980). }\end{array}$ \\
\hline Figura 33-34 & $\begin{array}{l}\text { Exposición Sound. MoMa PS1, NY, 1979. MoMA PS1 Archives, } \\
\text { II.A.186. The Museum of Modern Archives, New York. INPS1.186.2 Fuente: «Sound | } \\
\text { MoMA», The Museum of Modern Art, accedido } 21 \text { de junio de 2020, https://www.moma. } \\
\text { org/calendar/exhibitions/4121. }\end{array}$ \\
\hline Figura 35 & $\begin{array}{l}\text { Stephen Isola, oboe. } 1980-81 . \text { Fuente: «Cooper Union Archive : Student Project : Oboe } \\
\text { [ARCH_151_IsolaStephen_1980-81S]», accedido } 1 \text { de junio de 2020, https://archswc. } \\
\text { cooper.edu/Detail/objects/7398. }\end{array}$ \\
\hline Figura 36 & $\begin{array}{l}\text { Urban details. 1984-85. Fuente: John Hejduk et al., eds., Education of an architect (New } \\
\text { York: Rizzoli, 1988), } 68 .\end{array}$ \\
\hline Figura 37 & James Richards, The connection: a study in stasis and animation. 1984-85. Fuente: Ibid., 35. \\
\hline
\end{tabular}




\begin{tabular}{|c|c|}
\hline Figuras 38-39 & $\begin{array}{l}\text { Devices: A Manual of Architectural + Spatial Machines, 2006. Fuente: C. J Lim, Devices: A } \\
\text { Manual of Architectural + Spatial Machines (Amsterdam; London: Architectural Press, 2006), } \\
\text { 58, } 85 .\end{array}$ \\
\hline Figuras 40-42 & $\begin{array}{l}\text { Mark Smout y Laura Allen, Envirographic Instruments. Fuente: «Smout Allen», Smout Allen, } \\
\text { accedido } 1 \text { de julio de 2019, http://www.smoutallen.com/. }\end{array}$ \\
\hline Figura 43 & $\begin{array}{l}\text { Donald Scott Springer, City of Keyboard, Pipe Organ (1990-91). Fuente: «Cooper Union } \\
\text { Archive : Student Project : City of Keyboard Instruments [ARCH_151_SpringerScott_1990- } \\
91 \text { S]», accedido } 21 \text { de junio de 2020, https://archswc.cooper.edu/Detail/objects/2161. }\end{array}$ \\
\hline Figura 44 & $\begin{array}{l}\text { Bernhard Leitner. Headspaces. Sound Stars (2007). En Bernhard Leitner y Boris Groys, } \\
\text { Bernhard Leitner: P.U.L.S.E., ed. Z. K. M. Karlsruhe, Bilingual edition (Ostfildern: Hatje } \\
\text { Cantz, 2008), 189. }\end{array}$ \\
\hline Figura 45 & Bernhard Leitner. Headspaces. Sound Arches (2007). En Ibid. \\
\hline Figura 46 & $\begin{array}{l}\text { Robert Fludd, Monocordio (1617). Fuente: «Robert Fludd's Utriusque Cosmi maioris salicet } \\
\text { et minoris metaphysica... (1617-1619 CE)», accedido } 6 \text { de noviembre de 2019, http:// } \\
\text { billheidrick.com/Orpd/RFludd/. }\end{array}$ \\
\hline Figura 47 & Arnold Böcklin, Detalle de La isla de los muertos II (1880). \\
\hline Figura 48 & Caravaggio, Apolo tocando el laúd (1596). \\
\hline Figura 49 & René Magritte, La Cascade (1961). \\
\hline Figura 50 & $\begin{array}{l}\text { Iannis Xenakis. Sin título, 1959. Fuente: Marie-Haude Caraës, Nicole Marchand-Zanartu, y } \\
\text { Jean Lauxerois, Images de pensée (Paris: RMN, 2011), } 101 .\end{array}$ \\
\hline Figura 51 & $\begin{array}{l}\text { René Laënnec, Estetoscopio (1819). Fuente: «De l’auscultation médiate, ou, Traité du } \\
\text { diagnostic des maladies des poumons et du coeur, fondé principalement sur ce nouveau } \\
\text { moyen d'exploration», René Laënnec (1819) }\end{array}$ \\
\hline Figura 52 & Fotograma de la película Zelig (1983), dirigida por Woody Allen. \\
\hline Figura 53 & Fonoatógrafo de Édouard-Léon Scott de Martinville (1857) \\
\hline Figura 54 & $\begin{array}{l}\text { Thomas Alva Edison junto a su fonógrafo (1877). Fuente: «Edison, Thomas A. Photo by } \\
\text { L.C. Handy, 1877», still image, 1865, https://www.loc.gov/pictures/resource/cwpbh.04326. }\end{array}$ \\
\hline Figura 55 & Optófono de Fournier d' Albe (1921) \\
\hline Figura 56 & $\begin{array}{l}\text { El optófono de lectura en la portada de la revista Scientific American (1920). Fuente: } \\
\text { Scientific American, November 6, 1920, Vol. CXXIII, No. } 19 .\end{array}$ \\
\hline Figuras $57-58$ & Fotograma de la película La dolce vita (1960), dirigida por Federico Fellini. \\
\hline Figura 59 & $\begin{array}{l}\text { Diagrama de la cadena de acontecimientos que intervienen en la representación del paisaje } \\
\text { sonoro }\end{array}$ \\
\hline Figura 60 & $\begin{array}{l}\text { Clarinetista de Cornelis Jacobus van Oeckelen II (1838). Fuente: Ralph Van Wolffelaar, «Het } \\
\text { ongelooflijke verhaal van Cornelis van Oeckelen en zijn Androïde Klarinetspeler», bndestem. } \\
\text { nl, } 22 \text { de mayo de 2019, https://www.bndestem.nl/breda/het-ongelooflijke-verhaal-van- } \\
\text { cornelis-van-oeckelen-en-zijn-androide-klarinetspeler } \sim \text { a5458be4/. }\end{array}$ \\
\hline Figura 61 & $\begin{array}{l}\text { László Moholy-Nagy, Partiturskizze zu einer machanischen exzentrik (1924-5). Fuente: László } \\
\text { Moholy-Nagy:, «Partiturskizze zu einer mechanischen exzentrik», en Die Bühne im Bauhaus, } \\
\text { ed. Oskar S chlemmer et al. (Munich: Albert Langen Verlag, 1924), 44-45. }\end{array}$ \\
\hline Figura 62 & $\begin{array}{l}\text { John Cage en Kyoto, Japón (1962). Fuente: John Cage Trust, «John Cage Trust: John Cage: } \\
\text { Ryoanji (Catalog Raisonné, Volume I)», John Cage Trust (blog), } 10 \text { de julio de 2013, http:// } \\
\text { johncagetrust.blogspot.com/2013/07/john-cage-ryoanji-catalog-raisonne.html. }\end{array}$ \\
\hline Figura 63 & $\begin{array}{l}\text { Esquema de la evolución del arte sonoro desde Pitágoras hasta 1980. Fuente: Block et al., Für } \\
\text { Augen und Ohren. Von der Spieluhr zum akustischen Environment. Objekte - Installationen- } \\
\text { Performances, } 6 .\end{array}$ \\
\hline
\end{tabular}




\begin{tabular}{|c|c|}
\hline Figura 64 & Mecanismo de anclaje \\
\hline Figura 65 & $\begin{array}{l}\text { Merce Cunningham, Bonnie Bird, Syvilla Fort, y Dorothy Hermann, } \\
\text { en la Cornish School (1938). Fuente: John Cage Trust, «John Cage Trust: John Cage’s } \\
\text { Percussion Collection (July 8, 1940)», John Cage Trust (blog), } 14 \text { de septiembre de 2017, } \\
\text { http://johncagetrust.blogspot.com/2017/09/john-cages-percussion-collection-july-8.html. }\end{array}$ \\
\hline Figura 66 & $\begin{array}{l}\text { Vista exterior de la New Bauhaus, Chicago (1937/39). Fuente: «Moholy-Nagy Foundation», } \\
\text { accedido } 12 \text { de febrero de 2020, https://moholy-nagy.org/teaching/. }\end{array}$ \\
\hline Figura 67 & $\begin{array}{l}\text { László Moholy-Nagy en el Institute of Design, Chicago (1946). Fuente: «Moholy-Nagy } \\
\text { Foundation | Photo Album», accedido } 22 \text { de junio de 2020, https://moholy-nagy.org/photo- } \\
\text { album/. }\end{array}$ \\
\hline Figura 68 & $\begin{array}{l}\text { Exposición de los trabajos de los estudiantes del curso preliminar de la Nueva Bauhaus, } \\
\text { Chicago (1938). Fuente: «Moholy-Nagy Foundation». }\end{array}$ \\
\hline Figura 69 & $\begin{array}{l}\text { György Kepes, The New Landscape (1951). Fuente: Geögy Kepes, The New Landscape in Art } \\
\text { and Science. Academy Editions Ltd, 1956. }\end{array}$ \\
\hline Figura 70 & $\begin{array}{l}\text { Urban Form seminar. South Facades, Boylston Street, Former Berkeley Building, } \\
\text { Montgomery-Frost Co. (1954-1959). Photographer: Nishan Bichajian (American, 20th } \\
\text { Century), Researcher: Gyorgy Kepes (American, 1906-2001), Researcher: Kevin Lynch } \\
\text { (American, 1918-1984). Fuente: Kevin Lynch, «South Facades, Boylston Street, Former } \\
\text { Berkeley Building, Montgomery-Frost Co.», } 1959 \text { de 1954, http://dome.mit.edu/ } \\
\text { handle/1721.3/34097. }\end{array}$ \\
\hline Figura 71 & $\begin{array}{l}\text { John Cage en su apartamento. William-Cage House (1956). Fuente: Branden Wayne Joseph, } \\
\text { Experimentations: John Cage in music, art, and architecture, First edition (New York; } \\
\text { London: Bloomsbury Academic, 2016), } 121 .\end{array}$ \\
\hline Figura 72 & $\begin{array}{l}\text { György Kepes en el Center for Advanced Visual Studies (CAVS) del MIT, Cambridge, } \\
\text { Massachusetts (1967). Fotógrafo: Ivan Massar.Fuente:«Vision in Motion } \longrightarrow \text { Information } \\
\text { Landscapes - Articles - Bauhaus Imaginista», accedido } 22 \text { de junio de 2020, http://www. } \\
\text { bauhaus-imaginista.org/articles/4250/vision-in-motion-information-landscapes. }\end{array}$ \\
\hline Figuras 73-74 & $\begin{array}{l}\text { City-Links, 1974. Fotografía de Maryanne Amacher comprobando un micrófono en el puerto } \\
\text { de Boston para su proyecto City Links (1974). Fuente: CAVS online archive. http://act.mit. } \\
\text { edu/cavs }\end{array}$ \\
\hline Figura 75 & $\begin{array}{l}\text { Publicación del proyecto City Links en Arttransition, CAVS, MIT (1975). Fuente: } \\
\text { «Arttransition», 73, accedido } 21 \text { de febrero de 2020, http://act.mit.edu/cavs/item/CAVS_ } \\
\text { Arttransition?image=884c09f1e98e. }\end{array}$ \\
\hline Figura 76 & $\begin{array}{l}\text { Juan Navarro en su estudio del Center for Advanced Visual Studies, MIT. Fuente: } \\
\text { «EP[S] - Juan Navarro Baldeweg», EL PAÍS, } 5 \text { de febrero de 2006, https://elpais.com/ } \\
\text { cultura/2006/02/05/album/1139094001__10215.html. }\end{array}$ \\
\hline Figura 77 & $\begin{array}{l}\text { Maryanne Amacher en el Center for Advanced Visual Studies, MIT. Fuente: «Anywhere } \\
\text { City: Maryanne Amacher at the Center for Advanced Visual Studies MIT, Listening Session } \\
\text { \& Screening - Blank Forms», accedido } 2 \text { de octubre de 2019, https://blankforms.org/events/ } \\
\text { anywhere-city-maryanne-amacher-at-the-center-for-advanced-visual-studies-mit-listening- } \\
\text { session-screening/. }\end{array}$ \\
\hline Figura 78 & $\begin{array}{l}\text { Juan Navarro Baldeweg, To John Cage. Cartel para concierto homenaje a John Cage, } 1974 . \\
\text { Fuente: Archivo Juan Navarro Baldeweg. }\end{array}$ \\
\hline Figura 79 & $\begin{array}{l}\text { Estudio de Maryanne Amacher en el Center for Advanced Visual Studies, MIT. Fuente: } \\
\text { «Anywhere City: Maryanne Amacher at the Center for Advanced Visual Studies MIT - } \\
\text { Screening at Artists Space in New York», ArtRabbit, accedido } 22 \text { de junio de 2020, https:// } \\
\text { www.artrabbit.com/events/anywhere-city-maryanne-amacher-at-the-center-for-advanced- } \\
\text { visual-studies-mit-artists-space. }\end{array}$ \\
\hline
\end{tabular}




\begin{tabular}{|c|c|}
\hline Figura 80 & $\begin{array}{l}\text { Juan Navarro Baldeweg, cartel para el concierto de Maryanne Amacher Everything in the air, } \\
\text { city links (1974). Fuente: Juan Navarro Baldeweg, Escritos, 1. ed, Pre-textos. Ensayo } 1449 \\
\text { (Valencia: Pre-Textos, 2017), 290. }\end{array}$ \\
\hline Figura 81 & $\begin{array}{l}\text { John Cage, Score without Parts ( } 40 \text { Drawings by Thoreau): Twelve Haiku (1978). Fuente: John } \\
\text { Cage et al., eds., Every Day Is a Good Day: The Visual Art of John Cage ; [... on the Occasion } \\
\text { of John Cage: Every Day Is a Good Day; Exhibition Tour Baltic Centre for Contemporary } \\
\text { Art, Gateshead, } 19 \text { June - } 5 \text { September } 2010 \text {; Kettle's Yard, Cambridge } 25 \text { September - } 14 \\
\text { November } 2010 \text {; Huddersfield Art Gallery } 20 \text { November - } 8 \text { January } 2011 \text {...] (London: } \\
\text { Hayward, 2010), 82. }\end{array}$ \\
\hline Figura 82 & $\begin{array}{l}\text { Seminario Le temps musical. De izquierda a derecha: Elliott Carter, Pierre Boulez, Roland } \\
\text { Barthes, Jean-Claude Risset, Gerald Bennett, Michel Decoust, Michel Foucault, Gilles } \\
\text { Deleuze. París, } 23 \text { de febrero de 1978. Fotografía de Gilbert Uzan/Gamma-Rapho. Fuente: } \\
\text { Getty Images. }\end{array}$ \\
\hline Figura 83 & $\begin{array}{l}\text { Le temps musical. } 23 \text { de febrero de } 1978 \text {. Fotograma de la sesión. Fuente: «Le Temps musical : } \\
\text { séance de synthèse 1ère partie - Ressources», accedido } 19 \text { de marzo de 2019, https://medias. } \\
\text { ircam.fr/xcd4f03. }\end{array}$ \\
\hline Figura 84 & $\begin{array}{l}\text { Gilles Deleuze durante la grabación del tema Le Voyageur del grupo Schizo (1972). Fuente: } \\
\text { Publicado por Audionaut, «Audionautas», accedido } 12 \text { de mayo de 2020, http://www. } \\
\text { audionautas.com/2015/01/richard-pinhas-lethique.html. }\end{array}$ \\
\hline Figura 85 & $\begin{array}{l}\text { John Cage, Olivier Messiaen y Pierre Boulez en el Festival de música contemporánea de } \\
\text { Huddersfield (1989). Fotografía: Huddersfield contemporary music festival archive photos. } \\
\text { Fuente:«Huddersfield hits } 40 \text { with a broader scope but its spirit undimmed | Music| The } \\
\text { Guardian», accedido } 5 \text { de febrero de } 2020 \text {, https://www.theguardian.com/music/2017/ } \\
\text { nov/21/huddersfield-hits-40-contemporary-music-festival. }\end{array}$ \\
\hline Figura 86 & Paul Klee. Wald bai G (1925) \\
\hline Figuras $87-88$ & $\begin{array}{l}\text { Paul Klee. El molino de agua. Curso del } 27 \text { de febrero de 1922, p. 89. Fuente: «Bildnerische } \\
\text { Formlehre - Bildnerische Gestaltungslehre - Paul Klee - Zentrum Paul Klee, Bern», accedido } \\
6 \text { de marzo de 2020, http://www.kleegestaltungslehre.zpk.org }\end{array}$ \\
\hline Figura 89 & $\begin{array}{l}\text { Paul Klee. representación gráfica de los primeros compases del Adagio de la sexta sonata para } \\
\text { violín y clavicordio, BWV 1019/4, de Johann Sebastian Bach. Curso del } 16 \text { de enero de } \\
\text { 1922, p. 53. Fuente: «Bildnerische Formlehre - Bildnerische Gestaltungslehre - Paul Klee - } \\
\text { Zentrum Paul Klee, Bern», accedido } 6 \text { de marzo de 2020, http://www.kleegestaltungslehre. } \\
\text { zpk.org }\end{array}$ \\
\hline Figura 90 & $\begin{array}{l}\text { Paul Klee, Zimmerperspective mit Einwohnern (1921). Fuente: Pierre Boulez, Le pays fertile: } \\
\text { Paul Klee (Paris: Gallimard, 1989), } 71 .\end{array}$ \\
\hline Figura 91 & Paul Klee, Monument an der Grenze des Fruchtlandes (1929) \\
\hline Figura 92 & Frans Francken el Joven, Kunstkamer (1636) \\
\hline Figura 93 & $\begin{array}{l}\text { John Cage, Imaginary Landscape No. 1, páginas } 2 \text { y } 3 \text { (1939). Fuente: John Cage, Imaginary } \\
\text { Landscape No.1 (NY: Edition Peters, 1939). }\end{array}$ \\
\hline Figura 94 & $\begin{array}{l}\text { John Cage, Imaginary Landscape No. } 5 \text { (1952).Fuente: John Cage, Imaginary Landscape No. } 5 \\
\text { (NY: Edition Peters, 1952). }\end{array}$ \\
\hline Figura 95 & $\begin{array}{l}\text { John Cage, versión mecanografiada de 4’33” (Tacet) (1960). Fuente: Dieter Daniels y Inke } \\
\text { Arns, eds., Sounds like Silence: John Cage, 4’33": Silence Today: 1912, 1952, } 2012 \text { (Leipzig: } \\
\text { Spector, 2012), 131. }\end{array}$ \\
\hline Figura 96 & $\begin{array}{l}\text { John Cage, 433": For Any Inst[r]ument or Combination of Instruments. Graphic score in } \\
\text { proportional notation (1953). Fuente: Ibid., 116-26. }\end{array}$ \\
\hline
\end{tabular}




\begin{tabular}{|c|c|}
\hline Figura 97 & $\begin{array}{l}\text { Robert Fludd, Et sic in infinitum (1617). Fuente: «Robert Fludd's Utriusque Cosmi maioris } \\
\text { salicet et minoris metaphysica... (1617-1619 CE)». }\end{array}$ \\
\hline Figura 98 & $\begin{array}{l}\text { Robert Rauschenberg, White Painting [seven panel] (1951). Fuente: «White Painting } \\
\text { [Seven Panel]», Robert Rauschenberg Foundation, } 22 \text { de agosto de 2014, https://www. } \\
\text { rauschenbergfoundation.org/art/artwork/white-painting-seven-panel. }\end{array}$ \\
\hline Figura 99 & $\begin{array}{l}\text { John Cage interpretando Water-Walk (1959). Fuente: John Cage "Water walk», accedido } 8 \text { de } \\
\text { octubre de 2019, https://www.youtube.com/watch?v=gXOIkT1-QWY. }\end{array}$ \\
\hline Figura 100 & $\begin{array}{l}\text { George Maciunas interpretrando Drip Music en Amsterdam (1963). Foto: Oscar Van Alphen. } \\
\text { Fuente: George Brecht et al., eds., George Brecht, events: eine Heterospektive; [ [anlässlich der } \\
\text { gleichnamigen Ausstellung im Museum Ludwig, Köln, 17. September 2005 - 8. Januar } 2006 \\
\text { und im MACBA Museu d'Art Contemporani de Barcelona, 25. Mai - 3. September 2006] } \\
\text { (Köln: König, 2005), 134. }\end{array}$ \\
\hline Figura 101 & $\begin{array}{l}\text { George Brecht, Drip Music (1959). Fuente: «FONDAZIONE BONOTTO - Brecht, George } \\
\text { - Drip Music (1959)», accedido } 22 \text { de junio de 2020, http://www.fondazionebonotto.org/en/ } \\
\text { collection/fluxus/brechtgeorge/4/407.html. }\end{array}$ \\
\hline $\begin{array}{l}\text { Figuras 102- } \\
103\end{array}$ & $\begin{array}{l}\text { John Cage, Water Walk (1959). Fuente: John Cage, Water Walk | for Solo Television } \\
\text { Performance involving a large number of properties and a special single track tape (NY: } \\
\text { Edition Peters, 1959). }\end{array}$ \\
\hline Figura 104 & $\begin{array}{l}\text { Luc Ferrari, Presque rien no. } 1 \text { (1970). Fuente: Luc Ferrari, Presque rien no. 1: le lever du jour } \\
\text { au bord de la mer: œuvre sur support audio: cycle Presque rien, 1st edition (Paris: Maison } \\
\text { Ona, 2018). }\end{array}$ \\
\hline Figura 105 & $\begin{array}{l}\text { Robert Morris, Box with the Sound of Its Own Making (1961). Fuente: Robert Morris, } \\
\text { «Letters to John Cage», October } 81 \text { (1997): 70-79, https://doi.org/10.2307/779019 }\end{array}$ \\
\hline Figura 106 & $\begin{array}{l}\text { George Maciunas, Name card for Robert Morris (1964). Fuente: «George Maciunas. Name } \\
\text { Card for Robert Morris. c. } 1964 \text { | MoMA», The Museum of Modern Art, accedido } 23 \text { de } \\
\text { marzo de 2020, https://www.moma.org/collection/works/192952. }\end{array}$ \\
\hline Figura 107 & $\begin{array}{l}\text { Robert Morris in costume for War (1963). Fuente: Robert Morris, «Letters to John Cage», } \\
\text { October } 81 \text { (1997): 70-79, https://doi.org/10.2307/779019 }\end{array}$ \\
\hline Figura 108 & $\begin{array}{l}\text { George Maciunas, Name card for George Brecht (1964). Fuente: «George Maciunas. Name } \\
\text { Card for George Brecht. c. } 1964 \text { | MoMA», The Museum of Modern Art, accedido } 23 \text { de } \\
\text { marzo de 2020, https://www.moma.org/collection/works/192928. }\end{array}$ \\
\hline Figura 109 & $\begin{array}{l}\text { Robert Morris, Dibujos para Box with the Sound of Its Own Making (1965). Fuente: «Box } \\
\text { with the Sound of Its Own Making», The Seattle Art Museum, accedido } 13 \text { de junio de } \\
\text { 2020, http://localhost/objects/11616/box-with-the-sound-of-its-own-making;jsessionid=AE8 } \\
\text { 8C9E7CA0D74225016CAD20C1B8169. }\end{array}$ \\
\hline Figura 110 & $\begin{array}{l}\text { George Brecht interpretando Solo for Violin (1964). Foto: George Maciunas. Fuente: Brecht } \\
\text { et al., George Brecht, events, } 133 \text {. }\end{array}$ \\
\hline Figura 111 & $\begin{array}{l}\text { George Maciunas, Name card for George Maciunas (1964). Fuente: «George Maciunas. Name } \\
\text { Card for George Maciunas. c. } 1964 \text { | MoMA», The Museum of Modern Art, accedido } 22 \text { de } \\
\text { junio de 2020, https://www.moma.org/collection/works/192949. }\end{array}$ \\
\hline $\begin{array}{l}\text { Figuras 112- } \\
116\end{array}$ & $\begin{array}{l}\text { Juan Navarro Baldeweg, Arquitectura Informática. Transductor luz-sonido (1970-1971). } \\
\text { Fuente: Archivo Juan Navarro Baldeweg. }\end{array}$ \\
\hline Figura 117 & $\begin{array}{l}\text { Juan Navarro Baldeweg, Arquitectura Informática. Croquis para el emisor de luz (1970- } \\
\text { 1971). Fuente: Archivo Juan Navarro Baldeweg. Fuente: Archivo Juan Navarro Baldeweg. }\end{array}$ \\
\hline Figura 118 & $\begin{array}{l}\text { Juan Navarro Baldeweg, Arquitectura Informática. Dibujo para explicar el funcionamiento } \\
\text { del sistema (1970-1971). Fuente: Archivo Juan Navarro Baldeweg. }\end{array}$ \\
\hline Figura 119 & Paul Klee, Paukenspieler (1940) \\
\hline
\end{tabular}




\begin{tabular}{|c|c|}
\hline Figura 120 & $\begin{array}{l}\text { Juan Navarro Baldeweg, Arquitectura Informática. Fotomontaje (1979-1971). Fuente: } \\
\text { Archivo Juan Navarro Baldeweg. }\end{array}$ \\
\hline Figura 121 & Juan Navarro Baldeweg, Arado (1975). Fuente: Archivo Juan Navarro Baldeweg. \\
\hline Figura 122 & Juan Navarro Baldeweg, Partitura (1973). Fuente: Archivo Juan Navarro Baldeweg. \\
\hline Figura 123 & $\begin{array}{l}\text { Juan Navarro Baldeweg, La columna y el peso (1972). Fotografía : Juan Navarro Baldeweg. } \\
\text { Fuente: Archivo Juan Navarro Baldeweg. }\end{array}$ \\
\hline Figura 124 & Adolf Loos \\
\hline Figura 125 & Le Corbusier (1951). Hulton Archive. Fuente: Getty images. \\
\hline Figura 126 & $\begin{array}{l}\text { Le Corbusier frente a la escultura Ozon II. Fuente: «MONDOBLOGO: the sculptures of le } \\
\text { corbusier», MONDOBLOGO (blog), } 25 \text { de abril de 2013, http://mondo-blogo.blogspot. } \\
\text { com/2013/04/the-sculptures-of-le-corbusier.html. }\end{array}$ \\
\hline Figura 127 & Croquis para la capilla de Ronchamp (1950). FLC. 7470 \\
\hline Figura 128 & $\begin{array}{l}\text { Juan Navarro Baldeweg, Casa de la lluvia (1978) @ Juan García Rosell (IVAM). Fuente: } \\
\text { Archivo Juan Navarro Baldeweg. }\end{array}$ \\
\hline Figura 129 & $\begin{array}{l}\text { Juan Navarro Baldeweg, Dibujo para Casa de la lluvia (1978). CJuan Navarro Baldeweg. } \\
\text { Fuente: Archivo Juan Navarro Baldeweg. }\end{array}$ \\
\hline Figura 130 & $\begin{array}{l}\text { Juan Navarro Baldeweg, Casa de la lluvia (1978). ( Juan Navarro Baldeweg. Fuente: Archivo } \\
\text { Juan Navarro Baldeweg. }\end{array}$ \\
\hline Figura 131 & $\begin{array}{l}\text { Portada de la revista The Etude (enero, 1927). Benjamin Franklin tocando la armónica de } \\
\text { cristal. Fuente: “"The Etude” Magazine, Published by Theodore Presser. Cover Images - "The } \\
\text { Etude" Magazine», accedido } 22 \text { de junio de 2020, http://etudemagazine.com/gallery/Etude_ } \\
\text { Covers/?g2_page=19. }\end{array}$ \\
\hline Figura 132 & Paul Klee, Alter Klang (1925) \\
\hline Figura 133 & $\begin{array}{l}\text { Christine Sun Kim, (Listen) (2006). Fuente: Avant.org y Christine Sun Kim, «(LISTEN)», } \\
\text { http://avant.org/event/listen/. }\end{array}$ \\
\hline Figura 134 & $\begin{array}{l}\text { Donald Scott Springer, City of Keyboard, Clock Tower (1990-91). Fuente: «Cooper Union } \\
\text { Archive : Student Project : City of Keyboard Instruments [ARCH_151_SpringerScott_1990- } \\
91 \text { S]». }\end{array}$ \\
\hline
\end{tabular}



Bibliografía 

«1919 Rainer Maria Rilke: Ur-Geräusch». Accedido 17 de abril de 2019. https://www.uni-due.de/ lyriktheorie/texte/1919_rilke2.html.

1962 WiesbadenFLUXUS1982. Eine kleine Geschichte von Fluxus drei Teilen. Belines Künstler programm des DAAD. Wiesbaden, Kassel, Berlin, 1983. Catálogo de exposición.

Aalto, Alvar, Stanford Anderson, Gail Fenske, y David Fixler, eds. Aalto and America. New Haven [Conn.] ; London: Yale University Press, 2012.

«Academic course catalog, MIT Center for Advanced Visual Studies, fall semester 1974». Accedido 21 de febrero de 2020. http://act.mit.edu/cavs/item/cavs_coursecat_F74?image=4260b3c06f7b.

Adorno, Theodor W. «Sobre algunas relaciones entre la música y la pintura». En Sobre la música, 4164. Barcelona: Paidós, 2002.

«Advertising flyer for the concert at Harvard University, Kirkland House. Black offset on white paper, 28 x 21.6 cm.», 1974. Fondazione Bonotto. https://www.fondazionebonotto.org/.

Agamben, Giorgio. Signatura rerum: sobre el método. Barcelona: Anagrama, 2010.

Amacher, Maryanne. «CV Maryanne Amacher», s. f. https://calls.ars.electronica.art/media/ assets/14006af3fe7bec64d189b3f4a8bc2002.pdf.

«Anywhere City: Maryanne Amacher at the Center for Advanced Visual Studies MIT, Listening Session \& Screening - Blank Forms». Accedido 2 de octubre de 2019. https://blankforms. org/events/.

«Architecture at Black Mountain College». Accedido 11 de junio de 2020. https:// blackmountaincollegeproject.org/

Arnheim, Rudolf. «Image and Thought». En Sign Image Symbol, editado por György Kepes, 1st edition. New York: Braziller, 1966.

«Ars Electronica Archiv». Accedido 20 de febrero de 2020. http://archive.aec.at/.

Arteaga, Alex, y Boris Hassenstein. Architecture Without Walls. Errant Bodies Press, 2016.

«Arttransition». Accedido 21 de febrero de 2020. http://act.mit.edu/cavs/item/CAVS_Arttransition?im age $=884 \mathrm{c} 09 \mathrm{fl}$ e98 $\mathrm{e}$.

Assunto, Rosario. Il paesaggio e l'estetica. Palermo: Novecento, 2005.

Barber, Llorenç, y Círculo de Bellas Artes (Madrid). John Cage. Madrid: Círculo de Bellas Artes, 1985.

Barthelmes, Barbara, Christoph Metzger, Bill Fontana, y Ulrich Eller, eds. Vol. 01: Drawings, Sounds \& Ambiences. Heidelberg, Neckar: KEHRER Heidelberg, 2012.

Barthes, Roland. The Responsibility of Forms: Critical Essays on Music, Art, and Representation. Reprint edition. Berkeley: University of California Press, 1991.

Benjamin, Walter. La obra de arte en la época de su reproducción mecánica, 2017. Colección Historia. Casimiro, 2013.

Benson, Timothy O., ed. Raoul Hausmann et les avant-gardes. L' écart absolu. Dijon: Les Presses du Réel, 2014.

Berger, John. Cuatro horizontes. Edición: 1. Barcelona: Editorial Gustavo Gili, S.L., 2015.

Bergson, Henri. Materia y memoria: ensayo sobre la relación del cuerpo con el espiritu. Buenos Aires: 
Cactus, 2010.

Bergson, Henri, y Gilles Deleuze. Memoria y vida. Madrid: Alianza, 2016.

Bienal Espańola de Arquitectura y Urbanismo, Gerard García-Ventosa, Espanya, Ministerio de Fomento, y Fundación Caja de Arquitectos, eds. XII Bienal Española de Arquitectura y Urbanismo = 12th Spanish Architecture and Urbanism Biennial. Barcelona: Fundación Caja de Arquitectos, 2013.

«Bildnerische Formlehre - Bildnerische Gestaltungslehre - Paul Klee - Zentrum Paul Klee, Bern». Accedido 6 de marzo de 2020. http://www.kleegestaltungslehre.zpk.org/ee/ZPK/ BF/2012/01/01/092/?from_search=true.

«Bill Fontana, essay, Sound As Virtual Image». Accedido 15 de mayo de 2018. http://resoundings.org/ Pages/sound\%20As\%20Virtual\%20Image.html.

Blasco Veganzones, Covadonga. «La dimensión sonora del paisaje. Herramientas, modelos y prototipos aplicados para la interpretación del paisaje sonoro pretérito». Máster en Proyectos Arquitectónicos Avanzados, E.T.S. Arquitectura (UPM), 2014. http://oa.upm.es/35474/.

— . «Sobre la dimensión sonora del paisaje. La representación del "paisaje sonoro” a través de intermediarios espaciales». Constelaciones: Revista de arquitectura de la Universidad CEU San Pablo, n. ${ }^{\circ} 6$ (2018): 63-74.

"Two Twittering Boxes: A spatial intermediary for studying the soundscape of the past». Displacements Journal, n. ${ }^{\circ} 2$ (enero de 2018): 191-201.

Blasco Veganzones, Covadonga, y Lucía Jalón Oyarzun. «War destruction and landscape design: from preserved memory to ecological listening». En ECLAS Conference 2017. Creation/Reaction., 189-200. University of Greenwich Department of Architecture \& Landscape London UK, 2017.

BLDGBLOG. Accedido 1 de julio de 2019. http://www.bldgblog.com/.

Blesser, Barry, y Linda-Ruth Salter. Spaces Speak, Are You Listening?: Experiencing Aural Architecture. Cambridge, Mass: Mit Pr, 2006.

Block, Réne, Lorenz Dombois, Nele Hertling, y Barbara Volkmann. Für Augen und Ohren. Von der Spieluhr zum akustischen Environment. Objekte - Installationen - Performances. 1. edition. Akademie der Künste Berlin, 1980. Catálogo de exposición.

Bohm, David. Wholeness and the Implicate Order. Edición: 1. London ; New York: Routledge, 2002.

Bonnet, Francois J. The Order of Sounds: A Sonorous Archipelago. Oxford: Urbanomic Media Ltd, 2016.

Borck, Cornelius. «Blindness, Seeing, and Envisioning Prosthesis: The Optophone between Science, Technology, and Art». En Artist as inventors, inventors as artists. Hatje Cantz, 2008.

Boulez, Pierre. Le pays fertile: Paul Klee. Paris: Gallimard, 1989.

Orientations: Collected Writings. Harvard University Press, 1990.

Pensar la música hoy. Murcia: Colegio Oficial de Aparejadores y Arquitectos Técnicos de la Región de Murcia : Consejería de Educación y Cultura de la Región de Murcia : Fundación Cajamurcia, 2009.

Pierre boulez eclats. Paris: Editions du Centre Pompidou, 1992. 
Boulez, Pierre, y John Cage. «The Americans». October. The MIT Press 65 (Summer de 1993): 52-76. https://doi.org/10.2307/778763.

—. The Boulez-Cage Correspondence. Cambridge University Press, 1995.

Boursier-Mougenot, Céleste, John Cage, Manon de Boer, Florian Hecker, Ryoji Ikeda, Wassily Kandinsky, Paul Klee, et al. Art \& Music: Search for New Synesthesia. 東京: Museum of Contemporary Art Tokyo, 2012.

The Seattle Art Museum. «Box with the Sound of Its Own Making». Accedido 13 de junio de 2020. http://localhost/objects/11616/box-with-the-sound-of-its-own-making

Braunschweig, Kunstverein, Jule Hillgärtner, Carsten Nicolai, Rainer Maria Rilke, y cyan. Ur-Geräusch / Primal Sound. 1 edition. Leipzig: Spector Books OHG, 2016.

Brecht, George, Julia Robinson, Alfred M. Fischer, Uta Hoffmann, Brigitte Kalthoff, Ausstellung George Brecht. Events, Museum Ludwig, y Museu d'Art Contemporani de Barcelona, eds. George Brecht, events: eine Heterospektive ; [anlässlich der gleichnamigen Ausstellung im Museum Ludwig, Köln, 17. September 2005 - 8. Januar 2006 und im MACBA Museu d'Art Contemporani de Barcelona, 25. Mai - 3. September 2006]. Köln: König, 2005. Catálogo de exposición.

«British Exploratory Land Archive». Accedido 25 de enero de 2018. http://bartlettdesignresearchfolios. com/british-exploratory-land-archive.

Broeckmann, Andreas. Machine Art in the Twentieth Century. MIT Press, 2016.

Bush, Douglas Earl, y Richard Kassel. The Organ: An Encyclopedia. Psychology Press, 2006.

Cage, John. «A composer's confession». Making the Right Choices: A John Cage Centennial Celebration. Accedido 13 de junio de 2020. https://www.nws.edu/JohnCage/ AComposersConfession.html.

—. «An Autobiographical Statement». Accedido 18 de noviembre de 2019. https://www. johncage.org/autobiographical_statement.html.

- - «El futuro de la música: Credo». En Escritos al oído, 51-57. Arquitectura 38. Murcia: Colegio Oficial de Aparejadores y Arquitectos Técnicos de la región de Murcia, 2007.

-. Imaginary Landscape No.1. NY: Edition Peters, 1939.

_. Imaginary Landscape No.5. NY: Edition Peters, 1952.

—. Para los pájaros. Alias, 2013.

«Ritmo etc.» En Escritos al oido, 115-33. Arquitectura 38. Murcia: Colegio Oficial de Aparejadores y Arquitectos Técnicos de la región de Murcia, 2007.

- Silence: Lectures and Writings. Repr. London: Marion Boyars, 1999.

—. The Selected Letters of John Cage. Wesleyan University Press, 2016.

- Water Walk | for Solo Television Performance involving a large number of properties and a special single track tape. NY: Edition Peters, 1959.

Cage, John, y Richard Kostelanetz. «A Conversation about Radio». The Musical Quarterly 72, n. ${ }^{\circ}$ No. 2: 216-27. Accedido 20 de noviembre de 2019. https://www.jstor.org/ stable/948120?seq=1\#page_scan_tab_contents. 
Cage, John, Jeremy Millar, BALTIC Centre for Contemporary Art, Kettle’s Yard, y Huddersfield Art Gallery, eds. Every Day Is a Good Day: The Visual Art of John Cage ; [... on the Occasion of John Cage: Every Day Is a Good Day; Exhibition Tour Baltic Centre for Contemporary Art, Gateshead, 19 June - 5 September 2010 ; Kettle's Yard, Cambridge 25 September - 14 November 2010 ; Huddersfield Art Gallery 20 November - 8 January 2011 ...J. London: Hayward, 2010.

Cage, John, Carmen Pardo. Escritos al oido. Murcia: Colegio Oficial de Aparejadores y Arquitectos Técnicos de la región de Murcia : Consejería de Educación y Cultura de la Región de Murcia : Fundación CajaMurcia, 2007.

Campbell, Edward. Boulez, music and philosophy. Music in the twentieth century 27. New York: Cambridge University Press, 2010.

—. Music After Deleuze. A\&C Black, 2013.

Caraës, Marie-Haude, Nicole Marchand-Zanartu, y Jean Lauxerois. Images de pensée. Paris: RMN, 2011.

Careri, Francesco. Walkscapes: walking as an aesthetic practice. 6th print run. Land \& scape series 1. Barcelona: Gili, 2009.

Carlyle, Angus, ed. On listening. Axminster, Devon: Uniformbooks, 2013.

Carpenter, Edmund, y Marshall McLuhan. "Acoustic Space». En Explorations in Communication: An Anthology, editado por Edmund Carpenter y Marshall McLuhan, 6th print., 65-70. Beacon Paperback Language 218. Boston: Beacon Press, 1970.

Carpenter, Edmund, Eberhard Otto, Fritz Spiess, y Jørgen Meldgaard. Eskimo realities. 1st ed. New York: Holt, Rinehart and Winston, 1973.

Carroll, Lewis. The Hunting of the Snark, 1876.

Alice's adventures in Wonderland: and, Through the looking-glass and what Alice found there. The Modern Library Classics. New York: Modern Library, 2002.

Cassirer, Ernst. An Essay on Man: An Introduction to a Philosophy of Human Culture. Edición: Reprint. New Haven, CT: Yale University Press, 1962.

CAVS. «Tone and Place (Work1) Pier 6, Boston Harbor». Editado por Massachusetts Institute of Technology. Arttransition, 1975. http://act.mit.edu/cavs/item/CAVS_ Arttransition?image $=884 \mathrm{c} 09 \mathrm{fl} \mathrm{e} 98 \mathrm{e}$.

«CAVS History». Accedido 22 de febrero de 2020. http://bit.ly/1p2RADq.

Chatwin, Bruce. The songlines. Penguin classics. New York, N.Y: Penguin Books, 2012.

Chion, Michel. Guide des objects sonores: Pierre Schaeffer et la recherche musicale. Nouv. éd. Bibliothèque de recherche musicale. Paris: Buchet/Chastel [usw.], 1995.

- L'audio-vision - 4e éd. - Son et image au cinéma. Edición: 4 e édition revue et augmentée. Armand Colin, 2017.

Chion, Michel, y Antonio López Ruiz. La audiovisión: introducción a un análisis conjunto de la imagen y el sonido. Barcelona: Paidós, 2011.

Chion, Michel, y James A. Steintrager. Sound: An Acoulogical Treatise. Durham: Duke University Press, 2016. 
Cline, David. The Graph Music of Morton Feldman. Cambridge University Press, 2016.

Coe, La, y Jodi Lynn. «Constructing Vision: László Moholy-Nagy’s Partiturskizze Zu Einer Mechanischen Exzentrik, Experiments in Higher Spatial Dimensions», 1 de mayo de 2019. https://vtechworks.lib.vt.edu/handle/10919/89334.

Coll López, Jaime. «Le Corbusier : la forma acústica». Ph.D. Thesis, Universitat Politècnica de Catalunya, 1994. http://www.tdx.cat/handle/10803/482045.

Collectif. Klee et la Musique -Catalogue Exposition - Centre Georges Pompidou, Musée National d'Art Moderne - Paris - 1985. Paris: Editions du Centre Pompidou, 1992.

«Cooper Union Archive : Search Projects : instruments». Accedido 1 de junio de 2020. https:// archswc.cooper.edu/Search/projects?search=instruments.

Coromines, Joan. Breve diccionario etimológico de la lengua castellana. 3. ed. muy rev. y mejorada. Biblioteca románica hispánica : 5, Diccionarios ; [2]. Madrid: Gredos, 1973.

Cox, Christoph, y Daniel Warner, eds. Audio culture: readings in modern music. New York: Continuum, 2004.

Cox, Paul, y Percussion Group Cincinnati. «Cage’s Credo: The Discovery of New Imaginary Landscapes of Sound». En JOHN CAGE: The Works for Percussion 1, Vol. 229. NY: Mode Records, s. f. http://media.dramonline.org/content/notes/mode/mo229.pdf.

«DAAD Artists-in-Berlin Program». Accedido 11 de junio de 2020. https://www.daad.de/en/ study-and-research-in-germany/scholarships/programmes-music-art/daad-artists-in-berlinprogram/.

Daniels, Dieter. «Artist as Inventors and Invention as Art: A Paradigm Shift from 1840 to 1900». En Artist as inventors, inventors as artists. Hatje Cantz, 2008.

Daniels, Dieter, y Inke Arns, eds. Sounds like Silence: John Cage, 433": Silence Today: 1912, 1952, 2012. Leipzig: Spector, 2012.

Daniels, Dieter, y Barbara U. Schmidt, eds. Artists as inventors, inventors as artists. Ostfildern, Germany: Hatje Cantz, 2008.

Deleuze, Gilles. Cine III. Verdad y tiempo. Potencias de lo falso. Buenos Aires: Cactus, 2018.

- Conversaciones. Traducido por José Luis Pardo Torio. Edición: 1. Valencia: Editorial PreTextos, 1995.

—. Dos regimenes de locos. Textos y entrevistas. Valencia: Editorial Pre-Textos, 2008.

- «El cerebro es la pantalla». En Dos regimenes de locos. Textos y entrevistas, 255-62. Valencia: Editorial Pre-Textos, 2008.

—. Estudios sobre cine. Barcelona: Paidós, 1984.

—. «Hacer audibles fuerzas que en sí mismas no lo son». En Dos regímenes de locos. Textosy entrevistas, 149-52. Valencia: Editorial Pre-Textos, 2008.

- Pintura: el concepto de diagrama. Buenos Aires: Cactus, 2016.

_. Proust y los signos. Barcelona: Editorial Anagrama S.A., 1995.

Deleuze, Gilles, y Félix Guattari. Mil mesetas: capitalismo y esquizofrenia. 5. ed. Pre-Textos Ensayo 94. Valencia: Pre-Textos, 2002. 
- ¿Qué es la filosofía? Barcelona: Círculo de lectores, 1995.

Derrida, Jacques. Políticas de la amistad: seguido de El oído de Heidegger. Madrid: Trota, 2010.

Didi-Huberman, Georges. Ante la imagen: pregunta formulada a los fines de una historia del arte. Murcia: CENDEAC, Centro de Documentación y Estudios Avanzados de Arte Contemporáneo, 2010.

Didi-Huberman, Georges, Clément Chéroux, Francisco Javier Arnaldo Alcubilla, y Alberto Santamaría Fernández. Cuando las imágenes tocan lo real. Traducido por Inés Bértolo Fernández. Edición: 1. Madrid: Editorial Círculo de Bellas Artes, 2018.

Diederichsen, Diedrich, y Constanze Ruhm. «Interview with Holger Schulze». En Utopia of Sound: Immediacy and Non-Simultaneity, editado por Christoph Cox, 246-59. Wien: Schlebrugge Editor, 2012.

Dietz, Bill. «maryanne.amacher.foundation@blankforms.org», 25 de febrero de 2020.

Dosse, François. Gilles Deleuze y Félix Guattari: Biografía cruzada. Buenos Aires: Fondo de Cultura Económica, 2009.

Duchamp, Marcel. Escritos: Duchamp del signo, seguido de notas. Barcelona: Galaxia Gutenberg, 2012.

Duling, Kaitlyn. Benjamin Franklin: Inventor and Founding Father. Cavendish Square Publishing, LLC, 2019.

Egashira, Shin, y David Greene. Alternative Guide to the Isle of Portland: Diploma Unit 11. London: Architectural Association Publications, 1998.

Museo Nacional del Prado. «El Oído - Colección». Accedido 5 de marzo de 2019. https://www. museodelprado.es/coleccion/obra-de-arte/el-oido/074adedf-40f0-476f-b132-fe450e71e0f3.

Museo Nacional del Prado. «El sonido de la pintura en el Museo del Prado@es|||». Accedido 5 de marzo de 2019. https://www.museodelprado.es/actualidad/multimedia/el-sonido-de-lapintura-en-el-museo-del-prado/

«El universo musical de Paul Klee, con motivo de la exposición "Paul Klee: maestro de la Bauhaus":» Fundación Juan March, abril de 2013. http://www.march.es/musica/musica.asp.

EL PAÍS. «EP[S] - Juan Navarro Baldeweg», 5 de febrero de 2006. https://elpais.com/ cultura/2006/02/05/album/1139094001_910215.html.

Erlmann, Veit. «resonance». En Keywords in sound, editado por David Novak y Matt Sakakeeny, 17382. Durham; London: Duke University Press, 2015.

Escuchar con los ojos. Arte sonoro en España, 1961-2016. Edición: 1. Madrid: Fundación Juan March, 2016.

Evan Mantri. Jaron Lanier plays 7000 year old instruments. Accedido 5 de marzo de 2019. https://www. youtube.com/watch?v=XW1BBbvrEYA.

Feiereisen, Florence, y Alexandra Merley Hill. Germany in the Loud Twentieth Century: An Introduction. Oxford University Press, USA, 2012.

Fellini, Federico. La Dolce Vita. Karma Films, 1960.

Fernandez Rodriguez, M. Aurora, y Luis Andrés de Fontcuberta Rueda. «Marcel Breuer y el sueño de la cabaña americana». RA. Revista Arquitectura, n. ${ }^{\circ} 14$ (junio de 2012): 51-60. http://www. 
unav.edu/web/escuela-tecnica-superior-de-arquitectura/colecciones.

Ferrari, Luc. Presque rien no. 1: le lever du jour au bord de la mer: auvre sur support audio: cycle Presque rien. 1st edition. Paris: Maison Ona, 2018.

Fetterman, William. John Cage's Theatre Pieces. Routledge, 2012.

Fezer, Jesko, y Martin Schmitz. Lucius Burckhardt Writings. Rethinking Man-made Environments: Politics, Landscape \& Design. Wien: Ambra, 2012.

Fiumara, Gemma Corradi. The Other Side of Language: A Philosophy of Listening. Revised edition. London ; New York: Routledge, 1995.

Flynt, Henry. «Concept art». En An Anthology, editado por La Monte Young y Jackson Mac Low. New York: Jackson Mac Low and La Monte Young, 1963.

Foucault, Michel. This Is Not a Pipe. Berkeley: University of California Press, 1983.

Frampton, Kenneth. Le Corbusier. Ediciones AKAL, 2001.

Fundació Joan Miró. ¿Arte sonoro? Barcelona: Fundació Joan Miró, 2019.

Gazapo de Aguilera, Darío, y Concha Lapayese Luque. «¿Desde dónde... se construye el paisaje?» AUS, n. 7 (2010): 12-15. https://doi.org/10.4206/aus.2010.n7-03.

Gehmann, Ulrich, Martin Reiche, y Gerd Stern, eds. Real virtuality: about the destruction and multiplication of world. Bielefeld: Transcript, 2014.

Gilbert, Simondon. El modo de existencia de los objetos técnicos. Buenos Aires: Prometeo Libros, 2014.

Goodman, Nelson. Los lenguajes del arte: aproximación a la teoría de los simbolos. Barcelona: Paidós, 2010.

Gregory, Derek. «Sounds of War». Geographical Imaginations (blog), 25 de julio de 2012. https:// geographicalimaginations.com/2012/07/25/sounds-of-war/.

Grosz, E. A. Chaos, territory, art: Deleuze and the framing of the earth. The Wellek library lectures in critical theory. New York: Columbia University Press, 2008.

Grubbs, David. Records ruin the landscape: John Cage, the sixties, and sound recording. Durham: Duke University Press, 2014.

Harren, Natilee. Fluxus Forms: Scores, Multiples, and the Eternal Network. University of Chicago Press, 2020.

Hausmann, Raoul. «Optophonétique». En Raoul Hausmann et les avant-gardes, editado por Timothy Benson y Hanne Bergius, 457-64. Dijon: Les Presses du Réel, 2014.

Hejduk, John, Richard Henderson, Elizabeth Diller, y Irwin S. Chanin School of Architecture, eds. Education of an architect. New York: Rizzoli, 1988.

Helmholtz, Hermann von. Science and Culture: Popular and Philosophical Essays. University of Chicago Press, 1995.

Helmreich, Stefan. «Listening Against Soundscapes». Anthropology News 51, n. 9 (diciembre de 2010): 10-10. https://doi.org/10.1111/j.1556-3502.2010.51910.x.

Hernández León, Juan Miguel. «Seminario: Transferencias, proyecto arquitectónico y pensamiento contemporáneo». MPAA-ETSAM, 2014. 
Ser-paisaje. Madrid: Abada Editores, 2016.

Herrero, Fernando. "Parsifal” de Wagner y su centenario». Biblioteca Virtual Miguel de Cervantes. Accedido 26 de octubre de 2019. http:/www.cervantesvirtual.com/obra-visor/parsifal-dewagner-y-su-centenario/html/.

Husserl, Edmund. Fenomenología de la conciencia inmanente del tiempo. Buenos Aires: Prometeo Libros, 2014

«IRCAM». Accedido 19 de marzo de 2019. https:/www.ircam.fr/playlists/le-temps-musical-seance-desynthese-2eme-partie/detail/.

Jakob, Michael. What is landscape? Ediz. illustrata. List, 2018.

«Jaron Lanier’s Homepage». Accedido 10 de junio de 2020. http://www.jaronlanier.com/.

«John Cage Complete Works». Accedido 22 de abril de 2019. https://www.johncage.org/pp/JohnCage-Work-Detail.cfm?work_ID=309.

«JOHN CAGE: Lecture on the Weather - STREAMING MUSEUM». Accedido 17 de noviembre de 2019. http://streamingmuseum.org/john-cage-lecture-on-the-weather/.

John Cage «Water walk». Accedido 8 de octubre de 2019. https://www.youtube.com/ watch?v=gXOIkT1-QWY.

Jonas, Hans. El principio vida: Hacia una biología filosófica. Edición: 1. Madrid: Editorial Trotta, S.A., 2000.

- «Homo Pictor: La libertad de la imagen». En El principio vida: Hacia una biología filosófica, Edición: 1., 217-45. Madrid: Editorial Trotta, S.A., 2000.

—. «La nobleza de la vista». En El Principio Vida. Hacia Una Biologia Filosófica, 191-216. Madrid: Trotta, 2000.

Joseph, Branden Wayne. Experimentations: John Cage in music, art, and architecture. First edition. New York ; London: Bloomsbury Academic, 2016.

Juarranz Serrano, Ángela. «La construcción del medio : hacia la mediación disciplinar como laboratorio de arquitectura (1967-2017)». Phd, E.T.S. Arquitectura (UPM), 2019. http:// oa.upm.es/53902/.

K. Frank, Lawrence. «The World as a Communication Network». En Sign Image Symbol, editado por György Kepes, 1st edition. New York: Braziller, 1966.

Kepes, György. ed. Arts of the environment. Vision + Value series. Henley: Aidan Ellis, 1972.

ed. Module, Proportion, Symmetry, Rhythm. First Printing edition. Vision + Value series. New York: George Braziller, 1966.

- The New Landscape in Art and Science. Academy Editions Ltd, 1956.

«Urban Form Seminar», 1954. http://dome.mit.edu/handle/1721.3/35673.

Kepes, Gyorgy, Marjorie Supovitz, y James R. Killian. Gyorgy Kepes: The MIT Years 1945-1977. Edición: New edition. Cambridge, Mass: MIT Press, 1978.

Klee, Paul. «Filosofía de la creación». En Teoría del arte moderno, Edición: 1ª ed., 1ª imp., 57-61. Buenos Aires: Cactus, 2007. 
—. Pädagogisches Skizzenbuch. Faks.-Nachdr., 3. Aufl. Neue Bauhausbücher. Mainz [etc.]: F. Kupferberg, 1981.

—. Teoría del arte moderno. Edición: $1^{a}$ ed., 1ªmp. Buenos Aires: Cactus, 2007.

. «Vías diversas en el estudio de la naturaleza». En Teoría del arte moderno, 1. a ed. Buenos Aires: Cactus, 2007.

—. "Wege des Naturstudiums». En Staatliches Bauhaus in Weimar 1919-1923, 24-25. WeimarMünchen: Bauhausverlag, 1923.

Klee, Paul, y Felix Klee. The diaries of Paul Klee, 1898-1918. Berkeley: University of California Press, 1964.

Kondratov, A. Sounds and Signs. Central Books Ltd, 1969.

Kostelanetz, Richard, y John Cage. Conversing with Cage. Psychology Press, 2003.

Kotz, Liz. «Máquinas Poéticas». En \pm 1961. La Expansión de Las Artes, 51-67. Madrid: Museo Nacional Centro de Arte Reina Sofía, 2013.

Kristeva, Julia. Sèmeiòtikè Semiótica. Madrid: Fundamentos, 1981.

LaBelle, Brandon. Background noise: perspectives on sound art. Second edition. New York: Bloomsbury Academic, 2015.

Lanier, Jaron. You Are Not a Gadget: A Manifesto. Penguin Creativity. London: Penguin Books, 2011.

Layton, Zach. «Moholy-Nagy and "Optical Sound” at the Guggenheim». Guggenheim (blog), 18 de julio de 2016. https://www.guggenheim.org/blogs/checklist/moholy-nagy-and-optical-soundat-the-guggenheim.

Lazcano, David. «Los escritos de Georg Simmel». Reis: Revista española de investigaciones sociológicas, n. ${ }^{\circ}$ 89 (2000): 269-88. https://dialnet.unirioja.es/servlet/articulo?codigo=250167.

Le Corbusier. El Modulor. Argentina: Poseidón, 1953.

—. Euvre complète. Vol. 5: 1946 - 1952. 11., reimpresión de la primera ed. 1953. Basel: Birkhäuser, 1999.

«Le Temps musical : séance de synthèse 1ère partie - Ressources». Accedido 19 de marzo de 2019. https://medias.ircam.fr/xcd4f03.

Leitner, Bernhard. «Sound Architecture». Artforum, marzo de 1971.

Leitner, Bernhard, y Boris Groys. Bernhard Leitner: P.U.L.S.E. Editado por Z. K. M. Karlsruhe. Bilingual edition. Ostfildern: Hatje Cantz, 2008.

Levin, Janna. Black Hole Blues. Edición: Reprint. New York: Random House USA, 2017.

_. Janna Levin: El Sonido Del Universo. Accedido 3 de mayo de 2020. https://www.ted.com/ talks/janna_levin_the_sound_the_universe_makes?language $=e s$.

Licht, Alan. Sound art: beyond music, between categories. New York, N.Y: Rizzoli International Publications, 2007.

Lim, C. J. Devices: A Manual of Architectural + Spatial Machines. Amsterdam; London: Architectural Press, 2006.

Loos, Adolf. «Das Mysterium der Akustik». En Trotzdem, 1900-1930, 116-17. Wien: Brenner-Verlag, 
1931.

Lucrecio. «De la naturaleza de las cosas: poema en seis cantos». Traducido por José Marchena. Biblioteca Virtual Miguel de Cervantes. Accedido 6 de noviembre de 2019. http://www. cervantesvirtual.com/obra-visor/de-la-naturaleza-de-las-cosas-poema-en-seis-cantos--0/html/ ff0be64e-82b1-11df-acc7-002185ce6064_8.html\#I_22_.

Lynch, Kevin. «South Facades, Boylston Street, Former Berkeley Building, Montgomery-Frost Co.», 1959 de 1954. http://dome.mit.edu/handle/1721.3/34097.

—. The Image of the City. Cambridge, Mass.: MIT Press, 1964.

Maderuelo, Javier. «Música gráfica». Arte y Parte, julio de 2015.

Maderuelo Raso, Javier. La idea de espacio en la arquitectura y el arte contemporáneos, 1960-1989. Ediciones AKAL, 2008.

Manaugh, Geoff, y Nevada Museum of Art, eds. Landscape Futures: Instruments, Devices and Architectural Inventions. Barcelona New York: Actar, 2013.

Marchant, Patricio. «Introducción: Presencia y escritura». En Tiempo y presencia, de Jacques Derrida. Santiago, Chile: Eds. Universidad Diego Portales, 2015.

«Maryanne Amacher». Accedido 15 de abril de 2019. http://act.mit.edu/cavs/person/ KuSTdtevcHYwcJtGmADnN9.

Marzoa, Felipe Martínez. Historia de la Filosofía II: Filosofía moderna y contemporánea. Edición: 1. Madrid: Ediciones Istmo, S.A., 2003

Merleau-Ponty, Maurice. Phenomenology of Perception. 2 edition. London: Routledge, 2002.

Milani, Raffaele. El Arte del paisaje. Madrid: Biblioteca Nueva, 2008.

Mitchell, W. J. T., ed. Landscape and Power. 2. ed., [Nachdr.]. Chicago, Ill.: Univ. of Chicago Press, 2009.

«Moholy-Nagy Foundation». Accedido 12 de febrero de 2020. https://moholy-nagy.org/teaching/.

Moholy-Nagy:, László. «Partiturskizze zu einer mechanischen exzentrik». En Die Bühne im Bauhaus, editado por Oskar S chlemmer, Farkas Molnar, Laszlo Moholy-Nagy, y Walter Gropius, 4445. Munich: Albert Langen Verlag, 1924.

Molina, Fernando Tula. «La individuación: a la luz de las nociones de forma y de información». Redes 20, n. ${ }^{\circ} 38$ (junio de 2014): 199-208.

Moreno, Ignacio. Dibujos mentales: Principios del universo creativo de Juan Navarro Baldeweg. Edición: 1. Madrid: Ediciones Asimétricas, 2017.

Moreno Soriano, Susana. Arquitectura y música en el siglo XX. Madrid: Fundación Caja de Arquitectos, 2008.

Morris, Robert. «Letters to John Cage». October 81 (1997): 70-79. https://doi.org/10.2307/779019. «Some Notes on the Phenomenology of Making: The Search for the Motivated.» Artforum, April.

Nancy, Jean-Luc. A la escucha. Buenos Aires: Amorrortu Editores, 2008.

Navarro Baldeweg, Juan. «Arquitectura informática». Editado por Colegio Oficial de Arquitectos de 
Madrid. Arquitectura, n. ${ }^{\circ} \mathrm{n}^{\circ} 161$ (mayo de 1972): 16-19.

Conversación con Juan Navarro Baldeweg. Entrevistado por Covadonga Blasco Veganzones, 4 de junio de 2017.

- Escritos. 1. ed. Pre-textos. Ensayo 1449. Valencia: Pre-Textos, 2017.

.Readymade/display». En Escritos, 1. ed. Pre-textos. Ensayo 1449. Valencia: Pre-Textos, 2017.

«Surtidor de signos». En Dibujos Mentales: Principios del universo creativo de Juan Navarro Baldeweg, de Ignacio Moreno. Madrid: Ediciones Asimétricas, 2017.

Una caja de resonancia. Valencia, Spain: Editorial Pre-Textos, 2008.

Novak, David, y Matt Sakakeeny, eds. Keywords in sound. Durham ; London: Duke University Press, 2015.

Nyman, Michael. Música Experimental: De John Cage en adelante. Documenta Universitaria, 2006.

Ortega y Gasset, José. «La doctrina del punto de vista». En El tema de nuestro tiempo, III, cap. X:197203. Obras completas. Madrid: Revista de Occidente, 1966.

Oskar Sala Mixtur-Trautonium 100th Anniversary 2010. Accedido 19 de abril de 2020. https://www. youtube.com/watch?v=Hh8-qTjPV9g.

Pessoa, Fernando. Livro do Desasocego. Editado por Jerónimo Pizarro. Vol. xii. Ediçao crítica. Lisboa: Imprensa Nacional - Casa da Moeda, 2010.

_. Libro del desasosiego. Valencia: Pre-Textos, 2014.

Pombo, Alvaro. Hacia una constitución poética del año en curso. Barcelona: La Gaya Ciencia, 1980.

Pritchett, James. The Music of John Cage. Cambridge University Press, 1996.

The Museum of Modern Art. «Production-Reproduction: The Circulation of Photographic Modernism, 1900-1950 | MoMA». Accedido 8 de junio de 2020. https://www.moma.org/ calendar/exhibitions/1500.

«Quelle est Belle Company». Accedido 3 de enero de 2020. https://www.qbc.fr/.

Rainer, Cosima, Manuela Ammer, y Lentos Kunstmuseum Linz, eds. See this sound: promises in sound and vision = Versprechungen von Bild und Ton. Buchhandelsausg. Köln : New York, NY: Verlag der Buchhandlung W. König ; Vertrieb ausserhalb Europas, Distributed Art Publishers, 2009.

redbox, Rogers Stirk Harbour + Partners +. «IRCAM - Rogers Stirk Harbour + Partners». Accedido 11 de junio de 2020. https:/www.rsh-p.com/projects/ircam/.

Rey, Anne, y Pascal Dusapin. "XENAKIS “Si Dieu existait, il serait bricoleur”». Le Monde de la Musique no 11 (1979): 92-97.

Rilke, Rainer Maria. Primal Sound (1919). Juan Andrés Mucarquer, 1919. http://archive.org/details/ rilkeprimalsound.

«Robert Fludd's Utriusque Cosmi maioris salicet et minoris metaphysica... (1617-1619 CE)». Accedido 6 de noviembre de 2019. http://billheidrick.com/Orpd/RFludd/.

Rodaway, Paul. Sensuous Geographies: Body, Sense, and Place. Routledge, 1994.

Rodríguez, Pablo. «Prólogo. El modo de existencia de una filosofía nueva». En El modo de existencia de los objetos técnicos, de Simondon Gilbert, 9-24. Buenos Aires: Prometeo Libros, 2014. 
Roger, Alain. «Histoire d'une passion théorique ou comment on devient un Raboliot du paysage». En La théorie du paysage en France :, 438-51. Seyssel: Champ Vallon Editions, 2009.

Palladio Museum. "Rosario Assunto, Paesaggio - Ambiente - Territorio. Un tentativo di precisazione concettuale, in "Bollettino CISA", n. XVIII, 1976, pp. 45 - 48.» Accedido 21 de julio de 2019. https://www.palladiomuseum.org/annali/1976/2/pdf.

Ross, Alex. El ruido eterno escuchar al siglo XX a través de su música. Barcelona: Círculo de Lectores, 2009.

«RPBW - Ircam». Accedido 11 de junio de 2020. http://www.rpbw.com/project/ircam.

Ruiz Mantilla, Jesús. «Pierre Boulez: "A mí lo que me mueve es la transgresión”». EL PAÍS Semanal, 19 de junio de 2013. https://elpais.com/elpais/2013/06/18/eps/1371549174_474928.html.

Saletnik, Jeffrey. «László Moholy-Nagy, John Cage Und Die Kreative Dynamik». En John Cage Und... Bildender Künstler - Einflüsse, Anregungen., editado por Wulf Herzogenrath, 60-70. Berlin: Akademie der Künste, 2012. https://www.academia. edu/13108047/_L\%C3\%A1szl\%C3\%B3_Moholy-Nagy_John_Cage_und_die_Kreative_ Dynamik_.

Sandford, Mariellen. Happenings and Other Acts. Routledge, 2003.

Sauvagnargues, Anne. Artmachines: Deleuze, Guattari, Simondon. Edinburgh: Edinburgh University Press, 2016.

Schaeffer, Pierre. Tratado de los objetos musicales. Madrid: Alianza, 2008.

Schafer, R. Murray. «Acoustic Space». Circuit: Musiques Contemporaines 17, n. 3 (2007): 83. https:// doi.org/10.7202/017594ar.

—_. El paisaje sonoro y la afinación del mundo. Barcelona: Intermedio, 2013.

«I Have Never Seen a Sound». Canadian Acoustics 37, n. 3 (1 de septiembre de 2009): 32-34. //jcaa.caa-aca.ca/index.php/jcaa/article/view/2123.

- The New Soundscape; a Handbook for the Modern Music Teacher. Scarborough, Ont.: Berandol Music; sole selling agents: Associated Music Publishers, New York, 1969.

The Tuning of the World. 1st edition. New York: Random House Inc, 1977.

Schopenhauer, Arthur. Sobre la música. Música. Madrid: Casimiro Libros, 2016.

Segalen, Victor. En un mundo sonoro; Entrevistas con Debussy. Segovia: La Uña Rota, 2018.

Sève, Bernard. El instrumento musical: Un estudio filosófico. Traducido por Javier Palacio Tauste. Edición: 1. Acantilado, 2018.

Shepherd, John. Continuum Encyclopedia of Popular Music of the World: VolumeII: Performance and Production. A\&C Black, 2003.

Simmel, Georg. Filosofía del paisaje. Madrid: Casimiro Libros, 2014.

Simondon, Gilbert. Curso sobre la percepción: (1964-1965), 2017.

Smithson, Robert. «The Artist as Site-seer; or, a Dintorphic Essay (1966-1967)». En Robert Smithson, the collected writings, 340-45. Berkeley: University of California Press, 1996.

Smout Allen. «Smout Allen». Accedido 1 de julio de 2019. http://www.smoutallen.com/. 
Smout, Mark, Laura Allen. Augmented landscapes. 1st ed. Pamphlet architecture 28. New York: Princeton Architectural Press, 2007.

Sobejano, Enrique, Fuensanta Nieto, y Sara de la Mata. «Entrevista: Juan Navarro». Editado por Colegio Oficial de Arquitectos de Madrid. Arquitectura, n. 274 (octubre de 1988): 114-23.

Soler, Ruth Nayibe Cárdenas, y Dennys Martínez Chaparro. «El paisaje sonoro, una aproximación teórica desde la semiótica». Revista de Investigación Desarrollo e Innovación: RIDI 5, n. ${ }^{\circ} 2$ (Enero-Junio) (2015): 129-40. https://dialnet.unirioja.es/servlet/articulo?codigo=6763096.

Sonic thinking: a media philosophical approach. Thinking media. New York: Bloomsbury Academic, an imprint of Bloomsbury Publishing, Inc, 2017.

Sonic Warfare. Erscheinungsort nicht ermittelbar: MIT Press - Books, 2012.

«Sons Dessus Dessous \#18 - Musical Time». Accedido 16 de marzo de 2019. https://www.ircam.fr/ article/detail/sons-dessus-dessous-18-le-temps-musical/.

Sound Ranging and the End of The War. Accedido 13 de noviembre de 2019. https://www.youtube. $\mathrm{com} /$ watch?v=1pjY9W-S3cI.

«SOUND THOUGHT 2016». Accedido 7 de junio de 2020. https://issuu.com/soundthought/docs/ st_program_final.

Spitzer, Leo. Ideas clásica y cristiana de la armonía del mundo: prolegómenos a una interpretación de la palabra "Stimmung». Traducido por Alfredo Brotons Muñoz. Lecturas de teoría literaria. Madrid: Abada, 2008.

Stafford, Barbara Maria. «Revealing Technologies/ Magical Domains». En Devices of wonder: from the world in a box to images on a screen, 1-142. Los Angeles, CA: Getty Research Institute, 2001.

Stafford, Barbara Maria, Frances Terpak, y Isotta Poggi. Devices of wonder: from the world in a box to images on a screen. Los Angeles, CA: Getty Research Institute, 2001.

Sterne, Jonathan. The Audible Past: Cultural Origins of Sound Reproduction. 47701st edition. Durham: Duke University Press Books, 2003.

Stravinsky, Igor. Poética musical: en forma de seis lecciones. Barcelona: Acantilado, 2013.

Szendy, Peter. En lo profundo de un oído: una estética de la escucha. Santiago de Chile: Metales Pesados, 2015.

TEDxSF - Jaron Lanier - You Are Not a Gadget. Accedido 10 de junio de 2020. https://www.youtube. com/watch?v=IwbGumZ-FYg.

Terranova, Charissa N. Art as Organism: Biology and the Evolution of the Digital Image. Bloomsbury Publishing, 2015.

Thompson, Emily. The Soundscape of Modernity: Architectural Acoustics and the Culture of Listening in America, 1900-1933. Cambridge, Mass.: The MIT Press, 2004.

Thoreau, Henry David. Walden. Edición: 1. Madrid: Errata Naturae, 2013.

Tomkins, Calvin. The Bride and the Bachelors | Five Masters of the Avant-Garde. [Expanded Ed.]. New York: Viking Press, 1968.

Toop, David. «Pelude: Distant Music (on the contemplation of listening)». En Sinister Resonance: The Mediumship of the Listener, Edición: 1., vii-xv. Continuum, 2010. 
Sinister Resonance: The Mediumship of the Listener. Edición: 1. Continuum, 2010.

"The Mediumship of Listening: Notes on Sound in the Silent Arts». Editado por Margaret Schedel y Andrew V. Uroskie. Journal of Visual Culture 10, n. ${ }^{\circ} 2$ (agosto de 2011): 169-76. https://doi.org/10.1177/1470412911402887.

Trías, Eugenio. El canto de las sirenas: argumentos musicales. Serie Ensayo. Barcelona: Galaxia Gutenberg : Círculo de Lectores, 2007.

Trust, John Cage. «John Cage Trust: John Cage: Ryoanji (Catalog Raisonné, Volume I)». John Cage Trust (blog), 10 de julio de 2013. http://johncagetrust.blogspot.com/2013/07/john-cageryoanji-catalog-raisonne.html.

Vallet, Luis, y Jorge Oteyza (sic). «Memorial en honor del al Padre Donosti (sic), Capuchino y musicólogo". Munibe. Grupo de Ciencias Naturales Aranzadi. Suplemento de Ciencias Naturales del Boletín de la Real Sociedad Vascongada de Amigos del País., Año IX de 1957.

Van der Kloot, William. "Lawrence Bragg's role in the development of sound-ranging in World War I». Notes and Records of the Royal Society 59, n. 3 (22 de septiembre de 2005): 273-84. https:// doi.org/10.1098/rsnr.2005.0095.

Venturi Ferriolo, Massimiliano. «Lineamentidi estetica del paessagio». En Estetica del Paessaggio, de Massimiliano Venturi Ferriolo, L. Giacomini, y E. Pesci. Milán: Guerini, 1999.

Vogt, Günther, y Medea Hoch. Landscape as a Cabinet of Curiosities. In Search of a Position. Baden; London: Lars Müller : Springer [distributor, 2013.

Vv.Aa. Variaciones Sobre El Jardín Japonés. La Casa Encendida, 2014. Catálogo de exposición.

Walde, Alois. Lateinisches etymologisches Wörterbuch, 1910. http://archive.org/details/Lateinischesetymologisches-woerterbuch.

«Webdeleuze». Accedido 26 de febrero de 2020. https://www.webdeleuze.com/textes/184.

Williams, Paul. Hitler's Atlantic Wall: Normandy: Construction and Destruction. Pen and Sword, 2013.

Wolffelaar, Ralph Van. «Het ongelooflijke verhaal van Cornelis van Oeckelen en zijn Androïde Klarinetspeler». bndestem.nl, 22 de mayo de 2019. https:/www.bndestem.nl/breda/hetongelooflijke-verhaal-van-cornelis-van-oeckelen-en-zijn-androide-klarinetspeler-a5458be4/.

Zahan, Dominique. «Notes sur un luth dogon». Journal de la Société des Africanistes tomo 20, n. 2 (1950): 193-207.

Zeller, Bettina, Ingo Begall, Nikolaus Nessler, y Paul Klee. Paul Klee und die Musik. Berlin: Nicolaische Verlagsbuchhandlung, 1986 
Madrid, junio 2020 